\title{
Assessment of Research and Development (R\&D) \\ Needs in Ammonia Safety and Environmental Control
}

September 1981

Prepared for the U.S. Department of Energy under Contract DE-AC06-76RLO 1830

Pacific Northwest Laboratory Operated for the U.S. Department of Energy by Battelle Memorial Institute 


\title{
NOTICE
}

This report was prepared as an account of work sponsored by the United States Government. Neither the United States nor the Department of Energy, nor any of their employees, nor any of their contractors, subcontractors, or their employees. makes any warranty, express or implied, or assumes any legal liability or responsibility for the accuracy, completeness or usefulness of any information, apparatus. product or process disclosed, or represents that its use would not infringe privately owned rights.

The views. opinions and conclusions contained in this report are those of the contractor and do not necessarily represent those of the United States Government or the United States Department of Energy.

\author{
PACIFIC NORTHWEST LABORATORY \\ operated by \\ BATTELLE \\ for the \\ UNITED STATES DEPARTMENT OF ENERGY \\ Under Contract DE-AC06-76RLO 1830
}
Printed in the United States of America
Available from
National Technical Information Service
Uniled States Department of Commerce
5285 Port Royal Road
Springfield. Virginia 22151

Price: Printed Copy $\$$

- Microfiche $\$ 3.00$

NTIS

- Pages Selling Price

$\begin{array}{lr}001-025 & \$ 4.00 \\ 026-050 & \$ 4.50 \\ 051-075 & \$ 5.25 \\ 076-100 & \$ 6.00 \\ 101-125 & \$ 6.50 \\ 126-150 & \$ 7.25 \\ 151-175 & \$ 8.00 \\ 176-200 & \$ 9.00 \\ 201-225 & \$ 9.25 \\ 226-250 & \$ 9.50 \\ 251-275 & \$ 10.75 \\ 276-300 & \$ 11.00\end{array}$


ASSESSMENT OF RESEARCH AND

DEVELOPMENT (R\&D) NEEDS

IN AMMONIA SAFETY AND

ENVIRONMENTAL. CONTROL

\section{L. Brenchley}

Task Manager

Technical Contributors

G. F. Athey

H. J. Bomeiburg

D. L. Brenchley

C. E. Cowan

T. E. Donovan

W. J. Eadie

R. M. Emery

J. T. Hardy

P. C. Owczarski

T. M. Poston

J. L. Warren

Prepared for the

Environmental and Safety

Engineering Division

U.S. Department of Energy

under Contract DE-AC06-76RL0 1830

Pacific Northwest Laboratory

Richland, Washington 99352 

FOREWORD

This report is one of a series prepared by Pacific Northwest Laboratory (PNL) to communicate results of the Liquefied Gaseous Fuels (LGF) Safety Studies Project, being performed for the U.S. Department of Energy, Office of Environmental Protection, Safety and Emergency Preparedness (DOE/EP). The DOE/EP Office of Operational Safety, Environmental and Safety Engineering Division (ESED), is conducting the DOE Liquefied Gaseous Fuels Safety and Environmental Control Assessment Program. The LGF Safety Studies Project contributes research, technical surveillance and program development information in support of the ESED Assessment Program. This assessment of ammonia safety and environmental control benefited from the technical direction and guidance provided by Dr. John M. Cece and Dr. Henry F. Walter of the ESED.

Completed effort in other tasks of the PNL project includes a scoping assessment of release prevention and control systems in liquefied natural gas (LNG) facilities and an assessment of research and development (R\&D) needs in the safety and environmental control of liquefied petroleum gas (LPG) plants and systems. The results of these studies are reported in:

1. A Scoping Assessment of LNG Release Prevention and Control Systems (PNL-4014)

2. Assessment of R\&D Needs in LPG Safety and Environmental Control (PNL-3991).

Work in progress includes more detailed studies of topics identified in the LNG scoping assessment as being worthy of further investigation. Other reports of this series are in preparation on the following subjects:

- Import Terminal Release Prevention Analysis

- Peakshaving Plant Release Prevention Analysis

- Storage Tank Analysis

- Fire Prevention and Control Assessment

- Human Factors in LNG Operations. 

PNL CONTRIBUTORS

Many members of the PNL project team contributed to the preparation and publication of this report. The following list acknowledges the individual contributions of the principal authors and others who assisted this effort.

\section{LGF Safety Studies Project Manager}

J. G. DeSteese

Arunonia Assessment Task Manager

D. L. Brenchley

Executive Summary

D. L. Brenchley

Chapter 1. Introduction

D. L. Brenchley

Chapter 2. Amonia Production, Storage and Transportation

H. J. Bomelburg

Chapter 3. Uses of Armonia

H. J. Bomelburg

Chapter 4. Ammonia Accidents

G. F. Athey

Chapter 5. Ammonia Hazards

P. C. Owczarski, Land Spills

W. J. Eadie, Cloud Dispersion

C. E. Cowan, Ecological Effects

R. M. Emery, Freshwater Impacts

T. M. Poston, Freshwater Impacts

J. L. Warren, Terrestrial Impacts

J. T. Hardy, Marine Impacts

H. J. Bomelburg, Fire and Explosion Hazards

D. L. Brenchley, Health Effects

Chapter 6. Release Prevention and Control

H. J. Bomelburg

Chapter 7. Knowledge Gaps and Recommended R\&D

H. J. Bomelburg

D. L. Brenchley

C. E. Cowan

P. C. Owczarski 
Appendix A. Accidental Spills and Human Exposure

G. F. Athey

D. L. Brenchley

Appendix B. Adiabatic Mixing of Ammonia (Liquid) and Air

P. C. Owczarski

Appendix C. An Analytical Examination of the Fire and Explosion Hazards of Ammonia

T. E. Donovan

Appendix D. Environmental Impact Rating Tables

C. E. Cowan

R. M. Emery

J. T. Hardy

T. M. Poston

J. L. Warren

Technical and Editorial Review

N. M. Burleigh

D. L. Brenchley

C. A. Counts

J. G. DeSteese

Word Processing and Report Preparation

N. M. Burleigh

M. M. Hale

K. E. Rodriguez

M. E. Thielges 


\section{EXECUTIVE SUMMARY}

Ammonia is a common substance in nature and it is widely used in agriculture and industry. In addition, ammonia may be used in many energy-related applications including fuel use and as a heat transfer fluid. The production and use of ammonia is beneficial to the quality of life. However, these benefits are accompanied by a level of risk because ammonia is potentially hazardous when improperly handled or accidentally released. Much has been done to minimize these risks but a sufficient number of accidents occur each year to promote public concerns regarding ammionia safety and environmental control practices. Currently both industry and government are responding to these concerns.

The ammonia industry is a mature industry supplying an essential material in a generally safe and reliable manner. It has a vast quantity of technological experience and operational expertise that has been developed over the past 50 years. It is active in developing standards and practices that tend to minimize the incidence and consequences of accidental ammonia releases.

The U.S. Department of Energy (DOE) is one of the government agencies working on ammonia safety-related issues. The Environmental and Safety Engineering Division requested the Pacific Northwest Laboratory (PNL) to characterize the ammonia industry operations, review current knowledge of ammonia release and subsequent impacts, summarize the status of release prevention and control methods and identify research and development (R\&D) needs for safety and environmental control. The following conclusions and recommended efforts are appropriate for the DOE Program and as R\&D by other agencies and the ammonia industry.

EXPLOSION AND FIRE HAZARDS

Additional work should be conducted to enhance the understanding of the causes of explosions (BLEVES) that occur in ammonia storage and transportation tanks. The research should focus on probable causes such as galvanic corrosion, stress corrosion cracking, improper maintenance and others. The research results would provide a basis for mitigation strategies and improved codes 
and regulations. Since this problem is not unique to ammonia, the focus on ammonia should be done in the context of a broader study covering flanmable and nonflanmable materials.

The question of ammonia fires has always been controversial. It is concluded here that anmonia spill fires are practically impossible. While anmonia flash fires may occur, they are expected to be of short duration (seconds). This assessment indicates that there is insufficient heat transfer from the flame to evaporate the liquid ammonia needed to sustain the flame. However, it is still possible that a flash fire may occur and ignite other combustible materials nearby. In view of these results, no R\&D recommendations are presented for anmonia spill fires.

\section{ACCIDENT STATISTICS}

A comprehensive data collection and analys is system should be developed for accident statistics. At the present time several special interest organizations and agencies collect certain types of information depending on the size of the spill and the extent of human injury. A common system would allow more accurate recording and retrieval of accident information and provide a sound data base for evaluating consequences as a function of many different parameters including occupationa], type of industry, nature of injury, extent of injury, exposure conditions, type of accident, and others. Such an analysis would provide a method for identifying areas where improved safety and environmenta] control practices are required.

\section{DISPERS ION OF AMMONIA}

Additional research should be conducted to improve the ability to describe the generation and dispersion of negatively buoyant amonia plumes. Both pressurized and refrigerated ammonia spills have the potential to produce negatively buoyant plumes that linger and result in high concentrations of ammonia at ground level. Current models can estimate concentrations within a factor of about 10 whereas with additional research this could be improved to within a factor of 2 or 3 or better. 
ECOLOGICAL EFFECTS

Research on ammonia effects is needed in both the individual organism and ecological areas. Additional research on individual organisms should focus on two important areas: 1) the determination of the 1 ife stages of plants and animals that are most sensitive to ammonia and 2) evaluation of the toxicity and sublethal effects on these organisms. For example, in the marine environment the toxicity and sublethal effects of ammonia to eggs and larval stages of organisms need to be determined because insufficient data exists to evaluate these effects. In addition research is needed into the effects of ammonia on community stability and resiliency as the result of a spill. Currently it is not known if spills of ammonia would cause irreversible changes to an ecological community or in what time frame the community could expect to recover from the effects of the spill. Expansion of data bases in these areas would help to refine and expand the evaluation of the effects of ammonia spilis.

An initial assessment of ammonia emissions to the atmosphere indicated that this is not a significant problem area. Therefore no R\&D recommendations are presented. The natural nitrogen cycle mechanisms can easily and quite rapidly assimilate the ammonia. Furthernore, such emissions may have a beneficial rather than a deleterious effect. For example, ammonia enhances the ability of plants to absorb atmospheric carbon dioxide, and this may tend to reduce the "greenhouse effect" caused by carbon dioxide.

\section{HEALTH EFFECTS}

Additional work is needed in two areas of human health effects from accidental exposures. First, more case studies are needed to clearly define the long-term health problems associated with acute toxic exposures. Second, exposure time and concentration guidelines need to be developed for use in defining emergency procedures in the event of major spills in populated areas.

\section{ANTICIPATED SAFETY PROBLEMS WITH SPECIFIC APPLICATIONS}

Amonia as a Fuel

When using ammonia as a fuel in combustion engines, the possibility of a liquid spill and adverse consequences exists. This could possibly represent a 
major hindrance in a widespread use of ammonia as automobile fuel. Even though a major car accident with a fuel tank rupture would not produce a fire as easily as with gasoline, the rapid vaporization of the toxic ammonia would present a serious hazard, particularly in congested traffic situations and in densely populated areas. Fortunately, however, the quantities involved in such accidents would be rather small (maximum 20 gallons), so that unimpaired people could probably run away from the spill. Although it appears to be technically feasible to construct ruptureproof tanks or to reduce the leak rate significantly if a tank does rupture, there are no current plans to develop these tanks. Thus, if the use of ammonia as automobile fuel is seriously considered in the future, this will be the most serious safety problem to be resolved.

Armonia in Binary Cycle Applications

In binary cycle applications, ammonia is contained under high pressure (up to 2500 psi) as a vapor and as a Tiquid. Obviously, it is possible that leaks or even ruptures can occur in these systems (e.g., in the heat exchanger, in the pump, or in the piping, etc.) as they might occur in steam systems. However, since the corrosion behavior of ammonia vapor loops at high temperatures is not well known, such loops might involve some safety hazards that cannot be estimated very well at the present time. Therefore, it is recomended that research be conducted into materials compatability with $\mathrm{NH}_{3}$ at medium-to-high temperatures $\left(\sim 300^{\circ} \mathrm{F}\right.$ to $\left.2500^{\circ} \mathrm{F}\right)$, particularly in respect to stress corrosion cracking. Loop materials that are exposed to high pressures and temperatures and that also undergo temperature cycles could accumulate stresses superimposed on the stresses developed by the interna? pressurization of the loop. Since $\mathrm{NH}_{3}$ becomes increasingly dissociated with temperature into $\mathrm{H}_{2}$ and $\mathrm{N}_{2}$, the possibility of hydrogen embrittiement and hydrogen permeation must also be considered as potential safety problems.

Ammonia in OTEC Systems

Safety requirements and precautions for ammonia aboard OTEC plants are not more than for those existing within the ammonia manufacturing, fertilizing, and refrigeration industries. In fact, they may be less since the ammonia is only under moderate pressures (up to $\$ 50 \mathrm{psi}$, corresponding to warm sea water of less 
than $100^{\circ} \mathrm{F}$ ), and the total amount within the closed loop is limited. Problems of inadvertent leakage can occur as a result of metal corrosion but do not seem to present a serious safety hazard. Storage of large quantities of ammonia aboard the OTEC plant should not generate any problems which would be different from those encountered on land-based facilities. In fact, a remote offshore facility appears to be fundamentally safer, just because of its remoteness from populated areas.

Ammonia in Refrigeration Technologies

Amtronia has been used for refrigeration purposes for such a long time that there has been a substantial amount of experience with accidents in ammonia refrigeration plants. Of the explosive accidents that have occurred in such plants, most occurred in mechanical compressor plants, whereas absorption plants were hardly affected at all. What appears to have caused the explosions is the "foul" gas, which usually appears and collects in certain parts of an ammonia refrigeration system. The "foul" gas originates from a mixing and reaction of ammonia with the lubricating oil in the system.

Present knowledge indicates that because ammonia is such a powerful solvent, any contact or mixing with certain organic materials may result in the development of highly combustible gases. Therefore, it is advisable to avoid any contact of amrionia with these materials.

It is recommended that a list be compiled for organic substances which should not be used in contact with ammonia. Laboratory tests will probably be required for the evaluation of materials. The various conditions for generating "foul" gas should also be investigated in these tests because it is conceivable that an oil mist suspended in ammonia vapor can form an explosive mixture, even if the oil is not soluble in $\mathrm{NH}_{3}$.

Ammonia Used for NO Reduction

The most promising and furthest-developed method for removing $\mathrm{NO}_{x}$ from boiler flue gases uses ammonia. Widespread use of ammonia for $\mathrm{NO}_{x}$ abatement purposes would noticeably increase the demand for ammonia. 
The usual safety hazards associated with liquid amononia are present in ${ }^{N}{ }_{x}$ treatment facilities as well, but they are not considered to be more critical than in any other ammonia storage facility. Therefore, it is expected that existing codes and regulations for handling ammonia will be sufficient for plants using the $\mathrm{NO}_{x}$ treatment. 


\section{CONTENTS}

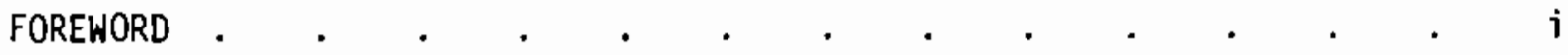

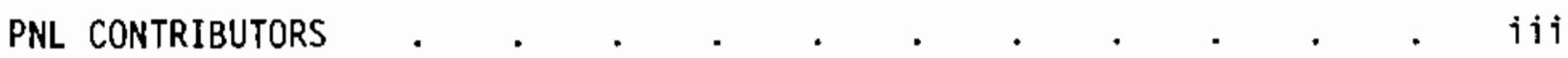

EXECUTIVE SUMMARY

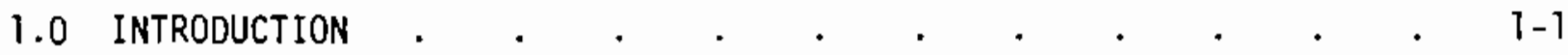

2.0 AMMONIA PRODUCTION, STORAGE AND TRANSPORTATION $. \quad . \quad . \quad$. $2-1$

2.1 PROPERTIES OF AMMONIA $\quad \cdot \quad \cdot \quad . \quad+\quad \cdot \quad \cdot \quad \cdot \quad \cdot \quad 2-1$

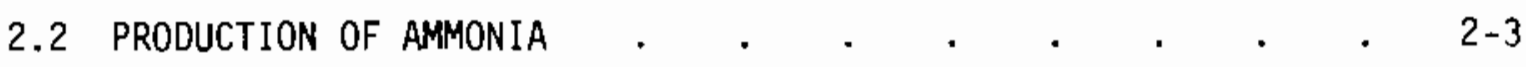

2.2.1 Hydrogen Production . . . . . . . 2-4

2.2.2 Ammonia Synthesis . . . . . . . . . 2-6

2.3 AMMONIA STORAGE AND DISTRIBUTION . . . . . . . . . $\quad$. $2-7$

2.3.1 Storage Containers . . . . . . . . 2-8

2.3.2 Distribution Systems . . . . . . . . . . 2-9

3.0 USES OF AMMONIA $\quad . \quad$. . . . . . . . . . . . . . . . . .

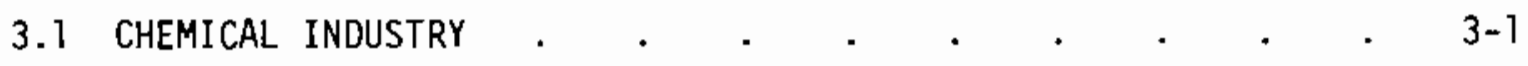

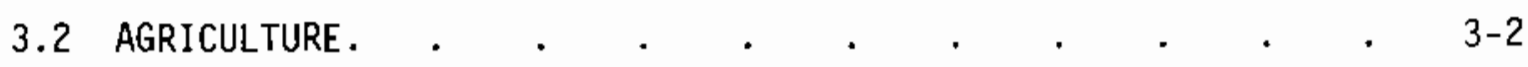

3.3 ENERGY-RELATED APPLICATIONS . . . . . . . . . 3-3

3.3.1 Fuel Use $. \quad . \quad . \quad . \quad . \quad . \quad . \quad . \quad . \quad . \quad 3-3$

3.3.2 Binary Cycle Applications . . . . . . . 3-4

3.3.3 Cooling Towers . . . . . . . . . . . . 3-5

3.3 .4 OTEC Systems. . . . . . . . . . . . . . $3-7$

3.3.5 Refrigeration . . . . . . . . . 3-11

3.3 .6 Heat Pipes . . . . . . . . . . . $3-16$

3.3.7 Thermochemical Energy Transfer and Storage. . . 3-18 


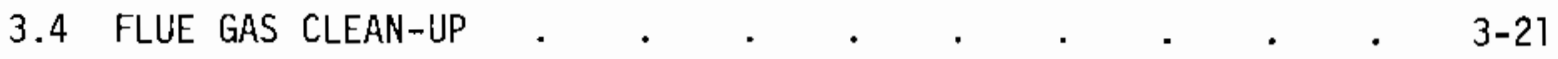

$3.4 .1 \mathrm{NO}_{\mathrm{x}}$ Removal . . . . . . . . . . $3-21$

$3.4 .2 \mathrm{SO}_{2}$ Removal . . . . . . . . . . . . 3-25

3.5 THE COAL INOUSTRY . . . . . . . . . . . . . . . . $3-26$

3.5.1 Chemical Comminution . . . . . . . . 3-26

3.5.2 Gasification of Coal . . . . . . . . 3-27

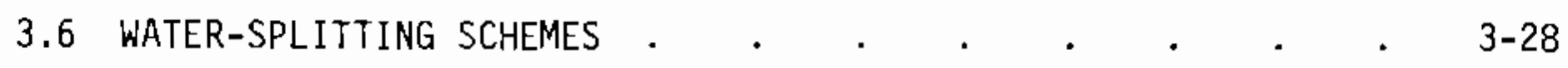

3.7 AMMONIA AS A MEANS OF STORING HYDROGEN . . . . . . . 3-28

4.0 AMMONIA ACCIDENTS . . . . . . . . . . . . . . . . . . . . $4-1$

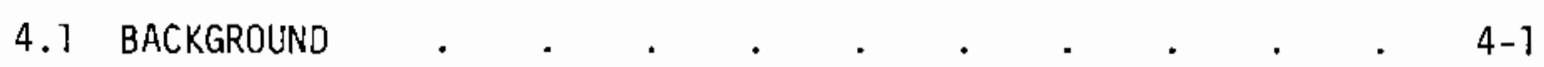

4.2 APPROACH . . . . . . . . . . . . . . . . . . . . . $4-2$

4.3 DATA RESOURCES USED . . . . . . . . . . . . . . . . . 4-4

4.3.1 DOT - Materials Transportation Bureau . . . . 4-6

4.3.2 California Department of Industrial Relations,
Division of Labor Statistics and Research . . . 4-10

4.3.3 Idaho Industrial Commission . . . . . . . . 4-15

4.3.4 Oregon Workers' Compensation Department . . . 4-19

4.3.5 Supplementary Data System (SDS) . . . . . . 4-21

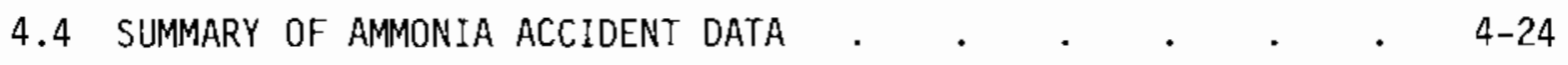

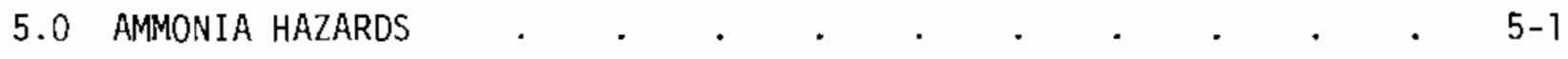

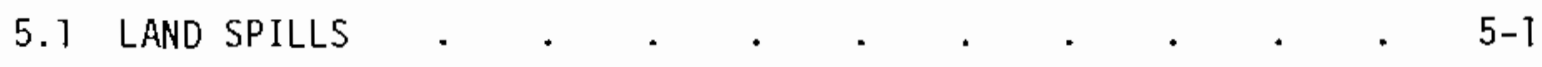

5.1 .1 Types of Spills . . . . . . . . . . . 5-1

5.1 .2 Review of Relevant Literature . . . . . . 5-4

5.1.3 Calculations for Refrigerated Spills . . . . . 5-7

5.1 .4 Calculations for Pressurized Spills . . . . . 5-10 
5.2 CLOUD DISPERSION

5.2.1 Dispersion Mode1s . . . . . . . . . . 5-16

5.2.2 Dispersion Calculations . . . . . . . . 5-19

5.3 ENVIRONMENTAL EFFECTS OF AMMONIA RELEASES . . . . . 5-21

5.3.1 Freshwater-Scenario Description and Assumptions . . 5-22

5.3.2 Freshwater-Spi11 Impact Assessment . . . . 5-24

5.3.3 Freshwater-Neutralization and Restoration Methods . 5-29

5.3.4 Freshwater-Adequacy of Information . . . . 5-30

5.3.5 Terrestrial-Spill Scenarios and Assumptions . . 5-31

5.3.6 Terrestrial-Spill Impact Assessment . . . . 5-32

5.3.7 Terrestrial-Adequacy of Information . . . . 5-38

5.3.8 Marine - Spiil Scenarios and Assumptions . . . 5-38

5.3.9 Marine - Spill Impact Assessment . . . . . 5-41

5.3.10 Marine - Adequacy of Information and Research Needs . 5-50

5.4 ASSESSMENT OF THE AMMONIA FIRE AND EXPLOSION HAZARDS . . 5-50



5.5 HUMAN HEALTH EFFECTS . . . . . . . . . . . $5-57$

5.5.1 Burns of the Eyes. . . . . . . . . $5-57$

5.5.2 Effects on Skin . . . . . . . . . . . 5-58

5.5.3 Effects on Upper Respiratory Tract and Lungs . . 5-59

5.5.4 Air Quality Standards . . . . . . . 5-60

5.5 .5 Conclusions . . . . . . . . . . . . 5-61

6.0 RELEASE PREVENTION AND CONTROL . . . . . . . . . . 6-1

6.1 RELEASE PREVENTION . . . . . . . . . . . . . . . . .

6.1.1 Regulations for the Ammonia Industry . . . . 6-2 
6.1.2 Safety Precautions for Ammonia Facilities . . . 6-6

6.2 RELEASE CONTROL . . . . . . . . . . . 6-7

7.0 KNOWLEDGE GAPS AND RECOMMENDED R\&D . . . . . . . . . . 7-1

7.1 CURRENT AMMONIA USE SYSTEM . . . . . . . . . . . . . 7-2

7.1.1 Galvanic Corrosion . . . . . . . 7-2

7.1.2 Stress Corrosion Cracking . . . . . . 7-2

7.1 .3 Explosion Hazards . $. \quad . \quad . \quad . \quad . \quad . \quad$. $7-2$

7.1.4 Accidents Statistics . . . . . . . 7-3

7.1.5 Dispersion of Anmonia . . . . . . . . 7-3

7.1 .6 Ecological Effects . . . . . . . . $7-4$

7.7.7 Health Effects . . . . . . . . . 7-4

7.2 ANTICIPATED SAFETY PROBLEMS WITH NEW APPLICATIONS
OF AMMONIA

7.2.1 Armonia as a Fuel . . . . . . . . . . 7-5

7.2.2 Anmonia in Binary Cycle Applications . . . . 7-6

7.2.3 Ammonia in OTEC Systems . . . . . . . 7-8

7.2.4 Amnonia in Refrigeration Technologies. . . . 7-8

7.2.5 Armonia Used for $\mathrm{NO}_{x}$ Reduction . . . . . 7-10

7.2.6 Anmonia in Other Applications . . . . . . . 7-11

REFERENCES . . . . . . . . . . . . . . Ref-1

ANNOTATED BIBLIOGRAPHY . . . . . . . . . . . . . . Bib-1

APPENDIX A - ACCIDENTAL SPILLS AND hUMAN EXPOSURE . . . . . . . A-1

APPENDIX B - ADIABATIC MIXING OF $\mathrm{NH}_{3}$ (LIQUID) AND AIR . . . .

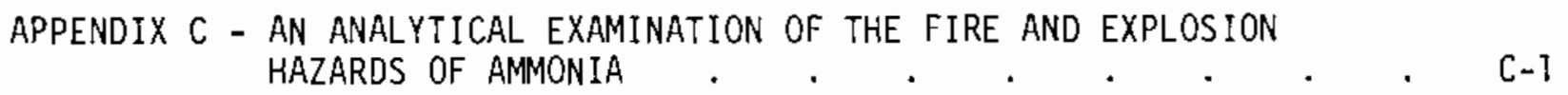

APPENDIX D - ENVIRONMENTAL IMPACT RATING TABLES . . . . . . D-1 
FIGURES

2.1 Typical Flowsheet for Kellogg-Designed Ammonia Plant . . . 2-5

3.1 Simplified Schematic of Power Plant Ammonia Heat Rejection

System . . . . . . . . . . . . 3-6

3.2 Schematic of OTEC Closed Rankine Cycle . . . . . . 3-8

3.3 OTEC Heat Exchanger Test Facility at ANL . . . . . 3-10

3.4 Closed Armonia Refrigeration Systems . . . . . . . 3-12

3.5 Basic Scheme of an Ammonia Condensing Cycle . . . . . 3-14

3.6 Schematic Illustration of a Heat Pipe . . . . . . 3-17

3.7 Heat Pipes on Alaska Pipeline. . . . . . . . . 3-18

3.B Using Ammonia for the Transfer of Solar Energy . . . . 3-19

3.9 Armoniated Salt Heat Storage System in Heating Mode . . . 3-20

5.1 Density of an Amonia Cloud Initially Containing Some Liquid
Ammonia as it is Oiluted with Ory Air . . 5-6 . . .

5.2 Oensity of an Amonia Cloud Containing Some Liquid Amonia
as it is Diluted with Wet Air. . . 5-7 . . . . .

5.3 $\mathrm{NH}_{3}$-Air Mixture Density, Temperature and Ammonia Concentration for Fractional Adiabatic Evaporation of a Cold Pool of Liquid $\mathrm{NH}_{3}$ Producing a Saturated Mixture. . . . . . . . 5-11

5.4 Characteristics of the 3-D Jet Mixing Model . . . . . 5-14

5.5 Ranges of $\mathrm{NH}_{3}$ Concentrations Generated by Each Spill Scenario . 5-25

5.6 A General Spectrum of Impact Suggested for a Broad Range of $\mathrm{NH}_{3}$
Concentrations. . . . . . . . . .

5.7 Ranges of Concentration and Exposure Time for Each Spill Scenario and Significance of Impact to Plants and Animals. . . . 5-33

5.8 Ranges of $\mathrm{NH}_{3}$ Concentrations Generated by Each Spill Scenario and Significance of Impact as Defined in Figure 5.7 . . . 5-42

5.9 A General Spectrum of Impact for a Broad Range of $\mathrm{NH}_{3}$ Concentra-
tion. . . . . . . . . . . . 
B.1 Steady-State Evaporation Rates for Square Liquid P0ols . . . B-4

B.2 Vapor Pressure of Liquid Ammonia . . . . . . . B-6

B.3 Cloud Density and Temperature for Adiabatic Mixing of Dry Air at $25^{\circ} \mathrm{C}, 1$ ATM and Pure $\mathrm{NH}_{3}$ at $-33^{\circ} \mathrm{C}$. Region of No Liquid

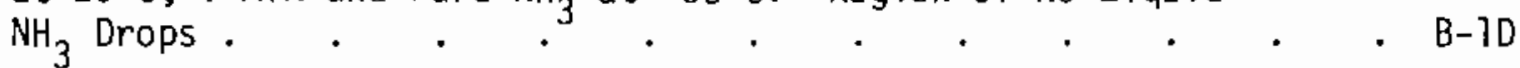

B.4 Cloud Density and Temperature for Adiabatic Mixing of Dry Air at $25^{\circ} \mathrm{C}, \mathrm{I}$ ATM and Pure $\mathrm{NH}_{3}$ at $-33^{\circ} \mathrm{C}$. Region of No Liquid $\mathrm{NH}_{3}$ Drops

C.T Graph of the $y(\phi)$ Function . . . . . . . . C-2

C.2 AFT Versus Equivalence Ratio . . . . . . . . C-4

C.3 Thermal $\mathrm{Flame} \mathrm{Structure} \mathrm{.} \mathrm{.} \mathrm{.} \mathrm{.} \mathrm{.} \mathrm{.} \mathrm{.} \mathrm{.} \mathrm{.} \mathrm{C-7}$

C.4 Flame Velocities in Anmonia Versus $\phi$. . . . . . . C-12

C.5 Critical Temperature Versus Size (Three Geometries) . . . C-16

C.6 Thermal Radiation from Ethanol and Anmonia Combustion Incident on the Base of a Hemispherical Cloud Versus Radius, $L$, of the Hemispherical Cloud. . . . . . . . . . C-22

C.7 Boiloff Rates for Ethanol and Armonia Versus Cloud Diameter. . C-23 


\section{TABLES}

2.1 Physicochemical Properties of Anhydrous Ammonia . . 2-2.

4.1 Information Data Bases Searched by Computer . . . . . . 4-3

4.2 Classification of Organizations Contacted for this Study . . 4-5

4.3a Ammonia Incidents by Transport Mode and Year of Occurrence . 4-7

4.3b Number of Injury Incidents by Transport Mode and Year of Occur-

rence . . . . . . . . . . . 4-8

4.4 Ammonia Transport Accidents - Sumary of Incidents Involving Injury and/or Death . . . . . . . . . . . 4-8

4.5 Summary of Primary Failures (Materials Transportation Bureau) 4-9

4.6 Transportation Ammonia Incidents by States (1971 to May 1980) . 4-11

4.7 Workers' Compensation, Disabling Work Injuries and I1lnesses Caused by Alkalies and Ammonia in 1977, 1978 and 1979 . . 4-12

4.8 Alkali and Ammonia Incidents by Industry (California, 1977-1979) . 4-13

4.9 Alkali and Ammonia Incidents by the Nature of Injury (California 1977-1979) . . . . . . . . . . . 4-74

4.10 Alkali and Ammonia Incidents by Part of Body Injuries (California 1977-1979) . . . . . . . . . . . . 4-15

4.11 Industry Breakdown of Alkali and Ammonia Incidents (Idaho, 19771978)

4.12 The Five Industries Having Highest Number of Ammonia Incidents (Idaho, 1973-May 1980) . . . . . . . . . 4-17

4.13 Breakdown of Alkali and Ammonia Incidents by Nature of Injury (Idaho, 1977-1978) . . . . . . . . . . 4-18

4.14 Breakdown of Alkali and Ammonia Incidents by Parts of Body Injuries (Idaho, 1977-1978) . . . . . . . . 4-18

4.15 Summary of Nature of Injury for These Ammonia Incidents Classed

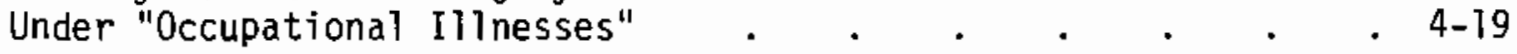

4.16 Ammonia Incidents in Idaho by Type of Accident (1973-198D) . 4-20

4.17 Industry and 0ccupation of the 38 Alkali Cases in Oregon During 1978 (Ammonia Cases are Indicated by $\star$ ) . 
4.18 Number of Alkali Cases by State (1977-1978) . . . . . 4-23

4.19 Alkali Incidents from SDS by Major Industry Group (1977-1978) . 4-25

4.20 A]kali Incidents from SDS by Nature of Injury (1977-1978) . . 4-25

4.21 Alkali Incidents from SDS by Part of Body Injured (1977-1978) . 4-25

4.22 Distribution of SDS Alkali Incidents Within the Major Occupation Groupings (1977-1978) . . . . . . . . . 4-26

4.23 The Fifteen Occupational Having the Greatest Number of Alkali Incidents - SDS (1977-1978) . . . . . . . . . 4-26

5.1 Upstream Vesse1 and Downstream Exit Conditions . . . . 5-13

5.2 Results of Pressurized Spill Calculations for D Stability (Neutral) $U=5 \mathrm{~m} / \mathrm{sec}$ (Day or Night, Strong Winds) . . . . . 5-20

5.3 Results of Pressurized Spill Calculations for F Stability (Very Stable), $U=1 \mathrm{~m} / \mathrm{sec}$ (Night, Clear Sky, Light Meandering Winds) . . . . . . . . . 5-20

5.4 Results of Refrigerated Spill Calculations for Stability D (Neutral) (Day or Night, Strong Winds) . . . . . . 5-20

5.5 Results of Refrigerated Spill Caiculations for F Stability (Night Clear Sky, Light Meandering Winds) . . . . . . . 5-21

5.6 Terrestrial Ammonia Spili Scenarios . . . . . . 5-31

5.7 Concentration of Unionized Ammonia (UIA) in Seawater Resulting from Four Spill Scenarios, Assuming 60\% of the Spilled Ammonia Enters Seawater and $11 \%$ of that Remains in the Unionized Form . 5-40

5.8 Responses of Marine Biota to Ammonia Enrichment . . . . 5-5i

C.1 Heats of Formation and Specific Heats . . . . . . C-3

C.2 Sensible Enthalpy Functions . . . . . . . . C-4

C.3 Adiabatic Flame Temperature (AFT) in ${ } K$ Versus Equivalance Ratio, $\phi$ (Ammonia Combustion in Air). . . . . . . . C -5

C.4 Upper and Lower Flame Speeds Versus Equivalence Ratio . . . C-13

C.5 Critical Temperature for Various Sizes and Geometries . . . C-16

C.6 Properties for Thermal Radiation Calculation. . . . . C-2l 
C.7 Radiation Emissivity and Boiloff Versus Radius of Cloud, L . . C-22

D.1 Hazards Ratings for Scenario 1 . . . . . . . D-3

D.2 Hazards Ratings for Scenario 2 . $\quad$. $\quad$. $\quad$. . . . . . D-4

D.3 Hazards Ratings for Scenario 3 . . . . . . . . D-5

D.4 Hazards Ratings for Scenario 4 . . . . . . . . D-6

D.5 Hazards Ratings for Scenario 5 . . . . . . . . . . . D-7

D.6 Hazards Ratings for Scenario 6 . . . . . . . . D-8

D.7 Hazards Ratings for Scenario 7 . . . . . . . . D-9

D.8 Hazards Ratings for Scenario 8 . . . . . . . D-10

D.9 Impact Ratings for Ammonia Spill Scenarios in Forest, and
Grassland Ecosystems . . . . . D-12

D.10 Hazard Ratings for Marine Spill Scenarios . . . . . D-14 



\subsection{INTRODUCTION}

Anmonia is found in nature and widely used in agriculture, industry and by the public. Its total use is increasing rapidly and the types of uses are also growing in number. Since 1970 ammonia has ranked first in the value of chemicals manufactured in the United States. About 75-80 percent of the ammonia is used in the production of fertilizer but there are also about 2500 industrial products derived from it as well. Ammonia also has a number of energy-related uses including fuel and heat transfer fluid.

Although ammonia is a common substance it poses potential concerns because, in excessive doses, it is hazardous to all forms of life. For example, it is highly soluble in water and therefore it causes skin burns, eye irritation, respiratory discomfort and, in high concentrations, death. Even if people survive near-lethal doses, total recovery is not likely and in fact further longterm complications may occur.

The ammonia industry is a mature industry with a vast quantity of experience, technology and operational expertise that has been developed over the past 50 years. The combined influence of industry-generated standards and governmental regulations has promoted safe and environmentally acceptable practices that tend to minimize the incidence and consequences of accidental ammonia releases.

Yet, against this favorable background, there $l$ ies the concern about the hazardous nature of ammonia and the knowledge that ammonia is statistically involved in a few spectacular accidents each year. These receive widespread news media coverage. In addition there are more numerous but smaller incidents that receive less publicity. The news media coverage emphasizes the casualties and the damage and potential hazards of these events. Therefore, there is public concern regarding current ammonia safety and environmental control practices in addition to the needs sterming from newer uses and applications. While much has already been done to minimize these risks, there is a concensus in the industry and in government that more safety-related research and development (R\&D) should be undertaken. The U.S. Department of Energy (DOE) is one of the government agencies working on ammonia safety-related problems. 
The DOE Office of the Assistant Secretary for Environmental Protection, Safety and Emergency Preparedness (EP) has the responsibility for identifying, characterizing and mitigating environmental, safety and health issues associated with the commercial use of specific energy materials. The EP Environmental and Safety Engineering Division (ESED) is responsible for assessing some of the materials, including liquefied gaseous fuels. To fulfill this responsiblity, the ESED is conducting a R\&D program on the safety and environmental control of liquefied natural gas (LNG), liquefied petroleum gas (LPG), ammonia and hydrogen. The objectives are to gather, analyze and disseminate technical information that will aid future decisions made by industry, regulatory agencies and the general public on facility siting, system operations, and accident prevention and mitigation. This effort is known as the DOE Liquefied Gaseous Fuels (LGF) Safety and Environmental Control Assessment Program. The LGF Program is coordinated with the related efforts of other agencies. Program and subprogram R\&D is being conducted by national laboratories, universities, technical institutions and industrial research contractors.

As a contribution to the LGF Program, the ESED requested Pacific Northwest Laboratory (PNL) to prepare this report on R\&D needs in the area of Ammonia Safety and Environmental Control. A principal purpose of this PNL project is to provide the ESED with an information and data base that assists the future planning and implementation of the DOE Subprogram on Ammonia. In addition, this assessment offers a comprehensive perspective on ammonia safety and environmental control issues that may aid decision-making and R\&D planning activities of both the ammonia industry and other government agencies.

Four major objectives were established to fulfill the requirements of this project:

1. characterize the ammonia industry covering all operations from production to end use,

2. review current knowledge of ammonia release, dispersion and impacts,

3. summarize the status of current ammonia release prevention and control methods, and

4. identify remaining safety and environmental problems and recommend R\&D that may mitigate these problems. 
These objectives were accomplished by perfoming seven major subtasks. The results and findings of these subtasks were then integrated in the preparation of this report. The subtasks were:

- Task 1 - Health Effects Review - Extract from previous reports an overview of the health effects and toxicity of accidental ammonia spills. Identify human and ecological damage thresholds to provide a basis for determining the required controls.

- Task 2 - Technology Review - Describe and analyze the energy-related uses and include consideration of production, storage and transportation. Focus on accidental releases, controls and the differences between current systems and the ones necessary for new energy-related uses.

- Task 3 - Vapor Generation and Dispersion Analysis - Evaluate how well anmonia spills, dispersion and the associated hazards can be predicted. Evaluate current analytical and experimental methods and identify the need for improved models and/or more experimental information.

- Task 4 - Fire hazards Analysis - Assess the fire and explosion hazards associated with accidental spills. Compare the hazards of ammonia with better known energy materials such as alcohol and hydrocarbons.

- Task 5 - Accident Statistics - Collect and categorize historic accident data for ammonia spills. Use this compilation as a background reference to assess mitigation and control methods for new energy-related uses.

- Task 6 - Ecological Effects and Hazards - Identify and assess potential hazards of increased ammonia use including impacts caused by spills.

- Task 7 - Control and Mitigation Assessment - Identify and evaluate the release control and mitigation strategies which can be applied to limit the effects of accidental releases of ammonia. Use this information as a basis for assessing the adequacy of current mitigation methods. Determine information gaps and develop $R \& D$ reconmendations pertaining to accidental spills. 
The report consists of six major chapters covering the technical aspects of the assessment plus five appendices to document data bases and methodologies used in the work. In addition a comprehensive annotated bibliography according to subject areas is included.

Chapter 2 describes the basic properties and characteristics of ammonia and outlines the current production, storage and transportation systems. It also focuses on some of the safety problems now being faced.

Chapter 3 provides a listing and brief description of the varied uses of ammonia. Some effort is spent on current industrial and agricultural uses but the main focus is on newer energy-related applications such as cooling towers, heat pipes and thermochemical energy storage systems.

Chapter 4 presents the results of work to identify, collect and evaluate accident data. The main sources include National Transportation Safety Board, U.S. Bureau of Labor Statistics and various state industrial comissions and workers compensation departments. Appendix A includes some case histories of human exposure to ammonia.

Chapter 5 is an in-depth assessment of the hazards associated with large spills of ammonia. It contains a review of anatytical and empirical methods for describing spills and the subsequent dispersion of ammonia clouds. Several spill scenarios are defined and original calculations methods and results are presented. The details of these caiculations are given in Appendix $B$.

Another section of Chapter 5 focuses on the potential for fire and explosion hazards. This includes some analytical work to evaluate the possibility of a sustained fire should an ignition source be present during or after a 1arge spil1. Details of these calculations are in Appendix $C$.

Chapter 5 also includes a review of the effects of ammonia on humans and an assessment of the potential environmental impacts of ammonia spills. Several spill scenarios for trucks, railroad tank cars, pipelines, barges and ships have been considered. Lakes and streams, estuaries and oceans have been evaluated to determine their ability to sustain shock loads of ammonia. Short-term and long-term impacts to the ecosystems are considered. Much of the extensive analyses for the environmental analyses are documented in Appendix D. 
Chapter 6 reviews current environmental and safety regulations for ammonia. Current control and mitigation methods are also discussed. Particular attention is given to the potential problems for newer energy-related applications of ammonia.

Chapter 7 summarizes the knowledge gaps discovered by this assessment and lists specific recommendations for further R\&D. 



\section{D AMMONIA PRODUCTION, STORAGE AND IRANSPORTATION}

Ammonia represents a very important resource for use in a wide variety of applications. It is manufactured in large quantities all over the world, and it is likely that the number of uses will increase in the future. This section briefly reviews the properties of ammonia, describes the principal elements of production, storage and transportation and projects the development of these systems in the future.

\subsection{PROPERTIES OF AMMONIA}

The physical and chemical properties of ammonia $\left(\mathrm{NH}_{3}\right)$ have been extensively investigated and are well known. A wide variety of reports are available for further reference (LeBlanc et a1. 1979, Haar and Gallagher 1978, Anhydrous Ammonia 1977, Ahrendh and Baehr 1979, Slack and James 1974-1979). The effect of ammonia on living matter has also been the subject of numerous studies (for example, National Research Council 1979).

Ammonia is regarded as toxic because of its powerful corrosive action on human and animat tissue, especialiy that of the mouth, throat, and lungs. $A$ detailed coverage of this subject matter is presented in Chapter 5.

For the purpose of the present investigation, it is important to mention that amrnonia must be stored in sealed containers, either as a gas under pressure or as a liquid at temperatures below $-30^{\circ} \mathrm{C}$. Liquid anhydrous ammonia is lighter than water $\left(682 \mathrm{~kg} / \mathrm{m}^{3}\right)$ at its normal boiling point $\left(-33^{\circ} \mathrm{C}\right)$, while ammonia vapor is lighter than air by a factor of 0.6 under ambient conditions. Table 2.1 contains its important physical and chemical properties.

Ammonia dissolves very easily in water, resulting in "aqueous anmonia". This is an exothermic process generating $8.4 \mathrm{k} \mathrm{cal} / \mathrm{mole}$. At $0^{\circ} \mathrm{C}$ one volume of water dissolves more than 1000 volumes of ammonia vapor. The solubility decreases rapidly with increasing temperature. A small part of the dissolved ammonia 
TABLE 2.1. Physicochemical Properties of Anhydrous Ammonia

\begin{tabular}{|c|c|}
\hline Chemica] Formula & $\mathrm{NH}_{3}$ \\
\hline Molecular weight & 17.031 \\
\hline Melting Point & $-77.7^{\circ} \mathrm{C}$ \\
\hline Normal Boiling Point (NBP) & $-33.4^{\circ} \mathrm{C}$ \\
\hline \multicolumn{2}{|l|}{ Density at Norma] Boiling Point } \\
\hline Vapor & $0.901 \mathrm{~kg} / \mathrm{m}^{3}$ \\
\hline Liquid & $690 \mathrm{~kg} / \mathrm{m}^{3}$ \\
\hline \multicolumn{2}{|l|}{ Density at $21^{\circ} \mathrm{C}$} \\
\hline Vapor & $0.702 \mathrm{~kg} / \mathrm{m}^{3}$ \\
\hline Liquid & $616 \mathrm{~kg} / \mathrm{m}^{3}$ \\
\hline Lower Heating Value & $278,630 \mathrm{~kJ} / \mathrm{kg}$ \\
\hline Heat of Vaporization at NBP & $1360 \mathrm{~kJ} / \mathrm{kg}$ \\
\hline Flammable Limits in Air & $16-27$ vol\% \\
\hline Autoignition Temperature & $651^{\circ} \mathrm{C}$ \\
\hline Specific Heat $(C p)$ & $2.10 \mathrm{~kJ} / \mathrm{kg}\left(\right.$ at $\left.1 \mathrm{~atm}, 0^{\circ} \mathrm{C}\right)$ \\
\hline \multicolumn{2}{|l|}{ Critical Data } \\
\hline Critical Temperature & $133.0^{\circ} \mathrm{C}$ \\
\hline Critical Pressure & $11,425 \mathrm{kPa}$ \\
\hline Critical Density & $235 \mathrm{~kg} / \mathrm{m}^{3}$ \\
\hline \multirow[t]{4}{*}{ Solubility in Water } & $42.8 \%$ (wt) (at I atm, $\left.0^{\circ} \mathrm{C}\right)$ \\
\hline & $33.1 \%$ (wt) (at $\left.1 \mathrm{~atm}, 20^{\circ} \mathrm{C}\right)$ \\
\hline & $23.4 \%$ (wt) (at $\left.1 \mathrm{~atm}, 40^{\circ} \mathrm{C}\right)$ \\
\hline & $14.1 \%$ (wt) (at $\left.1 \mathrm{~atm}, 60^{\circ} \mathrm{C}\right)$ \\
\hline $\begin{array}{l}\text { Heat of Solution of } \mathrm{NH}_{3} \text { Vapor } \\
\text { in Water }\end{array}$ & $2180 \mathrm{~kJ} / \mathrm{kg}$ \\
\hline
\end{tabular}

reacts chemically with the water to form alkaline ammonium hydroxide $\left(\mathrm{NH}_{4} \mathrm{OH}\right)$. (a) Generally, as a chemical compound $\mathrm{NH}_{3}$ is highly associated and stable. Dissociation into $\mathrm{N}_{2}$ and $\mathrm{H}_{2}$ begins to occur at $450^{\circ} \mathrm{C}$ and atmospheric pressure. In the presence of certain catalysts it begins to dissociate at lower temperatures.

(a) In a 1 molar solution of $\mathrm{NH}_{3}$ in $\mathrm{H}_{2} \mathrm{O}$ only $0.4 \%$ of the ammonia is in the form of $\mathrm{NH}_{4} \mathrm{OH}$, which in turn is almost completely dissociated into $\mathrm{NH}_{4}^{+}$and $\mathrm{OH}^{-}$ions. 
Amonia-air mixtures will generally not ignite below $850^{\circ} \mathrm{C}$ and then only within a range of $16-25$ vol\% of $\mathrm{NH}_{3}$. Due to this low susceptibility to fire, ammonia is classified by the Department of Transportation (DOT) as a nonflammable gas.

Chemically, ammonia is quite reactive, forming ammonium salts with inorganic or organic acids. Dther classes of reaction products are amines, amides, and amoniates. Most common metals are not affected by ammonia; however, when combined with water, ammonia will attack copper, zinc, or their alloys. Therefore, such materials are not used in contact with ammonia. Stress corrosion cracking can be caused by ammonia in certain steels.

Ammonia is an excellent solvent and, in this capacity, is rated second only to water. It can also form, like water, numerous addition compounds, the ammoniates, which are analogous to the hydrates. In analogy to the hydrolysis reactions of water one or more of the $H$ atoms in the ammonia can be replaced by other atoms or radicals. This process is, accordingly, called ammonolysis. In the inorganic field many ammonolytic reactions have gained practical importance. The most important and widely known inorganic reaction of this kind is the urea reaction.

$$
\mathrm{CO}_{2}+2 \mathrm{NH}_{3}+\mathrm{CO}\left(\mathrm{NH}_{2}\right)_{2}+\mathrm{H}_{2} \mathrm{O}
$$

Ammonia is commercially available in four grades with increasing purity: commercial grade, 99.5 wt\% minimum; agricultural grade, 99.7 wt\% minimum; refrigeration grade, 99.95 wt\% minimum; metaliurgical grade, 99.995 wt\% minimum. The impurities usually consist of water and oil.

\subsection{PRODUCTION OF AMMONIA}

Most ammonia is produced today from hydrogen and nitrogen by use of the Haber-Bosch process. In all cases, the synthesis gas (i.e., three parts $\mathrm{H}_{2}$ and one part $\mathrm{N}_{2}$ ) must be very pure, since contaminants may easily destroy the catalysts used in the final ammonia synthesis (Noyes 1967). Therefore, the main task in ammonia manufacture consists of the production and cleaning of the synthesis gas. For this purpose, many approaches are possible (STack and James 1974-1979). In the U.S. the required hydrogen is produced mainly by the 
steam reforming of natural gas. Some other countries utilize feedstocks such as liquid hydrocarbons (naphtha), heavy fuel oils, or coal in a partial oxidation process. The nitrogen is always obtained from air.

When considering the principal feedstocks for ammonia, it has been shown that, both in regard to plant investment and required energy costs for operating large ammonia plants, the feedstocks rank in this order, as of 1979: natura1 gas is the most economical, followed by naphtha, fuel oil, and coa? (Czuppon and Buividas 1979).

If natural gas becomes less abundant and more expensive in the future, it is likely that ammonia production from coal will become more widely acceptable, even in this country (Buivadas 1980, Tennessee Valley Authority 1979). Whereas many overseas ammonia plants are based on naphtha as feedstock, the use of this alternative is being reduced (Spear 1980). In fact, some large overseas ammonia plants already are using coal feedstock (Partridge 1976). The variety of actual and potential coal-based ammonia processes is aimost as large as that for coal gasification. This is because the generation of hydrogen is a common feature of coal gasification and ammonia production. Recent data show about $60 \%$ of all hydrogen produced in the United States is being used for ammonia manufacture (Corneil and Hinzelmann 1980). However, this share is expected to decrease in the future, when more hydrogen is required for synfuel production.

\subsubsection{Hydrogen Production}

Steam reforming of natural gas (or of other 1 ight hydrocarbons, e.g., naphtha) is a proven and widely-used process for the production of hydrogen, and the first step in manufacturing ammonia. Basically, the process consists of a catalytic conversion of hydrocarbons and steam to hydrogen and carbon oxides. In order to insure a long life of the catalysts used in the process, the feedstock must first be desulfurized as indicated in Figure 2.1. It is then mixed with process steam and reformed over a nickel-based catalyst in the reformer furnace, where the following reactions take place:

$$
\begin{aligned}
& \text { generaliy } \mathrm{C}_{n} \mathrm{H}_{\mathrm{m}}+\mathrm{nH}_{2} \mathrm{O} \neq \mathrm{nCO}+\frac{2 n+m_{H_{2}} \text { or }}{2} \\
& \mathrm{CH}_{4}+\mathrm{H}_{2} \mathrm{O}=\mathrm{CO}+3 \mathrm{H}_{2} \text { when using methane. }
\end{aligned}
$$




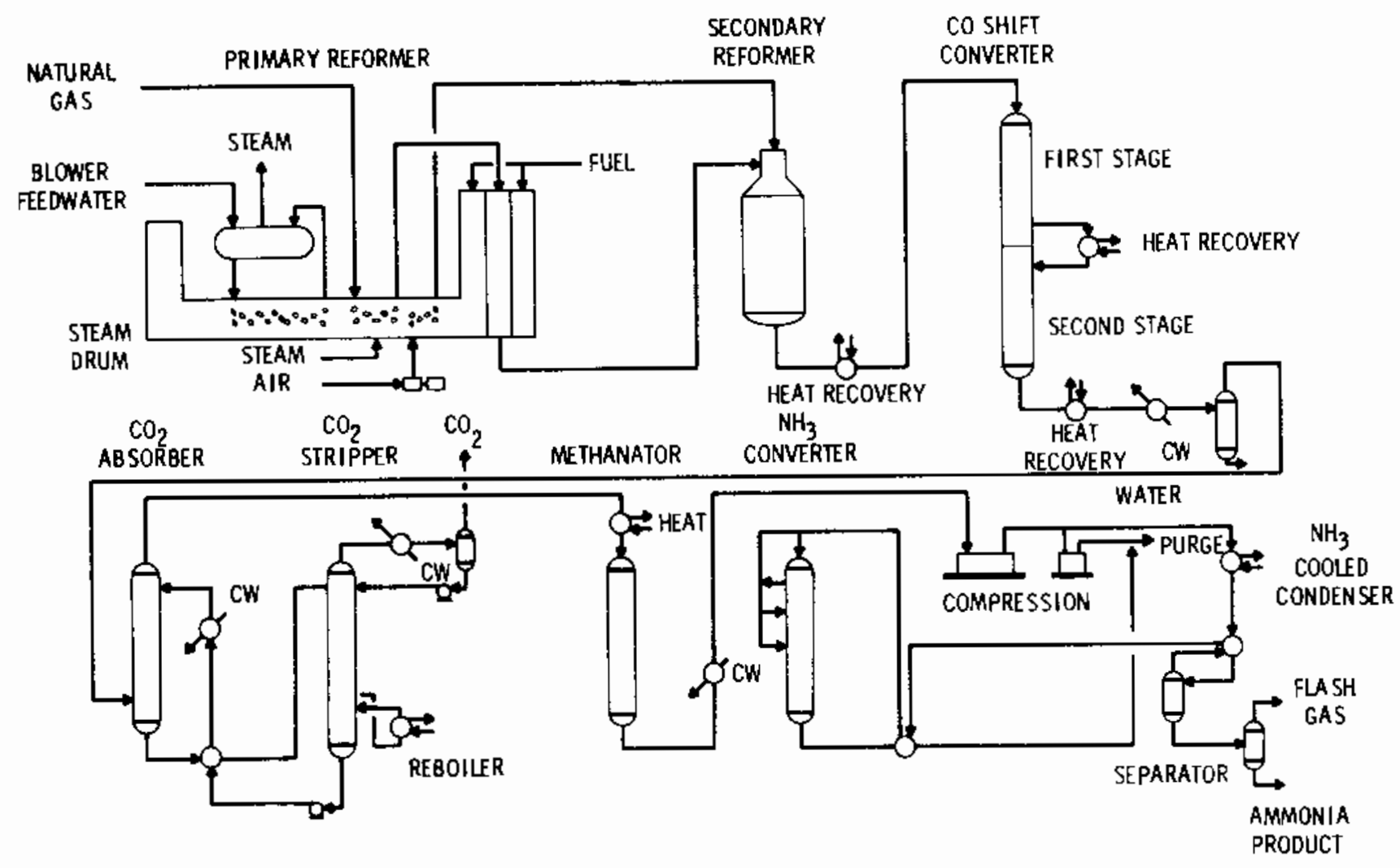

FIGURE 2.1. Typical Flowsheet for Kellogg-Designed Amtionia Plant

The catalysts are usually contained in vertical tubes ( 24 to 5 in. ID), and the process gas passes through these catalyst tubes. Since the overall reforming reaction is highly endothermic, the catalyst tubes are placed in a furnace which supplied the required heat of reaction by a number of burners fed by naturai gas. The equilibrium composition of the outlet gas is determined by the steam-to-carbon ratio, outlet pressure (about $3 \mathrm{D}$ atm) and temperature (normally about $700^{\circ} \mathrm{C}$ ). Although it is possible to steam reform hydrocarbons in a single stage, it has become common practice to utilize an unheated second-stage reformer. This allows more efficient operation at lower temperatures and higher pressures. Since the secondary reformer uses air (or oxygen-enriched air) instead of steam, this is a convenient place for introducing the nitrogen required into the system for the later $\mathrm{NH}_{3}$ synthesis. The nitrogen passes through the following stages of the synthesis gas preparation essentially as a diluent, taking no part in the ongoing chemical reactions. This type of approach minimizes the requirements for separate air separation equipment. 
The raw process gas from the reformer is cooled down to about $350^{\circ} \mathrm{C}$ before entering the high-temperature shift catalyst bed, where a major portion of the $\mathrm{CO}$ is converted into $\mathrm{CO}_{2}$ and hydrogen is produced, according to

$$
\mathrm{H}_{2} \mathrm{O}+\mathrm{CO} \rightleftharpoons \mathrm{CO}_{2}+\mathrm{H}_{2} .
$$

Since this reaction is exothermic, there is a temperature increase along the bed. Therefore, the high temperature shift effluent is cooled down to about $200^{\circ} \mathrm{C}$ before entering the low temperature shift reactor, where the $C 0$ conversion reaction proceeds further to reduce the CO content in the gas to 0.2 vol\%. After additional cooling, the gas is then fed into a $\mathrm{CO}_{2}$ absorber, (a) where $\mathrm{CO}_{2}$ is reduced to a level of $0.1 \%$ or less.

The small amounts of residual $\mathrm{CO}$ and $\mathrm{CO}_{2}$ in the now-almost pure hydrogen are removed in the methanator over a nickel catalyst at about $350^{\circ} \mathrm{C}$ according to:

$$
\begin{gathered}
\mathrm{CO}+3 \mathrm{H}_{2} \rightarrow \mathrm{CH}_{4}+\mathrm{H}_{2} \mathrm{O} \\
\mathrm{CO}_{2}+4 \mathrm{H}_{2} \rightarrow \mathrm{CH}_{4}+\mathrm{H}_{2} \mathrm{O} .
\end{gathered}
$$

\subsubsection{Armonia Synthesis}

By combining these processes, the $\mathrm{CO}$ and $\mathrm{CO}_{2}$ levels are reduced to 5-10 ppm, which is tolerable for the ammonia synthesis process. The now-pure synthesis gas (consisting of 3 parts $\mathrm{H}_{2}$ and 1 part $\mathrm{N}_{2}$ ) is compressed from 230 atm to above $200 \mathrm{~atm}$ in a large compressor train (Stokes 1979). This step in the ammonia production represents a relatively large cost factor. In the synthesis converter which follows, the conversion of the hydrogen and nitrogen to ammonia takes place at elevated pressures and temperatures (up to $500^{\circ} \mathrm{C}$ ) in the presence of suitable catalysts (mainly iron oxides). Since the synthesis reaction itself is exothermic, no heat input from the outside is required. On the contrary, usually cooling (quenching) is necessary to prevent overheating. The product gas from the converter is cooled and passed to one or more separators,

(a) Sometimes the $\mathrm{CO}_{2}$ absorber is followed by a $\mathrm{CO}_{2}$ stripper, serving essentially the same purpose? 
where the ammonia product is recovered, and unreacted synthesis gas is returned to the converter. The ammonia is finally depressurized, condensed, and refrigerated so that it can be sold as an anyhdrous liquid at atmospheric pressure.

As with the synthesis gas production steps, the ammonia synthesis itself can also be subject to different variations, too numerous and too detailed to be included in this report. Only the main features of the overall ammonia production process have been described here. Many details have been omitted. (a)

\subsection{AMMONIA STORAGE AND DISTRIBUTION}

Most $\mathrm{NH}_{3}$ production plants store ammonia at atmospheric pressure. The liquid $\mathrm{NH}_{3}$ in the storage vessels boils, and the resulting vapors are continuously refrigerated, condensed, and pumped back into the storage tanks. Liquid storage at atmospheric pressures involves far less capital investment than storage under pressure. From the storage tanks at the manufacturing plants the ammonia is shipped by truck, rail, barge, or pipeline to receiving tanks at the various distributing centers.

Liquid anmonia storage in underground caverns has been attempted. However, the anmonia frequently dissolves impurities from the cavern wall (Sherman 1970) and must, therefore, usually be distilled before it can be sold, unless contaminated $\mathrm{NH}_{3}$ is acceptable to the buyer.

Any facility as complex as an ammonia plant is apt to have breakdowns and accidents. The ammonia industry has tried to share information on operating experience and circumstances. This desire to share information has led to the occurrence of unscheduled events in the form of periodic conferences on "Ammonia Plant Safety", which have now been held for 25 years. From the records of these meetings it has become clear that most of the plant incidents did not involve ammonia directly. Rather, the many individual components which make up the entire process train were the main cause of failures (Williams 1978). Only in rare cases was ammonia released as spills or major leaks.

The overall impression is that anmonia plants have been relatively safe as far as accidents caused by toxic ammonia are concerned. More of the accidents

(a) For a more thorough description, see Noyes 1967, Slack and James 1974-1979. 
involving $\mathrm{NH}_{3}$ have occurred in the ammonia distribution system and at the consumer end of the system. The reason may be that the ammonia plants themselves are operated by a rather small number of experienced people who are well-acquainted with safe operational procedures. On the other hand, once the ammonia leaves the plant, it is transported and used by literaliy thousands of people who are much less experienced and knowledgeable in the proper handling of anmonia.

\subsubsection{Storage Containers}

Anmonia is always stored commercially as a liquid, either at full pressure (up to 15 bar) at ambient temperatures, partially refrigerated, or fully refrigerated (at $-33^{\circ} \mathrm{C}$ ) at ambient pressure. Storage at full pressure is the simplest method but is restricted to relatively small vessels, usually uninsulated and cylindrical in shape with dished heads. If necessary, the pressure can be reduced by withdrawing the $\mathrm{NH}_{3}$ vapor as it is generated, liquefying it, and recycling it. If the pressure is partially reduced, the vessel is usually spherical and must be insulated. If the pressure is fully reduced to atmospheric, normally flat-bottomed, vertically mounted, insulated cylindrical tanks are used.

The material of the container for storing and transporting liquid armonia is usually one or another of the varieties of carbon steel. Since such steels may be subjected to temperatures as low as $-33^{\circ} \mathrm{C}$, they are more liable to brittle fracture under stress. Such fracture usually originates from stresses concentrated by a notch or crack, generally in association with a weld. Relieving thermal stress after fabrication of a vessel can reduce these stresses significantly.

Besides this problem of brittle fracture, certain carbon steels are also subject to stress corrosion cracking (SCC) when exposed to ammonia. Since the general problem of SCC is not fully understood, expert advice in the design and procurement of all equipment for liquid ammonia is usually sought out. A detailed discussion of the various types of armonia storage tanks can be found in Slack and James 1974-1979.

Suitable safety devices are usually fitted to both atmospheric and pressure storage vessels to avoid overfilling, overpressurizing, or accidental mishandling. 
Dual relief valves are important to insure that if the relief valve lifts, the ammonia vapor is vented harmlessly, e.g., through a stack. A liquid separator is often introduced in the vent $l$ ine if there is a danger of a gaseous/liquid mixture escaping through the relief valves. Tanks which operate at full pressure or in the semi-refrigerated state can usually withstand vacuum conditions. However, a cylindrical flat-bottomed tank can only withstand a small vacuum, and these tanks should be fitted with vacuum breakers, in addition to relief vaives.

Since it is also important to observe the quantity of liquid ammonia in the vessel at all times to avoid overfilling, the installation of liquid level indicators is necessary. Usually, two independent meters are installed in each tank. It is nomal for level indicators to be fitted with high-level alarms to warn the operator when the maximum filling level has been reached. Atmospheric and semipressure storage tanks must have instrumentation to insure that the design pressure is not exceeded. Atmospheric tanks may be filled to within a few inches of the roof-weld seam. It has been usual to fit the vessels with independent highlevel alarms. Atmospheric and semi-pressure tanks would vent to atmosphere in the event of a total failure of the refrigeration plant. The most likely cause of total failure would be a power failure. Normally, it would take several hours for the pressure to rise to a relief valve pressure, by which time the power might have been restored. It is good safety practice to place a quick-response value on the outlet of the tank.

Since ammonia storage vessels are pressure vesse1s, they are subject to statutory, periodic examinations. Vessels made of high-strength steel (that are prone to SCC) are very thoroughly inspected, both externally and internally. Before filling or refilling a storage vessel, it is carefully purged so that no oxygen remains in the vessel. The cooling down to $-33^{\circ} \mathrm{C}$ is done very carefully to avoid thermal stresses in the vessel material.

\subsubsection{Distribution Systems}

There are more than 100 ammonia manufacturing plants in the United States. Therefore, it is usually not necessary to distribute ammonia over very long distances. Because transportation of ammonia as a vapor is not commercially economical, it is always shipped and stored as compressed and liquefied gas. The transportation of ammonia by rail, highway, air, water, or pipeline is 
governed by federal authority under regulations by DOT. These regulations include specifications for the construction, marking, and qualification of transportation containers for amonia. Additional regulations are issued for water transport by the Intergovernmental Maritime Consultative Organization (IMCO) and for air transport by the International Air Transport Association (IATA). The storage and handling of ammonia is regulated by the Department of Labor through the Occupational Safety and Health Administration (OSHA). Furthermore, municipal, county, and state regulations also exist in many localities, affecting the transportation, storage, and handling of ammonia. A survey of the various codes and regulations is given in Chapter 6. 'A brief summary of their main points follows:

1. Ammonia must always be properly identified as "anyhdrous ammonia" and classified as "nonflammable gas".

2. Shipping containers constructed of quenched and tempered steel must contain at least $0.2 \%$ (by weight) water, and only authorized containers, manufactured according to DOT specifications, can be used.

3. The containers may not be filled to more than $57 \%$ by volume to provide a cushion for the pressurization caused by the thermat expansion of the ammonia, should its temperature increase. A pressure relief device is also required on each container. The tanks are designed for a working pressure of 225 psig (15.5 bars, which corresponds to a temperature of the liquid ammonia of $110^{\circ} \mathrm{F}\left(43^{\circ} \mathrm{C}\right)$. Pressure relief valves would be activated if the temperature of the liquid should rise above $110^{\circ} \mathrm{F}$ on a very hot day.

4. For rail transportation a shipment of ammonia is authorized only in specia? tank cars, which may or may not be thermally insulated. Most of these cars can hold 26 tons of ammonia. Some larger (jumbo) cars hold about 80 tons. The fabrication of tank cars is regulated by detailed codes and specifications.

5. Loading and unloading facilities, as well as the procedures for their operation, are subject to detailed regulations to insure maximum safety. Particular attention has been given to proper valving (check valves and safety relief valves). 
6. Tank cars for road transportation are, similarly, covered by DOT specifications. Capacity is 1 imited to 25 tons gross weight.

7. Portable tanks, those which are not permanently attached to a vehicle, are also covered by numerous detailed specifications. Most of the nurse and applicator tanks used on farms for fertilizing purposes fall into this category.

8. Cylinders holding only small amounts (2-50 1b) of ammonia are, nonetheless, subject to rigid and detailed specifications.

9. Barges and tankers must be specially designed for the transportation of ammonia.

10. Artunionia pipelines are becoming the most economical way for the transportation of ammonia. So far, their use has been limited in the USA to one major pipeline system (the Gulf Central Pipeline), extending from the Gulf Coast (Louisiana) to lowa and Nebraska. Special codes and regulations govern the construction and operation of such pipelines.

11. Stationary containers used for temporary storage of ammonia range from a $2-m^{3}$ to $170-m^{3}$ capacity. Again, construction and maintenance of such containers is strictly regulated. The same holds for piping and equipment connected with the operation of such containers.

12. For maintaining safety and security around the various ammonia installations OSHA has issued pertinent rules and regulations (Federal Register 39, No. 125) e.g., protective clothing, including splash goggles, should be worn by workers potentially exposed to ammonia. Gas masks and safety showers should be available within easy reach. Installations should be fenced in and be guarded, etc.

A large volume of written information, articles, incident reports, etc., is available, based on many decades of routine handling of ammonia. A predominant publication in this field are the yearly issues of "Ammonia Plant Safety" by Chemical Engineering Program, which, have run for 25 years. 



\subsection{USES OF AMMONIA}

Armonia manufacturing plants exist in many different sizes, with outputs ranging from as little as $10 \times 10^{3}$ tons per year to more than $1000 \times 10^{3}$ tons per year. Total U.S. production in 1979 was approximately $16 \times 10^{6}$ tons and world production about $75 \times 10^{6}$ tons. Ammonia cost has been varying widely over the last 10 years, between $\$ 80$ to more than $\$ 200 /$ ton .

Since about 1970, ammonia has ranked first in value of all chemicals produced in the United States (Blouin 1979). About 75 to $80 \%$ of this ammonia is used as fertilizer, either by direct application or as feedstock for the production of most other types of fertilizers. Much of the remaining industrially-produced ammonia is used by the chemical industry as the primary raw material for making over 80 inorganic and 1,000 organic compounds. Anhydrous ammonia and its derivatives are used in the manufacture of nearly 2,500 industrial products throughout the world. The purpose of this section is to highlight current uses and to identify the areas where potentialiy large new applications may be developed.

\subsection{CHEMICAL INDUSTRY}

The most important ammonia-based product of the chemical industry is nitric acid, which is used to manufacture many other products, such as various fertilizers, plastics, and explosives. About $99 \%$ of the industrial explosives produced in the United States are nitrogen-based, and about 0.5 million tons of ammonia are used annually in their production. Military explosives are also predominantiy nitrogen-based. Their production figures are not available.

About 2,000,000 tons of ammonia are used yearly in the United States for polymeric materials. There is a vast array of plastics, resins, copolymers, cellulose derivatives, acrylic phenolics, nylons, urethanes, rubbers, polyvinyl amines, amino resins (mainly urea formaldehyde), epoxy resins, polyesters, etc., on the market that are based on or use anhydrous ammonia or ammonia derivatives. For other industrial chemicals (such as anilines, hydrazine, ammonium chlorides, and many others) about 300,000 tons per year of ammonia are currently being used. 
Miscellaneous other uses of $\mathrm{NH}_{3}$, or $\mathrm{NH}_{3}$ derivatives, can be found in water treatment applications, in petroleum refining, in engraving and biueprint photography, for food and beverage treatment, in the pharmaceutical industry, in the manufacture of solvents, cleaners, and detergents, for the production of dyes and inks, for textile and leather treatment, for pump and paper production and rubber manufacture. In the mineral industry ammonia is used in extracting certain metals such as copper, nickel, and molybdenum from their ores.

\subsection{AGRICULTURE}

The application of ammonia as fertilizer has increased in the U.S. about four times since 1957. As a result, directly applied $\mathrm{NH}_{3}$ today is the most widely used nitrogen fertilizer source. The primary reason for this growth has been the low cost of ammonia (about 20-30\% less) relative to other nitrogen fertilizers, virtually all of which are made from $\mathrm{NH}_{3}$. This economic advantage holds particularly true for large farming operations, which own advanced farming machinery able to combine tilling, $\mathrm{NH}_{3}$ injection, liquid starter and herbicide application at planting into one simultaneous pass. Evaporative $\mathrm{NH}_{3}$ losses during such an operation can be held to less than $1 \%$ if proper soil conditioning and injection depths are practiced. On the other hand, injection into dry, light, sandy soils may result in appreciable losses.

Among the indirect ammonia fertilizers, ammonium nitrate and urea are the most important types. They can be applied either as a solid or in liquid solution. Other $\mathrm{NH}_{3}$-derived fertilizers are ammonium sulfate, ammonium-phosphate, -super phosphates, -polyphosphates, nitric phosphates, etc.

In addition to its use as a source for direct or indirect fertilizer, anhydrous ammonia has found a number of nonfertilizer applications in agriculture. They include use of $\mathrm{NH}_{3}$ as harvest aid (defoliant) for cotton, as supplemental animal feed (source of protein) for ruminant livestock, as an algae control in irrigation ponds, as a sealant in concrete pipes (used for field irrigation), as a pest control (fumigant) in the control of rodents, insects, mold, etc. 


\subsection{ENERGY-RELATED APPLICATIONS}

The use of ammonia as a fuel and other energy-related applications are the subject of the following sections of this chapter. It is this type of new use which is likely to expand significantly in the future and which, therefore, might possibly add to future environmental problems, particularly since little practical experience with these new applications is available yet.

\subsubsection{Fuel Use}

On several occasions in the past, anhydrous ammonia has been considered and actually been used as a fuel for combustion engines. Ammonia Casale obtained patents for such applications in the 1930s. During World War II ammonia was used occasionally in Europe, with remarkable success as fuel for public transportation. For instance, a fleet of about 100 buses was operated in Brussels during 1942-1943. In the 1960s the U.S. Army considered ammonia as a fuel for its vehicles overseas and intended to manufacture it with electrical energy obtained from mobile nuclear reactors. Extensive tests showed at that time that ammonia can be used successfully in slightly modified diesel engines, gas turbines, and regular spark-ignition engines. But since the required mobile reactors were never fully developed, the whole idea was eventually dropped around 1970. In separate, independent investigations it was shown that ammonia is also suitable as a rocket fuel and for use in fuel cells.

As a result of such development work it has become evident that there are both advantages and disadvantages connected with using ammonia as a fuel:

- It has been demonstrated in various tests that the thermal efficiency of combustion engines is slightly higher with ammonia than with conventional fuels.

- Ammonia is a nonfossil fuel that can be generated from just water and air and energy. The energy, of course, can also come from nonfossil sources such as nuclear power. This might become of prime importance when fossil fuels become scarce and when fusion power becomes available.

- Since ammonia is noncarbonaceous, its combustion products are free of $\mathrm{CO}_{2}$. Thus, its use would counteract the problem of growing $\mathrm{CO}_{2}$ accumulation in the atmosphere. The output of other common exhaust pollutants 
(such as $\mathrm{NO}_{x}$ and sulfur oxides) would also be greatly reduced, since ammonia is basically a very clean fuel which, upon combustion, ideally yields merely water and nitrogen. However, $\mathrm{NO}_{\mathrm{x}}$ generation could become significant under unfavorable combustion conditions.

- A distinct drawback of ammonia as a fuel, when, e.g., compared to gasoline, is its toxicity.

- It has a relatively low energy content $(28,000 \mathrm{Btu} / 1 \mathrm{~b}$ versus $218,000 \mathrm{Btu} / 1 \mathrm{~b}$ gasoline) and would thus require rather large fuel tanks. However, economically ammonia is still quite competitive (on a dollar/Btu basis) with conventional fuels.

On balance, it must, therefore, be concluded that presently ammonia is not a serious contender for substituting conventional fuels, but in the future (perhaps within a few decades) ammonia might well become a viable alternate energy source.

\subsubsection{Binary Cycle Applications}

Since basic steam cycles have inherent limitations for obtaining higher efficiencies and a higher cost-effectiveness, it has often been proposed to use other working fluids than water (Meyer and Fischer 1962). Anmonia is one of the most frequently mentioned choices -- e.g., for improving the efficiency at the low temperature end of a Rankine cycle, it can be used advantageously for the following reasons: If steam is expanded in a turbine down to a temperature of $100^{\circ} \mathrm{F}$, its saturation pressure is about 1 psia. This very low pressure means very large exhaust volumes. For ammonia the vapor pressure at $100^{\circ} \mathrm{F}$ is about $200 \mathrm{psi}$. If one were to use ammonia as the low temperature exhaust fluid instead of steam, one could replace the large, low pressure steam turbines by a single medium pressure ammonia turbine (Wood 19691970; Meyer and Fischer 1962). Therefore, "binary cycle" systems have come under serious consideration in the last decade. An ammonia bottoming cycle operating at the low temperature end of a regular steam cycle would be able to use more of the heat that otherwise has to be rejected to the atmosphere (i.e., as waste heat) and thus increase the overall cost-effectiveness of the system. Of particular interest are such cycles for cases in which the energy 
is only available at a rather low temperature level, such as in geothermal or some solar applications, etc. In times past, when energy was inexpensive, the extra complexities of bottoming cycles or the use of geothermal or solar energy could seldom be justified for economical reasons. Therefore, it is only now that real interest in alternate working fluids for power generation has surfaced. It is expected to grow in the future.

Ammonia is not the only working fluid considered for binary cycle applications. Certain hydrocarbons and fluorocarbons have also been considered, but in most cases the $\mathrm{NH}_{3}$ appears to be superior (Schuster, Vrable and Huntsinger 1976). Compared with the other possible choices, ammonia permits a supercritical cycle operation with good thermal efficiency; it has particularly good thermophysical properties for binary cycle applications and thus allows for substantially reducing the size of the binary cycle turbine and condenser. Because of its good heat transfer characteristics it makes better use of the available heat transfer area in heat exchangers.

For such reasons, ammonia has been selected as the working fluid for the HTGR (High Temperature Gas-Cooled Reactor) gas turbine secondary cycle (McDonald and Vrable 1976). This optional secondary power cycle has been added to the design since it allows for the conversion of a substantial portion of the reactor's waste heat into additional power. The ammonia turbines and pumps required for that system have already been designed on a conceptual basis (McDonald and Vepa 1977). No particular sealing problems are anticipated for the closed ammonia cycle that have not been routinely encountered and overcome in similar applications with other working fluids. The same holds for the ammonia heat exchangers (McDonald and Vrable 1976).

\subsubsection{Cooling Towers}

To preserve precious water (particularly in arid regions) in the operation of power plants, there is a tendency now to switch to dry cooling towers, even though dry cooling generally results in higher generating costs than wet cooling (Steigelmann, Seth and Wachtell 1972; Hesse and Augustine 1980). Of particular interest is the combination of binary cycle power plants with dry cooling 
(Steigelmann, Seth and Wachtell 1972; Slusarek 1969; Blanc-Feraud and Fleury 1978; Fleury 1978). In such a case, the binary fluid (ammonia) is condensed in an air-cooled condenser, which essentially acts like a dry cooling tower. It has been shown that such a binary cycle approach is economically superior to a conventional one with dry cooling (Fleury 1978; Slusarek 1969). Electricite de France is constructing a pilot demonstration plant on this basis, to be put into service at the end of 1981 (Blanc-Feraud and Fleury 1978). Recently the use of ammonia in full binary cycle applications has also become the subject of conceptual studies in the U.S. under DOE sponsorship.

In the U.S. the use of ammonia in cooling towers has been under study for the last few years as one of the advanced cooling tower concepts. It is not a strict binary cycle application as discussed above. Rather, the ammonia serves as a heat transfer fluid between the power plant and its cooling tower (Allemann, Johnson and Smith 1976). Exhaust steam from the last stage of the turbine is condensed in the condenser/reboiler, located directly below the turbine (Figure 3.1). Liquid amnonia is partially evaporated as it is pumped through the tubes of the reboiler. The flow rate of ammonia is regulated to yield outlet vapor qualities of $50-90 \%$. The vapor is separated from the mixture and piped to the direct condensing cooling tower; the remaining liquid is recycled through the reboiler. The driving force for the ammonia

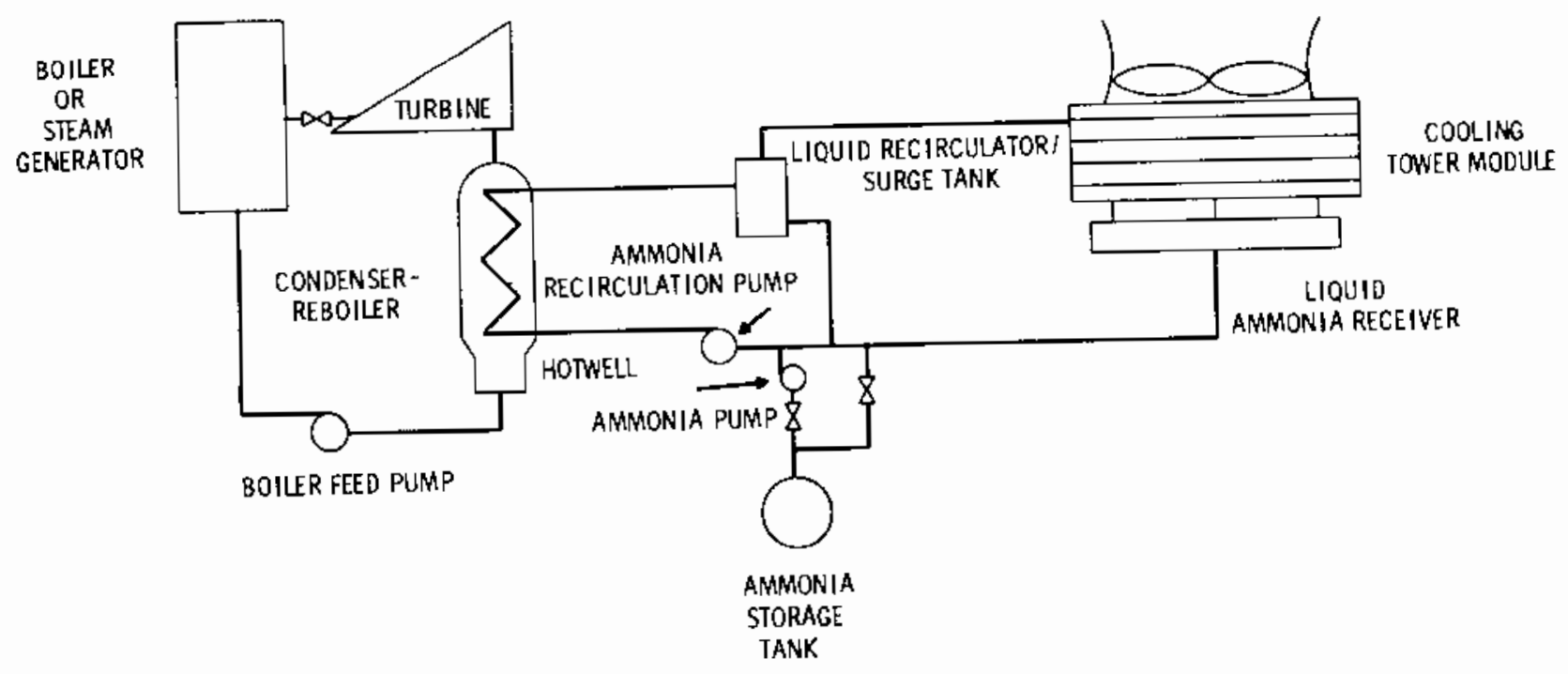

FIGURE 3.1. Simplified Schematic of Power Plant Ammonia Heat Rejection System 
vapor transport from the reboiler to the condenser is the difference between the saturation pressures in these components. Condensed liquid ammonia is returned to the reboiler by a gravity primed pump (Zaloudek et al. 1976).

Compared with other advanced cooling tower concepts, this type of ammonia heat rejection system in a dry cooling tower, when combined with metal finned tube-deluge water augmentation, showed the lowest capitalized operating cost (Bartz et al 1976). Similar conclusions regarding the cost-effectiveness of such cooling tower systems were arrived at in Tokarz et al (1978), Woodhull, Hu and Englesson (1978), Chait and Marchmont (1978), and Power Generating Cooling Systems (1975). As a result of these favorable appraisals a test facility is now under construction near Bakersfield, California, to evaluate the concept (Zaloudek 1978). It is expected that test operations will begin in 1981 .

One of the uncertainties to be resolved in the Bakersfield test facility operation is the potential noncompatibility of ammonia with certain candidate dry cooling tower system materials (Pratt 1976).

\subsubsection{OTEC Systems}

Ocean thermal energy conversion (OTEC) plants have been under study and development for half a century (Clinch 1978; Lavi 1980). Whereas the first plants were of the open cycle type, it was soon realized that a closed Rankine cycle system employing a suitable working fluid in an evaporator-turbine-condenser-pump loop could be developed more easily using existing technology drawn largely from the refrigeration/air-conditioning industry (Dugger, Francis and Avery 1978). Various types of working fluids for OTEC systems have been investigated in the U.S. over the years, with the result that anhydrous ammonia is now the preferred option (Ganic and Wu 1980; Ganic and Wu 1979; Carmichael 1979). Independently, the Japanese have come to the same conclusions (Kamogawa 1980).

Ammonia has a boiling point which is commensurate with the warm surface sea water. It is passed through an evaporator and a demister to generate dry ammonia vapor under pressure (Figure 3.2). The vapor is then expanded through a turbine and passed into the condenser, through which cold sea water, pumped from depths in excess of $600 \mathrm{~m}(\sim 2000 \mathrm{ft})$, is circulated. The condensed 


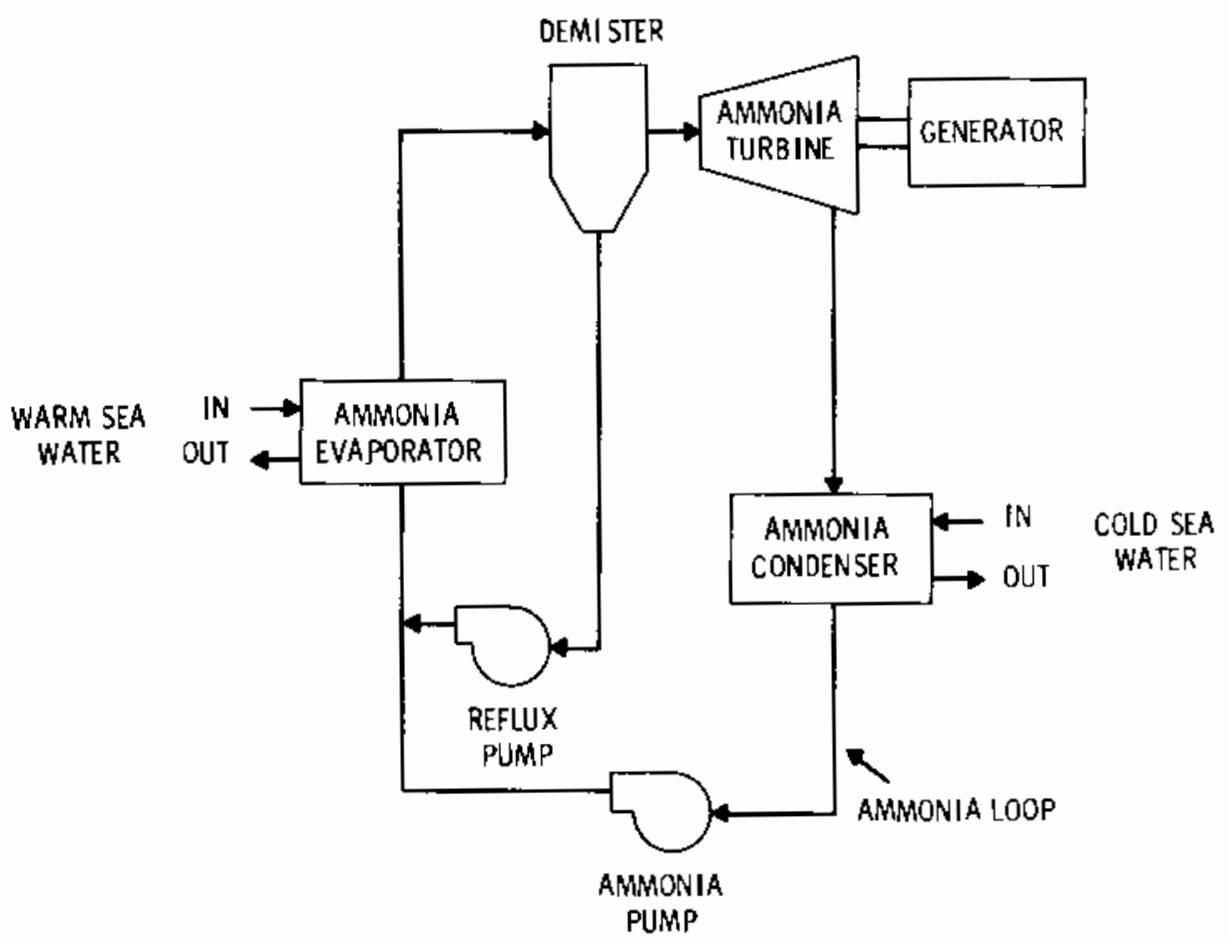

FIGURE 3.2. Schematic of OTEC Closed Rankine Cycle

ammonia is then pumped back to the evaporator to complete the closed loop. In the closed cycle system, the working fluid (ammonia) has a larger vapor density than the water vapor in the open cycie so the size of the turbine is reduced by operating at pressures greater than atmospheric (Carmichael 1979). Compared to other working fluids, such as propane and certain fluorocarbons, ammonia possesses a larger specific enthalpy change across the turbine (Ganic and wu 1979). This results in a lower mass flow of armonia for the same turbine generator output. In addition, ammonia has a higher thermal conductivity and higher liquid film heat transfer coefficient than any of the other working fluids. If propane is used instead of ammonia, a larger heat transfer surface area would be needed at increased costs to process the same amount of heat. The major disadvantage for ammonia is that it is highly soluble in water. A water leak in the ammonia cycle can have a detrimental effect on cycle performance. A recent analysis (Hafezzadah et al. 1977), indicates that even extremely low water concentrations in the ammonia cycle can degrade power performance. This is because the dew point is raised relative to the bubble point 
temperature with increasing water vapor concentration so that not all the ammonia is vaporized in the evaporator. For this reason, a liquid vapor separator (demister in Figure 3.2) is needed to remove water from the ammoniawater mixture leaving the evaporator. Thus, a major design goal in OTEC ammonia power cycles is to ensure that the heat exchangers (both evaporators and condensers) are fully protected against leaks.

Unquestionably, the heat exchangers are the most important components in the closed OTEC power cycle in terms of both performance and cost. If they fail to meet the desired performance, the OTEC cycle efficiency (which is inherently low) will be further degraded, resulting in reduced power production. The heat exchangers are projected also to be the most costly components of the OTEC plant. Estimates indicate that the heat exchangers could account for more than $50 \%$ of the total plant cost. Because of the sma11 temperature differences available between the sea water and the ammonia, extremely large heat exchanger surfaces are required to exchange the enormous quantities of heat. Therefore, it is a design goal to increase the overall heat transfer coefficient by "surface enhancement" techniques (see below) so as to reduce the heat exchanger size and cost (Sabin and Poppendiek 1979; McGowan 1979).

For the development and testing of OTEC heat exchangers special ammonia heat transfer test loops have been erected, e.g., at Argonne National Laboratory, Oak Ridge National Laboratory, and at Applied Physics Laboratory of Johns Hopkins University. Figure 3.3 shows the OTEC heat exchanger test facility at ANL. Surface enhancement by using fluted tubes in shell-and-tube type ammonia heat exchangers has proven quite successful (Lorenz et a1. 1979; Lewis and Sather 1979; Murphy and Hoffman 1979). In tests at ORNL it was found that by adding external flutes to the tubes the condensing heat transfer coefficient for anmonia on the outside surface could be increased up to seven times (Combs 1978). Studies of ammonia evaporation inside fluted tubes have been initiated (Murphy and Hoffman 1979). In order to minimize cost, simple two-phase flow heat exchangers made of large diameter aluminum tubes (ammonia inside, sea water outside) have also been considered (Dugger et al. 1977).

Because of potential corrosion problems the material selection for the heat exchanger is quite crucial; therefore, studies have been underway to 


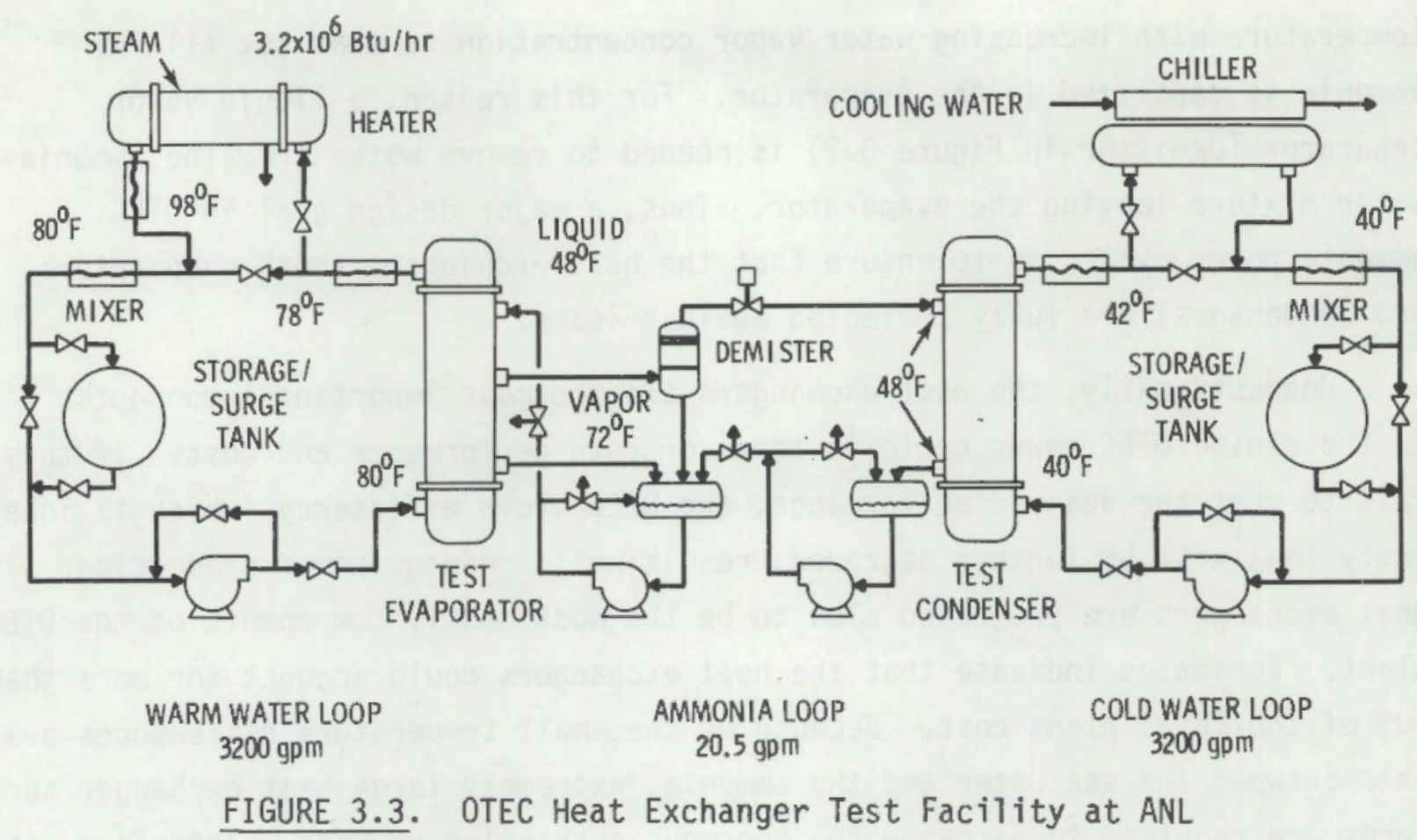

investigate materials behavior in ammonia-sea water environments. In particular, the possibility of either an ammonia or sea water intrusion (leak) in either the OTEC evaporator or condenser has been of concern (Schrieber, Grimes and McIlhenny 1979). Even low concentrations of ammonia in sea water, and conversely, low concentrations of sea water in ammonia were thought to impair material performance. However, tests have shown that corrosion and scaling problems may be within acceptable limits, particularly if materials such as titanium (Saaski and Owzarski 1977) or certain pre-treated aluminum alloys are used (Schrieber, Grimes and McIlhenny 1979). (a) It is anticipated that ammonia pumps and turbines for OTEC applications will not pose any serious development problems (Kostors and Vincent 1979).

Several methods have been proposed for utilizing the electrical energy produced on board a floating OTEC platform. Direct transmission of electrical energy by undersea cable is a direct approach, while conversion of electrical energy into an intermediate chemical product--which is shipped to shore for use

(a) For additional information on corrosion problems with ammonia see Chapter 6 . 
as a fuel or for reconversion to electrical energy--has also been investigated (Biederman et a1. 1978; Talib et a1. 1979; Cohen and Tschupp 1978; Konopka et al 1977).

A third method for energy utilization is the manufacture of an energy intensive product aboard the OTEC platform. The principal contenders in the latter category are aluminum smelting and hydrogen or ammonia production (Konopka et al. 1976; Dugger and Francis 1977; TWR Systems and Energy 1976; Cohen and Tschupp 1978). Since air, water, and energy are readily available at an OTEC power plant, such a facility would be self-sufficient for the synthesis of ammonia. Hydrogen generated by electrolysis of water on board is generally considered only as an intermediate product used for $\mathrm{NH}_{3}$ manufacture. Anhydrous ammonia would be stored in liquid form aboard the OTEC platform and periodically transported ashore by barge (Dugger and Francis 1977; Dugger, Francis and Avery 1978; Tal ib et a1. 1979). It has been shown that such a chemical storage/transmission system could be more economical than the transmission of electricity in submarine cables from an OTEC plant (Konopka et al. 1976; Biederman et al. 1978; Konopka et al. 1977). It could also be more economical than shipping the hydrogen either in gaseous or liquid form.

Whereas most design studies for economically operating OTEC plants (Trimble and Potash 1980) have been in the 100-MW(e) class or larger, the first test facility which is presently under construction is a $50-\mathrm{kW}$ plant off Hawaii. It uses the closed Rankine cycle with ammonia as working fluid (Energy Resource and Technology 1979).

\subsubsection{Refrigeration}

Since ammonia's normal boiling point is at $-33^{\circ} \mathrm{C}$ and because of other desirable thermodynamic properties, and also because of its relatively low cost, anhydrous ammonia is extensively used as a refrigerant, particularly in large commercial and industrial installations. As in most other applications, its most undesirable features are its toxicity and its corrosive action on certain metals, e.g., copper. It can be used both in mechanical compression type refrigeration systems and in absorption-adsorption systems. (See Figure 3.4). In the latter category, the ammonia-water system and the PlatenMunters system are the more important applications. 


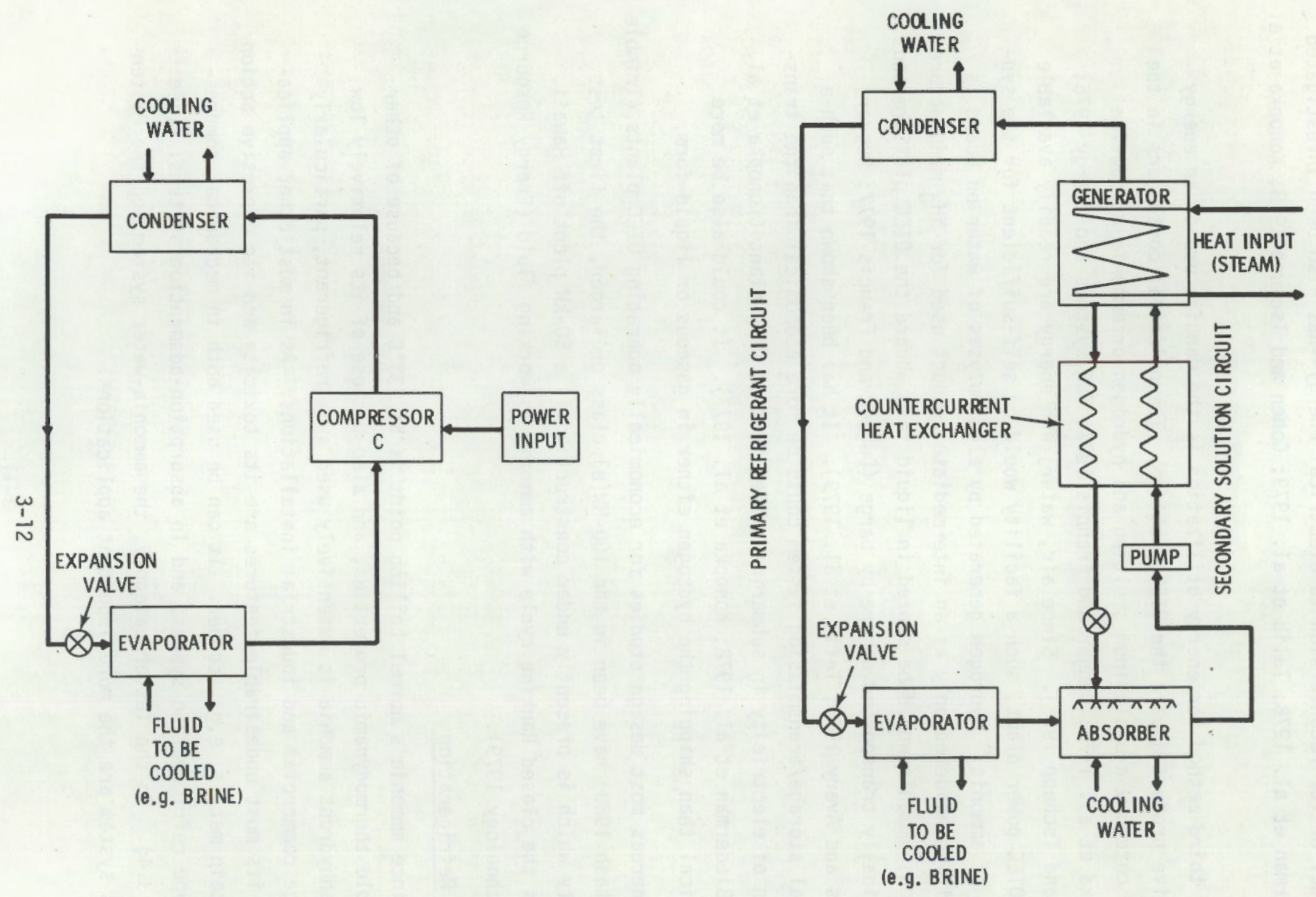

FIGURE 3.4. Closed Ammonia Refrigeration Systems 
Besides the standard closed-cycle operation of ammonia refrigeration plants, it is also possible to use ammonia in an open cycle system (Elliott and Fischer 1971). The open cycle ammonia refrigeration system uses low commercial grade ammonia on a once-through basis. Liquid ammonia is fed continuously from a supply tank to evaporators. After vaporization and refrigeration effect, ammonia is burned in a catalytic burner, and the resulting nitrogen and water vapors discharge to the atmosphere. The exhaust gases are pollution-free since they contain no carbon oxides and nitrogen oxides are less than $100 \mathrm{ppm}$. Due to simplicity of equipment and design, there are no power, utility, or auxiliary requirements. Capital cost and upkeep are relatively low, whereas operating cost is relatively high. The combination of these features make it best suited for standby systems, systems for short seasonal usage, and for refrigerated transport.

Since the flaring (i.e., catalytic burning) of the $\mathrm{NH}_{3}$ is actually a waste of energy, this free, available energy has been put to practical use in several applications. During World War II refrigeration trucks used their ammonia both for cooling their cargo and also for propulsion by burning it in their engines (ASHRE Handbook 1980).

Other applications of open cycle systems are certain ice cream trucks and strictly seasonal installations such as for salmon freezing in the Pacific Northwest (used for only about 35 days/yr) (Elliott and Fischer 1971).

In the basic direct cycle a mechanical compressor increases density, pressure and temperature of the ammonia vapor. In the following condenser ammonia is cooled below its boiling point and will, therefore, condense. Upon expansion it will evaporate again and, thereby, cool off. In a heat exchanger arrangement the cold is transferred directly to the medium to be cooled or to another heat transfer fluid. The majority of all mechanical refrigeration systems (whether using ammonia or another refrigerant) work along this basic principle. Since such systems are "closed," there is normally no loss of ammonia to the environment.

Instead of using ammonia in compression cycles for refrigeration, it is also possible, but not nearly as common, to use it in condensing cycles. 
Figure 3.5 shows the principle of such a cycle. On the right-hand side the process fuel to be cooled makes the ammonia evaporate. On the left-hand side the ammonia condenses, giving off the latent heat of condensation to a coolant which could be dry ice (i.e., solid $\mathrm{CO}_{2}$ ). Such a scheme has been in use for a long time in breweries. Another heat sink could be freon which in turn is cooled in a regular mechanical compression-evaporation cycle (Lipman 1979). In many cases, the use of ammonia for refrigeration purposes can be thermodynamically more efficient and, thus, more economical than the use of more standard cycles.

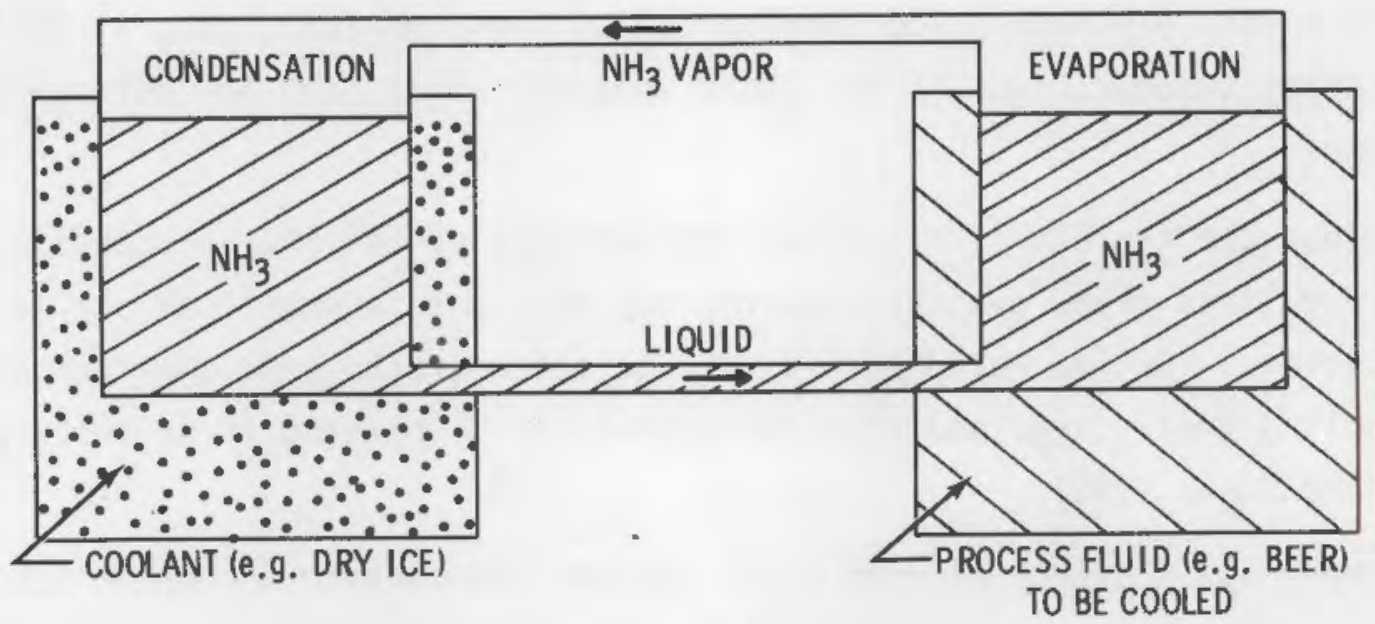

FIGURE 3.5. Basic Scheme of an Ammonia Condensing Cycle

Whereas in the refrigeration cycles based on mechanical compression, ammonia is one of many usable refrigerants, it is practically the only one used for absorption-type refrigeration cycles. In such a cycle mechanical compression is essentially replaced by thermally-activated vapor compression. Such systems have been in use for many decades (first tried by Faraday in 1824). Of particular interest is a version (Platen-Munters or Electrolux types, sometimes used in household refrigerators), in which the mechanical pump is el iminated and the ammonia operates in a hermetically-sealed system under uniform pressure. A system of this type does not require electricity for operation; merely thermal

(a) For a more detailed description of the working principle of absorption for refrigeration, see ASHRAE Handbook 1980. 
energy sources of only moderate temperatures are required. Thus, it has recently gained new significance since solar, geothermal, and waste heat-powered refrigeration systems can be designed on such a principle (Huang and Chang 1978).

Improved versions of the absorption refrigeration cycles (Dao 1978a; Dao 1978b) have been under investigation for a few years. They promise higher coefficients of performance and again use ammonia as the working fluid. The primary applications appear to be solar-driven air conditioners and heat pumps (Dao et al. 1980; Dao et al. 1977).

The idea of using solar energy for air conditioning and refrigeration is not new. It was considered as far back as 1936 and was demonstrated to be practical in 1956 by using an ammonia-water absorption system connected to flat plate solar panels (Eisenstadt et al. 1959). Other possible absorption and adsorption fluid combinations have been tested, but the ammonia/water combination proved to be the most effective (Williams et al. 1957; Mansoori and Patel 1979). This can be attributed to both the very favorable pressure-temperatureconcentration relationship of this particular combination and to the high latent heat of ammonia (Eisenstadt et a1. 1959; Farber et al. 1966). More recently, however, other investigators have claimed that lithium bromide-water systems should be thermodynamically more efficient than ammonia-water systems (Wilbur and Mitchell 1975). A comparison test of the two rival systems is underway at the University of Louisville (Murray and Bordolai 1978) but so far no conclusive results have been obtained.

Tests at University of California Laboratory at Berkeley have demonstrated that it is possible to use the ammonia-water absorption cycle for cooling with a heat source temperature below $200^{\circ}$ and a heat sink temperature (using air cooling) below $110^{\circ} \mathrm{F}$ (Dao et a1. 1977a; Dao et al. 1977b). Optimization of this ammonia-water air conditioning system is still going on (Dao et a1. 1980). However, a variety of units is already available from various manufacturers. It can be expected that the use of solar air conditioning will grow as the cost of electricity increases. It has also been shown that solar dehumidification systems are technically feasible on the same absorption-refrigeration principle (Arnas 1978). 
Most of the presently used home air conditioners are based on the mechanical compression refrigeration cycle and use freons as working fluids. Ammonia can be used also and is, in fact, preferred for large commercial-industrial installations. Equipment of this type can be designed easily to operate as a heat pump which is suitable for both cooling and heating. Such heat pumps can be operated either as a compressor type or as an absorption type. In the latter case, ammonia/water is, again, the preferred working fluid combination. An example of this type is described in Williams and Tiedemann (1974). By using the Platen-Munters ammonia-water cycle, it is possible to operate the heat pump (in a hermetically sealed system without moving parts) completely on solar energy, even in arctic regions.

\subsubsection{Heat Pipes}

In its simplest form the heat pipe consists of an evacuated cylindrical envelope, whose inside surface is clad with a porous capillary structure, which contains a small amount of vaporizing fluid. For the temperature range from $-40^{\circ} \mathrm{C}$ to $+60^{\circ} \mathrm{C}$ anhydrous ammonia is the best working fluid (Münzel 1978) mainly because the figure of merit and the critical thermal flux are higher for ammonia than for any other known fluid in this temperature range (Lamp 1978).

The heat pipe transports and distributes heat by means of evaporation and condensation of its working fluid. A simple heat pipe is illustrated schematically in Figure 3.6. Liquid ammonia is evaporated at the heat input or evaporator end, thereby absorbing energy via latent heat. The ammonia vapor is condensed in the heat rejection or condenser end of the heat pipe, where it releases energy absorbed during evaporation. This condition of evaporation at one end, and condensation at the other end, provides the driving force to move the vapor from one end of the envelope to the other. After the ammonia is condensed it is recycled to the evaporator end via capillary forces generated by the wick structure. Evaporation and condensation can occur at nearly the same temperature and account for the nearly isothermal operation of the heat pipe. 


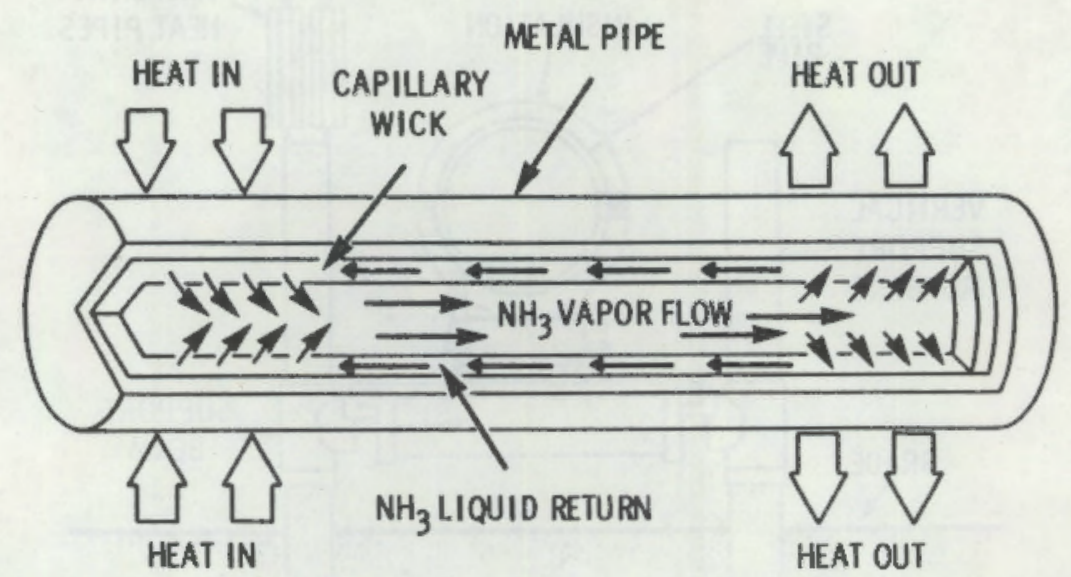

FIGURE 3.6. Schematic Illustration of a Heat Pipe

Ammonia heat pipes have found an extensive application for the thermal stabilization of permafrost in arctic areas (Vasiliev et al. 1978). Over 100,000 of such heat pipes were installed with the Alaskan pipeline (0llendorf 1978; Waters et a1. 1975) (See Figure 3.7). The seasonal temperature cycles can cause frost-heaving or uplifting of the surface in winter and settling of the soil during summer thaw; therefore, it is necessary to keep the soil in a continually frozen state. The heat pipes do this by extracting heat from below the surface during the winter, forming an ever-increasing block of frozen soil beneath the support pilings. As the heat pipes are vertical and under the influence of gravity, they will act as diodes and not pump heat into the soil during summer.

Heat pipe thermal diodes using ammonia have also been applied in various space applications (Groll et al. 1978). Since such a diode lets heat flow only in one direction, it may protect sensitive components from overheating during certain critical periods such as launch or re-entry operations.

It is important that the ammonia inside the heat pipe be completely free of water, otherwise corrosion problems resulting in liberation of noncondensable gases might occur over extensive time periods (years), thus, reduce the thermal efficiency of the heat pipe (Münzel, 1978). 


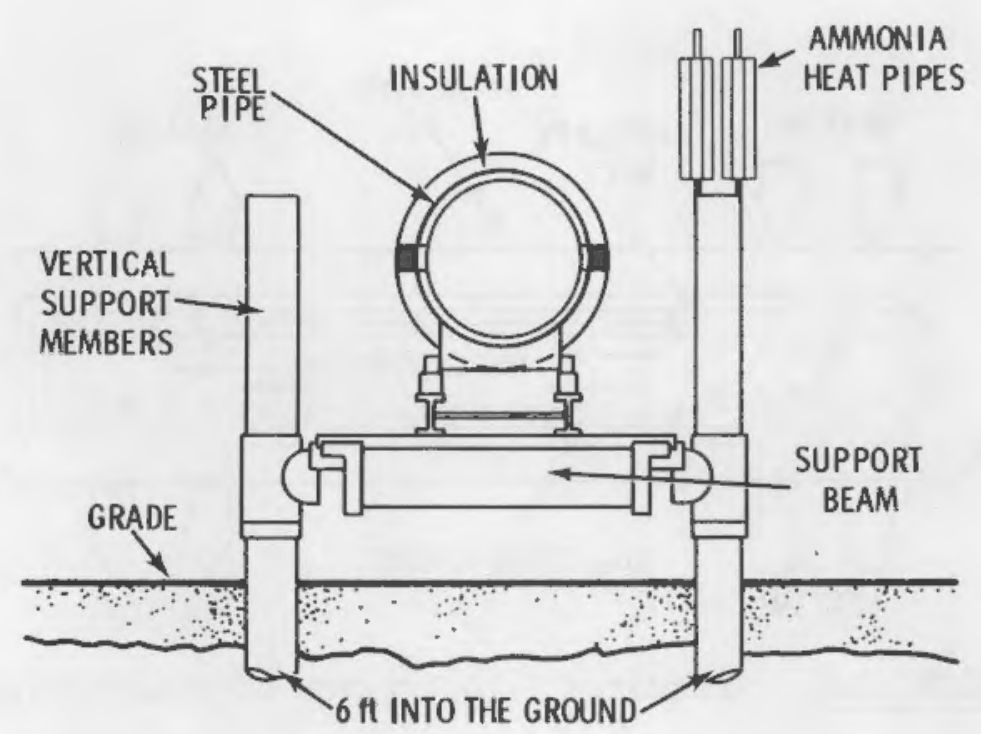

FIGURE 3.7. Heat Pipes on Alaska Pipeline

\subsubsection{Thermochemical Energy Transfer and Storage}

Thermochemical reactions are one of several available methods of transferring and/or storing energy for various purposes (e.g., load leveling of power stations, etc.). For solar systems a number of reversible reactions have been proposed, one of which is based on the ammonia dissociation/synthesis reaction (Carden 1977):

$$
2 \mathrm{NH}_{3} \rightleftharpoons \mathrm{N}_{2}+3 \mathrm{H}_{2}
$$

The forward reaction (dissociation) is endothermic, whereas the reverse reaction (synthesis) is exothermic. For a solar energy transfer system $\mathrm{NH}_{3}$ under pressure (300 bars) is heated in a parabolic solar collector (Figure 3.8) to about $700^{\circ} \mathrm{C}$, thereby undergoing dissociation into $\mathrm{H}_{2}$ and $\mathrm{N}_{2}$, which in turn can be piped away from the collectors after being cooled in a recuperator by the incoming $\mathrm{NH}_{3}$ flow. At the central power generating station $\mathrm{H}_{2}$ and $\mathrm{N}_{2}$ are recombined to form $\mathrm{NH}_{3}$ again, giving off about $0.8 \mathrm{kcal} / \mathrm{g}$ as heat of formation, which could be used in a Rankine cycle for electric power generation. It is claimed that, 


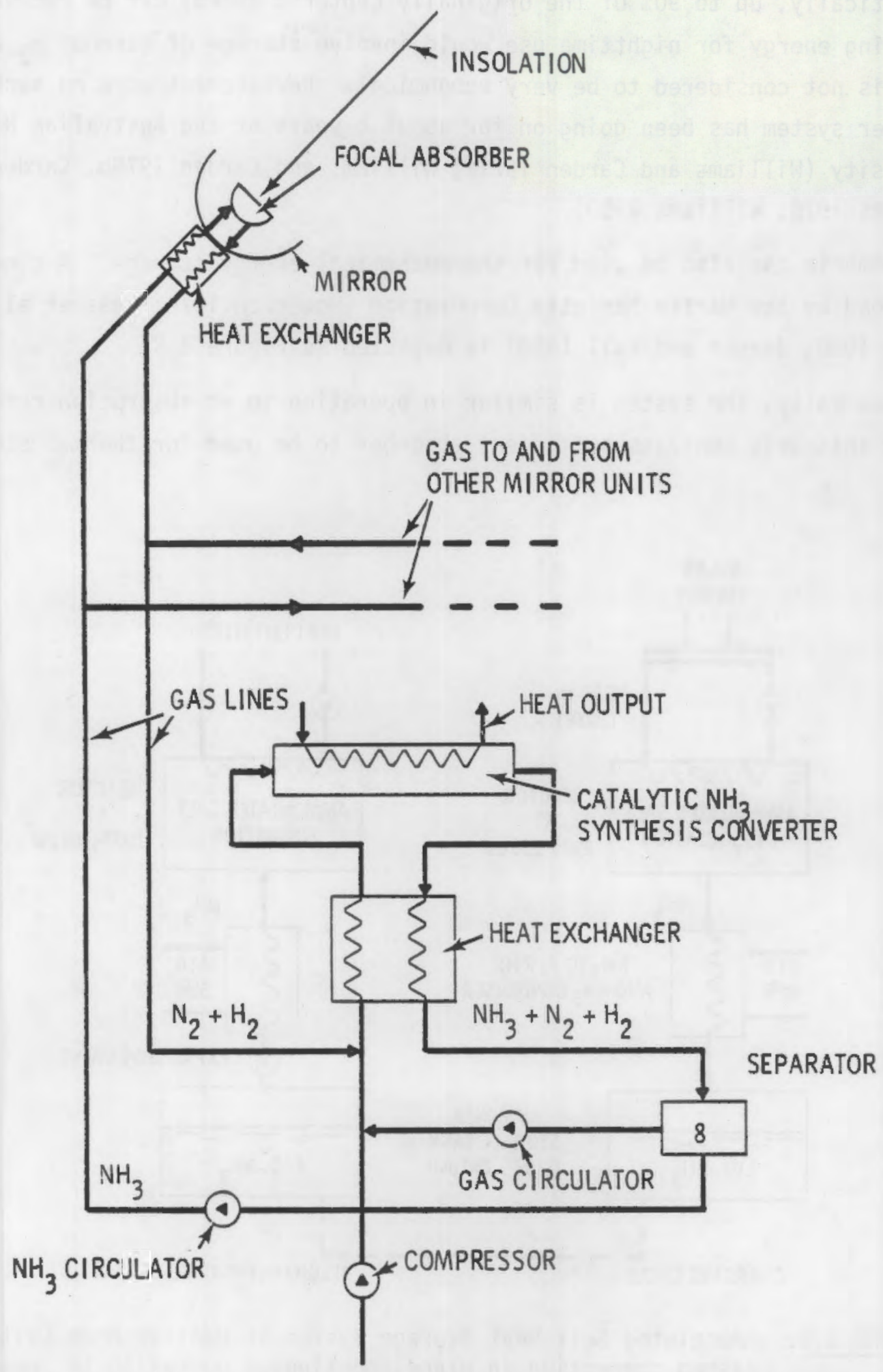

FIGURE 3.8. Using Ammonia for the Transfer of Solar Energy 
theoretically, up to $90 \%$ of the originally captured energy can be recovered. Providing energy for nighttime use would involve storage of gaseous $\mathrm{H}_{2}$ and $\mathrm{N}_{2}$, which is not considered to be very economical. Development work on such energy transfer system has been going on for about 6 years at the Australian National University (Williams and Carden 1979a; Williams and Carden 1979b, Carden and Williams 1978; Williams 1980).

Ammonia can also be used for thermochemical energy storage. A concept developed by the Martin Marietta Corporation (Howerton 1978; Haas et a1. 1979; Jaeger 1980; Jaeger and Hall 1980) is depicted in Figure 3.9.

Basically, the system is similar in operation to an absorption refrigerator except this unit contains sufficient absorber to be used for thermal storage



FIGURE 3.9. Ammoniated Salt Heat Storage System in Heating Mode (With the dashed connection in place, continuous operation is possible) 
and operates in the batch mode, rather than continuously. The unit consists of two reactors, ammonia condenser, ammonia storage tank, expansion valve, evaporator, and heat exchangers. The reactors are filled with an ammoniated salt (e.g., $\mathrm{NH}_{4} \mathrm{NO}_{3} \cdot 3 \mathrm{NH}_{3}$ or $\mathrm{NH}_{4} \mathrm{Cl} \cdot 3 \mathrm{NH}_{3}$ ) (Nissin 1979).

In the charging mode, when the reactors are heated (e.g., by solar heat at $280^{\circ} \mathrm{F}$ ), the ammoniated salt absorbs heat and dissociates endothermically, thereby releasing hot ammonia gas. The gas can be used, for example, to heat a building and then can be condensed. After condensation the ammonia is stored in a storage tank.

In the discharge mode liquid ammonia flows from the storage tank through an expansion valve where it is vaporized and absorbs heat from a low temperature source at $40^{\circ} \mathrm{F}$. It then flows to the reactor, where it re-forms the ammoniated salt, thereby giving off heat at $120^{\circ} \mathrm{F}$. A fluid loop is used to transfer this heat to a forced air heat exchanger and then into the building. The same basic arrangement can also be used for cooling (e.g., air conditioning).

In another thermochemical storage concept involving ammonia the reversible decomposition reaction of ammonium hydrosulfate can be exploited, (Wentworth et al. 1979) according to the following reaction:

$$
\mathrm{NH}_{4} \mathrm{HSO}_{4} \longrightarrow \mathrm{NH}_{3}+\mathrm{H}_{2} \mathrm{O}+\mathrm{SO}_{3} .
$$

This method is under development at the University of Houston.

\subsection{FLUE GAS CLEAN-UP}

Amolonia can be used in combustion gases to control oxides of nitrogen $\left(\mathrm{NO}_{\mathrm{X}}\right)$ and sulfur oxides $\left(\mathrm{SO}_{\mathrm{x}}\right)$.

\subsubsection{N0 Removal}

Armonia has emerged over the last few years as potentially the most effective agent for reducing $\mathrm{NO}_{x}$ from combustion exhaust gases (Burnett and Faucett 1979). At the same time it can also be used for their desulfurization. 
Since $\mathrm{NO}_{\mathrm{x}}$ levels in the atmosphere are projected to increase significantly (by more than 50\%) over the next decade, this particular use of $\mathrm{NH}_{3}$ may become of utmost importance.

In terms of total $\mathrm{NO}_{\mathrm{x}}$ emissions, large fossil fuel boilers represent by far the largest class of stationary sources, releasing over 4.7 milijion tons of $\mathrm{N}_{\mathrm{x}}$ in 1975 (Burnett and Faucett 1979). At the present time, two different types of $\mathrm{NO}_{x}$ control methods for these large boilers are undergoing development in the United States and Japan:

1. Combustion modifications, which seek to reduce $\mathrm{NO}_{x}$ emissions by controlling boiler operating conditions, and thus preventing the formation of $\mathrm{NO}_{x}$, are receiving considerable attention in the United States. Although these combustion modifications are relatively inexpensive when compared with other alternatives, they are apparently limited to reducing $\mathrm{NO}_{\mathrm{x}}$ emissions by about $50 \%$.

2. Flue gas treatment systems which are capable of removing up to $90 \%$ of the ${ }^{N}{ }_{x}$ emitted are receiving the major emphasis in Japan, primarily because the current $\mathrm{NO}_{x}$ emission regulations are much more stringent in Japan. As their name implies, these systems involve treating and removing the $\mathrm{NO}_{x}$ from the flue gas after it has been formed.

The reason for the different efficiencies in $\mathrm{NO}_{\mathrm{x}}$ removal can be found in the two basically different mechanisms responsible for $\mathrm{NO}_{x}$ production. One involves the oxidation of atmospheric nitrogen (therma $1 \mathrm{NO}_{x}$ ), and the other results in $\mathrm{NO}_{x}$ production from nitrogen chemically bound to fuel molecules (fuel $\mathrm{N}_{\mathrm{x}}$ ). In combustion systems burning the heavier fossil fuels, the fuel and thermal mechanisms are of nearly equal importance in $\mathrm{NO}_{x}$ generation (Eitzen et a1. 1979). The two formation mechanisms depend differently on temperature and have characteristicaliy different reaction times. Conventional abatement technologies that are based upon modifying the combustion process to prevent the formation of thermal $\mathrm{NO}_{x}$ are less effective in reducing fuel $\mathrm{NO}_{\mathrm{x}}$ and thus are limited to the removal rate of about $50 \%$ quoted above.

Among the various types of flue gas treatment, there are two basically different types which involve the use of ammonia. The first selectively 
removes $\mathrm{NO}_{\mathrm{x}}$ from the combustion effluent gases through homogeneous reaction with ammonia and oxygen at high temperatures without the use of any catalyst. The second method removes the $\mathrm{NO}_{x}$ from the exhaust gases at a lower temperature by reactions with the ammonia over a suitable catalyst.

\subsubsection{The Non-Catalytic Method}

In the non-catalytic method, (Muzio, Arand and Maloney 1978; Brown et al. 1979; Lyon 1979; Eitzen et a1. 1979) ammonia is contacted with the effluent in such a manner that the temperature at the point where the ammonia mixes with the $\mathrm{NO}_{x}$ containing combustion effluents is in the range $1600-2000^{\circ} \mathrm{F}$ and preferably from $1700-1900^{\circ} \mathrm{F}$. It is essential, however, that the ammonia be contacted with the combustion gas in the presence of oxygen. The oxygen content must be from $0.1-20$ vol.\% based on the total volume of the effluent gas. The amount of ammonia must be from 0.4 to 10 molecules of ammonia per molecule of N0, preferably from 0.5 to 1.5 molecules of ammonia per molecule of NO. The reaction may be carried out at a pressure from 0.1 to $100 \mathrm{~atm}$. The velocities of the combustion effluents, as well as the mixing of the ammonia in the first combustion zone, are regulated so that there is a sufficient residence time to enable the ammonia to remove the NO from the combustion effluents. The residence time of the reaction ranges from 0.001 to 10 seconds.

In various tests it has been shown that no effective reduction of N0 was observed in the absence of $\mathrm{O}_{2}$ throughout the temperature range of 1240 to $2000^{\circ} \mathrm{F}$, while substantial reductions were obtained in the presence of $\mathrm{O}_{2}$ between $1600-2000^{\circ} \mathrm{F}$. It should also be noted that below $1600^{\circ} \mathrm{F}$ ammonia was ineffective for $N 0$ reduction, while above $2000^{\circ} \mathrm{F}$ the use of ammonia was counter-productive, i.e., increasing No rather than decreasing it.

The described process is selective, because for a nonselective reduction of $\mathrm{NO}$ one would expect substantial $\mathrm{NO}$ reduction to occur only when enough $\mathrm{NH}_{3}$ was put in to consume both the $\mathrm{NO}$ and the $\mathrm{O}_{2}$. For $\mathrm{NH}_{3}$ reducing $\mathrm{O}_{2}$ according to the equation $4 / 3 \mathrm{NH}_{3}+\mathrm{O}_{2}=2 \mathrm{H}_{2} \mathrm{O}+2 / 3 \mathrm{~N}_{2}$, the reduction of $4.6 \% \mathrm{O}_{2}$ would require $6.13 \% \mathrm{NH}_{3}$. Test data have shown, however, substantial $\mathrm{NO}$ reduction for $\mathrm{NH}_{3}$ inputs much smaller than $6.13 \%$ through the range $1600-2000^{\circ} \mathrm{F}$. Such tests, therefore, clearly illustrate the "selective" reduction of NO by ammonia. 


\subsubsection{The Catalytic Methods}

Numerous catalytic reduction processes for $\mathrm{NO}_{x}$ removal have been investigated (Marzo and Fernandez 1980; Matsuda et al. 1980). Several of them involve the use of ammonia. The high selectivity of $\mathrm{NH}_{3}$ for $\mathrm{NO}$, combined with the enhanced reaction rate in the presence of $0_{2}$, makes $\mathrm{NH}_{3}$ the preferred reducing agent over $\mathrm{CO}, \mathrm{H}_{2}$, or hydrocarbons, which are less selective for reaction with N0. Catalysts used in a commercial plant must possess high activity and selectivity, since the volume of flue gas to be treated is extraordinarily large. In addition, the catalyst must be resistant to the $\mathrm{SO}_{\mathrm{x}}$ poisoning, since sulfur dioxide and sulfur trioxide are usually contained in an oil-or coal-fired boiler flue gas. As catalysts various zeolite types have been tested and have been found to be very efficient (Thomas and Pence 1974; Kiorky et al. 1979; Salyama et al. 1979; Mizumoto et al. 1979; Williamson and Lumsford 1976). Other catalysts such as Pt (Todo et a1. 1974) have also been successfully tried out. It is not yet clear at present which would provide the most economical approach. It seems that for different situations, different reduction methods might be required for optimal performance and cost efficiency. Catalyst poisoning is, of course, a possibility which must always be avoided to the utmost possible degree. $\mathrm{TiO}_{2}$-based catalysts show a high activity and selectivity, but also good resistance to the $\mathrm{SO}_{\mathrm{x}}$ poisoning over a wide range of temperatures, 200$450^{\circ} \mathrm{C}$ (Matsuda et al. 1980).

A potential drawback of all $\mathrm{NO}_{x}$ reduction methods involving $\mathrm{NH}_{3}$ is the possibility of $\mathrm{NH}_{3}$ breakthrough, i.e., the discharge of unreacted armonia into the atmosphere. However, it seems that this can be avoided almost completely for properly selected and maintained operating conditions. Besides, catalytic destruction of excess $\mathrm{NH}_{3}$ by oxygen is always possible (Bruggeman, Meynendonck and Goosens 1978).

A great deal of experimental and theoretical effort has been spent to fully and quantitatively understand the chemical reactions taking place in the ${ }^{N}{ }_{x}$ removal process involving ammonia. It has become evident that the kinetics of these processes are very complex and almost aiways are governed by intermediate formation of various radicals (See Boettner, Gaillard-Cusin and James 1978; Katzer 1975; Miller et a1. 1979; Haynes 1977; Kaskan and Hughes 1973; 
Roose, Hanson and Kruger 1979; Roose, Hanson and Kruger 1978; Miller et al. 1980; Fenimore 1980; Lyon and Benn 1978; Hack et a1. 1978; I izuka and Lunsford 1978; Scott and Lamb 1970).

Aside from the well-known power plant combustion sources, there are other industrial plants, such as nitric acid plants, future nuclear reprocessing plants (Bruggeman, Meynendonck and Goosens 1978) and open cycle MHD plants (Harvey et a). 1979) etc, which are or also would be contributors to the ${ }^{N 0}{ }_{x}$ found in the atmosphere. (a) For these sources ammonia flue gas treatment might also be desirable.

Using ammonia for $\mathrm{NO}_{x}$ abatement purposes on increasingly larger scales would noticeably increase the demand for ammonia. However, it has been concluded (Burnett and Faucett 1979) that the $\mathrm{NH}_{3}$ demand for this purpose would begin gradually and rise at only relatively slow rates, giving the domestic $\mathrm{NH}_{3}$ market time to adjust to the increased demand. Since, as of 1980, there exists an oversupply capacity for $\mathrm{NH}_{3}$ manufacture, there should not be any serious concern in this respect. If, by the year 2000, all large boilers in the U.S. Would use ammionia for $\mathrm{NO}_{x}$ abatement, an estimated 13,000,000 tons per year of $\mathrm{NH}_{3}$ would be required, which would represent $39 \%$ of the estimated thenexisting U.S. capacity (Burnett and Faucett 1979).

\section{$3.4 .2 \quad \mathrm{SO}_{2}$ Removal}

Several processes have been proposed during the last 50 years which utilize the absorption of sulfur dioxide from plant flue gases by ammoniacal solutions forming ammonium bisulfate. Both $\mathrm{NH}_{3}$ and $\mathrm{SO}_{2}$ can be recovered for recycle and for use as chemical feedstock, respectively (Breed and Hollinden 1976). Thus, in this process, ammonia is not used up as in the $\mathrm{NO}_{\mathrm{x}}$ removal processes.

Other $\mathrm{SO}_{2}$ removal procedures with the aid of $\mathrm{NH}_{3}$ involve gas-phase reactions for which ammonia vapor is injected into the flue gas (Tock, Hoover and Faust 1979; Shale 1973). The type of reaction that occurs (some solid crystals are

(a) At one time, the use of $\mathrm{NH}_{3}$ for conversion of $\mathrm{NO}_{x}$ in automobile exhaust gases has even been considered (Wise 1975). 
formed) is not exactly agreed upon (Scott and Lamb 1970). It is claimed, however, that the ammonia can be generated for recycle by wet scrubbing (Shale 1973).

Simultaneous removal of the $\mathrm{SO}_{2}$ and partial removing of $\mathrm{NO}_{x}$ from the vapor phase by $\mathrm{NH}_{3}$ injection has been demonstrated (Shale, Simpson and Lewis 1971). The ammonia can be separated for recycle and the sulfur dioxide can be recovered as a byproduct. It is also possible to convert the reaction products to ammonium sulfate, which can be used as a fertilizer.

If one of the proposed $\mathrm{SO}_{2}$ removal methods were to be used to remove $10 \%$ of the estimated 80 million tons of $\mathrm{SO}_{2}$ potentially to be emitted in the year 2010, about 4 miltion tons of $\mathrm{NH}_{3}$ would be required, and 16 million tons of armmonium sulfate could be formed (Tock, Hoover and Faust 1979). The sale of this fertilizer could make such an otherwise expensive process economical.

\subsection{THE COAL INDUSTRY}

Amrionia is an effective benefication agent for the treatment of coat, oil and other fossil fuels.

\subsubsection{Chemical Comminution}

Ammonia (as gas and anhydrous or hydrous liquid) has the capability of fracturing (comminuting) coal spontaneously. This feature (known for about 30 years)(Datta et a1. 1976; Howard and Datta 1977) has gained considerable interest recently for various applications in coal preparation technology. Such chemical comminution provides a unique way of cracking coal for mineral matter liberation (Keller and Smith 1976; Datta and Howard 1978). In particular, considerably more pyritic sulfur can be liberated than with mechanical crushing. Apparent7y, the adsorption and absorption of ammonia causes the coal to swell, crack, and disintegrate into fine particles. This usually occurs within one or two hours of treatment. There appears to be no unique behavior among the various coal types, since all coats imbibe liquid ammonia. Also, all coals were essentially desorbed from the ammonia when exposed to air. The exact mechanism of the involved processes is still poorly understood, (Howard et al. 
1977; Aldrich 1977) and additional research is underway. So far, it appears that chemical comminution is competitive with other processes currently being under consideration for producing clean coal (Datta et al. 1976).

It has also been demonstrated that the same ammonia approach can be used for fracturing of certain oil shales (Chan and Yen 1979). This might prove to be quite important in the future since the process could probably be applied to in situ retorting. By pumping liquid ammonia into the underground oil shale deposits, an extensive network of channels would be created, which would increase the surface area and, thus, the retorting efficiency. A possible environmental hazard in applying this technique might be the possibility that ammonia could mix underground with water and, thus, contaminate certain wells used for providing water for human consumption. For an ex situ (aboveground) conminution the ammonia would be used in a closed system since it is recoverable after the two-hour comminution process (Keller and Smith 1976).

\subsubsection{Gasification of Coal}

It has been reported (Matida, Nishiyama and Tamai 1977, 1978a, 1978b 1979a, 1979b, 1979c; Tama i et a1. 1978) that coals, pretreated with liquid ammonia, can be gasified more easily than untreated coals. At $1000^{\circ} \mathrm{C}$ the resulting gasification rates were found to be 2-8 times larger than those for untreated coa7s. Pretreatment with other solvents showed similar, though slightly smaller, effects. The effects were demonstrated for both hydrogen and steam gasification, though they were more pronounced with the former.

The mechanism responsible for enhanced gasification is not yet clearly understood. It is suspected that the treatment with ammonia reduces agglomeration ability of the coals and increases their porosity. The gasification rates are still further increased by impregnating the coals with nickel catalysts.

So far, these results have been obtained merely on a laboratory scale and apparently only in Japan. The tests have clearly shown, so far, that anmonia pretreatment and nickel loading are effective in lowering the gasification temperature and increasing coal conversion to gas. Thus, it might be possible that a double benefit could accrue from the ammonia pretreatment of coal. First, it would effectively fracture the coal, and, secondly, it would then effect an increased gasification rate. 


\subsection{WATER-SPLITTING SCHEMES}

Among the various thermochemical cycles to produce hydrogen and oxygen from water, some recently introduced cycles use liquid ammonia as a chemical carrier. Since the carrier is continuously recycled, it is not used up. It is claimed that such a cycle may have certain advantages over similar cycles in that it shows higher thermal efficiency and in that it may require less heat transfer area because it avoids gas-to-gas heat exchange. So far, none of the thermochemical water-splitting cycles is used on a large scale.

\subsection{AMMONIA AS A MEANS OF STORING HYDROGEN}

Many reports have been written in the last few years on the potential use of hydrogen as automobile fuel. Even though hydrogen has been demonstrated by prototype testing to be a suitable engine fuel with highly desirable characteristics, (such as clean exhaust), it has major drawbacks. There are doubts about safe fueling, operation, garaging and maintenance of vehicles, of their susceptibility to collision damage and the consequences of substantial liquid hydrogen spills. Hydrogen leaks more readily and rapidly than any other substance, is flammable under a very wide range of hydrogen/air ratios and also detonates easily. When stored in a metal hydride instead of as a liquid hydrogen, most of its advantages based on high specific energy content are lost. It has also been pointed out that a vast infra-structure for producing, transmitting and distributing liquid hydrogen would be needed, which can be expected to require high capital cost outlays and long time delays (Hydrogen Fuel 1980).

In contrast, ammonia does not have these drawbacks, at least, not to the same extent and it appears to be preferable from an energy conservation viewpoint than storing hydrogen in liquid form. Even with the most modern 1 iquefaction equipment (Baker and Shaw 1978) about 5kWh of energy must be expended to 1 iquefy 1 pound of hydrogen. About $0.4 \mathrm{kWh}$ is required to produce a pound of ammonia (Barnett and Wi ison 1960). However, since 1 pound of 1 iquid hydrogen contains about 6 times as much energy as 1 pound of ammonia (Gregory and Rosenberg 1973), the ratio of $0.4 / 5$ must be multiplied by 6 in order to compare the efficiencies of the two processes. Nevertheless, the energy cost of 
liquefying hydrogen is twice that of producing an equivalent amount of anmonia. The capital costs of a hydrogen liquefaction plant is also considerably higher than for an ammonia manufacturing plant (both plants based on an equal energy output).

The storage of hydrogen is most compact in liquid form, but this requires a temperature of $-256^{\circ} \mathrm{C}\left(-429^{\circ} \mathrm{F}\right)$; close to absolute zero. Storage of liquid ammonia is possible at $-35^{\circ} \mathrm{C}\left(-31^{\circ} \mathrm{F}\right)$ at atmospheric pressure and at room temperature, $21^{\circ} \mathrm{C}\left(70^{\circ} \mathrm{F}\right)$, at $840 \mathrm{kPa}(129 \mathrm{psig})$. Storage of hydrogen in the form of liquid ammonia is more compact ${ }^{(a)}$ than any other form of hydrogen storage. Loss from storage is practically unavoidable for liquid hydrogen (about 5\% a day) even with the most elaborate insulation system, whereas, it can be kept extremely low with ammonia. Moreover, hydrogen air mixtures are more easily detonated than ammonia, which is hard to ignite and almost impossible to detonate. This makes ammonia a safer and more easily handled fuel. Also, there is a much larger practical experience available with ammonia than with hydrogen.

Proponents of the "hydrogen economy" concept have listed a number of reasons why they believe that hydrogen is superior even to electricity as an energy form in many applications for perhaps half of our energy needs (Casazza et a1. 1975). If further impetus for hydrogen-fueled systems develops, the above arguments suggest ammonia as the most favorable medium for hydrogen storage.

(a) Additionally, gaseous hydrogen can be dissolved in liquid armonia to a limited degree (Wiebe 1934). It is not known whether this feature has ever been practicaliy exploited for combustion improvement. 



\subsection{AMMONIA ACCIDENTS}

Both the growth of current applications and the development of new uses may increase the frequency and magnitude of accidents. The purpose of this work is to identify the current accident records and to I) evaluate their suitability for assessing the current and future health and safety impacts and 2) identify areas where safety precautions could be applied to reduce these impacts.

\subsection{BACKGROUND}

Currently there is not a comprehensive system used to gather and compile all types of ammonia accident data. It seems that the type and amount of information available depends on the size of the spill and the extent of human injury.

The size of the ammonia spill is important. For example, a leakage of ammonia vapors at a cold storage facility may be a common occurrence, and it would possibly be recorded only on the plant maintenance records. However, a large release from a pipeline rupture may be reported in newspapers and investigative reports. In general, as the size of the spill increases the amount of detailed information available also increases.

The extent of human injury is the second factor that affects the amount of information available. In these cases, newspaper, police and hospital reports are made. In addition there are usually other reports required by law. For example, if an employee were injured by inhaling ammionia vapors at a cold storage facility, the state government requires a Workers' Compensation report.

As the size of the spill and/or the severity of human injury increases, the details of the accident are better preserved. In some cases, there are well-defined procedures for reporting the information and compiling it into a common data base. Two examples of this are the Hazardous Materials Incident reports and the Workers' Compensation reports. 
If an ammonia spill occurs during transport, the carrier must file a report within 15 days to the National Transportation Safety Board (NTSB). Immediate verbal notification is required for severe cases, such as those involving death or extensive damage. At a later time, the NTSB may decide to investigate further and will produce a detailed final report.

If the injured person is covered by workers' compensation, the primary source of information is the individual claim. However, the details are lost as the case data are compiled. For example, ammonia cannot be identified as the accident material if the state uses a general "alkali" category instead of coding specifically for ammonia. Thus, until a more specific coding system is used the only source of specific data for ammonia is the individual workers' compensation reports.

Other sources of information include police reports, newspaper accounts and reports of special investigative teams. For example, if a number of people are injured, there are often medica? research reports. In recent years, laws have been passed that require formal reporting of accidents; in these cases such federal agencies as the Environmental Protection Agency and the 0ccupational Safety and Health Administration are often involved. The Anerican Institute of Chemical Engineers holds annual meetings to focus on ammonia plant safety. In the proceedings, numerous case studies have been reported; although the principal emphasis is on equipment and procedures rather than the impacts and injuries. However, this is one mechanism in which company reports of accidents do enter the general literature. There are probably large numbers of accidents with non-disabling effects that are not reported. For example, a farm worker may be exposed while handling or applying the anhydrous ammonia to his fields. A] though irritation or skin burns may occur, no record is made, even if he goes to a physician. If the physician does report the event, the records are not reported to a common place and therefore are not easily retrieved and compiled.

\subsection{APPROACH}

Computer literature searches were performed of the data bases 1isted in Table 4.1. A tota? of 188 references were obtained using the keyword "arimonia" 
TABLE 4.1. Information Data Bases Searched by Computer

\begin{tabular}{|c|c|}
\hline Source & Scope \\
\hline National Technical Information Service & $1964-1980$ \\
\hline Engineering Index & $1970-1980$ \\
\hline $\begin{array}{l}\text { Government Printing Office (GPO) Monthly } \\
\text { Catalog }\end{array}$ & $1976-1980$ \\
\hline Agricola & $1970-1980$ \\
\hline Chemical Industry Notes & $1974-1980$ \\
\hline New York Times Index & $1969-1980$ \\
\hline Magazine Index & $1977-1980$ \\
\hline National Newspaper Index & $1979-1980$ \\
\hline Transportation Research Information Service & $1970-1980$ \\
\hline Chemical Abstracts & $1967-1980$ \\
\hline
\end{tabular}

with qualifiers of "injury", "accident", and "hazard." Many of the references were not specifically applicable to the accident section. However, those which contain related information have been included in the bibliography.

Two studies report the difficulties in obtaining specific accident and injury data. Burkhart and deGroot (1975) and Burkhart, deGroot and Wolferson (1970), working under contract to the National Institute of Occupational Safety and Health (NIOSH), studied occupational illness and injury in agriculture. Their study used workers' compensation case data and information from the National Safety Council's Farm Accident Survey. The study does not specifically cover anhydrous ammonia. However, it does give insight into both the agricultural chemical hazards and the problems of data availability. Buckley and Wiener (1978) analyzed historical data on hazardous materials spills including anhydrous ammonia. They report twenty spills from the period 1971 through June 1973. Data were from the EPA, USCG, DOT, and Office of Pipeline Safety.

In this study a number of agencies and organizations were contacted about the availability of ammonia accident and injury data on an individual case level. Based upon their response, the contacts are grouped into three classes:

I. The organization had no data available of sufficient detail to be of use to this study. Most state workers' compensation departments do not code 
their records for ammonia as a source of injury. Thus, after contacting several states it was known which ones were able to provide the specific information. Other organizations had information on safety and handling but none of a specific nature on accidents and injuries.

II. The organization had usable information available or was willing to compile it. However, either the organization would not provide their data or it was decided based on financial or time constraints, not to request data compilation.

III. The organization had usable information and it was obtained for use in the study.

All the organizations contacted are listed in Table 4.2 according to these classifications and are discussed in the following section. The data obtained fall into two general categories: 1) Accident reports that provide details of release incidents (e.g., location, container type, failure mode and cause) and 2) injury reports that give relevant information about the individuals affected (e.g., occupation, nature of injury, part of body injured).

\subsection{DATA RESOURCES USED}

The accident and injury data analyzed are from the five following organizations:

T. U.S. Department of Transportation; Materials Transportation Bureau

2. California Department of Industrial Relations

3. Idaho Industrial Commission

4. Oregon Workers' Compensation Department

5. U.S. Bureau of Labor Statistics - Supplementary Data System

Each data set is discussed separately. A complete overview of the number of ammonia accidents and injuries within the U.S. is not within the scope of this study. However, the following subsections summarize the information provided by each organization. Although each covers different aspects, they he]p provide a general review of ammonia accidents and injuries. 
TABLE 4.2. Classification of Organizations Contacted for This Study

I. No specific ammonia accident or injury data available:

$\begin{array}{ll}\text { National Safety Council Library } & \text { Chicago, Illinois } \\ \text { National Fertilizer Development Center } & \text { Muscle Shoals, Alabama } \\ \text { Manufacturing Chemists Association } & \text { Washington, D.C. } \\ \text { National Institute for Farm Safety } & \text { Madison, Wisconsin } \\ \text { American Institute of Chemical Engineers } & \text { New York, New York } \\ \begin{array}{l}\text { National Institute for Occupational Safety } \\ \text { and Health - Health Hazard Evaluation }\end{array} & \text { Washington, D.C. } \\ \begin{array}{l}\text { Occupational Safety and Health - } \\ \text { U.S. Department of Labor }\end{array} & \text { Washington, D.C. } \\ \begin{array}{l}\text { U.S. Transportation Systems Center } \\ \text { North Carolina Department of Labor }\end{array} & \text { Cambridge, Massachusetts } \\ \text { Tennessee Department of Labor } & \text { Raleigh, North Carolina }\end{array}$

II. Specific ammonia accident and injury data existing but not available to this study:

Wisconsin Department of Industry, Madison, Wisconsin Labor and Human Relations

Worker $5^{\prime}$ Compensation Division (Department would not provide existing data available for specific ammonia-related work injuries)

III. Specific accident and injury data obtained:

$\begin{array}{ll}\text { National Transportation Safety Board } & \text { Washington, D.C. } \\ \text { Materials Transportation Bureaus } & \\ \text { U.S. Department of Transportation } & \\ \begin{array}{l}\text { California Department of Industrial Relations } \\ \text { Division of Labor Statistics and Research }\end{array} & \text { San Francisco, California } \\ \text { Idaho Industrial Commission } & \text { Boise, Idaho } \\ \begin{array}{l}\text { Oregon Workers ' Compensation Department } \\ \text { Research and Statistics Section }\end{array} & \text { Salem, Oregon } \\ \begin{array}{l}\text { U.S. Bureau of Labor Statistics } \\ \text { Occupational Safety and Health Statistics }\end{array} & \text { Washington, D.C. }\end{array}$

Transportation accident data are very complete because of specific reporting requirements. The California data do not contain case level detail but provide some insight into the percentages of ammonia cases contained in the 
broader alkali classification. Both Idaho and Oregon provided individual case data which illustrate the variety of industries and occupations that generate ammonia accident data. Finally, the Supplementary Oata system files represent the best national coverage possible. However, ammonia cases are grouped under alkali as the source of injury, and this reduces the usefulness of this information.

\subsubsection{DOT - Materials Transportation Bureau}

The reporting requirements for transportation incidents involving hazardous materials (such as ammonia) are set down in CFR TitTe 49. Any accidental release of a hazardous material must be reported in writing by the carrier within 15 days of the occurrence. In severe cases, such as those involving loss of life or extensive damage, reporting must be immediate. This nationwide system for reporting was established in 1971 to provide Dor with the factual data necessary to comply with the Hazardous Materials Transportation Control Act of 1970. As a result of these federat regulations, there exists an excellent data resource on transportation accidents.

The information available is a listing of Hazardous Material Incident Reports for ammonia releases from 1971 through May 1980. The following data elements are recorded in 585 incident records:

1. Report number

2. Incident Tocation

3. Date of incident

4. Commodity (anhydrous armonia) reieased

5. Cormodity class (non-flarmable gas)

6. Number of resultant deaths

7. Number of resultant injuries

8. Oamages

9. Container type

10. Type of container failure

11. Result of release

12. Mode of transportation. 
Table 4.3a shows the number of ammonia incidents tabulated by mode of transportation and year of occurrence. The total number of incidents per year increased over the ten-year period. This increase is especially evident for rail transportation. Highway incident numbers remain more constant. The increase may reflect an increase in the volume of ammonia transported over the period. The number of injury incidents, tabulated in Table $4.3 \mathrm{~b}$, increased through 1976, but has since decreased. Iniproved safety regulations and safety training may be responsible for the decrease. The numbers would be more meaningful if they could be normalized to incidents per volume of ammonia transported or per mile traveled. Nevertheless, the incident frequencies substantiate the magnitude of the transportation hazard.

Table 4.4 summarizes the injury incidents of the entire period. Railroad accidents account for nearly three-quarters of the transportation releases. Yet only eight percent of these resulted in human injury or death. In contrast, highway incidents represent only one-fourth of the releases, but over 40 percent resulted in injury or death. Transportation by other modes (e.g., air, water and pipeline) are virtually accident free in comparison. Employee safety training and equipment maintenance may be less stringent for the highway mode. And a larger number of persons, vehicles and transfer operations are involved. As noted above, there is no information available to normalize the numbers.

TABLE 4.3a. Armonia Incidents by Transport Mode and Year of Occurrence Number of Incidents

\begin{tabular}{|c|c|c|c|c|c|c|c|c|c|c|c|}
\hline & \\
\hline Mode & 1971 & 1972 & $\underline{1973}$ & 1974 & 1975 & 1976 & 1977 & 1978 & 1979 & $\begin{array}{l}\text { May } \\
1980 \\
\end{array}$ & Total \\
\hline Railroad & 21 & 17 & 22 & 37 & 52 & 55 & 52 & 70 & 74 & 37 & 431 \\
\hline $\begin{array}{l}\text { Highway } \\
\text { Hire }\end{array}$ & 13 & 11 & 10 & 5 & 20 & 13 & 16 & 17 & 10 & 0 & 115 \\
\hline $\begin{array}{l}\text { Highway } \\
\text { Private }\end{array}$ & 1 & 0 & 2 & 2 & 6 & 5 & 5 & 3 & 8 & 1 & 33 \\
\hline Water & 1 & 0 & 0 & 0 & 0 & 0 & 0 & 0 & 0 & 0 & 1 \\
\hline Air & 0 & 0 & 0 & $\mathrm{~T}$ & 0 & 0 & 0 & 0 & 0 & 1 & 2 \\
\hline Other & $\underline{0}$ & $\underline{0}$ & 1 & 0 & 0 & $\underline{0}$ & 1 & 1 & $\underline{0}$ & $\underline{0}$ & $\underline{3}$ \\
\hline Total & 36 & 28 & 35 & 45 & 78 & 73 & 74 & 91 & 92 & 33 & 585 \\
\hline
\end{tabular}


TABLE 4.3b. Number of Injury Incidents by Transport Mode and Year of Occurrence ${ }^{(a)}$

\begin{tabular}{|c|c|c|c|c|c|c|c|c|c|c|c|}
\hline \multirow[b]{2}{*}{ Mode } & \multicolumn{11}{|c|}{ Number of Incidents } \\
\hline & 1971 & 1972 & 1973 & 1974 & 1975 & 1976 & 1977 & 1978 & 1979 & $\begin{array}{l}\text { May } \\
1980\end{array}$ & Total \\
\hline Railroad & 1 & 3 & 2 & 3 & 3 & 7 & 3 & 5 & 5 & 3 & 35 \\
\hline $\begin{array}{l}\text { Highway } \\
\text { Hire }\end{array}$ & 4 & 3 & 3 & 4 & 8 & 8 & 10 & 5 & 5 & 0 & 50 \\
\hline $\begin{array}{l}\text { Highway } \\
\text { Private }\end{array}$ & $\underline{0}$ & $\underline{0}$ & 2 & 0 & $?$ & 3 & 2 & 1 & 2 & 1 & 13 \\
\hline Total & 5 & 6 & 7 & 7 & 13 & 18 & 15 & 11 & 12 & 4 & 98 \\
\hline
\end{tabular}

(a) No injury incidents occurred on the air, water or other transportation modes.

TABLE 4.4. Ammonia Transport Accidents - Summary of Incidents Involving Injury and/or Death

\begin{tabular}{|c|c|c|c|c|c|c|c|c|c|c|}
\hline \multirow[b]{2}{*}{ Transportation Mode } & \multirow[b]{2}{*}{$\begin{array}{l}\text { Number of } \\
\text { Incidents }\end{array}$} & \multirow[b]{2}{*}{$\begin{array}{l}\text { Percent } \\
\text { of Total } \\
(585) \\
\end{array}$} & Incldents & & \multicolumn{3}{|c|}{ Number of Incidents } & \multicolumn{2}{|c|}{ Number of Person } & \multirow{2}{*}{$\begin{array}{l}\text { Involved } \\
\text { Average } \\
\text { per Injury } \\
\text { Incident }\end{array}$} \\
\hline & & & $\begin{array}{l}\text { Injury } \\
\text { Number of } \\
\text { Incidents } \\
\end{array}$ & $\begin{array}{l}\text { Death } \\
\text { Percent of } \\
\text { Mode Total }\end{array}$ & $\begin{array}{l}\text { Injury } \\
\text { Only } \\
\end{array}$ & $\begin{array}{l}\text { Death } \\
\text { Onily }\end{array}$ & $\begin{array}{l}\text { Death } \\
\text { and } \\
\text { Injury }\end{array}$ & Injured & killed & \\
\hline Railroad & 431 & 73.7 & 35 & 8.1 & 33 & 0 & 2 & 141 & 3 & \\
\hline Highway for Hire & 115 & 19.7 & 49 & 42.6 & 42 & 2 & 5 & 238 & $1^{(a)}$ & $5.1^{(a)} / 1.9$ \\
\hline Highway Private & 33 & 5.6 & 14 & 42.4 & 11 & 1 & 2 & 51 & 3 & 3.9 \\
\hline Water & i & 0.2 & 0 & 0 & 0 & 0 & 0 & 0 & 0 & -- \\
\hline Air & 2 & 0.3 & 0 & 0 & 0 & a & 0 & 0 & 0 & -- \\
\hline Other & -3 & 0.5 & $\underline{0}$ & $\underline{0}$ & $\underline{0}$ & $\underline{0}$ & $\underline{0}$ & $D$ & $\underline{0}$ & $\because$ \\
\hline Total & 585 & 100.0 & 98 & 16.8 & 86 & 3 & $\overline{9}$ & 430 & $\overline{17}$ & $4.6^{(a)} / 3.0$ \\
\hline
\end{tabular}

(a) Includes the May 11. 1976, truck-trailer crash at Houston, Texas in which 150 were injured and $5 \mathrm{kitled.}$

The above numbers and percentages can also be misleading. Railroads have the best safety record in terms of injury prevention for a given release, but they have the highest average number of individuals injured per injury incident. Highway for hire has a much better injury record when the 1976 Houston truck incident is not included.

Accident data provide details of the physical situation associated with release events but not the individuals injured. From the case data, all records were grouped into one of four categories of primary failures: 
I. Container physically abused:

Dropped in handling

External puncture

Damaged by other freight

Damaged by other liquid

External heat

Internal pressure

Vehicular accident

II. Container failure:

Rust of corrosion

Failure of inner receptacle

Bottom failure

Body or side failure

Weld failure

Chime failure

III. Problems with fittings, valves, couplings, or hoses: loading or unloading:

Defective fitting, valve or coupling

Loose fitting, valve or coupling

Hose burst

Loading/unToading spill

Venting

IV. Other causes or cause not specified

A breakdown of 585 cases by primary failure category and mode is shown in Table 4.5.

TABLE 4.5. Summary of Primary Failures (Materials Transportation Bureau)

Number of Incidents and Percent by

\begin{tabular}{|c|c|c|c|c|c|}
\hline Data & $\begin{array}{l}\text { Number of } \\
\text { Incidents }\end{array}$ & $\frac{\text { Prima }}{I}$ & ry Fail & lure cat & $\frac{\text { egory }}{\text { IV }}$ \\
\hline $\begin{array}{l}\text { All Transportation } \\
\text { Included }\end{array}$ & 585 & $\begin{array}{l}90 \\
15.4 \%\end{array}$ & $11.9 \%$ & $\begin{array}{l}403 \\
68.9 \%\end{array}$ & $\begin{array}{l}81 \\
13.8 \%\end{array}$ \\
\hline Al1 Highway Included & 148 & $\begin{array}{l}23 \\
15.5 \%\end{array}$ & $\begin{array}{l}5 \\
3.4 \%\end{array}$ & $\begin{array}{l}69 \\
46.6 \%\end{array}$ & $\begin{array}{l}51 \\
34.5 \%\end{array}$ \\
\hline Highway for Hire & 115 & $\begin{array}{l}12 \\
10.4 \%\end{array}$ & $\stackrel{2}{1.7 \%}$ & $\begin{array}{l}56 \\
48.7 \%\end{array}$ & $\begin{array}{l}45 \\
39.1 \%\end{array}$ \\
\hline Highway Private & 33 & $\begin{array}{l}11 \\
33.3 \%\end{array}$ & $\begin{array}{l}3 \\
9.1 \%\end{array}$ & $\begin{array}{l}13 \\
39.4 \%\end{array}$ & $\begin{array}{l}6 \\
18.2 \%\end{array}$ \\
\hline Railroad & 431 & $\begin{array}{l}67 \\
15.6 \%\end{array}$ & $\begin{array}{l}6 \\
1.4 \%\end{array}$ & $\begin{array}{l}238 \\
76.1 \%\end{array}$ & $\begin{array}{l}30 \\
6.9 \%\end{array}$ \\
\hline Injury Incidents & 98 & $\begin{array}{l}23 \\
23.5 \%\end{array}$ & $\begin{array}{l}3 \\
3.1 \%\end{array}$ & $\begin{array}{l}47 \\
47.9 \%\end{array}$ & $\begin{array}{l}25 \\
25.5 \%\end{array}$ \\
\hline
\end{tabular}


Overa11, nearly 70 percent of the releases occurred because of problems with fittings, valves, couplings or hoses or during a loading or unloading operation. And of the injury incidents, almost 50 percent resulted from the same failure. The lowest percentage was observed in the category of container failure in which the problem occurred in normal usage. The high percentage shown in Category IV - Highway - may indicate the need for more detail in incident reporting.

TabTe 4.6 lists the reported incidents and injuries by the state in which they occurred. The data are of interest to document where accidents have occurred. However, without data on actual amounts transported within each state, it is not possible to discuss relative state safety programs or road conditions. Since most incidents involved a transfer operation, the number of incidents probably correlates with traffic in the states involved in ammonia production or large volume use.

\subsubsection{California Department of Industrial Relations, Division of Labor Statistics and Research}

California is one of the few states in the country which codes workers' compensation cases specificaliy for ammonia as a source of injury. However, individual case records were not obtained from the state. It was felt that the standard tabulations available provided sufficient detail for analysis. The tabulations are derived from the disabling work injuries and ilinesses under workers' compensation.

In addition to the data on ammonia-related injuries, we also obtained tabulations of the broader category of alkali, of which ammonia is a subset. The alkali category is the group in which ammonia is included by most states and the U.S. Bureau of Labor Statistics. The California data provides a clear picture of ammonia-related injuries and gives an indication of how representative the alkali data of other sources might be of ammonia. The information available is provided by summary tables of workers' compensation, disabling work injuries and illnesses caused by alkalies and ammonia in 1977, 1978 and 1979. Statistics are tabulated by industry type, nature of injury and part of body injured. The number of cases considered per year are shown in Table 4.7. 
TABLE 4.6. Transportation Ammonia Incidents by States (1971 to May 1980)

$$
\begin{array}{cc}
\begin{array}{c}
\text { Al1 } \\
\text { Incidents }
\end{array} & \begin{array}{c}
\text { Injury } \\
\text { Incidents }
\end{array} \\
\hline
\end{array}
$$

Alabama

Alaska

Arizona

Arkansas

California

Colorado

Connecticut

Delaware

District of Columbia 0

Florida

Georgia

Hawa $i$

Idaho

Illinois

Indiana

Iowa

Kansas

Kentucky

Louisiana

Maine

Maryland

Massachusetts

Michigan

Minnesota

Mississippi
16

0

8

5

36

7

0

8

35

17

0

11

68

21

27

20

6

23

0

6

3

17

36

6

1

0

3

1

4

1

0

2

0

3

3

0

2

13

6

3

3

2

1

0

1

1

6

5

0
Missouri

Montana

Nebraska

Nevada

New Hampshire

New Jersey

New Mexico

New York

North Carolina

North Dakota

Ohio

Oklahoma

Oregon

Pennsylvania

Rhode Island

South Carolina

South Dakota

Tennessee

Texas

Utah

Vermont

Virginia

Washington

West Virgina

Wisconsin

Wyoming
A11 Injury

Incidents Incidents

15

1

19

0

2

17

2

4

6

11

18

7

6

17

0

0

2

2

45

0

0

5

17

1

8

1
2

0

3

0

0

\section{5}

0

2

1

1

5

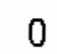

2

2

0

0

1

0

9

0

1

0

3

0


TABLE 4.7. Workers' Compensation, Disabling Work Injuries and I11nesses Caused by Alkalies and Anmonia in 1977, 1978 and 1979

\begin{tabular}{|c|c|c|}
\hline Year & Alkali & Anmonia \\
\hline 1977 & 552 & 246 \\
\hline 1978 & 67) & 273 \\
\hline 1979 & 696 & 226 \\
\hline
\end{tabular}

The three years of data (1977-1979) were combined into a single group. Table 4.8 shows a breakdown of alkali and ammonia incidents by major industry grouping. The categories are the major subheadings of the Standard Industrial Classification (SIC). Workers for manufacturing firms accounted for over 40 percent of the alkali injuries. The remainder of incidents were distributed more eventy between the other industrial groups.

The ammonia summary shows a shift in the percentages. Agriculture, retail trade and government show significant increases, while manufacturing shows decreases. This redistributing emphasizes those industries in which ammonia is a major component of the alkali injuries. Manufacturing, retail trade, state and local government, service and agriculture account for almost 84 percent of the ammonia injuries.

The ratio of ammonia to alkali incidents shows where ammonia is the dominent alkali involved in accidents. As might be expected, nearly 80 percent of agricultural injuries were ammonia related. Fifty to sixty percent of alkali injuries in the wholesale and retail trades, service, and government were caused by ammonia. Without data on the relative rates of usage of anmonia versus other alkalies, it is difficult to assess the hazard potential of ammonia within a given industry group.

Table 4.9 presents details on the nature of the injuries. Alkali injuries fall into two main groups - burns or scalds and occupational illnesses. Much detail is lost within the latter grouping. However, for alkalies, ingestion, inhalation or adsorption of the chemical is generally indicated. For ammonia injuries, more than 75 percent were 1 isted as occupational i11nesses. This probably reflects the gaseous nature of ammonia versus other alkaljes which generally are encountered as liquids. 
IABLE 4.8. Alkali and Ammonia Incidents by Industry (California, 1977-1979)

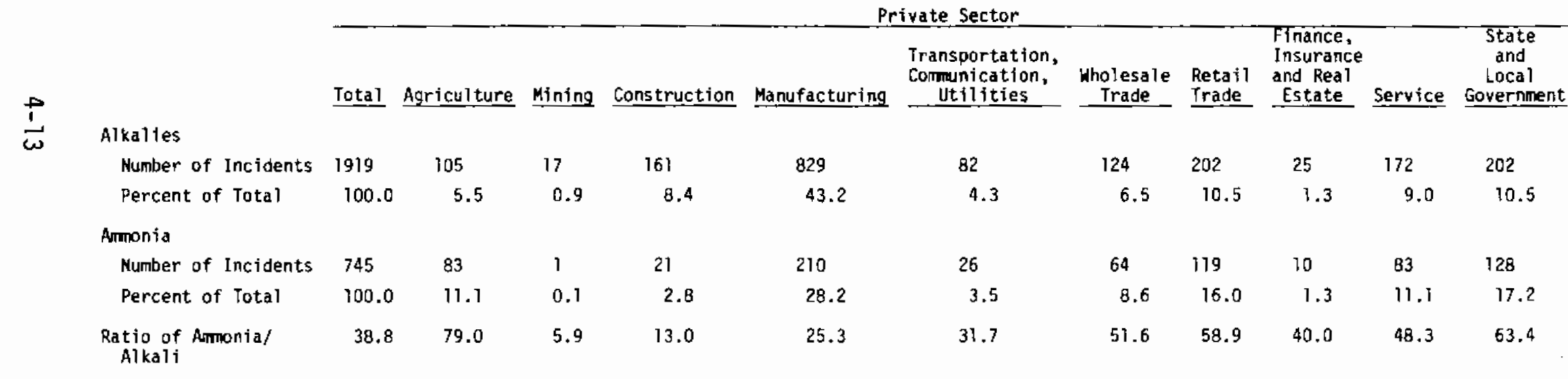


TABLE 4.9. Alkali and Ammonia Incidents by the Nature of Injury (California, 1977-1979)

$\begin{gathered}\text { Burns } \\ \text { and }\end{gathered}$ Abrasions, Strains, Occupational
Iotal Stature
Not
Scalds Scratches Sprains

$\begin{array}{lcccccc}\text { Alkalies } & & & & \\ \quad \text { Number of Incidents } & 1919 & 785 & 6 & 2 & 1103 & 23 \\ \begin{array}{l}\text { Percent of Total } \\ \text { Ammonia }\end{array} & 100.0 & 40.9 & 0.3 & 0.1 & 57.5 & 1.2 \\ \quad & & & & & \\ \quad \begin{array}{l}\text { Number of Incidents } \\ \text { Percent of Total }\end{array} & 745 & 162 & 3 & 0 & 573 & 7 \\ \begin{array}{l}\text { Ratio of Ammonia/ } \\ \text { Alkali }\end{array} & 38.8 & 21.7 & 0.4 & -- & 76.9 & 0.9 \\ \end{array}$

(a) Ocupational illnesses encompass: multiple injuries, systemic poisoning, dermatitis and other skin conditions, eye injuries and eye diseases, conditions of the respiratory system.

Table 4.10 summarizes information on injuries to parts of the body. For alkali exposure, nearly 40 percent were eye injuries. An additional 33 percent involved the extremities or multiple parts. The data suggests spraying, splashing or spilling of the material. For the anmonia exposures, nearly 75 percent of the injuries fall into two classes: eyes and body systems. Irritations and damage to the eyes and lungs are to be expected from a volatile water-soluble alkali such as ammonia.

The California data illustrate the occurrence of ammonia exposure in all the major industry groups. However, with the exception of agriculture and mining, there is no clear information to allow extrapolation of alkali statistics to ammonia. The nature and parts of body information emphasizes the volatile nature of ammonia and does provide some means of separation. To develop a scheme for distinguishing ammonia cases from the alkali records would require much more extensive characterization of known ammonia cases. 
TABLE 4.10. A]kali and Ammonia Incidents by Part of Body Injuries (California, 1977-1979)

\begin{tabular}{|c|c|c|c|c|c|c|c|c|c|c|c|}
\hline & Total & Eyes & $\begin{array}{l}\text { Head, } \\
\text { Face }\end{array}$ & $\underline{\text { Neck }}$ & $\begin{array}{l}\text { Back, } \\
\text { spine }\end{array}$ & $\begin{array}{c}\text { Trunk } \\
\text { M.E.C. (a) } \\
\end{array}$ & $\begin{array}{c}\text { Upper } \\
\text { Extremities } \\
\end{array}$ & $\begin{array}{c}\text { Lower } \\
\text { Extremities }\end{array}$ & $\begin{array}{l}\text { Multiple } \\
\text { Parts } \\
\end{array}$ & $\begin{array}{l}\text { Body } \\
\text { Systems }\end{array}$ & $\begin{array}{l}\text { other } \\
\text { or Not } \\
\text { Stated }\end{array}$ \\
\hline \multicolumn{12}{|l|}{ Alkalies } \\
\hline Nunber of Incidents & 1919 & 757 & 124 & 0 & 5 & 41 & 179 & 226 & 224 & 340 & 23 \\
\hline Percent of Total & 100.0 & 39.4 & 6.5 & 0.0 & 0.3 & 2.1 & 9.3 & 11.8 & 11.7 & 17.7 & 1.2 \\
\hline \multicolumn{12}{|l|}{ Amonia } \\
\hline Number of Incidents & 745 & 264 & 61 & 0 & 0 & 12 & 48 & 17 & 49 & 287 & 7 \\
\hline Percent of Total & 100.0 & 35.4 & 8.2 & 0.0 & 0.0 & 1.6 & 6.4 & 2.3 & 6.6 & 38.5 & 0.9 \\
\hline $\begin{array}{l}\text { Ratio of Ansonia/ } \\
\text { Alkali }\end{array}$ & 38.8 & 34.9 & 49.2 & $\cdots$ & 0.0 & 29.3 & 26.8 & 7.5 & 21.9 & 84.4 & 30.4 \\
\hline
\end{tabular}

(a) H.E.C. means"not elsewhere classified."

\subsubsection{Idaho Industrial Commission}

The State of Idaho codes their workers' compensation records specifically for ammonia as a source of injury. The data provided covers the period from 1973 through July 1980. The data were summarized in two groups. The entire span of records was used in tabulating ammonia incidents by industry, nature of injury and part of body injured. In addition, the 1977 and 1978 records were summarized and compared with the Idaho records of alkali injuries provided by the Bureau of Labor Statistics. Information from this source covers 202 incidents in the period 1973 through 1980 and 77 incidents in 1977 and 1978. The cases involve individual workers' compensation for disabling work injuries and illnesses caused by ammonia. The records contain the following:

1. Date of incident

2. Extent of disability

3. Part of body injured

4. Type of accident

5. Nature of injury

6. SIC code

7. Source of injury

The standard breakdown of incidents by industry is shown in Table 4.11. The distribution is similar to that observed for California. More than a third of the injuries occur in the manufacturing industry and another third 
TABLE 4.11. Industry Breakdown of Alkali and Amonia Incidents (Idaho, 1977-1978)

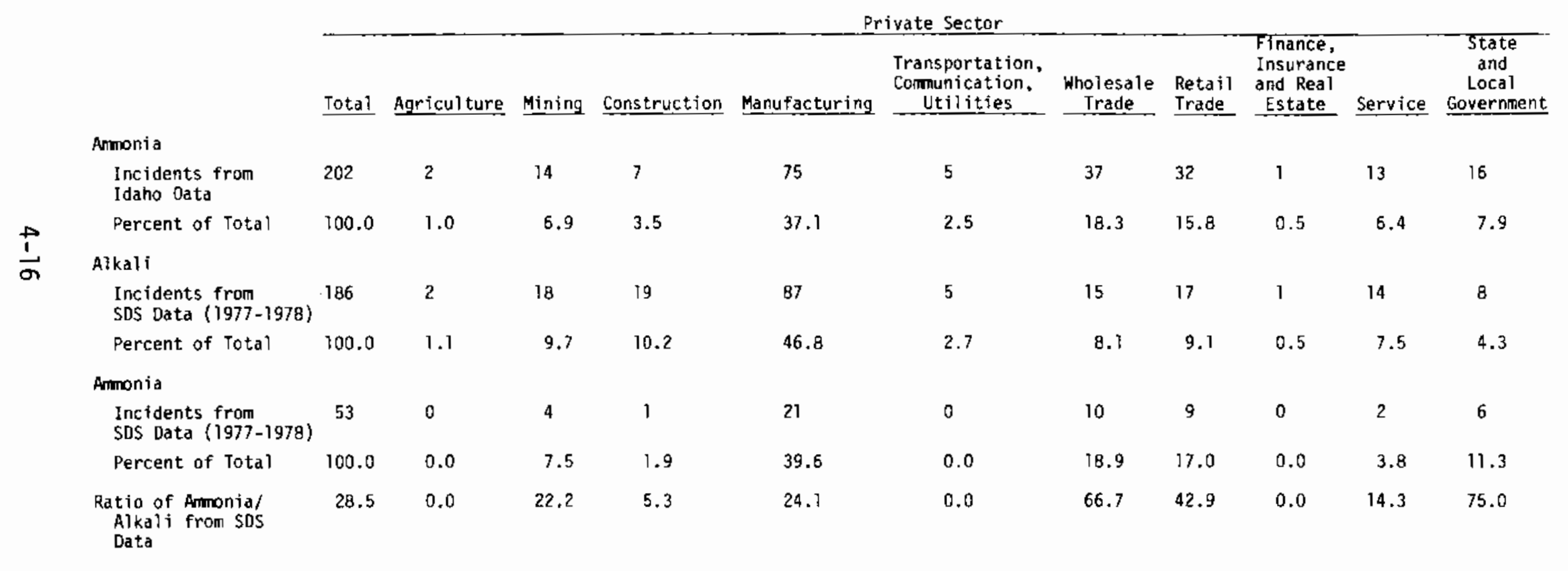


occurs in the wholesale and retail trades. However, there are no incidents reported from agriculture and fewer from both service and government. The sma 11 number of incidents in the 1977-1978 period makes the anmonia to alkali ratios somewhat insignificant. Both general trends observed in California persist in these data from Idaho.

Table 4.12 lists the five specific industries having the highest number of ammonia incidents over the 7-year period. The greatest number of injuries are associated with industries using ammonia as a refrigerent. Ammonia is a byproduct in both phosphate fertilizer manufacture and the mining of phosphate rocks. It is interesting that alt the agricultural related accidents were classed as farm supplies. The greatest number of ammonia transfer operations probabiy take place at the fertilizer dealer supply depot. Finally, in restaurants, exposure to ammonia is probably in the form of cleaning solutions. None of the incidents appear to be directly associated with ammonia manfacture.

Tables 4.13 and 4.14 present the standard tabulations by nature of injury and part of body injured. There are variations in the percentages from the California data but the trends are the same. Most injuries occur to the eyes or body systems. The majority are classified as burns or occupational ilinesses. The latter classification places so many specific items under a single heading that important detail is lost. Table 4.15 presents a breakdown of the 148 occupational illness incidents by their specifically coded nature. Details of the incident description are masked by using the standard data groupings.

TA8LE 4.12. The Five Industries Having Highest Number of Ammonia Incidents (Idaho, 1973-May 1980)

\begin{tabular}{lcc} 
& $\begin{array}{c}\text { Number of } \\
\text { Incidents }\end{array}$ & $\begin{array}{c}\text { Percent of Total } \\
\text { Incidents (202) }\end{array}$ \\
\cline { 2 - 3 } Frozen Fruits and Vegetables & 18 & 8.9 \\
(Phosphatic) Fertilizer & 13 & 6.4 \\
Manufacture & 13 & 6.4 \\
Farm Supplies & 9 & 4.5 \\
Mining Phosphate Rock & $\underline{9}$ & $\underline{4.5}$ \\
Eating Places & 62 & 30.7 \\
Total &
\end{tabular}



TABLE 4.13. $\begin{aligned} & \text { Breakdown of A7kali and Ammonia Incidents by Nature of Injury } \\ & \text { (Idaho, 1977-1978) }\end{aligned}$

\begin{tabular}{|c|c|c|c|c|c|c|c|}
\hline & Total & $\begin{array}{l}\text { Burns } \\
\text { and } \\
\text { Scalds }\end{array}$ & $\begin{array}{c}\text { Cuts, } \\
\text { Punctures }\end{array}$ & $\begin{array}{l}\text { Abrasions, } \\
\text { Scratches }\end{array}$ & $\begin{array}{l}\text { Strains, } \\
\text { Sprains }\end{array}$ & $\begin{array}{l}\text { Occupationa } \\
\text { Illnesses (a) }\end{array}$ & $\begin{array}{c}\text { Nature } \\
\text { Not } \\
\text { Stated }\end{array}$ \\
\hline \multicolumn{8}{|l|}{ Ammonia } \\
\hline $\begin{array}{l}\text { Incidents from } \\
\text { Idaho Data }\end{array}$ & 202 & 53 & 0 & 0 & 1 & 148 & 0 \\
\hline Percent of Tota1 & 100.0 & 26.2 & 0.0 & 0.0 & 0.5 & 73.3 & 0.0 \\
\hline \multicolumn{8}{|l|}{ Alkali } \\
\hline $\begin{array}{l}\text { Incidents from SDS } \\
\text { Data }\end{array}$ & 186 & 78 & 1 & 60 & 0 & 46 & $?$ \\
\hline Percent of Total & 700.0 & 41.9 & 0.5 & 32.3 & 0.0 & 24.7 & 0.5 \\
\hline \multicolumn{8}{|l|}{ Ammonia } \\
\hline $\begin{array}{l}\text { Incidents from SOS } \\
\text { Data }\end{array}$ & 53 & 14 & 0 & 0 & 0 & 36 & 0 \\
\hline Percent of Total & 100.0 & 26.4 & 0.0 & 0.0 & 0.0 & 67.9 & 0.0 \\
\hline $\begin{array}{r}\text { Ratio of Ammonia/ } \\
\text { Alkali SDS Data }\end{array}$ & 28.5 & 17.9 & 0.0 & 0.0 & -- & 78.3 & 0 \\
\hline
\end{tabular}

(a) Ocupational ilinesses encompasses the following: multiple injuries, systemic poisoning, dermatitis and other skin conditions, eye injuries and eye diseases, conditions of the respiratory system.

TABLE 4.14. Breakdown of Alkali and Ammonia Incidents by Parts of Body Injuries (Idaho, 1977-1978)

\begin{tabular}{|c|c|c|c|c|c|c|c|c|c|c|c|}
\hline & Tota] & Eyes & $\begin{array}{l}\text { Head. } \\
\text { Face }\end{array}$ & Neck & $\begin{array}{l}\text { Back, } \\
\text { Spine }\end{array}$ & $\begin{array}{l}\text { Trunk. } \\
\text { N.E.C. }\end{array}$ & $\begin{array}{c}\text { Upper } \\
\text { Extremities }\end{array}$ & $\begin{array}{c}\text { Lower } \\
\text { Extremities }\end{array}$ & $\begin{array}{l}\text { Multiple } \\
\text { Parts } \\
\end{array}$ & $\begin{array}{l}\text { Body } \\
\text { Sys tems }\end{array}$ & $\begin{array}{l}\text { Other } \\
\text { or Not } \\
\text { Stated }\end{array}$ \\
\hline \multicolumn{12}{|l|}{ Amronia } \\
\hline $\begin{array}{l}\text { Incidents from } \\
\text { Idaho Data }\end{array}$ & 202 & 56 & 14 & 1 & 2 & 9 & 32 & 8 & 14 & 53 & 13 \\
\hline Percent of Total & 100.0 & 27.7 & 6.9 & 0.5 & 1.0 & 4.5 & 15.8 & 4.5 & 5.9 & 26.2 & 6.4 \\
\hline \multicolumn{12}{|l|}{ Alkali } \\
\hline $\begin{array}{l}\text { Incidents from SDS } \\
\text { Data }\end{array}$ & 186 & 74 & 14 & 1 & 0 & 4 & 23 & 30 & 10 & 29 & 1 \\
\hline Percent of Tota1 & 100.0 & 35.8 & 7.5 & 0.5 & 0.0 & 2.2 & 12.4 & 16.1 & 5.4 & 15.6 & 0.5 \\
\hline \multicolumn{12}{|l|}{ Aminonia } \\
\hline $\begin{array}{l}\text { Incidents from SDS } \\
\text { Data }\end{array}$ & 53 & 13 & 6 & 0 & 0 & 1 & 3 & 2 & 1 & 27 & 0 \\
\hline Percent of Total & 100.0 & 24.5 & 11.3 & 0.0 & 0.0 & 1.9 & 5.7 & 3.8 & 1.9 & 50.9 & 0 \\
\hline $\begin{array}{l}\text { Ratío of Anmonia/ } \\
\text { Alkalf from SOS Data }\end{array}$ & 28.5 & 17.6 & 42.9 & 0.0 & - & 25.0 & 13.0 & 6.7 & 10.0 & 93.1 & 0.0 \\
\hline
\end{tabular}


TABLE 4.15. Summary of Nature of Injury for Those Anmonia Incidents Classed Under "Occupational Illnesses"

$\begin{array}{lcc}\text { Eye Injuries, Not Elsewhere Classified } & & \begin{array}{c}\text { Number of } \\ \text { Incidents }\end{array} \\ \text { Diseases of Respiratory System } & & 55 \\ \text { Internal Injuries (Fainting) } & 46 \\ \text { Effects of General Working Conditions } & 26 \\ \text { Poisoning } & 2 \\ \text { Diseases of the Skin and Subcutaneous Tissue } & 3 \\ \text { Other Injuries, Not Elsewhere Classified } & 2\end{array}$

Information can be lost by grouping many specific details under a single heading. In contrast, data can be misleading if it is not properly classified. In workers' compensation claims, the worker or employer must file a written description of the accident. From this report the incident is classified based on the reader's interpretation. Table 4.16 gives a breakdown of ammonia incidents by type of exposure or accident. In the majority of the cases, the type corresponds to the normal expectations for ammonia incidents, i.e., contact with a toxic substance. In the cases footnoted in Table 4.16, the association with ammonia is not as clear. If an individual was struck by a spray of ammonia liquid, it is not clear whether the injury would be attributed to the physical impact or the chemical interaction. These ambiguities confuse the data analysis.

\subsubsection{Oregon Workers ' Compensation Department}

The State of Oregon provided records of 1978 alkali cases. In addition, the files were searched manually for detai7s of ammonia cases. Some brief case histories of these ammonia related accidents are included in Appendix $A$. The number of records include 38 alkali and 14 ammonia cases relating to individual workers' compensation for disabling work injuries and illnesses caused by alkali and ammonia in 1978 . The following data elements are recorded:

1. Classification of industry (SIC)

2. Occupation of workers

3. Date of incident 
TABLE 4.16. Ammonia Incidents in Idaho by Type of Accident (1973-1980)

Accident Type Description
$\begin{aligned} & \text { Contact With Radiations, Caustics, Toxic or Noxious } \\ & \text { Substances by Inhalation }\end{aligned}$
Other (i.e., Not Inhalation, Adsorption or Ingestion)
Contact With Radiations, Caustics, Toxic or Noxious
Substances
Contact With Radiation, Caustics, Toxic or Noxious
Substances by Adsorption
Struck by Falling or Flying Object (a)
Flareback (A Burst, as of Flane, Back or Out in a
Direction Other Than Normal) (a)
Struck by Object While Handling (a)
Contact With Toxic by Ingestion
Strain or Overexertation (a)
Foreign Substance in Eye (a)
Contact With Cold Object or Substance (a)

(a) Not immediately suspect as being ammonia related.

4. Source of injury

5. Type of accident or exposure

6. Nature of injury

7. Part of body injured

The Oregon data set represents a small number of cases. As such, the breakdowns by industry group, nature of industry and part of body injured are not included. However, the data were useful in examining the specific industries and occupations in which alkali and ammonia accidents occur.

Table 4.17 lists the SIC titles and occupation titles for the 38 alkali incidents of 1978. The fourteen records shown with asterisks are ammonia. Most of the jobs did not directly involve ammonia handling. The worker was often engaged in a task unrelated to ammonia when the exposure occurred. The list strongly emphasizes the problem of trying to identify ammonia 
TABLE 4.17. Industry and Occupation of the 38 Alkali Cases in Oregon During 1978 (Ammonia Cases Are Indicated by *)

\begin{tabular}{|c|c|}
\hline Major Industry Group & SIC Title \\
\hline Agriculture & *General Farms, Primarily Crop \\
\hline Construction & $\begin{array}{l}\text { Industrial Building and Warehouses } \\
\text { Water, Sewer and Utility Lines } \\
\text { Plumbing, Heating and Air Conditioning } \\
\text { Painting, Paperhanging, Decorating } \\
\text { Electrical Work } \\
\text { Masonry and Other Stonework } \\
\text { Plastering, Drywall and Insulation } \\
\text { Plastering, Drywall and Insulation } \\
\text { Concrete Work }\end{array}$ \\
\hline Manufacturing & $\begin{array}{l}\text { Sausages and Prepared Meats } \\
\text { Pickles, Sauces and Salad Dressings } \\
\text { *Frozen Fruits and Vegetables } \\
\text { *Frozen Fruits and Vegetables } \\
\text { Frozen Specialties } \\
\text { Frozen Specialties } \\
\text { *Canned and Cured Seafoods } \\
\text { *Sawmills and Planning Mills, General } \\
\text { Wood Preserving } \\
\text { Paperboard Mili } \\
\text { Paperboard Mill } \\
\text { Concrete Products } \\
\text { *Alkalies and Chlorine } \\
\text { Steel Investment Founderies } \\
\text { *Primary Non-Ferrous Metals } \\
\text { *Primary Non-Ferrous Metals } \\
\text { Primary Non-Ferrous Metals }\end{array}$ \\
\hline $\begin{array}{l}\text { Transportation, } \\
\text { Communication, } \\
\text { Utilities }\end{array}$ & $\begin{array}{l}\text { *Trucking, Except Local } \\
\text { *Trucking, Except Loca? } \\
\text { *Refrigerated Warehousing }\end{array}$ \\
\hline Retail Trade & $\begin{array}{l}\text { *Grocery Stores } \\
\text { New and Used Car Dealers }\end{array}$ \\
\hline $\begin{array}{l}\text { Finance, Insurance, } \\
\text { and Real Estate }\end{array}$ & Real Estate Agent \\
\hline Service & $\begin{array}{l}\text { *Hotels, Motels and Tourist courts } \\
\text { Armature Rewinding Shops } \\
\text { Individual and Family Services } \\
\text { Job Training and Related Services } \\
\text { *Engineering and Architectural }\end{array}$ \\
\hline
\end{tabular}

Dccupation Title

Farm Laborers, Wage Workers

Carpenters

Not Specified Laborers

Plumbers and Pipefitters

Painter, Construction and Maintenance

Electricians

Construction Laborers

Plasterer Apprentices

Construction Laborers

Foremen

Not Specified Laborers

Not Specified Laborers

Bottling and Canning Operatives

Heavy Equipment Mechanics

Not Specified Laborers

Miscellaneous Operatives

Foremen

Heavy Equipinent Mechanics

Hiscellaneous Laborers

Machine Operatives

Not Specified Operatives

Not Specified Laborers

Not Specified Laborers

Miscelianeous Dperatives

Stock Clerk and Storekeeper

Furnacemen, Smeltermen and Pourers

Plumber and Pipefitters

Truck Drivers

Truck Drivers

Building Managers and Superintendents

Meat Cutters and Butchers, Except Manufacturing Janitors and Sextons

Manager and Administrator, n.e.c. (a)

Dishwashers

Miscellaneous Mechanic and Repaimen

Clinical Laboratory Technician

Not Specified Laborer

Not Specified Laborer

(a) n.e.c. means "not elsewhere classified."

accidents from a listing of alkali records. A very extensive characterization of the industries and jobs with potential exposure would be required. Even then, it is doubtful that the standard workers' compensation records contain sufficient detail to allow proper separation of ammonia incidents.

4.3.5 Supplementary Data System (SDS)

The U.S. Bureau of Labor Statistics, Supplementary Data System was deve1oped to improve the understanding of injury and illness occurrences in industry. 
It supplements the Bureau's annual survey with individual case data. The first report of injury submitted to state workers' compensation agencies is the basic source of information. A complete description of the background and evolution of the program is contained in the SDS User's Guide.

Records of workers' compensation cases of disabling work injuries and illnesses caused by alkaljes occurring in 27 states during 1977 and 1978 were reviewed. The number of records were 1,261 in 1977 and 1,562 in 1978. Data elements included were:

1. State in which case reported

2. Date of injury

3. Occupation of worker

4. Ciassification of industry (SIC)

5. Nature of injury

6. Part of body injured

7. Type of accident of exposure

8. Source of injury.

The two years of SDS information were combined into a single data set. Twenty-six states contributed in 1977 and twenty-seven contributed in 1978 . The data is coded for alkali as a source of injury with ammonia as a subset. Despite the recognized limitations, these data were examined to provide some measure of ammionia exposure nationally.

Table 4.18 lists the number of alkali cases for each participating state in the period 1977-1978. It must be noted that some states did not contribute in both years. It is difficult to assess how well these states represent the potential ammonia exposures nationally. Based on farm acreages per state reported in Statistical Abstracts of the U.S., 1979, the states listed include $528 \mathrm{million}$ farm acres out of a national total of $1049 \mathrm{milition}$ (or $50.3 \%$ ). However, a significant portion of the Midwest, Kansas, North Dakota, Okiahoma and Texas, are not included. No information was available about state usage of anhydrous ammonia in agriculture. It is difficuit to know whether the lack of farm-state coverage is significant. 
TABLE 4.18. Number of Alkali Cases by State (1977-1978)

\begin{tabular}{|c|c|c|c|}
\hline State & $\begin{array}{c}\text { Number } \\
\text { of } \\
\text { Cases }\end{array}$ & State & $\begin{array}{c}\text { Number } \\
\text { of } \\
\text { Cases }\end{array}$ \\
\hline Alaska & 39 & Minnesota & 8 \\
\hline Arkansas & 18 & Missouri & 37 \\
\hline California & 710 & Nebraska & 40 \\
\hline Colorado & 71 & New Jersey & 43 \\
\hline Connecticut & 33 & New Mexico & 12 \\
\hline De\}dware & 2 & North Carolina & 68 \\
\hline Hawa i i & 137 & Oregon & 78 \\
\hline Idaho & 263 & South Carolina & 4 \\
\hline Indiana & 41 & South Dakota & 62 \\
\hline Iowa & 19 & Tennessee & 17 \\
\hline Kentucky & 321 & Utah & 13 \\
\hline Maine & 24 & Vermont & 4 \\
\hline Maryland & g & Washington & 386 \\
\hline Michigan & 26 & Wisconsin & 265 \\
\hline & & Wyoming & 82 \\
\hline
\end{tabular}

The 1980 Directory of Chemical Producers 1 ists 79 ammonia production plants with an annual capacity of $\$ 8.8$ million metric tons. The states represented in the SDS account for 40 percent of these plants and only 26 percent of the capacity. The three major producing states, Louisiana, 0klahoma and Texas, are not represented.

It was initially hoped that a scheme could be developed for extracting the ammonia cases from the alkali data. However, it became apparent that with such a wide variety of industries and occupations and the variance in case descriptions, such a scheme would not be practical. It is possible to extrapolate from the ratios of ammonia to alkali obtained with the California and Idaho data. However, each state is different in its composition of ammonia using industries and occupations. The SDS information is valuable solely as an indicator of what the national picture may be. 
Tables $4.19,4.20$ and 4.21 present the standard tabulations of SDS alkali incidents. The percentage have a distribution similar to those observed for the individual states discussed in earlier sections. The SDS data have the additional data element of the injured persons occupation. Table 4.22 shows the distribution of the alkali incidents by major occupational group. Craftsmen, operatives and laborers accounted for nearly three-quarters of the incidents. Table 4.23 lists the fifteen occupations with the greatest number of alkali injuries. These figures are of limited value since they are so generai.

\subsection{SUMMARY OF AMMONIA ACCIDENT DATA}

This analysis provides insight into the frequency and types of ammonia accidents and the resultant injuries. Human exposure to ammonia takes place in a variety of work situations. In the over 200 Idaho records examined, 77 different SIC industry codes were found. In the 1977 SDS data, 133 different occupations were found in the over 1200 records. The predominant conclusion is that reported exposures occur infrequently during ammonia production and agricultural use. The National Safety Council Farm Accident Survey reports that only about one percent of the total work injuries involved chemicals, and only one in four of these involved anhydrous ammonia. However, it is estimated that a large number of small ammonia spil1s that occur in agricultural applications go unreported.

Accidental spills of ammonia occur during production and storage but most of the accidents involving frequent and significant exposure to individuals happen during transportation and use. Injury accidents occurring during production are relatively few in number and this appears to corroborate that equipment and procedures used in the ammonia industry have been developed on sound safety principles. When accidents have happened, the plants have been shut down and the spills quickly contained.

Analysis of the various state records allows some generaizations about ammonia injuries. In the transportation and use of ammonia, accidents are caused predominantly by equipment failure and human errors. Transportation data strongly emphasized the hazards associated with ammonia transfer operations. As would be expected, most injuries involved a chemical type burn or 
TABLE 4.19. Alkali Incidents from SDS by Major Industry Group (1977-1978)

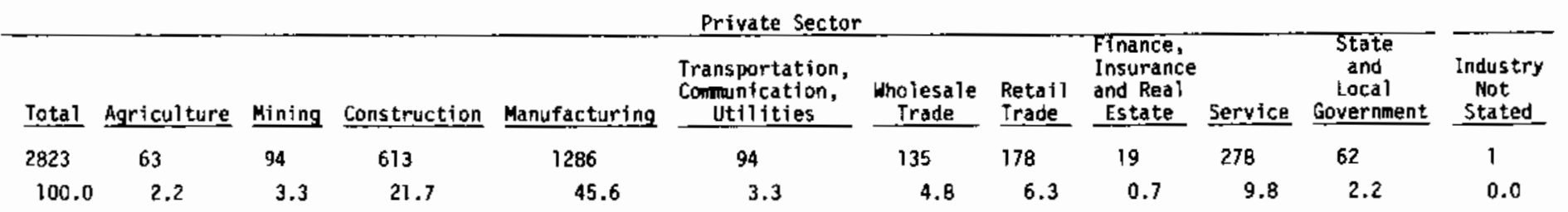

TABLE 4.20. Alkali Incidents from SDS by Nature of Injury (1977-1978)

\begin{tabular}{|c|c|c|c|c|c|c|}
\hline & Total & $\begin{array}{l}\text { Burns } \\
\text { and } \\
\text { Scalds }\end{array}$ & $\begin{array}{l}\text { Abrasions, } \\
\text { Scratches }\end{array}$ & $\begin{array}{l}\text { Strains, } \\
\text { Sprains }\end{array}$ & $\begin{array}{l}\text { Occupational } \\
\text { Illnesses }\end{array}$ & $\begin{array}{c}\text { Nature } \\
\text { Not } \\
\text { Stated }\end{array}$ \\
\hline unber of Incidents & 2823 & 1866 & 127 & 15 & 718 & 73 \\
\hline Percent of Total & 100.0 & 66.8 & 4.5 & 0.5 & 25.4 & 2.6 \\
\hline
\end{tabular}

TABLE 4.21. Alkali Incidents from SDS by Part of Body Injured (1977-1978)

\begin{tabular}{|c|c|c|c|c|c|c|c|c|c|c|c|}
\hline & Total & Eyes & $\begin{array}{l}\text { Head, } \\
\text { Face }\end{array}$ & $\underline{\text { Neck }}$ & $\begin{array}{l}\text { Back, } \\
\text { Spine }\end{array}$ & $\begin{array}{l}\text { Trunk, } \\
\text { N.E.C. }\end{array}$ & $\begin{array}{c}\text { Upper } \\
\text { Extremities }\end{array}$ & $\begin{array}{c}\text { Lower } \\
\text { Extremities }\end{array}$ & $\begin{array}{l}\text { Multiple } \\
\text { Parts } \\
\end{array}$ & $\begin{array}{c}80 d y \\
\text { Systems }\end{array}$ & $\begin{array}{l}\text { Other } \\
\text { or Not } \\
\text { Stated }\end{array}$ \\
\hline umber of Incidents & 2823 & 633 & 370 & 6 & 14 & 58 & 329 & 570 & 327 & 488 & 28 \\
\hline Percent of Total & 100.0 & 22.4 & 13.1 & 0.2 & 0.5 & 2.1 & 11.7 & 20.2 & 11.6 & 17.3 & 1.0 \\
\hline
\end{tabular}


IABLE 4.22. Distribuition of SDS Alkali Incidents Within the Major Occupation Groupings (1977-1978)

\begin{tabular}{|c|c|c|}
\hline Occupation & $\begin{array}{l}\text { Number of } \\
\text { Incidents }\end{array}$ & $\begin{array}{l}\text { Percent of } \\
\text { Incidents }\end{array}$ \\
\hline $\begin{array}{l}\text { Professional, Technical and Kindred } \\
\text { Workers }\end{array}$ & 83 & 2.9 \\
\hline Managers and Administrators, Exc. Farm & 73 & 2.6 \\
\hline Sales Workers & 12 & 0.4 \\
\hline Clerical and Kindred Workers & 53 & 1.9 \\
\hline Craftsmen and Kindred Workers & 587 & 20.8 \\
\hline Operatives, Exc. Transport & 698 & 24.7 \\
\hline Transport Equipment Operatives & 112 & 4.0 \\
\hline Laborers, Exc. Farm & 788 & 27.9 \\
\hline $\begin{array}{l}\text { Farmers and Farm Laborers, Managers, } \\
\text { Foremen }\end{array}$ & 48 & 1.7 \\
\hline Service Workers, Exc. Private Househoids & 322 & 11.4 \\
\hline Private Househo?d Workers & 0 & 0.0 \\
\hline Occupation Not Reported & $\underline{48}$ & 1.7 \\
\hline Tota? & 2,824 & 100.0 \\
\hline
\end{tabular}

IABLE 4.23. The Fifteen Occupations Having the Greatest Number of Alkali Incidents - SDS (1977-1978)

\begin{tabular}{|c|c|c|}
\hline Occupation & $\begin{array}{l}\text { Number of } \\
\text { Incidents }\end{array}$ & $\begin{array}{l}\text { Percent of } \\
\text { incidents }\end{array}$ \\
\hline $\begin{array}{l}\text { Construction Laborers, Except Carpenter's } \\
\text { Helpers }\end{array}$ & 291 & 10.2 \\
\hline Miscelleous Laborers & 269 & 9.5 \\
\hline Machine Operatives & 189 & 6.6 \\
\hline Miscelieous Operatives & 120 & 4.2 \\
\hline Not Specified Laborers & 106 & 3.7 \\
\hline Truck Drivers & 86 & 3.0 \\
\hline Foremen, N.E.C. (a) & 79 & 2.6 \\
\hline Cement and Concrete Finishers & 71 & 2.5 \\
\hline Janitors and Sextons & 62 & 2.2 \\
\hline Miscelleous Mechanics and Repairmen & 62 & 2.2 \\
\hline Carpenters & 61 & 2.2 \\
\hline Managers and Administrators & 55 & 1.9 \\
\hline Occupation Not Reported & 48 & 1.7 \\
\hline Farm Laborers; wage Workers & 45 & 1.6 \\
\hline Cleaners and Charpersons & 45 & 1.6 \\
\hline Total & $i, 584$ & 55.7 \\
\hline
\end{tabular}

(a) N.E.C. means "not elsewhere classified." 
damage to a body system, primarily the lungs. The most frequently damaged body parts were the eyes, extremities, and respiratory tract. Information on the actual types of accident was often ambiguous. The data confirms the exposure characteristics expected from a volatile water-soluble alkali.

The principal cause of death from exposure to ammonia is inhalation asphyxiation. Some victims die inmediately, other die later of complications resulting from previous exposure. While there are many cases of ammonia exposure to humans and quite often in acute toxic concentrations, there is a lack of case studies to document any late effects, if they do occur.

Specific data on ammonia accidents and injuries is available. Each state probably has workers' compensation case reports on file which specifically indicate ammonia as the source of injury. However, such detail is lost in the data reduction process. To have each state pull all the ammonia files for a given year would be time consuming and expensive. The specific ammonia data available from a few studies illustrate the overail portion of ammonia spili frequency and injuries. However, without national coverage, the information is incomplete.

Appendix A contains brief case histories to illustrate the variability of accident circumstances and consequences. 



\subsection{AMMONIA HAZARDS}

The environmental and health hazards of ammonia spitls are identified and evaluated in this chapter. The work is conducted by defining some "worst case" spill scenarios and then assessing the potential impacts to aquatic and terrestriai environments and humans. The fire and explosion hazards of ammonia plumes are also considered.

\subsection{LAND SPILLS}

This section examines the variabies and conditions that affect the development of ammonia clouds after a spil1. The "worst case," negatively buoyant plumes, is considered for spills with refrigerated and pressurized storage systems. The major thrust is to define the initial pool and cloud conditions for subsequent dispersion calculations. These results are needed to assess the environmental and health impacts.

\section{1 .1 Types of Spin1s}

The most important variables affecting spills are the nature of the ammonia storage, the magnitude and rate of the spill and the influence of the ambient air. Certain combinations of these variables can lead to long lasting denserthan-air ammonia clouds (negatively buoyant).

Liquid ammonia is stored in essentially two ways: either at ambient temperature and high pressure or at a lower pressure under refrigeration. The latter method has the potential of keeping the pressure at or below one atmosphere if the 1 iquid temperature is $-33^{\circ} \mathrm{C}$ or 1 ower. The first method requires pressure vessels for containers and therefore has a practical size iimit for individual containers. High-pressure storage can have almost instant accidental releases, whereas the refrigerated storage leaks proceed slower. However, with larger size of refrigerated vessels, the overall consequences may be greater than with high pressure storage leaks. Both types of storage failures can produce denserthan-air ammonia vapor-air mixtures if most of the heat of vaporization comes from the air. This is called the degree of adiabatic evaporation. Any heat 
transfer to the ammonia pool by other sources, such as the ground or the sun, will produce a less dense vapor cloud and lead ultimately to a positively buoyant cloud.

Two simple experiments show this effect (Blanken 1980). If an open flask of 1 iquid at $-33^{\circ} \mathrm{C}$ ammonia is heated from the outside, the resulting boiling will produce a vapor of pure ammonia of density $0.905 \mathrm{~kg} / \mathrm{m}^{2}$ (dry room air at $25^{\circ} \mathrm{C}$ one atmosphere is $1.185 \mathrm{~kg} / \mathrm{m}^{3}$ ) which will readily rise. When this vapor mixes with the air, all concentrations of vapor and air will be less dense than the air. In the second experiment, the above flask is insulated from all outside heat sources. The dry room air $\left(25^{\circ} \mathrm{C}, 1 \mathrm{~atm}\right)$ is bubbled through the 1 iquid ammonia. Adiabatic evaporation will slowly cool the 1 iquid down to $-70.7^{\circ} \mathrm{C}$. At that point the air saturated in ammonia, also at $-70.7^{\circ} \mathrm{C}$, will have $6.2 \%$ (by wt) ammonia and will be at a density of $1.67 \mathrm{~kg} / \mathrm{m}^{3}, 41 \%$ more dense than the ambient air. Somewhere during that experiment, the $\mathrm{NH}_{3}$ saturated air will have had the same density as the incoming air. This occurs at $46 \% \mathrm{NH}_{3}$ (by wt) at $-43^{\circ} \mathrm{C}$. All accidents involving liquid $\mathrm{NH}_{3}$ contact with air will produce a mixture that will be somewhere between the buoyant pure vapor and negatively buoyant $6.2 \%$ ammonia at $-70.7^{\circ} \mathrm{C}$. The basic question then becomes one of relative heat transfer. To what degree is direct air contact or how much is external heat (sun, ground, etc.) causing the evaporation?

If the leak path is from the container vapor space in refrigerated storage $^{(a)}$ to the environment, little ammonia vapor will escape. If this occurs in pressurized storage, the release depends on the rate of the leak. A slow leak will bleed only pure buoyant vapor. A huge hole suddenly appearing above the liquid will probably end in near violent eruption of the whole contents into the ajr. About $20 \%$ of the contents would end up as vapor at $-33^{\circ} \mathrm{C}$ and $80 \%$ as liquid. A large fraction of the liquid will become drops and therefore candidates for mixing with air.

In refrigerated storage, the hydrostatic head and flow resistance of the break control the leakage rate. If the liquid leak is slow, the ammonia will probably receive adequate heat from external surfaces to form a buoyant vapor.

(a) From this point on all refrigerated storage will be considered to be at $-33^{\circ} \mathrm{C}$ and one atmosphere. 
If the leak is rapid and a long pool of ammonia is formed and remains in contact with the ambient air, the conditions can cause the relative heat transfer to favor formation of denser-than-air $\mathrm{NH}_{3}$-air mixtures. This case is treated quantitatively in Section 5.1.3.

In pressurized storage, the leak from liquid space can have many variations. A slow leak can lead to either buoyant or non-buoyant clouds, depending on the relative heat transfer to the liquid phase leaking. A large hole can produce a liquid jet that rapidly flashes into two phases. If the liquid phase remains suspended with the vapor phase its droplets evaporate by direct contact with air, and the resulting cloud will likely be negatively buoyant. Any pure vapor phase escaping the liquid will be buoyant. Thus two types of ammonia clouds can occur, one buoyant and one negatively buoyant. If the pressurized break occurs in a line leading from a storage vessel, the resulting blowdown will primarily be a two-phase cloud of vapor and droplets that mix with air and produce an denser-than-air cloud. The ammonia has time to reach thermodynamic equilibrim as it passes from high pressure to atmospheric pressure and to form two phases flowing at high velocity. This is a form of classic atomization. Smal1-scale experiments and some of the accidents have shown nearly complete atomization. Surfaces in the flow path have become wet and have collected some of the drops. The unrestricted flow line break will probably be a highly dispersed jet that will totally vaporize upon contact with ambient air.

In refrigerated spills, the porosity and conductivity of the soil, the area of the pool, and the wind determine the cloud characteristics. A highly porous and conducting soil will provide heat to vaporize the ammonia into buoyant vapor. In contrast, an impervious soil of low conductivity will not provide much heat for evaporation. The area of the pool exposed to wind and the wind velocity are directly related to the rate of evaporation.

In pressurized spills the degree of mixing with the air is controlled by the atomization of the flow. Some droplets remain airborne but some fall to a pool. A large portion of the latter will probably lead to buoyant vapor formation due to eventual contact with, and evaporation from, the pool. 
Evaporation of anmonia into air is also influenced by the relative humidity of the air. Since water and $\mathrm{NH}_{3}$ react exothermally the resulting temperature increase acts to raise the buoyancy of any $\mathrm{NH}_{3}-\mathrm{air}-\mathrm{H}_{2} \mathrm{O}$ mixture. Thus dry air enhances the likelihood that a negatively buoyant plume will be formed. This effect is discussed in the literature of 5.1.2.

\section{1 .2 Review of Relevant Literature}

Since both refrigerated and pressurized spills can result in denser-thanair ammonia clouds, relevant articles were reviewed to provide a better understanding and to aid in calculations. The primary focus is on spill definition and usefulness in making caiculations needed for this project.

Blanken (1980) qualitatively discusses both land and water spills. He provides some good insights; however, some conclusions are speculative or not properly qualified and, therefore, are controversial. The author states that, based on the span of conditions between pure ammonia vapor formation at conditions of boiling at $-33^{\circ} \mathrm{C}$ and at saturation with air at $20^{\circ} \mathrm{C}$, all mixtures containing greater than 45 weight \% ammonia are less dense than air. This is true if qualified properly. Certainly there are conditions in cases where heat loss and gain can change the density of any cloud. The other controversial conclusion is that a ruptured pressure vessel of ammonia will give a primarily buoyant cloud. This conclusion is not backed up by experience or by the analyses provided in this chapter. He is correct, based on his assumptions, that the pressurized ammonia eventually separates into two portions: a pure vapor cloud at $-33^{\circ} \mathrm{C}$ and a 7 iquid spill at $-33^{\circ} \mathrm{C}$. No known catastrophic ruptures have initially produced a cloud that was totally buoyant, although some fraction of these spills may have been lost due to buoyancy.

$B l a n k e n$ has summarized some useful data on pressurized releases through ducts. Here small scale experiments have shown that $\mathrm{NH}_{3}$ jets that impact on surfaces can leave residual liquid on these surfaces, especially if the jet impinges vertically downward onto a surface. As much as $70 \%$ was collected in two such experiments. Blanken considers a break in the liquid region of a pressurized tank where the hole is essentially a sharp-edged orifice. He cites 
saturated water data that showed no breakup of the liquid prior to passing through the break. Some data are needed on the partitioning of $\mathrm{NH}_{3}$ liquid and vapor from, and the mixing with, air in such a break where thermodynamic equilibrium might not exist during flow out of the break.

The final conclusion of Blanken's paper is that further studies to produce spill models or construct dikes, etc., to contain spills are not worthwhile; but rather efforts should be made to make ammonia storage and transportation fail safe.

Griffiths and Kaiser (1979) give an excellent review of articles with qualitative descriptions of refrigerated spills onto water and land and pressurized spills. This review contains a scan of virtually all pertaining literature where quantitative information is available. The pressurized spill discussions range from accidents with small to large holes in the vapor space to holes in the liquid space. In the last situation, they correctly predict the probable heavier-than-air mixture of ammonia and air based on some qualitative data in the literature.

Kaiser and Walker (1978) are pioneers in predicting the long term behavior of denser-than-air mixtures of air and ammonia resulting from pressurized container failure. The bulk of the paper deals, quantitatively, with slumping, cloud heating, air entrainment after formation of these heavier-than-air clouds. Only general discussions on mixing during initial cloud formation are found with a 10:1 air-to-ammonia ratio being likely.

Haddock and williams (1978 and 1979) provided the first quantitative predictions of ammonia-air mixture densities and temperatures resulting from evaporation of $\mathrm{NH}_{3}$ with air and mixing of the vapor and cooled air. They also showed how air humidity affects the cloud density. Their two figures, redrawn below, have been referred to by nearly all subsequent papers on ammonia spills. The value of their work cannot be overstated for this assessment. Using simple thermodynamic principles they computed the densities and the temperatures of gas mixtures of $\mathrm{NH}_{3}$-air formed by evaporation of ammonia aerosol. The initial ammonia aerosol is at $-33^{\circ} \mathrm{C}$ and one atmosphere pressure and the value $\mathrm{F}$ is 
the weight \% of ammonia in the aerosol present as liquid drops. Figure 5.1 shows the initial aerosol density asymptomatically approaching that of the diluent air at $20^{\circ} \mathrm{C}$ as the air $/ \mathrm{NH}_{3}$ ratio increases. Of major significance in this figure is the cutoff at $F=8 \%$ where the cloud is just denser than the diluent dry air. For diluent air saturated in water at $20^{\circ} \mathrm{C}$, the cutoff is at a higher $F$ value. Ammonia reacts exothermally with water vapor and the

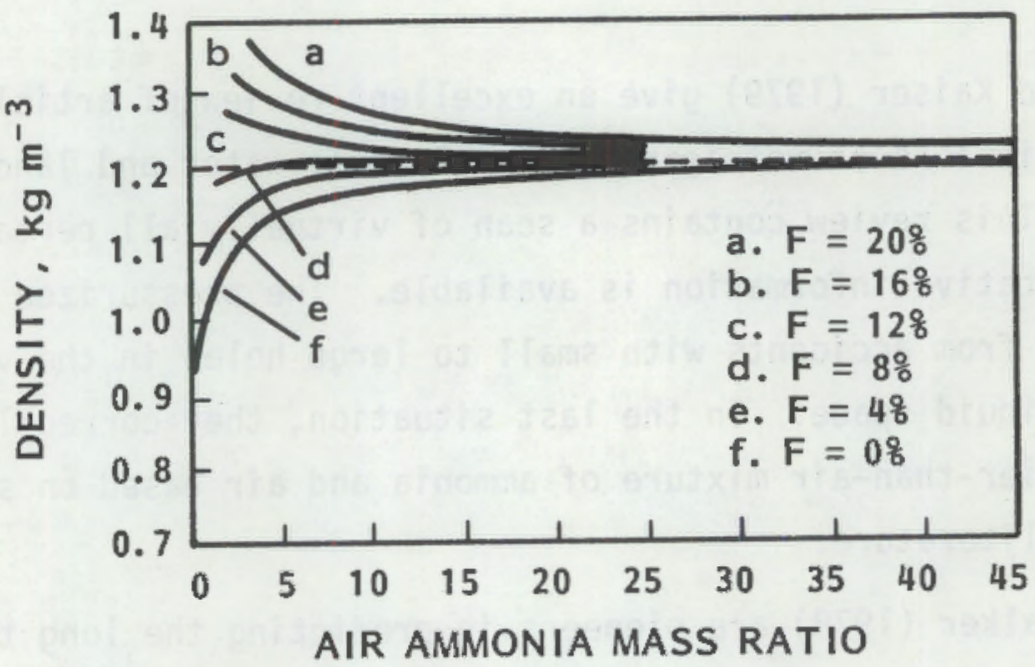

FIGURE 5.1. Density of an Ammonia Cloud Initially Containing Some Liquid Ammonia as it is Diluted with Dry Air

resulting temperature increase lowers the density of the mixture. Figure 5.2 is the set of densities of $\mathrm{NH}_{3}$-wet air mixtures corresponding to the set for dry air $-\mathrm{NH}_{3}$ in Figure 5.1. We see that the cut off is between $\mathrm{F}=16-20 \%$ as compared to $8 \%$ for dry air.

Bal1 (1969) presents useful data and calculations of past temperatures of, and evaporation rates from, pools of liquid ammonia. Evaporation data for one and 10-ton spills and unsteady-state calculations of evaporation rates for other spills were presented that provide a useful basis for understanding the pool evaporation process. Ball calculated the steady-state evaporation rates at wind speeds of 5 to $25 \mathrm{mph}$ and for temperatures of $40^{\circ} \mathrm{F}$ and $80^{\circ} \mathrm{F}$, and for 


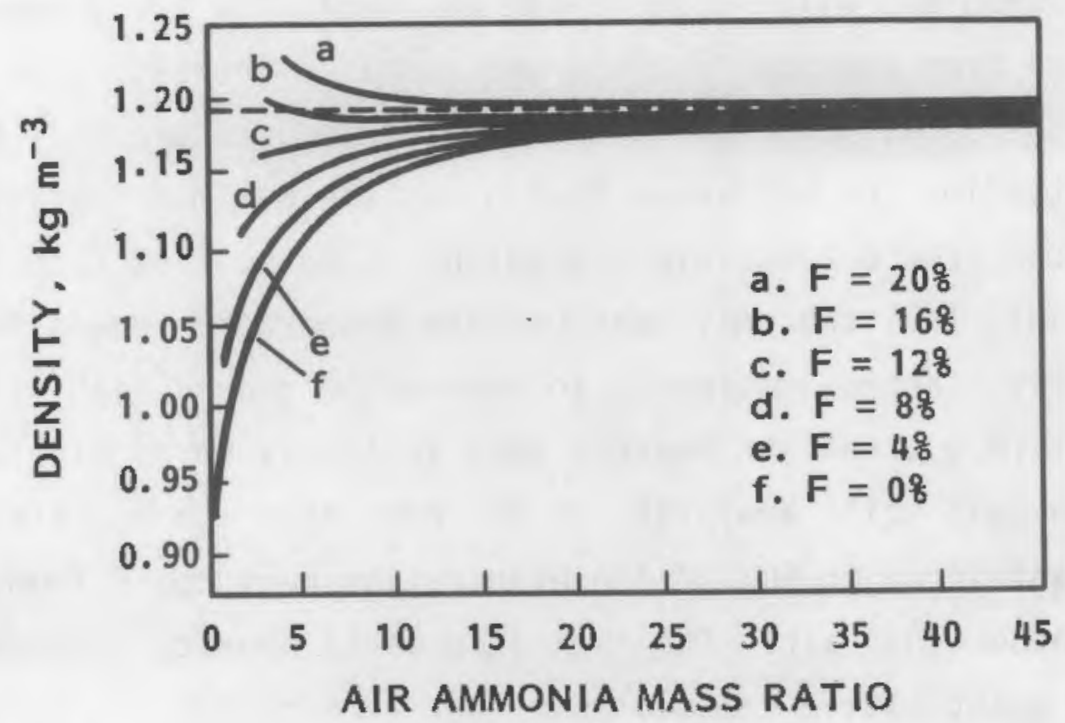

FIGURE 5.2. Density of an Ammonia Cloud Containing Some Liquid Ammonia as it is Diluted with Wet Air

various pools sizes of 10 to 500 feet. However, he has not clearly presented the details of his evaporation model; this would have been very helpful in modeling scenarios that depart significantly from the parameter values he considered. Since the evaporation rate has a strong influence on the downwind ammonia concentration, a better understanding of the model used here is definitely desirable. Although Ball presents some data that are of the same magnitude as those predicted by his model, there are no data that verify the functional relationships of the model. Ball's results should be investigated further before using them.

\subsubsection{Calculations for Refrigerated Spills}

To precisely describe the cold spill evaporation process requires more information than is apparently available, but some reasonable approximations can be made. First, the influence of the ground can be quite variable. Wet soil will react with $\mathrm{NH}_{3}$ to make a solution that will finally freeze. An unsteady-state temperature profile will always exist through the ground to the bottom of the liquid ammonia pool which will be the coldest point. Little, 
if any, thermal gradient will exist in the $\mathrm{NH}_{3}$ pool. (a) The average temperature profile will rise from the pool surface and continue increasing as distance increases from the pool. Eventually the ambient temperature will be reached. The limiting situation for this case that gives the maximum density ammonia-air mixture is for the ground temperature gradient to be so flat (and ground heat flux insignificant) that the only heat-causing evaporation comes from the air. Therefore, the first approximation is to ignore the ground heat flux and any other heat input (e.g., radiant energy) that is likely to be minor. In the last part of the cold spill analysis, it is shown that the $\mathrm{NH}_{3} /$ air mixture is negatively buoyant if up to $90 \%$ of the evaporation heat comes from the ground or any sources other than air. The next step is to provide a scenario that illustrates the quantitative calculations that were made.

\subsubsection{Cold Spill Scenario}

For this case a 40 -ton 1iquid ammonia (refrigerated to $-33^{\circ} \mathrm{C}, 1 \mathrm{~atm}$ ) spill occurs over a 4.4-hour period into a 100-ft $\times 100-\mathrm{ft}(30.5-\mathrm{m} \times 30.5-\mathrm{m})$ square pool of evaporating liquid of negligible depth. A 5-mph wind moves steadily across the pool. The bottom of the pool is a perfect insulator, i.e., no heat from the ground to aid in evaporation. The atmosphere is dry at $25^{\circ} \mathrm{C}$ with a density of $1.185 \mathrm{~kg} / \mathrm{m}^{3}$. The pool is assumed to be at a steady-state temperature of $-70^{\circ} \mathrm{C}$ with a saturated heavy layer of ammonia-in-air mixture being swept by wind where it is continually mixing with the $25^{\circ} \mathrm{C}$ air and being diluted, but it always will be heavier that the $25^{\circ} \mathrm{C}$ air as long as no other heat source (air only) warms the gas mixture. The following properties, quantities and rates concerning the saturated cloud were calculated: $(a)$

- Temperature, $-70^{\circ} \mathrm{C}$

- Density, $1.66 \mathrm{~kg} / \mathrm{m}^{3}$

- Ammonia concentration, $7 \%$ by weight or $11.4 \%$ by volume

- Volume rate of formation, $7.77 \times 10^{4} \mathrm{~m}^{3} / \mathrm{hr}$

- Total volume, $3.42 \times 10^{5} \mathrm{~m}^{3}$.

(a) Heating the pool from the bottom and cooling the pool by evaporation from the top will both create unstable layers within the $\mathrm{NH}_{3}$ to cause mixing, and a fairly uniform pool temperature will result. 
This saturated cloud in reality has a 3-D concentration, density and temperature profile as it is diluted with bulk dry air. From turbulent boundary layer theory, the rate of dilution and the concentration profile above the pond could be estimated, but the estimation is not needed here.

A slight variation on the above case is as follows: instead of a steady leak over 4.4-hour period, the spill of refrigerated $\mathrm{NH}_{3}$ is sudden and there is a complete spill into the same size poor, this time $5.94 \mathrm{~cm}$ deep. Since the pool is at $-33^{\circ} \mathrm{C}$ and at one atmosphere pressure, evaporation using pool heat is assumed to ensue until a steady pool temperature of $-70.7^{\circ} \mathrm{C}$ results. The initial cloud is modeled as $11.4 \%$ of the liquid instantly evaporating as a buoyant pure $\mathrm{NH}_{3}$ cloud at $-33^{\circ} \mathrm{C}$ having a density of $0.905 \mathrm{~kg} / \mathrm{m}^{3}$ and a continuously generated high density saturated cloud with the following properties:

- Density, $1.67 \mathrm{~kg} / \mathrm{m}^{3}$

- Temperature, $-70.7^{\circ} \mathrm{C}$

- Concentration, $6.24 \% \mathrm{NH}_{3}$ by weight, $10.2 \%$ by volume

- Volume, (88.6\% of $\mathrm{NH}_{3}$ present) $3.38 \times 10^{5} \mathrm{~m}^{3}$.

The evaporation will occur over a 3.9 -hour period ( $88.6 \%$ of $4.4 \mathrm{hr}$ ). If the buoyant pure $\mathrm{NH}_{3}$ cloud is added to the above cloud so that a uniform cloud results, its properties and volume will be the same as the cloud of the initial scenario. Because these two possible ways of viewing a cold spill can cause confusion, it is further assumed that the sensible heat in the ammonia at $-33^{\circ} \mathrm{C}$, which is above the resulting steady pool temperature is added to the overall heat balance to produce only one cloud at one temperature. This was done in the first case.

\subsubsection{Non-Adiabatic Effects}

The density of the cloud of ammonia in dry air in the first case is $40 \%$ greater than the ambient. The independent variable chosen to indicate the changing properties with different levels of non-adiabatic heat is the percent adiabatic evaporation with air. At $100 \%$ adabatic evaporation, the saturated

(a) See Appendix B for calculation methods. 
gas cloud has the properties of the first case. At $0 \%$ adiabatic evaporation, the saturated gas cloud is pure ammonia at $-33^{\circ} \mathrm{C}$ with density of $0.905 \mathrm{~kg} / \mathrm{m}^{3}$. (a) Al1 points in between $0 \%$ and $100 \%$ adiabatic can be calculated by combining appropriate portions of heat from the air and from external sources and carrying out a thermal balance with the necessary conditions for saturation to exist. The results of these calculations are shown in Figure 5.3. The most noteworthy point is on the density versus \% adiabatic saturation curve at the intersection of $\rho=1.185$, the ambient air density. This intersection occurs at $6 \%$ adiabatic saturation. Thus, nearly 16 times $(.94 / .05)$ as much heat can come from the ground and from radiation as from the air itself, and still maintain a neutrally buoyant cloud. This is extremely significant for the cold spill; it should therefore be that the vapor-air cloud from a cold spill is denser than the ambient air except at the very beginning of a spill. In the cases already discussed, the air heat flux to the ammonia in a 5 -mph wind was $1177 \mathrm{Btu} / \mathrm{hr} \mathrm{ft}^{2}$ or $8.9 \times 10^{-2} \mathrm{cal} / \mathrm{cm}^{2} \mathrm{sec}$. The soil flux is infinite initially upon receiving a sudden spill of $\mathrm{NH}_{3}$. The $16 x$ flux level from the soil is reached after only $0.4 \mathrm{sec}$ for a low conductivity soil to $7 \mathrm{sec}$ for a high conductivity soil. If the $\mathrm{NH}_{3}$ spill is big enough to sustain a puddle beyond 7 seconds, then the vapor cloud generated in a 5 -mph wind is more dense than the ambient air. This seems highly likely for spills of any significant size.

Water vapor in the air will change the results in the above analysis toward less ground heat required to get to the buoyant cloud, but as in Griffiths and Kaiser (1979), the humidity effect will not likely be significant. Certainly, assuming that water vapor will help the situation is not a conservative assumption nor is it very helpful.

\subsubsection{Calculations for Pressurized Spills}

The pressurized method of storage has the advantage of not requiring refrigeration systems, but rather has the disadvantage of requiring pressure vessels as containers to withstand the high vapor pressure of liquid ammonia

(a) This would be the cloud formed by a pool of boiling liquid ammonia where the heat is supplied at the bottom of the pool (or by external radiation) and the surrounding air provides no heat of evaporation. 

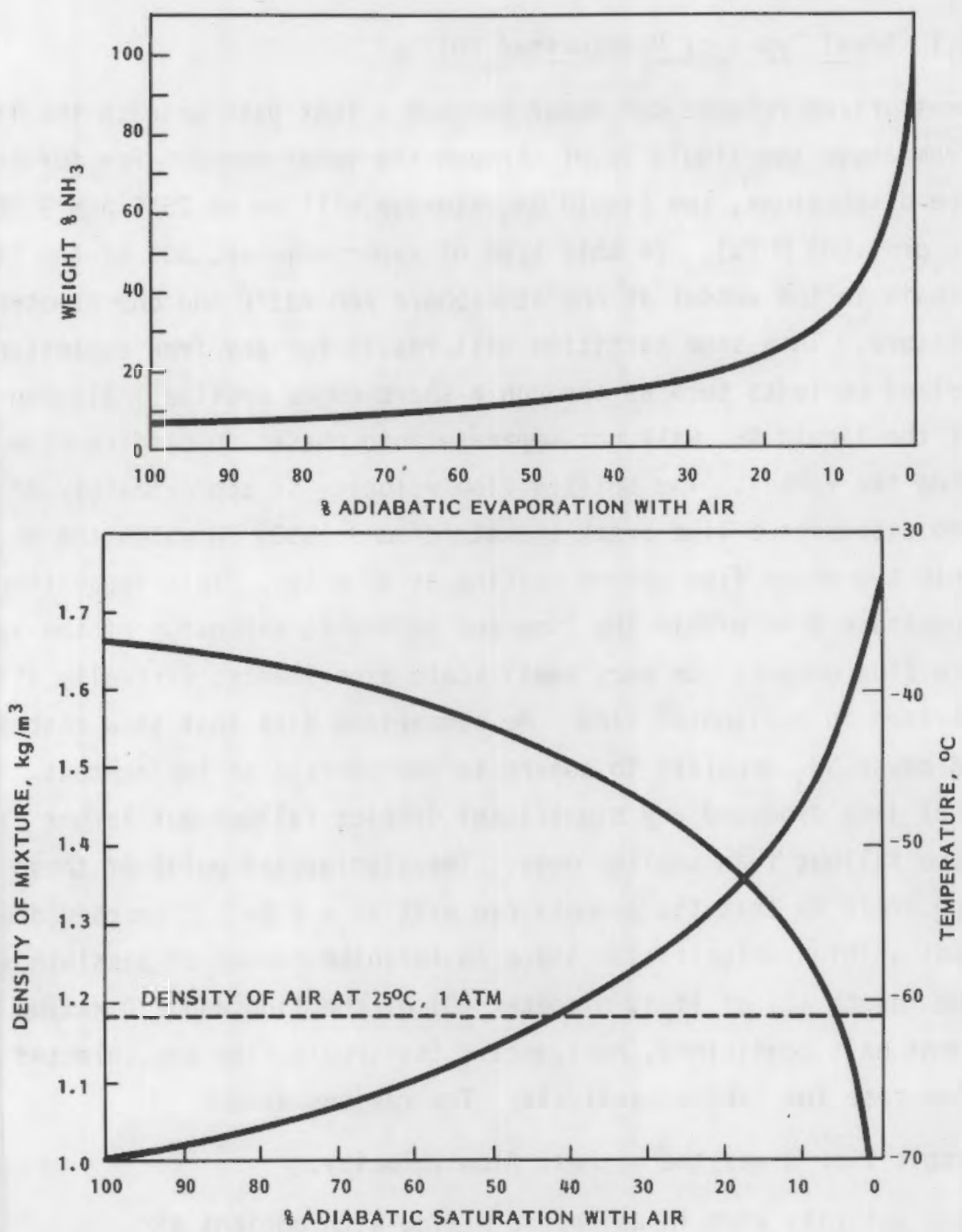

FIGURE 5.3. $\mathrm{NH}_{3}$-Air Mixture Density, Temperature and Ammonia Concentration for Fractional Adiabatic Evaporation of a Cold Pool of Liquid $\mathrm{NH}_{3}$ Producing a Saturated Mixture

at ambient temperatures. When pressure vessels fail, their mode of failure is likely to be far more catastrophic than the cold spill failure because of the high pressure of the stored ammonia. For the purposes of this report, only the violent rapid depressurization of ammonia will be discussed. The slow leak in this case or in the case of the refrigerated liquid is likely to be of much smaller environmental consequence. 


\subsubsection{Ideal Types of Pressurized Spills}

The pressurized release can occur through a leak path beneath the liquid level or from above the liquid level through the vapor space. For further quantitative discussions, the liquid $\mathrm{NH}_{3}$ storage will be at $25^{\circ} \mathrm{C}$ and $9.90 \mathrm{~atm}$ (145.4 psia or $1.003 \mathrm{M} \mathrm{Pa}$ ). In this type of vapor release, $80 \%$ of the liquid $\mathrm{NH}_{3}$ will remain in the vessel at one atmosphere and $-33^{\circ} \mathrm{C}$ and one atmosphere partial pressure. This same partition will result for any free expansion of the pressurized contents such as through a sharp-edged orifice. Blanken (1980) claims that the liquid $\mathrm{NH}_{3}$ will not separate into phases in orifice flow until it is outside the vessel. The orifice flow velocity is approximately $30 \mathrm{~m} / \mathrm{sec}$. Blanken also discusses a line break (length/diam - 1500) in which the $\mathrm{NH}_{3}$ will separate into two-phase flow before exiting at $80 \mathrm{~m} / \mathrm{sec}$. This separation is caused by pressure drop within the line and adiabatic expansion of the vapor as two-phase flow occurs. In very small scale experiments, virtually all drops of $\mathrm{NH}_{3}$ vaporized in horizontal flow. He summarized data that show that an impinging jet can cause $\mathrm{NH}_{3}$ droplets to adhere to the surface of impingement. However, no horizontal jets produced any significant droplet fallout but larger diameters produced more fallout than smaller ones. The signigicant point of these data and the line break is that the ammonia can exit as a highly dispersed dropletvapor aerosol at high velocities. Since an infinite number of possible variations on the length (L) of line, diameter (D) of the line and L/D ratios will give different exit conditions, horizontal, isentropic flow was selected as the limiting flow case for further analysis. The reasons are:

- isentropic flow gives the highest flow velocity.

- the high velocity aids in adiabatic mixing with ambient air.

- the velocity is independent of break diameter, therefore scaling is simplified and modeling mixing with air will be independent of diameter as well.

- horizontal flow keeps the denser-than-air cloud near the ground and maximizes consequences. 


\subsubsection{Isentropic Blowdown}

Results are presented of an isentropic blowdown of 40 tons of ammonia initially at $25^{\circ} \mathrm{C}, 9.9 \mathrm{~atm}$ into dry air at $25^{\circ} \mathrm{C}, 1 \mathrm{~atm}$. The cloud formed in mixing with air is described in this section using a 3-D jet as a model for mixing (see Appendix $\mathrm{B}$ ) of the $\mathrm{NH}_{3}$ jet with air. The effects of gravity on the plume are neglected.

Isentropic flow is an idealized description of flow out an exit that is best represented by a converging nozzle such as the upstream half of a venturi. The flow neglects friction losses so only thermodynamic principles are needed to describe the exit conditions of the ammonia jet. Using a temperatureentropy chart or table for ammonia, the upstream vessel and downstream exit conditions are shown in Table 5.1 .

TABLE 5.1. Upstream Vessel and Downstream Exit Conditions

\begin{tabular}{llll} 
& \multicolumn{1}{c}{ Vessel } & & \multicolumn{1}{c}{ Exit } \\
\cline { 2 - 2 } Temperature & $+25^{\circ} \mathrm{C}$ & & $-33^{\circ} \mathrm{C}$ \\
Pressure & $9.90 \mathrm{~atm}$ & & $1.0 \mathrm{~atm}$ \\
Density & $602.8 \mathrm{~kg} / \mathrm{m}^{3}$ & & $5.336 \mathrm{~kg} / \mathrm{m}^{3}$ \\
\% Vapor & 0 & 17 \\
Enthalpy & $71.7 \mathrm{gcal} / \mathrm{g}$ & $62.2 \mathrm{gcal} / \mathrm{g}$ \\
Entropy & $0.26 \mathrm{gcal} / \mathrm{g}^{\circ} \mathrm{C}$ & $0.26 \mathrm{gcal} / \mathrm{g}^{\circ} \mathrm{C}$
\end{tabular}

With an enthalpy balance, the exit velocity of the 2-phase mixture is calculated to be $282 \mathrm{~m} / \mathrm{sec}$. Sonic (critical) velocity for pure $\mathrm{NH}_{3}$ vapor at $-33^{\circ} \mathrm{C}$ is $392 \mathrm{~m} / \mathrm{sec}$. We have assumed that the two phases are intimately dispersed and travel together without separation.

To continue with the 3-D jet mixing model, we have assigned dimensions to the 40 -ton blowdown. The break is a circle with diameter of $0.92 \mathrm{~m}$. It takes 40 seconds for the blowdown to occur. From the model the characteristics of the cloud or plume were obtained and plotted in Figure 5.4. In this figure the flow is from left to right and shows the centerline velocity which diminishes rapidly from $282 \mathrm{~m} / \mathrm{sec}(630 \mathrm{mph})$ to $6.6 \mathrm{~m} / \mathrm{sec}(15 \mathrm{mph})$ at the end of the cloud. 




FIGURE 5.4. Characteristics of the 3-D Jet Mixing Model

With this type of velocity, the cigar-shaped cloud, at 40 seconds, will detach from the break and continue to move to the right. Its shape and position at its resting point were not estimated. Judging from the centerline velocities above and the momentum spread radially, the cloud will stop developing within 1000 meters of the source after a few minutes when it will have a similar but fatter appearance. Gravity (previously neglected) will cause the cloud to be ellipsoidal (along the major axis) and cut in half horizontally. The more dense center line region of $\mathrm{NH}_{3}$-air will have slumped to the bottom. This cloud in dry air will be invisible. The $\mathrm{NH}_{3}$ droplets shown as "visible" in Figure 5.4 will have evaporated. In very humid air, the cloud will probably be visible as observed in the catastrophic spills. For the purposes of dispersion calculations, the average conditons of the cloud should suffice. As noted on the figure, these are:

- volume $=1.25 \times 10^{6} \mathrm{~m}^{3}$

- density $=1.29 \mathrm{~kg} / \mathrm{m}^{3}$

- temperature $=-4^{\circ} \mathrm{C}$

- $\mathrm{NH}_{3}$ concentration $=2.8 \%$ by weight $(4.65 \%$ by volume $)$. 
Appendix $B$ shows curves of density, temperature and composition of the above cloud as it formed and as it will be at further adiabatic mixing with dry air. In this, the air- $\mathrm{NH}_{3}$ mixture from the blowdown is about $20.1 \mathrm{air} / \mathrm{NH}_{3}$ by volume. Any other case having less flow energy out the break will be less dilute. Clouds from the Pontchefstroom accident (Kaiser and Walker 1978) have been estimated as about 10:1 initially based on visible volumes. Since the degree of humidity influences the visibility, the observed cloud will always be smaller than the total cloud surrounded by an invisible layer with conditions below saturation. The Pontchefstroom air was $19^{\circ} \mathrm{C}$ and $30-35 \%$ relative humidity (Lonsdale 1974). This break also was likely to be very close to an isentropic flow situation since the end of a horizontal tank containing 30 tons blew out releasing the $\mathrm{NH}_{3}$ horizontally with the tank itself serving as a "line" for channeling and directing the flow. The irregular shape of the hole at the end of the tank probably caused the cloud to have a more irregular and wider shape than that of the above scenario even though their areas were nearly the same. The Pontchefstroom initial cloud was $150 \mathrm{~m}$ in diameter and 20 meters deep and grew in minutes to $300 \mathrm{~m}$ in width.

\subsubsection{Uncertainties Remaining}

The largest uncertainty for a pressurized break of any large size is in the partition of liquid ammonia into drops that vaporize before hitting the ground and those that are large enough to contact the ground before vaporizing. However, unless the non-airborne fraction can be shown experimentally to be $>80-90 \%$, the air- $\mathrm{NH}_{3}$ cloud will always be denser than air and the pressurized break hazard should be considered to produce the denser-than-air cloud. None of the catastrophic breaks indicates that any significant fraction fell to the earth.

The model used to obtain the blowdown cloud has some assumptions that need further consideration. The biggest question is the effect of changing density on the momentum and mass distributions. Since the clouds described in the case seem reasonable based on observed accidental breaks, an improved mixing model for accidents does not seem necessary. 


\subsection{CLOUD DISPERSION}

The previous section noted that negatively buoyant clouds can result from either refrigerated or pressurized spills of ammonia. In this section, models for predicting cloud dispersion are discussed and the results of dispersion calculation presented.

\subsubsection{Dispersion Models}

Atmospheric dispersion models of denser gases are typically divided into three stages: 1) a source model, 2) a gravity spread model and 3) a neutral trace dispersion model (McNaughton and Berkowitz, 1979). The source model depends on the characteristics of the gas release and describes gas emission to the atmosphere. The gravity spread model describes the spreading and dilution of the gas cloud under the influences of gravity and edge mixing or entrainment. The dispersion model accounts for the final transport and dispersion of the gas cloud until it is no longer hazardous. In any given model, two or more of these stages may be linked together. Most existing descriptions and models of ammonia cloud dispersion omit consideration of one of the above stages. The impacts of ammonia spills depend on environmental conditions including land, water, wind, stability, temperature, humidity, surface roughness, and soil conditions. Only a few of these environmental conditions are accounted for in the existing descriptions of amonia cloud dispersion in the atmosphere.

The factors which influence ammonia cloud density and dispersion are discussed by Griffiths and Kaiser (1979). The circumstances under which anmonia can form a mixture which is either buoyant, neutrally buoyant or denser-thanair are reviewed. Each of the many amononia release mechanisms is analyzed and some of the factors which influence ammonia cloud dispersion for each release mode are discussed.

The evaporation of large liquid ammonia pools spilled on land and the resulting dispersion of ammonia clouds are discussed by Ball (1970). The bas is of evaporation description is theoretical calculations, and resulting calculations of ammonia cloud dispersion are based on empirical descriptions of atmospheric diffusion. 
It is calculated that steady-state pool temperatures and evaporation rates vary only slightly with anmonia pool sizes. However, early temperatures are lower and early evaporation rates higher for shallow pools. Consequently a shallow pool reaches steady-state conditions more quickly than a deep pool. It was calculated that $1000 \mathrm{ppm}$ ammonia concentrations occurred at a distance of about 10 pool diameters downwind under neutral conditions and $5 \mathrm{mph}$ wind speed. Under stable atmospheric conditions, the 1000-ppm ammonia concentration is reached at approximately 30 pool diameters downwind. There is no discussion of the determination of anmonia pool sizes for unimpounded land spills.

The behavior of a dense anmonia cloud which is released to the atmosphere as a result of the faiture of a pressurized container is modeled by Kaiser and Walker (1978). The gravity slumping, cloud heating and entrainment of air, and dispersion by atmospheric turbulence are quantitatively dealt with to produce hazard ranges for the spill. While the mechanism discussed for the initial production of a heavier-than-air mixture of ammonia and air is similar to that discussed in Subchapter 5.1 , namely the adabatic evaporation of liquid anmonia droplets in direct contact with air, the treatment is not so quantitative. The importance of this analysis of the impacts of an ammonia release from a catastrophic failure of a pressurized container is in the application of a simple model containing all the major elements used modeling the dispersion of more studied dense gases such as LNG. It is calculated for a 20-ton ammonia spi11, under ambient conditions of a $3-\mathrm{m} / \mathrm{sec}$ wind speed and neutral stability, that the ammonia cloud is no longer fatal when exposure time exceeds about $340 \mathrm{sec}$, corresponding to a hazard range of about 1 kilometer.

It is worthwhile to summarize the opinions of the Kaiser and Walker concerning the strong point of their approach to determining the dispersion of an ammonia cloud released from a pressurized container as well as the major uncertainties. It was argued that three characteristic features are unlikely changed by $\mathrm{plan}$ site variations or complications in the model. These are:

1. rapid formation of an ammonia cloud containing a mixture of air and ammonia that is more dense than the surrounding atmosphere 
2. gravitational slumping of the cloud and the rapid expansion of radius of the cloud; and

3. persistence of an ammonia cloud that does not rise from the surface under conmonly occurring weather conditions.

Major uncertainties are given as the entrainment of air into the slumping cloud and the scaling of effects for different sizes of ammonia spills from pressurized containers.

Experiments to assess the hazards presented by anmonia spills on water from refrigerated containers are reported by Raj, Hagopian and Kalelkar (1974), and Raj and Hagopian (1974). Mean partition ratios (the ratio of mass ammonia that dissolves in water to the spilled mass) of 0.73 are obtained from laboratory experiments, although wide ranges of partition ratios are obtained in swimming pool and lake experiments. Theoretical analysis of the interactions between ammonia and water (Raj and Reid 1978) yield partition ratios close to values obtained from the laboratory experiments. However for larger surface spills, the measured partition ratios vary between 0.5 and 0.6 and a rapid reaction is observed to iiberate a dense white fog of vapor probably containing a fraction of liquid ammonia droplets. Armonia clouds are observed to rise rapidly into the air, especially at low wind speeds. The path of the clouds is estimated to reasonable accuracy by existing plume rise theories.

Griffiths (1977) provides an alternative analysis of the ammonia cloud dispersion in these experiments based on grounds that some of the vertical dosage measurements show maximum values at ground level, which is not consistent with a plume that had lifted off from the surface. It suggested that the ammonia clouds are rendered nonbuoyant by the fraction of liquid ammonia droplets thrown in the vapor phase and evaporating under mixing with air.

An investigation of ammonia spills on land is reported by Resplondy (1969). Dispersion of ammonia clouds from pressurized releases are studied as well as spills of ammonia in earth dikes. Results of the tests with pressurized releases indicate that up to $20 \%$ of the ammonia fiashed into vapor and a large fraction of 10-30 micron aerosols are observed. The ammonia clouds hugged the ground while 
dispersing and the visible cloud boundary and the odorous region were coincident. At low wind speeds of $0.5 \mathrm{~m} \mathrm{sec}^{-1}$, the ammonia cloud from a dike spill rose and then fell to the ground.

\subsubsection{Dispersion Calculations}

Dispersion calculations were performed for 40-ton pressurized and refrigerated spills. A Gaussian plume model was used with Pasquill-Gifford plume dispersion coefficient $\sigma_{y}(x)$ and $\sigma_{x}(x)$. To accomodate negative buoyancy it was assumed that the plume did not 1 ift off the ground. Further conditions and assumptions for the calculations include:

- Assume $\sigma(x)=3 \sigma_{y}(x)$

- Plume dispersion coefficients used rather than data from "instantaneous" source experiments because of size of extended initial source and downwind distances involved.

- Extended Initiar Source $(H=10 \mathrm{~m}, \mathrm{R}=200 \mathrm{~m}) \mathrm{V}_{i}=H \pi \mathrm{R}^{2}=1.26 \times 10^{6} \mathrm{~m}^{3}$

- Initial Amronia Concentration=4.32 $\times 10^{-2}$ (volume) or $4.32 \times 10^{4} \mathrm{ppm}$

- Al1 mass is assumed to be spread uniformily between $\pm \sigma_{x}$ and $\pm \sigma_{y}$ for estimation of ammonia concentrations, exposure times and areas affected

- Exposure Time $\simeq \frac{2 \sigma}{U}$, where $U$ is wind speed

The results for the pressurized spill for two classes of meteorological conditions are given in Tables 5.2 and 5.3. The results for the D stability category may be off by a factor of 3 to 5 , whereas the F stability category may be off by an order of magnitude.

Calculation for the refrigerated spill were made for the following conditions and assumptions:

- Extended Initial Source at Ground Level $(30.5 \mathrm{~m} \times 30.5 \mathrm{~m})$

- Volume rate $=21.6 \mathrm{~m}^{3} / \mathrm{sec}$

- Ammonia concentration $=.114$ (volume) or $1.14 \times 10^{5} \mathrm{ppm}$

- Assumed Wind Speed $U=5 \mathrm{~m} / \mathrm{sec}$

- 4.4-hr Source Duration 
TABLE 5.2. Results of Pressurized Spill Calculations for D Stability (Neutral), $U=5 \mathrm{~m} / \mathrm{sec}$ (Day or Night, Strong Winds)

\begin{tabular}{|c|c|c|c|c|c|}
\hline Time (Sec) & $\begin{array}{l}\text { Downwind Distance } \\
\text { to Center of Cloud } \\
(\mathrm{m})\end{array}$ & $\begin{array}{c}\text { Ammonia } \\
\text { Concentration } \\
(\mathrm{ppm}) \\
\end{array}$ & $\begin{array}{c}\text { Exposure } \\
\text { Time } \\
\text { (sec) } \\
\end{array}$ & $2 \sigma_{x}(\mathrm{~m})$ & $2 \sigma_{y}(m)$ \\
\hline $2.25 \times 10^{2}$ & $1.12 \times 10^{3}$ & 5000 & $1.32 \times 10^{2}$ & $6.60 \times 10^{2}$ & $3.40 \times 10^{2}$ \\
\hline $4.10 \times 10^{2}$ & $2.05 \times 10^{3}$ & 1700 & $2.03 \times 10^{2}$ & $1.10 \times 10^{3}$ & $4.58 \times 10^{2}$ \\
\hline $6.45 \times 10^{2}$ & $3.22 \times 10^{3}$ & 700 & $2.89 \times 10^{2}$ & $1.44 \times 10^{3}$ & $5.93 \times 10^{2}$ \\
\hline $8.45 \times 10^{2}$ & $4.22 \times 10^{3}$ & 400 & $3.60 \times 10^{2}$ & $1.80 \times 10^{3}$ & $7.09 \times 10^{2}$ \\
\hline $1.61 \times 10^{3}$ & $8.05 \times 10^{3}$ & 100 & $6.20 \times 10^{2}$ & $3.10 \times 10^{3}$ & $1.14 \times 10^{3}$ \\
\hline
\end{tabular}

TABLE 5.3. Results for Pressurized Spill Calculaion for F Stability (Very Stable), $U=l \mathrm{~m} / \mathrm{sec}$ (Night, Clear Sky, Light Meandering Winds)

\begin{tabular}{|c|c|c|c|c|c|}
\hline Time (Sec) & $\begin{array}{l}\text { Downwind Distance } \\
\text { to Center of Cloud } \\
\text { (m) }\end{array}$ & $\begin{array}{l}\text { Anmonia } \\
\text { Concentration } \\
(\mathrm{ppm}) \\
\end{array}$ & $\begin{array}{c}\text { Exposure } \\
\text { Time } \\
\text { (sec) } \\
\end{array}$ & $2 \sigma_{x}(m)$ & $2 \sigma_{y}(m)$ \\
\hline $3.3 \times 10^{3}$ & $3.3 \times 10^{3}$ & 5000 & $7.78 \times 10^{2}$ & $7.98 \times 10^{2}$ & $3.51 \times 10^{2}$ \\
\hline $6.1 \times 10^{3}$ & $6.1 \times 10^{3}$ & 1700 & $1.25 \times 10^{3}$ & $1.25 \times 10^{3}$ & $5.06 \times 10^{2}$ \\
\hline $9.7 \times 10^{3}$ & $9.7 \times \mathrm{kO}^{3}$ & 700 & $1.85 \times 10^{3}$ & $3.85 \times 10^{3}$ & $7.01 \times 10^{2}$ \\
\hline $1.3 \times 10^{4}$ & $1.3 \times 10^{4}$ & 400 & $2.36 \times 10^{3}$ & $2.36 \times 10^{3}$ & $8.69 \times 10^{2}$ \\
\hline $2.6 \times 10^{4}$ & $2.6 \times 10^{4}$ & 100 & $4.82 \times 10^{3}$ & $4.82 \times 10^{3}$ & $1.52 \times 10^{3}$ \\
\hline
\end{tabular}

The results for the refrigerated spill are given in Table 5.4 and 5.5 for the same meteorological stability categories considered for the pressurized spill.

TABLE 5.4. ResuTts ${ }^{(a)}$ of Refrigerated Spill Calculations for Stability D (Neutral) (Day or Night, Strong Winds)

\begin{tabular}{|c|c|c|c|}
\hline Time (sec) & $\begin{array}{l}\text { Downwind } \\
\text { Distance } \\
\text { (m) }\end{array}$ & $\begin{array}{l}\text { Ammonia } \\
\text { Concentration } \\
\text { (ppm) }\end{array}$ & $2 \sigma_{y}(m)$ \\
\hline $1.0 \times 10^{1}$ & $5.0 \times 10^{1}$ & 5000 & $3.83 \times 10^{?}$ \\
\hline $2.46 \times 10^{1}$ & $1.23 \times 10^{2}$ & 1700 & $4.98 \times 10^{1}$ \\
\hline $4.76 \times 10^{1}$ & $2.38 \times 10^{2}$ & 700 & $6.71 \times 10^{1}$ \\
\hline $7.12 \times 10^{1}$ & $3.56 \times 10^{2}$ & 400 & $8.43 \times 10^{3}$ \\
\hline $1.82 \times 10^{2}$ & $9.08 \times 10^{2}$ & 100 & $1.61 \times 10^{2}$ \\
\hline
\end{tabular}

(a) All mass is assumed to be spread uniformly between \pm sy. 
TABLE 5.5. Resuits ${ }^{(a)}$ of Refrigerated Spill Calculations for F Stability (Night, Clear Sky, Light Meandering Winds)

$\begin{array}{lcccc}\text { Time }(\mathrm{sec}) & \begin{array}{c}\text { Downwind } \\ \text { Distance } \\ (\mathrm{m})\end{array} & \begin{array}{c}\text { Ammonia } \\ \text { Concentration } \\ (\mathrm{ppm})\end{array} & \frac{20 y(\mathrm{~m})}{2.10} \\ 2.2 \times 10^{1} & 1.1 \times 10^{2} & 5000 & 3.84 \times 10^{1} \\ 5.8 \times 10^{1} & 2.9 \times 10^{2} & 1700 & 5.11 \times 10^{1} \\ 1.19 \times 10^{2} & 5.95 \times 10^{2} & 700 & 7.19 \times 10^{1} \\ 1.8 \times 10^{2} & 9.00 \times 10^{2} & 400 & 9.20 \times 10^{1} \\ 4.89 \times 10^{2} & 2.45 \times 10^{2} & 100 & 1.88 \times 10^{2}\end{array}$

(a) Assuming that diffusion of cold plume is controlled by $F$ Stability (Very Stable) even though wind speed of $5 \mathrm{~m} / \mathrm{sec}$ is more appropriate for D stability.

\subsection{ENVIRONMENTAL EFFECTS OF AMMONIA RELEASES}

This section of the report examines the environmental risks and hazards associated with possible spills of anhydrous ammonia into the environment. The spills are defined by scenarios derived in Sections 5.1 and 5.2 describing both the amount of the spill and the type of environment impacted. This assessment considers fresh water, terrestrial and marine environment and identifies those biological components that could be impacted, determines the adequacy of the existing information concerning effects of ammonia and finally rates the probable level of impact. Appendix D gives the detailed rankings for each of the scenarios for freshwater, terrestrial and marine environment upon which the conclusions in the text are based.

The effect of past ammonia spills on ecosystems has not been documented so the rankings are based for the major part on laboratory studies of individual organisms. The least known and most important element in the analys is is the prediction of ecosystem level impacts. There is no information available from which to ascertain the resiliency of an area following an ammonia spill. Therefore, the ultimate consequences of ammonia spills are uncertain.

For both the freshwater and marine scenarios unionized ammonia is the form used for the assessment because unionized ammonia is toxic. The percentage of ammonia in the unionized form is primarily controlled by, and increases 
with, pH (See Section 5.3.9 for discussion of relationship). For the physical and chemical conditions assumed in the scenarios, the unionized ammonia (UIA) concentration would be approximately $11 \%$ of the total dissolved ammonia; therefore, there would be approximately one order of magnitude difference between the concentrations of ammonia and the concentration of unionized ammonia that would result in the same impact.

\subsubsection{Freshwater - Scenario Description and Assumptions}

This assessment involves eight freshwater scenarios.

Scenario 1: A barge coltision on a large lake $\left(A=1 \times 10^{9}\right.$ to $8.2 \times 10^{10} \mathrm{~m}^{2}$ [Lake Superior]) spi1]s 600 tons $\left(5.4 \times 10^{8}\right.$ g) of $\mathrm{NH}_{3}$ instantaneously and mixes down to $1 \mathrm{~m}$.

Scenario 2: A barge collision on a large river $\left(Q=1 \times 10^{5}\right.$ to $3.5 \times 10^{6} \mathrm{~m}^{3} / \mathrm{min}$ ([mouth of Mississippi River]) spil]s 600 tons $\left(5.4 \times 10^{8} \mathrm{~g}\right)$ of $\mathrm{NH}_{3}$ over a period of 1 hour.

Scenario 3: A railroad car spills 20 tons $\left(1.8 \times 10^{7} \mathrm{~g}\right)$ of $\mathrm{NH}_{3}$ instantaneously into a medium-sized lake $\left(A=1 \times 10^{7}\right.$ to $\left.1 \times 10^{9} \mathrm{~m}^{3}\right)$ and mixes down to $1 \mathrm{~m}$.

Scenario 4: A railroad car spills 60 tons $\left(5.4 \times 10^{7} \mathrm{~g}\right)$ of $\mathrm{NH}_{3}$ instantaneously into a medium-sized lake $\left(A=1 \times 10^{7}\right.$ to $\left.1 \times 10^{9} \mathrm{~m}^{3}\right)$ and mixes down to $7 \mathrm{~m}$.

Scenario 5: A railroad car spilis 20 tons $\left(1.8 \times 10^{7} \mathrm{~g}\right)$ of $\mathrm{NH}_{3}$ into a mediumsized river $\left(Q=1 \times 10^{3}\right.$ to $\left.7 \times 10^{5} \mathrm{~m}^{3} / \mathrm{min}\right)$ over a period of one hour.

Scenario 6: A railroad car spills 60 tons $\left(5.4 \times 10^{7} \mathrm{~g}\right)$ of $\mathrm{NH}_{3}$ into a mediumsized river $\left(Q=1 \times 10^{3}\right.$ to $\left.1 \times 10^{5} \mathrm{~m}^{3} / \mathrm{min}\right)$ over a period of one hour.

Scenario 7: A pipeline ruptures and spills 300 tons $\left(2.7 \times 10^{8} \mathrm{~g}\right)$ of $\mathrm{NH}_{3}$ instantaneously into a small lake $\left(A=1 \times 10^{5}\right.$ to $\left.1 \times 10^{7} \mathrm{~m}^{2}\right)$ and mixes down to $1 \mathrm{~m}$. 
Scenario 8: A pipeline ruptures and spills 300 tons $\left(2.7 \times 10^{8} \mathrm{~g}\right)$ of $\mathrm{NH}_{3}$ into a small river $\left(Q=1 \times 10^{1}\right.$ to $\left.1 \times 10^{3} \mathrm{~m}^{3} / \mathrm{min}\right)$ over a period of one hour.

Oata defining boundary dimensions for the various size categories of lakes and rivers were taken from numerous reports published by the U.S. Geological Survey. These data can be grouped into categories of small, medium-sized and Targe :

- Lakes, based on surface area (A):

- small $\left(A=1 \times 10^{5}\right.$ to $\left.1 \times 10^{7} \mathrm{~m}^{2}\right)$

- medium-sized $\left(A=1 \times 10^{7}\right.$ to $] \times 10^{9} \mathrm{~m}^{2}$ )

- large $\left(A=1 \times 10^{9}\right.$ to $8.2 \times 10^{10} \mathrm{~m}^{2}$, Lake Superior).

- Rivers, based on flow rates (Q):

- small ( $Q=1 \times 10^{1}$ to $\left.1 \times 10^{3} \mathrm{~m}^{3} / \mathrm{min}\right)$

- medium-sized $\left(Q=1 \times 10^{3}\right.$ to $\left.1 \times 10^{5} \mathrm{~m}^{3} / \mathrm{min}\right)$

- large $\left(Q=1 \times 10^{5}\right.$ to $3.5 \times 10^{6} \mathrm{~m}^{3} / \mathrm{min}$, mouth of Mississippi River).

Using the data shown above and the following assumptions, we established boundary concentrations (lowest and highest) for $\mathrm{NH}_{3}$ spilled into each freshwater environment:

- Lakes - Assume that the spilled $\mathrm{NH}_{3}$ is evenly mixed completely across the lake's surface and downward to a specified maximum depth of mixing ( $\mathrm{m}$ ).

- Rivers - Assume that the spilled $\mathrm{NH}_{3}$ is evenly mixed completely across the river at all depths throughout the spill duration (1-hour period of spilling).

For the largest of lakes and rivers, these assumptions preclude attempts to identify specific local impacts. However, there is no direct way to calculate localized concentrations of $\mathrm{NH}_{3}$ without using less valid assumptions. For lesser sized lakes and rivers, these assumptions should be more adequate. Attempted resulotion of localized impact for any scenario would require detailed and sitespecific information.

Based on these assumptions, $\mathrm{NH}_{3}$ concentrations in lakes were estimated with the equation 


$$
\left[\mathrm{NH}_{3}\right]=\frac{S}{A \cdot d}
$$

where $S$ is the amount of a spill, $A$ is the lakes' surface areas, and $d$ is the maximum depth of mixing. $\mathrm{NH}_{3}$ concentrations in rivers were estimated using the equation

$$
\left[\mathrm{NH}_{3}\right]=\frac{\mathrm{S} / \mathrm{t}}{\mathrm{O}}
$$

where $t$ is the duration of spill and $Q$ is the flow rate.

Estimating the duration of time, downstream travel, or distance from spill site over which the estimated $\mathrm{NH}_{3}$ concentrations will be sustained cannot be done with reasonable certainty. Those attendant and specific conditions influencing vertical mixing, hydraulic flushing, and chemical behavior would need to be resolved. The level of effort needed to account for those factors falls beyond the scope of this assessment.

Therefore, assumptions applying to durations of spili concentrations used in this assessment are:

- Lakes - Assume $\mathrm{NH}_{3}$ concentrations rise to the estimated range over an environmentally significant, albeit unspecified, length of time or distance from spill site.

- Rivers - Assume $\mathrm{NH}_{3}$ concentrations rise to the estimated range over an environmentally significant, a] though unspecified, length of time or distance downstream.

\subsubsection{Freshwater-Spil1 Impact Assessment}

Concentrations of $\mathrm{NH}_{3}$ generated by each spill scenario (expressed as unionized $\mathrm{NH}_{3}$ ) become the focus of this assessment. These values provide the basis with which to interpret significance of impact. Ranges of $\mathrm{NH}_{3}$ concentrations for each spitl scenario are shown in Figure 5.5. Collectively, the eight scenarios produce a broad spectrum of $\mathrm{NH}_{3}$ concentrations covering nine orders of magnitude. Impact ratings of the various scenarios are given in Appendix E. 




FIGURE 5.5. Ranges of $\mathrm{NH}_{3}$ Concentrations Generated by Each Spil1 Scenario (Significance of Impact Is Defined in Figure 5.6) 
A relative significance of these concentrations is shown in Figure 5.6 . Between $\mathrm{NH}_{3}$ concentrations of 0.001 and $1 \mathrm{mg} / \mathrm{l}$, we can identify a threshold of plant nutrition and toxic impact. $\mathrm{NH}_{3}$ concentrations of $\leq 0.1 \mathrm{mg} / \mathrm{l}$ may be nutritious to plant life but are not toxic to other aquatic biota. Any nutritional stimulation would be short-lived if the $\mathrm{NH}_{3}$ supply were not sustained, as was the case for our spill scenarios. The maximum permissible criteria for $\mathrm{NH}_{3}$ in freshwaters is $0.5 \mathrm{mg} / 2$ (U.S. FWPCA 1968). Certain fish will die if held for $>48$ hours in $\mathrm{NH}_{3}$ concentrations $>0.4 \mathrm{mg} / \mathrm{l}$ (Becker and Thatcher 1973), (Mckee and Wolf 1971, U.S. FWPCA 1968).

Concentrations of $\mathrm{NH}_{3}$ in a range from 1 to $1000 \mathrm{mg} / \mathrm{l}$ would produce a significant or perhaps serious toxic impact if sustained for more than one hour. The threshold of odor in domestic water suppiies is $5 \mathrm{mg} / \mathrm{l}$ (Mckee and Wolf 1971). Humans can taste $\mathrm{NH}_{3}$ in coffee at $35 \mathrm{mg} / \mathrm{l}$ (Campbell et al. 1958). Concentrations $>40 \mathrm{mg} / \ell$ were acutely toxic to aquatic plants (Kiussman et al. 1970). And $\mathrm{NH}_{3}$ concentrations $>200 \mathrm{mg} / \mathrm{l}$ (expressed as total $\mathrm{NH}_{3}$ ) were lethal

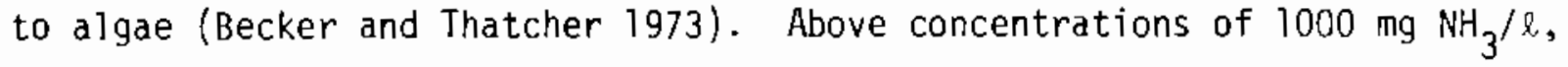
the immediate impact would be serious if not critical. Most forms of aquatic 1 ife would die rapidly (Becker and Thatcher 1973, Mckee and Wolf 1971).

Potential impacts on human health could not be visualized in any scenario except No. 8. In such a pipeline accident on a smail river, there could be injuries or fatalities among downstream swimers or boaters.

In terms of the survival and well-being of aquatic commuities, scenarios 1,3 and 4 would produce serjous impacts on only a few types of biota. Most biota in these large and medium-sized lakes would be largely undisturbed, although localized fatalities are possible near the spill site. Planktonic algae might be nutritionally stimulated momentarily and littoral-spawning fish might be seriously disturbed if spills occurred at critical times. There is also an uncertain risk to community structure and ontogeny, since little is known about these factors in the presence of elevated $\mathrm{NH}_{3}$ concentrations.

Scenarios 2, 5 and 6 would produce significant-to-serious toxic impact on their respective enviromments (1arge and medium-sized rivers). Survival and development of all life-forms would be challenged by this assault. Effects on 


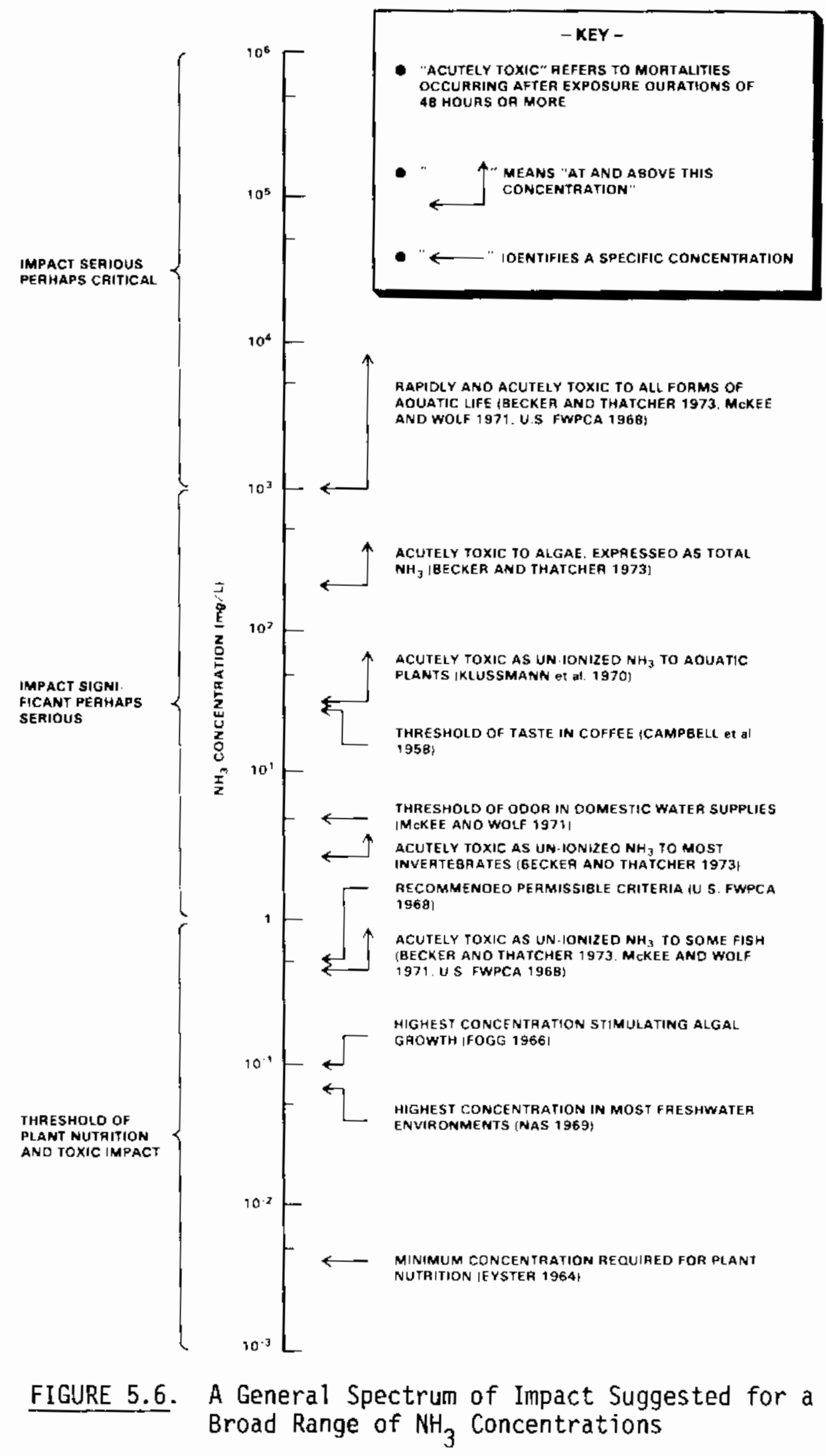


migratory fish populations could be serious, perhaps removing a year-class. Benthic populations would also suffer losses. And in these scenarios, there is also the potential-but-uncertain risk of disturbing community structure and ontogeny. However, in each case, substantial dilution and recovery could be expected to arise naturally from upstream resources.

Most severe of the eight scenarios were 7 and 8 . These pipe1ine accidents (on a small lake and a small river) could produce $\mathrm{NH}_{3}$ concentrations in excess of $1000 \mathrm{mg} / \mathrm{l}$. There would be many fatalities in all populations of aquatic life. Year-classes of fish and other biota could be largely destroyed. Structure and stability of these ecosystems might be seriously impacted, although we understand too little about the space-time significance of community ontogeny to be certain what this assault would actually mean.

Of the eight scenarios presented to us, we find three $(1,3$ and 4 ) occurring at the threshold of impact, three (2, 5 and 6) occurring with significant impact, and two (7 and 8) occurring with serious impact. But there is much to consider beyond the initial impact. Ammonia would not produce residual or Tongterm manifestations in these environments. And naturat recovery processes, al though unpredictable, may be rapid.

In conclusion, barge collisions on large Takes and rivers (Scenarios 1 and 2), and railroad accidents on medium-sized lakes ( 3 and 4 ), would not produce $\mathrm{NH}_{3}$ concentrations greater than $100 \mathrm{mg} / \ell$. However, higher concentrations would become involved with railroad accidents on medium-sized rivers (5 and 6 ) and pipeline fajlures near small lakes and streams (7 and 8). Scenario 1 would not produce $\mathrm{NH}_{3}$ concentrations in excess of thresholds for plant nutrition and toxicity. Whereas Scenarios 7 and 8 involved $\mathrm{NH}_{3}$ concentrations that could produce serious-if-not-critical impact. Scenarios 2, 3, 4, 5 and 6 fell in between these two extremes.

Scenario 1 would not create a serious hazard for aquatic life and human health except possibly in a localized sense where holistic meaning is difficult to resolve. Scenarios 3 and 4 would produce only minor hazards to most biota but several ecological components could be seriously impacted. Scenarios 3 and 4 would not endanger human health, however. Scenarios 2, 5 and 6 present 
moderate-to-serious hazards for most forms of aquatic life but were not considered hazardous to human health. And Scenarios 7 and 8 would create serious hazards for all types of aquatic life. There was even a potential hazard to human health generated in Scenario 8.

In all but Scenario 1, at least several forms of aquatic life could be impacted seriously by $\mathrm{NH}_{3}$ spills. Aside from the immediate and direct mortalities in Scenarios 2, 5, 6, 7 and 8, there were potential long-term hazards to biological productivity and community stability. In both lakes and rivers these impacts would last the longest in shallow waters. These would include important littoral zones, spawning grounds, and major stands of $\mathrm{plant}$ life. Impacts on the lakes in Scenarios 3 and 4 might also include momentary nutritional benefits to some forms of phytoplankton.

\subsubsection{Freshwater - Neutralization and Restoration Methods}

For non-persistent toxicants like armonia, artificial methods for neutralization and restoration are of questionable value. The effective means for ecological amelioration will probably involve natural processes. Nevertheless several restoration methods have been proposed whose impact on the freshwater ecosystem need to be examined. These methods are described in the A. D. Little, Inc. report for the U.S. Coast Guard (Raj et al. 1974).

Dispersal and containment are the most immediate and direct methods for minimizing impact. If natural dispersion (i.e., lake mixing or river turbulence is not sufficient, they recormmend churning the water with power boats. The authors also specify general performance characteristics that are desirable for $\mathrm{NH}_{3}$ containment booms.

Air sparging and sorption techniques are more rigorous and limited in their application. For some situations air sparging might effectively transfer $\mathrm{NH}_{3}$ into the atmosphere, but local terrestrial environments may be significantly impacted. This may also pose risks to human health. If sorbent booms, the type used for oil spill removal, are available they may prove useful. However, if either air sparging or sorption equipment were to be used effectively on $\mathrm{NH}_{3}$ spills, they would be needed immediately. Immediate availability may not be practical. 
Chemical neutralization of $\mathrm{NH}_{3}$ spills was judged an unwise technique for all but the very smalt and confined events (Raj et al. 1974). They specified potentially serious problems concerning the additional risks of introducing additional chemicals. Generally, the risks outweighed the benefits.

Artificial restoration techniques might be useful for supplementing losses of fish, and perhaps several other species. Regional fish hatcheries are the most accessible resources for fish stock and appropriate advice. Other aquaculture activities, such as crayfish and bait farms, may serve as potentiat resources for some invertebrate stocks. Specific restocking techniques are commonly known by most regional fish and wildlife specialists. However, their anticipated advice would be to expect rapid and thorough restoration from natural sources.

\subsubsection{Freshwater - Adequacy of Information}

The literature base was adequate for determining physical boundary conditions of the eight spill scenarios. However, we had to devise our own methods for defining $\mathrm{NH}_{3}$ concentration ranges produced by the accidents. $\mathrm{NH}_{3}$ dispersion models for lakes could not be located but Raj et a1. (1974) provide several dispersion equations for rivers. These equations were too rigorous, however, to be useful in our assessment. Their attendant assumptions and data requirements are directed at higher resolutions of $\mathrm{NH}_{3}$ concentrations at specific spill sites where detailed information must be obtainable. Our simpler equations for estimating $\mathrm{NH}_{3}$ concentrations were adequate for this level and scope of this assessment.

For our purposes of assessing the ecological impact of these eight spill scenarios, the literature base was barely adequate, and not without uncertainties. Since in all scenarios the impacts would be felt largely in littoral zones and other shallow habitats, there is an uncertainty regarding the Tife cycles of resident aquatic animals. For example, it is not certain if adults would survive sublethal concentrations while eggs and developmental stages suffer serious mortalities. Data bases addressing these questions would refine our picture of $\mathrm{NH}_{3}$ hazards. 
The greatest uncertainties confronting this assessment were present in decisions concerning potential changes in community stability (maintenance of ecological coherence and integrity) and ontogeny (preservation of self-crganizing properties). There are no data that associate these changes with $\mathrm{NH}_{3}$ concentrations. Observations of relevant changes could be made only from investigating experimental spill situations conducted in the field.

\subsubsection{Terrestrial - Spill Scenarios and Assumptions}

Four terrestrial ammonia spill scenarios, which were developed in Sections 5.1 and 5.2, are presented in Table 5.6. These spill conditions will be used

\section{TABLE 5.6. Terrestial Ammonia Spill Scenarios}

Scenario 1: Pressuried Spill in a Forest Ecosystem Under Light Wind - Conditions (1 m/sec)

\begin{tabular}{ccc}
$\begin{array}{c}\mathrm{NH}_{3} \\
\text { Concentration } \\
\text { (ppm) }\end{array}$ & $\begin{array}{c}\text { Exposure } \\
\text { Time } \\
\text { (min) }\end{array}$ & $\begin{array}{c}\text { Area } \\
\text { Affected } \\
\text { (km } \text { km }^{2}\end{array}$ \\
\cline { 1 - 2 } 5000 & 16.3 & 0.3 \\
1700 & 20.8 & 0.6 \\
700 & 30.8 & 1.3 \\
400 & 39.3 & 2.1 \\
100 & 80.3 & 7.3
\end{tabular}

Scenario 3: Refrigerated Spill in a Forest Ecosystem Under Light Wind Conditions ( $1 \mathrm{~m} / \mathrm{sec}$ )

\begin{tabular}{cccc}
$\begin{array}{c}\mathrm{NH}_{3} \\
\text { Concentration }\end{array}$ & $\begin{array}{c}\text { Exposure } \\
\text { Time } \\
\text { (min) }\end{array}$ & $\begin{array}{c}\text { Area } \\
\text { Affected } \\
\left(\mathrm{km}^{2}\right)\end{array}$ \\
\cline { 1 - 1 } 5000 & & 264 & 0.003 \\
1700 & & 264 & 0.01 \\
700 & & 264 & 0.03 \\
400 & & 264 & 0.06 \\
100 & 264 & 0.3
\end{tabular}

Scenario 2: Pressurized Spill in a Grassland Ecosystem Under Strong Wind Conditions ( $5 \mathrm{~m} / \mathrm{sec}$ )

\begin{tabular}{ccc}
$\begin{array}{c}\mathrm{NH}_{3} \\
\text { Concentration } \\
\text { (ppm })\end{array}$ & $\begin{array}{c}\text { Exposure } \\
\text { Time } \\
\text { (min) })\end{array}$ & $\begin{array}{c}\text { Area } \\
\text { Affected } \\
\left(\mathrm{km}^{2}\right)\end{array}$ \\
\cline { 1 - 2 } 5000 & 2.2 & 0.2 \\
1700 & 3.4 & 0.5 \\
700 & 4.8 & 0.9 \\
400 & 6.0 & 1.3 \\
100 & 10.3 & 3.5
\end{tabular}

Scenario 4: Refrigerated Spill in a Grassiand Ecosystem Under Strong Wind Conditions $(5 \mathrm{~m} / \mathrm{sec})$

\begin{tabular}{ccc}
$\begin{array}{c}\mathrm{NH}_{3} \\
\begin{array}{c}\mathrm{N}_{3} \text { (ppm) } \\
5000\end{array}\end{array}$ & $\begin{array}{c}\text { Exposure } \\
\text { Time } \\
\text { (min) }\end{array}$ & $\begin{array}{c}\text { Area } \\
\text { Affeçted } \\
\left(\mathrm{km}^{2}\right)\end{array}$ \\
\cline { 1 - 2 } 1700 & 264 & 0.001 \\
700 & 264 & 0.004 \\
400 & 264 & 0.01 \\
100 & 264 & 0.02 \\
& 264 & 0.1
\end{tabular}


to assess the potential impacts on two generalized ecosystem types: forests and grasslands. In a forest, wind speeds are generally stagnated due to both the local effect of horizontal and vertical canopy impedence and the regional effect of continental wind currents. Therefore, plume dissipation under light wind speed conditions (Scenarios 1 and 3) has been characterized as the more normal situation for a forest ecoystem. Conversely, grassland ecosystems have been assigned to the more characteristic strong wind speed conditions (Scenarios 2 and 4 ).

Two particular spilt situations involving the same ammonia concentrations have been generated for use in the impact analysis. The first involves a pressurized spill that creates a high energy burst of volatilized ammonia which is dissipated within 30 minutes during light winds (Scenario 1) and within 10 minutes during strong winds (Scenario 2). The second spill situation involves a refrigerated spill in which liquid ammonia pours out on the ground for a period of 4.4 hours in both ecosystem types (Scenario 3 and 4 ). This spill situation represents a greater hazard to the ecosystem than does the pressurized spill due to the long exposure times. However, the affected soil surface area is only about one third as large.

\subsubsection{Terrestrial - Spill Impact Assessment}

Concentrations versus exposure times generated for each of the scenarios provide the basis from which the significance of impact can be interpreted. The ranges of the concentration and exposure time for the different scenarios are illustrated in Figure 5.7. The relative significance of these conditions is also shown in Figure 5.7 where results of ammonia exposure on plants and animals are plotted. The impact ratings for the various biota for each scenario are given in Appendix $E$.

McCallan and Weedon (1940) observed ammonia toxicity in nine plant pathogenes and two animal pathogenes. Their findings revealed that ammonia concentrations differentially affected the species tested. $L T_{50}$ (time till death of $50 \%$ of organisms) values for the organisms were observed at exposure times of from 20 minutes to 10 hours at $1000 \mathrm{ppm}$. Therefore, Scenarios 2, 3 and 4 could potentially kill some fungal and bacterial populations within the 5000 and 


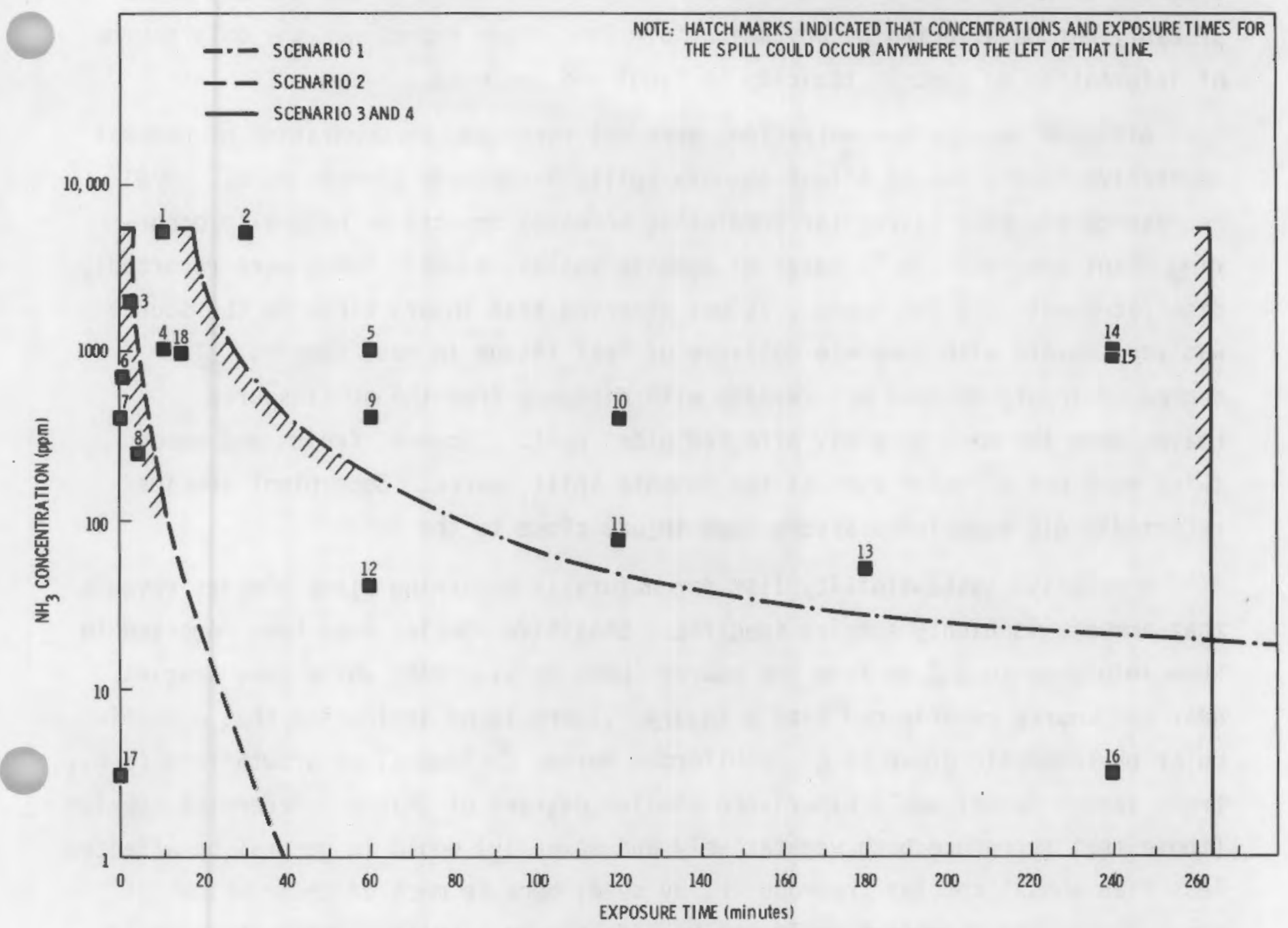

1. SOME MOUSE DEATH REPORTED

10. PERMANENT DISCOLORATION IN APPLE FRUIT

2. HUMAN DEATH REPORTED

3. WILD BIRD DEATH REPORTED

4. SOME CAT DEATH REPORTED DUE TO SECONDARY

11. HEIGHTENED SUSCEPTIBILITY TO RESPIRATORY INFECTIONS REPORTED IN SWINE RESPIRATORY DAMAGE

12. SOME VISIBLF LEAF INJURY

5. 50\% INJURY TO TOMATO STEMS

13. REDUCED SEED GERMINATION IN SOME SPECIES

6. IMMEDIATE IRRITATION OF EYES, NOSE IN HUMANS

14. WET RYE SEED FAILS TO GERMINATE

7. IMMEDIATE IRRITATION OF THROAT IN HUMANS

15. $6 \%$ KILL OF HOUSE FLIES

8. 50\% INJURY TO TOMATO LEAVES

16. MUSTARD ANO SUNFLOWER LEAVES SEVERLY INJURED

9. PERMANENT DISCOLORATION IN PEACH FRUIT

17. AMMONIA CONCENTRATIONS COMMONLY FOUND IN SOIL

18. LD 50 OF PLANT PATHOGENE Sclerotia detphinil

\section{FIGURE 5.7. Ranges of Concentration and Exposure Time for Each Spil1} Scenario and Significance of Impact to Plants and Animals 
$1700 \mathrm{ppm}$ affected areas. Sclerotia were highly resistant to ammonia and would probably not be affected by any scenario. This study represents the only source of information on ammonia toxicity in fungi and bacteria.

Although ammonia concentrations were not reported, documentation of natural vegetative injury due to actual ammonia spills in Ontario (Temple et al. 1979) represents the best source for predicting scenario impacts on naturally occurring plant species. In 12 cases of ammonia spills, ammonia fumes were reportediy dissipated within a few hours. It was observed that injury close to the source was very severe with complete collapse of leaf tissue in most species. The degree of injury dropped off rapidly with distance from the spill source. Leaves were the most severely affected plant part. Flowers, fruits and woody twigs were not affected even at the ammonia spill source. Some plant species reportedly did experience severe stem injury close to the spill.

A relative susceptibility list for naturally occurring plant species reveals that ammonia is highly species specific. Sensitive species have been reported to show injury up to $3.2 \mathrm{~km}$ from the source (Heck et al. 1970) while some species near the source experienced little injury. There is no indication that a particular phylogenetic group (e.g., coniferous versus deciduous) or growth form (e.g., trees versus forbs) would experience similar degrees of injury. Perennial species (those that reproduce both vegetatively and sexually) would in general be affected less than annual species (reproducing by seed) because much of their weight is woody tissue and therefore would not be affected by a spi11. Woody stems would be much more likely to resprout after an ammonia spill than would the herbaceous stems of annuals. Seed germination appears to be affected by high concentrations of ammonia when the seeds are moisture saturated (Barton 1940).

Ammonia spills characterized by Scenarios 3 and 4 might deplete seed viability within the area of high concentration. This could potentially reduce the following year's annual plant production. This would be especially true if the ammonia spill were to occur at the time of seed setting. This would probably be a very minimal impact because many viable seeds would be buried in the soil at the time of the spill and would not be exposed to the ammonia fumes. 
All of the scenarios, over much of their affected area, would result in some damage to the natural vegetation. Forested areas would show the greatest impact to the vegetation as would the refrigerated spill scenarios (3 and 4).

Ammonia spills would result in high economic loss for most leaf crops especially at peak harvest. Fruit and stenı crops would also be affected mostiy at the peak harvest stage. Brennan et a1. (1962) subjected various species of peach and apple fruits to $400 \mathrm{ppm}$ ammonia gas and found permanent discoloration at 60 and 120 minutes respectively for the most sensitive varieties (Figure 5.7). Some varieties, such as Golden Delicious apples, showed very little injury from ammonia exposure. Other crops such as root or seed crops would be less affected by an ammonia spill, although reduction in foliar growth would surely reduce yields to some degree.

Information concerning sensitivities of farm animals to ammonia gas is abundant in the form of studies directed at the chronic effects of organismproduced ammonia in confined housing. Little information, however, is available concerning acute exposures to faunal species. Animals, in general, have been assessed to be more resistant to ammonia toxicity than plants. A very helpful guide to the order of ammonia sensitivity of various classes of organisms was developed by the Boyce Thompson Institute Study (McCallan and Setterstron 1940) on ammonia toxicity done in 1940. They list the following relative sensitivities in order of decreasing sensitivity:

\section{Leaves $>$ Stems $>$ Seeds $>$ Animals $>$ Fungi and Bacteria $>$ Sclerotia}

As with plant species, animal species appear to be species specific in their sensitivity to ammonia gas. For example, $L_{50}(50 \%$ lethal kill) levels for mice have been reported at $5000 \mathrm{ppm}$ and for cats at $10,000 \mathrm{ppm}$ for an exposure time of 1 hour (The International Technical Information Institute 1976). $L_{50}$ levels for Swiss-Webster mice exposed for 30 minutes to ammonia gas were $21,430 \mathrm{ppm}$ in a study done by Hilado et al. (1978).

Amonia toxicity of faunal species usually results in some degree of morbidity to the individual rather than death. Heightened susceptibility to disease due to secondary respiratory infection would appear to be a major effect from an ammonia spill. Swine were reportedly more susceptible to infection 
after exposures of $100 \mathrm{ppm}$ for two to three hours (Figure 5.7). Cats exposed to $1000 \mathrm{ppm}$ for 10 minutes were found to contract secondary bronchitis, bronchiolitis and early bronchopneumonia after 21 days post-exposure with some deaths reported (Dodd and Gross 1980). Younger animals were found to be more sensitive to ammonia injury than older animals in a number of species (Horvath 1926). In general, poultry have been reported to be less susceptible to air pollution than other farm animals (National Research Council 1976) and this may be the case with ammonia as well.

Domestic animals would probably be severely debilitated within the highest concentration areas of Scenarios 3 and 4 , All other situations would probably result in mild transitory effects from the fumes.

No literature is available on the impact of ammonia spills on wildlife. The degree of mobility of natural animal species would be directly related to the severjty of the ammonia spill impact. The immediate irritation of sensitivity target organs (e.g., skin, eyes and lungs) would seem to be sufficient enough to prompt mobile organisms to move away from high ammonia concentrations. Flying insects and birds would be especially quick to escape injury. The relatively small area affected by high ammonia concentrations in Scenarios 3 and 4 would be expected to produce little harm to free-ranging organisms. Exceptions to these generalizations would be such things as young immobile animals (i.e., nestlings) or perhaps burrowing animals should their burrows become saturated. Areas in Scenarios 1 and 2 could possibly be large enough to cause some faunal impact. Conditions in Scenario 2 would be the most hazardous to wildlife species. The smail number of wildlife fatalities that might occur would not be expected to have any long-term impact.

Ammonia spill scenarios could result in some short-term impacts on the ecosystem. Animals would be affected much less than the vegetative components within an affected area. In a worst case situation, some individual animal species might be killed from the ammonia fumes within high concentration areas. Since ammonia spills generally create a relatively small area of impact, recruitment from peripheral populations back into the affected area would be rapid. 
The major expected impact from an ammonia spill would be damage to the vegetation. A refrigerated spill, as depicted in Scenarios 3 and 4, would produce the greatest injury to plants. Unfortunately, there is no information available concerning the resiliency of ammonia impacted areas. Questions such as how much of and for what length of time the residual ammonia is left within the living tissues and in the soil and litter are unknown and are assumed to be of little consequence. It must be assumed that conditions within the highest concentration areas are hazardous enough to destroy most of the herbaceous plant species. If this is the case, the consequences to the environment after a spill would depend on the natural processes of vegetative reestablishment. Because most of these highly impacted species fall into the seed-producing category, the chances for complete recovery of the area by the following growing season are good. Some degree of shifting in species dominance might occur. Weedy species could become more predominant in heavily impacted areas. Because of this possibility, ecosystem level impacts within the high concentration areas have been rated as moderate to severe. However, it is stressed that the majority of impacts to the ecosystem can be considered short-term perturbations and recovery for a11 but the most sensitive species would be rapid.

Generalizations can be made for the relative hazard potential of various environmental variables other than wind speed. For example, a higher moisture content within the leaves, seeds and other plant parts can produce more serious injury (Benedict and Breen 1955; Barton 1940). Therefore, recent precipitation and/or high humidity prior to an ammonia spill would result in more hazardous conditions. High temperatures may increase ammonia damage because of the added stress involved in increased transpiration. Time of day of the spill occurrence has been reported to have little effect on ammonia injury (Temple et al. 1979).

A very important environmental variable for plant injury is the time of year in which the ammonia spill occurs. This factor has already been discussed concerning its importance to crop damage. In a natural setting, should an anmonia spill occur in the winter when the plants are dormant, very little damage to the vegetation would be expected to occur. The age of the leaves has been reported to be a factor in injury incidence. Younger leaves have been shown to be less 
susceptible to ammonia damage than older leaves (Benedict and Breen 1955). Therefore, should the spill occur during the phase of new foliage deveiopment, the impact would be much more pronounced.

Vegetative structure can contribute significantly to an ammonia spill's hazard potential. Dense multilayered horizontal canopies such as those found in intemediate successional forests would effectively delay ammonia plume dissipation and result in much greater damage within a more localized area. In contrast, Tow monolayer ecosystems such as deserts, grasslands and shrublands would pose no barrier to the ammonia vapor thus creating a low hazard situation.

\subsubsection{Terrestrial - Adequacy of Information}

As the previous discussion emphasizes, with only a few exceptions, information on the effects of ammonia spills on North American ecosystems have not been documented. The vast majority of literature available for impact assessment of ammonia spills is based on laboratory studies. Although this does create problems when attempting to extrapolate laboratory studies to natural conditions, the problems are not serious. Ammonia spills in terrestrial environments are characteristically short-term perturbations. Thus, resulting injuries are acute in nature and therefore much more likely to produce similar symptoms both in the laboratory and in the field. Laboratory investigations have identified armonia dose-response relationships for a number of organisms, particulariy for farm animals and crop plants. Information on naturally occurring plants and animals, however, is scarce. The least known and most important element in this analysis is the prediction of ecosystem level impacts. There is no information available to ascertain the resiliency of an area following an ammonia spill. Therefore, the uitimate effects of an ammonia spill are questionable. Armonia toxicity appears to be a highly species specific hazard. Therefore, an anmonia spill will impose varying degrees of perturbation to the effected area. Its relative hazard potential will be entirely dependent on the site-specific variables at the time of the occurrence.

\subsubsection{Marine - Spill Scenarios and Assumptions}

Four hypothetical $\mathrm{NH}_{3}$ spill scenarios, which are derived in Sections 5.1 and 5.2, are considered: 1) a major collision or storm damage at an ocean 
thermal energy conversion (OTEC) pilot plant, 2) an OTEC storage tank leak, 3) a tanker accident in a bay or large harbor, and 4) a tanker loading accident in a restricted waterway or ship channel.

An accidental release of anhydrous 1 iquid ammonia over water would result in a vapor cloud, 60 to $70 \%$ of which would enter the water regardless of the size or method of spill, water temperature, or salinity (U.S. EPA 1977; Raj and Reid 1978).

The concentrations of $\mathrm{NH}_{3}$ in seawater at points in time after a spill (see Table 5.7) are estimated from published reports on "point release" experiments in the marine environment (0kubo 1971).

Scenario 1: An OTEC pilot plant accident could result in $84,000 \mathrm{~kg}$ of $\mathrm{NH}_{3}$ entering the ocean. After 24 hours under good mixing condition (wind speed $10 \mathrm{~m} / \mathrm{sec}$ ), the areas contaminated would be $1.5 \mathrm{~km}^{2}$ containing $50 \%$ of the $\mathrm{NH}_{3}$ and $4.5 \mathrm{~km}^{2}$ containing the remaining $50 \%$. A mixing depth of $60 \mathrm{~m}$ is assumed.

UIA concentration in the $1.5 \mathrm{~km}^{2}$ area for the $84,000 \mathrm{~kg}$ spill would be:

$$
\frac{11 \% \times 84,000 \mathrm{~kg}}{1.5 \times 10^{6} \mathrm{~m}^{2} \times 60 \mathrm{~m} \times 10^{3} \mathrm{l} / \mathrm{m}^{3}}=\frac{4.6 \times 10^{9} \mathrm{mg}}{90 \times 10^{9} \ell}=0.051 \mathrm{mg} / \ell
$$

and UIA concentration in the $4.5 \mathrm{~km}^{2}$ would be:

$$
\frac{11 \% \times 84,000 \mathrm{~kg} \times 50 \%}{4.5 \times 10^{6} \mathrm{~m}^{2} \times 60 \mathrm{~m} \times 10^{3} \mathrm{\ell} / \mathrm{m}^{3}}=0.017 \mathrm{mg} / \mathrm{l}
$$

In the case of little mixing, we assume that after 24 hours all the UIA would be in a volume of $0.8 \mathrm{~km}^{2} \times 60 \mathrm{~m}$ and result in a concentration of 0.19 $\mathrm{mg} / \ell$.

Scenario 2: An OTEC storage tank leaks releasing $42,000 \mathrm{~kg}$ of $\mathrm{NH}_{3}$ into the ocean. This would result in half the above levels.

In both mixing cases of scenarios 1 and 2, the 48-hour concentrations are assumed to be half the 24-hour concentrations and are assumed to occur in twice the area. 
TABLE 5.7. Concentration of Unionized Anmonia (UIA) in Seawater Resulting from Four Spill Scenarios, Assuming 60\% of the Spilled Anmonia Enters Seawater and $11 \%$ of That Remains in the Unionized Form

\begin{tabular}{lcc} 
Scenario & $\begin{array}{c}\text { Contaminated Area } \\
\left(\mathrm{km}^{2}\right)\end{array}$ After $24 \mathrm{hr}$ & $\begin{array}{c}\text { Concentration of UIA } \\
(\mathrm{mg} / \mathrm{l})\end{array}$ \\
\cline { 1 - 1 } $\begin{array}{l}\text { 1. Offshore OTEC Col- } \\
\text { lision or Storm, Good } \\
\text { Mixing }\end{array}$ & 1.5 & 0.051 \\
Little Mixing & 4.5 & 0.017 \\
2. Offshore OTEC Storage & 1.5 & 0.19 \\
Tank Leak, Good Mixing & 4.5 & 0.026 \\
Little Mixing & 0.8 & 0.009 \\
3. Large Bay or Harbor & 1 & 0.095 \\
Tanker Accident & 5 & 111 \\
Loading Spil1 & 1 & 11 \\
& 5 & 56 \\
4. Waterway or Ship Canal & 2.5 & 6 \\
Spil1 & & 132
\end{tabular}

Scenario 3: A tanker accident or loading spill occurs at a nearshore loading facility or in a large harbor or bay $\left(100-\mathrm{km}^{2}\right.$ area) releasing 15,000 tons of $\mathrm{NH}_{3}$ into the seawater or 7,200 tons in the case of the loading spill. The depth of mixing in these situations is assumed to be controlled by a pynocline at $10 \mathrm{~m}$. The areas contaminated after 24 hours are $1 \mathrm{~km}^{2}$ containing $67 \%$ of the $\mathrm{NH}_{3}$ and $5 \mathrm{~km}^{2}$ containing $33 \%$. The UIA concentrations for 35,000 tons of $\mathrm{NH}_{3}$ are:

$$
\begin{aligned}
& 1 \mathrm{~km}^{2} \text { area } \frac{15 \times 10^{12} \mathrm{mg} \times 11 \% \times 67 \%}{1 \times 10^{6} \mathrm{~m}^{2} \times 10 \mathrm{~m} \times 10^{3} \mathrm{\ell} / \mathrm{m}^{3}}=\frac{1.11 \times 10^{12} \mathrm{mg}}{1.0 \times 10^{10} \mathrm{\ell}}=111 \mathrm{mg} / \mathrm{l} \\
& 5 \mathrm{~km}^{2} \text { area } \frac{15 \times 10^{12} \mathrm{mg} \times 11 \% \times 33 \%}{5 \times 10^{6} \mathrm{~m}^{2} \times 10 \mathrm{~m}}=\frac{0.54 \times 10^{12} \mathrm{mg}}{50 \times 10^{9}}=11 \mathrm{mg} / \mathrm{l} .
\end{aligned}
$$

In ten days the volume of contaminated water would cover an area of $100 \mathrm{~km}^{2}$ to a depth of $10 \mathrm{~m}$. The UIA concentration would be $1.65 \mathrm{mg} / \mathrm{l}$. 
In the loading spill the UIA concentrations would be half those of the tanker accident scenario. In both cases, the 48-hour concentrations are assumed to be half the 24-hour concentrations and occur in twice the area.

Scenario 4: A tanker or loading accident results in 15,000 tons of ammonia entering a waterway $5 \mathrm{~km}$ long by $0.5 \mathrm{~km}$ wide. The mixing is restricted to a $5-\mathrm{m}$ depth. At the end of 24 hours the ammonia is uniformly mixed throughout the waterway. The UIA concentration would be:

$$
\frac{15 \times 10^{12} \mathrm{mg} \times 11 \%}{2.5 \times 10^{6} \times 5 \mathrm{~m} \times 10^{3} \mathrm{\ell} / \mathrm{m}^{3}}=132 \mathrm{mg} / \ell
$$

The UIA concentration in the waterway would decrease with time assuming a certain mixing exchange rate with ammonia free water from outside the waterway. A half-life for loss of mixed layer water could be in the range of days to months depending upon circulation in the waterway. Ansnonia is assumed to dissipate at the rate of mixing.

\subsubsection{Marine - Spill Impact Assessment}

The calculated concentrations of $\mathrm{NH}_{3}$ generated by each spill scenario (expressed as unionized ammonia) provide the basis for interpreting the significance of the impact. The ranges of concentration are shown in Figure 5.8. Collectively the four scenarios provide a broad spectrum of ammonia concentrations covering almost six orders of magnitude. The relative significance of these concentrations is shown in Figure 5.9. This spectrum of response agrees well with that formulated in the freshwater $\mathrm{NH}_{3}$ hazards section (Figure 5.6). In some cases, the values appear to be about one order of magnitude lower for equivalent responses. This discrepancy is undoubtedly due to the fact that our spectrum is based on unionized $\mathrm{NH}_{3}$ instead of the total $\mathrm{NH}_{3}$ present. When literature responses were reported as total ammonia, we assumed about $10 \%$ would be present in the unionized form.

Detailed impact ratings for the four scenarios is given in Appendix E.1. Relatively low concentrations of ammonia occur naturally in the marine environment as part of the nitrogen cycle. Ammonia may be generated from the bacterial 


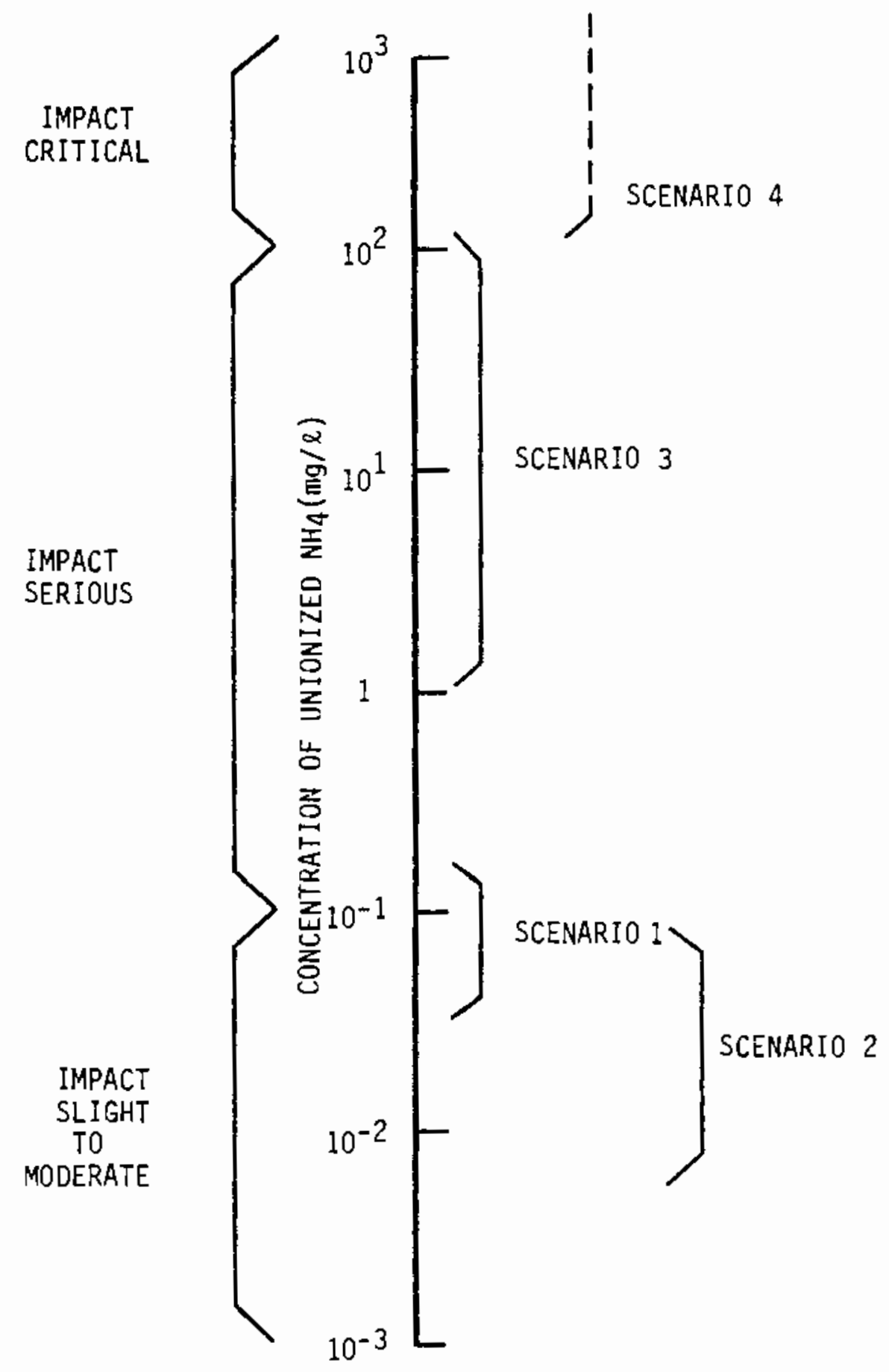

FIGURE 5.8. Ranges of $\mathrm{NH}_{3}$ Concentrations Generated by Each Spill Scenario and Significance of Impact as Defined in Figure 5.7 


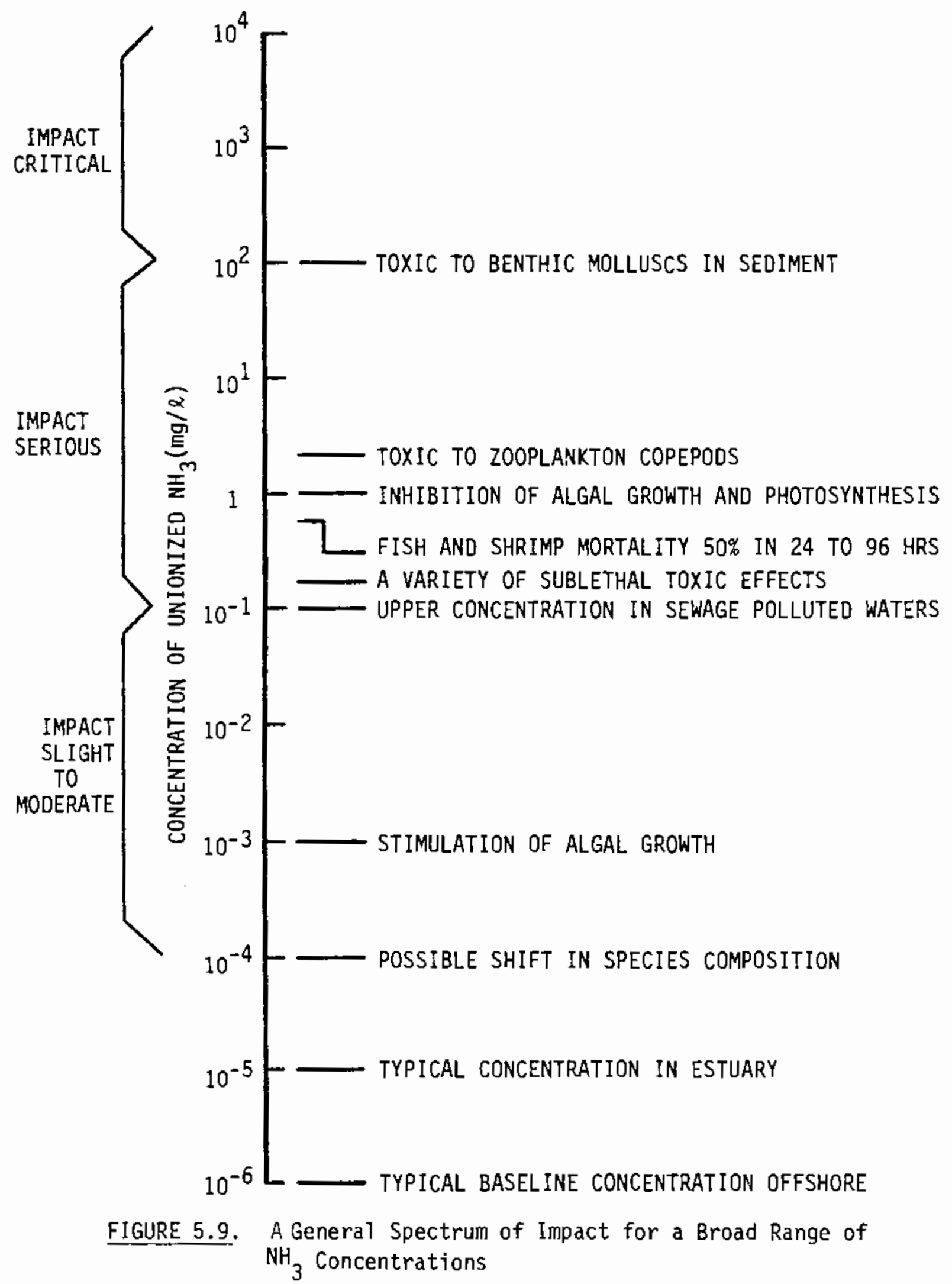


degradation of organic matter present in sediments or detrital particulate matter present in the water column. Excretion of amnonia by zooplankton provides an additional source. Seasonal cycles generally affect the relative ratios of ammonia and nitrate present in marine waters.

Typical ammonium concentrations in marine waters $\left(\times 10^{-3} \mathrm{mg} / \mathrm{l}\right)$ are: Atlantic Ocean 5 to 9 , coastal upwelling system 11 to 38 , continental shelf 5 to 47 and estuaries 54 to 144 or greater in the upper five meters (U.S. EPA 1977). In near shore coastal areas, sewage effluents and agricultural runoff can elevate ammonia concentrations, at least within 1 imited areas, to 90 to $1080 \times 10^{-3} \mathrm{mg} / \mathrm{l}$ (Jaslakian and Hardy 1976). Concentrations of anmonium in organic-rich deep water sediments are even higher, typically around $9 \mathrm{mg} / \ell$ in the interstitial water of the upper $10 \mathrm{~cm}$ where most organisms would exist, but concentrations increase with depth in the sediment up to 36 to $54 \mathrm{mg} / \ell$ (U.S. EPA 1977).

Like other plants, marine phytoplankton require a nitrogen source for growth. Ammonia is the preferred nitrogen source of marine phytoplankton and in nutrient poor oceanic areas, zooplankton anmonia release provides an important source of nitrogen for marine phytoplankton (Dugdale and Goering 1967).

Nitrogen is the critical limiting factor to algal growth and eutrophication in many marine waters. In the New York Bight area, for example, enrichment of seawater with $5.3 \mathrm{mg} /$ l ammonium chloride resuited in approximately 8 to 10 times more growth of a marine diatom than water without an enrichment or water enriched with $1.2 \mathrm{mg} / \ell$ sodium phosphate (Ryther and Dunstan, 1971).

The results of nutrient enrichment in the marine environment are particularly evidenced in coastal sewage enriched areas. Seawater values of up to $54 \times 10^{-3} \mathrm{mg} / \ell$ have been found at distances of $5 \mathrm{~km}$ from southern California sewage outfalls (Thomas and Carsola 1980). Sewage enriched with an ammonia concentration 3 to 5 times greater than unenriched areas resulted in a phytoplankton biomass approximately ten times greater than unenriched areas (Hardy and Jubay1i 1976) although other nutrients, such as phosphate, were simultaneously enriched.

Uptake of nitrogen (including ammonia) as well as growth of phytoplankton has been described by Michaelis-Menton kinetics (Dugdale 1967) or modifications thereof (Demanche et al. 1979). 
Thus, an armonia limited growth relationship can be described:

$$
\mu=\mu_{\max } \frac{S}{k_{S}+S}
$$

where $\mu=$ phytoplankton specific growth rate (limited by low $N$ ) in doubling/day

$S=$ observed nutrient concentration

$\mathrm{K}_{\mathrm{s}}=$ nutrient concentration $(\mathrm{mg})$ which supports a rate $=\mu_{\max } / 2$

For the eastern Tropical Pacific, Thomas (1970 and 1977) found $K_{s}=0.27 \mathrm{mg} / \ell$ $\mathrm{NH}_{4}^{+}-\mathrm{N}$ and $\mu_{\max }$ of $\mathrm{\sim l} .2$ doublings/day.

Therefore, $\quad \mu=(1.2) \frac{\left[\mathrm{NH}_{4}^{+}\right]}{1.5+\left[\mathrm{NH}_{4}^{+}\right]}$.

Accordingly, phytoplankton growth rates are likely to increase hyperbolically with increased ammonia concentration. Phytophankton in tropical areas are already generally adapted to lower nitrogen levels and will assimilate nitrogen faster at these lower levels than temperate species (MacIsaac and Ougdale 1969). This could result in more rapid responses and growth of phytoplankton populations to increased ammonia levels such as those of scenario 1 and 2 in tropical as opposed to temperate areas. Thus, low to moderate increases in ambient ammonia concentrations in the marine environment such as those of scenario 1 and 2 could well lead to stimulation of phytoplankton production leading to eutrophication.

Low levels of ammonia enrichment in marine waters may also lead to dramatic shifts in the species composition and community structure of both phytoplankton and near shore benthic macroalgae. Between 36 and $72 \mathrm{mg} / \ell$, ammonia may inhibit some species of phytoplankton diatoms while other species possess a much greater tolerance to ammonia (Admiraal and Peletier 1980). Coastal sewage enrichment has been shown to reduce phytoplankton species diversity causing a shift in dominance from species of diatoms to certain species of blue-green algae and dinoflagellates (Taslakian and Hardy 1976). Also, the species diversity of macroalgae has been found to decrease with increasing proximity to major coastal 
sewage effluents (Basson, Hardy and Lakkis 1976). Such reductions in diversity at the primary producer level are often reflected in corresponding reductions at higher tropic levels and reflect a generalized decrease in the richness of the biological community. Additions of amonia in the 0.5 to $1.1 \mathrm{mg} / \mathrm{l}$ range stimulated the primary productivity of the benthic alga ulva, while concentrations greater than $1.1 \mathrm{mg} / \ell$ inhibited productivity of UTva regardless of the phosphate concentration (Waite and Mitchel1 1972). Therefore, the low levels of anmonia associated with scenarios 1 and 2 could also result in dramatic shifts in species composition and community structures especially in phytoplankton and certain benthic macroalgae.

The primary factors affecting the toxicity of anowonia are: water temperature, dissolved oxygen, carbon dioxide concentration, and salinity (Willingham 1976). Research on the toxicity or sub-lethal effects of ammonia on marine species is extremely limited. Most studies have concentrated on freshwater organisms or on anadromous fish species in freshwater exposures. The toxicity of ammonia to aquatic or marine animals is generally considered to result from the undissociated $\mathrm{NH}_{3}$ form. Therefore, knowledge of the distribution of nitrogen between the toxic $\mathrm{NH}_{3}$ and the harmless $\mathrm{NH}_{4}{ }^{+}$form under different conditions of temperature, salinity, or other physical variables is of critical importance in assessing the potential toxicity of ammonia spills. For example, the concentration of undissociated ammonia resulting in acute toxicity $\left(24-\mathrm{hr} \mathrm{LC}_{50}\right.$ concentration causing $50 \%$ mortality) to salmon is about twice as great in seawater as freshwater (Alabaster et a1. 1979).

Nevertheless, many reports on the toxicity of ammonia to marine species disregard, or do not report, exposure conditions in terms of $\mathrm{pH}$, temperature, or oxygen concentration and fail, therefore, to determine the concentration of unionized (toxic) ammonia. Exposures are often reported in confusing terms of ammonia/l or ammonium chloride added.

The percentage of unionized ammonia in seawater can be predicted relatively well over a range of pH, salinity and temperature (Hampson 1977; Whitfield 1978).

$$
\% \text { UIA }=\frac{100}{1+10 x+.0324\left(298-T-\frac{.0415 P}{T}-p H\right)}
$$


where $\mathrm{x}=\mathrm{pk}_{\mathrm{as}}=$ Stoichiometric acidic hydrolysis constant of ammonium ions in saline water

$S=$ Salinity (parts per thousand)

$\mathrm{T}=$ Temperature $(\mathrm{K})$

$P=$ Pressure (atmosphere)

UIA = Unionized ammonia.

According to the above relationship, the toxicity of total ammonia generally increases with increasing $\mathrm{pH}$ and temperature and decreases with increasing salinity. Thus, at similar salinity and $\mathrm{pH}$ values (8.0) an ammonia spill in tropical waters of $25^{\circ} \mathrm{C}$ is likely to result in an undissociated $\mathrm{NH}_{3}$ concentration (i.e., toxic level) approximately four times greater than an equivalent spill in temperate waters of only $10^{\circ} \mathrm{C}$.

Among these physical conditions, pH usually has the greatest influence on the formation of unionized ammonia. As $\mathrm{pH}$ increases, the formation of unionized ammonia increases. For instance, at a pH of $7.0\left(25^{\circ} \mathrm{C}\right.$ and $\left.25 \% \circ \mathrm{S}\right)$ the unionized ammonia is $0.52 \%$ of the total, but increases to $4.98 \%$ at $\mathrm{pH} 8$.

Biologically, however, it has been pointed out that the toxicity of ammonia may be dependent not on the $\mathrm{pH}$ of the bulk water, but on that of the water on the surface of the gills of aquatic organisms. This pH value can be calculated from the bicarbonate alkalinity, temperature and free carbon dioxide concentration in the water and the free carbon dioxide excreted by the gills. Thus, as the oxygen concentration of the water is reduced, the concentration of excreted carbon dioxide at the gill surface is also reduced and the $\mathrm{pH}$ value of the water at this surface rises resulting in an increase in the toxicity of amrnonia. In freshwater, the concentration of ammonia resulting in acute toxicity to rainbow trout was estimated to be about 3.6 times lower at a dissolved oxygen concentration of $47 \%$ compared to the air saturation value (Lloyd 1961).

Probably the most relevant marine study is that by Venkataramiah et al. (1980) on the acute toxicity of OTEC plant components, primarily armonia, on marine animals from the Gulf of Mexico. They found 96-hr $L C_{50}$ values for Sargassum shrimp, file fish, large mullet, and small mullet of $0.94,0.69$, 
1.63 , and $2.4 \mathrm{mg} / \mathrm{l}$ of unionized $\mathrm{NH}_{3}$, respectively. Tests of the toxicity of unionized ammonia to stickle back fish (Gasterosteus aculeatus) in a static bioassay test gave a $96-\mathrm{hr}$ TLm of about $1.12 \mathrm{mg} / \ell$ (Hazel et a]. 1971).

An extremely informative, but totally unplanned, experiment on armonia effects in the marine environment occurred in August, 1979 when a tanker truck capsized spilling anhydrous ammonia over an area of about $6,200 \mathrm{~m}^{2}$ of intertidal habitat in Washington State. The intertidal was composed primarily of gravel-cobble and gravel-sand sediment types along with boulders. The temperature in the spill area was 18.0 to $18.6^{\circ} \mathrm{C}$. The biological impact of the spill was assessed (01sen 1979; Kittle 1979). The concentrations of unionized armonia 24, 120, and 360 hours after the spill, within the affected area, were 0.11 to 4.46 (mean 1.0 ); 0 to 0.02 (mean 0.01 ) and 0 to 0.002 (mean $0.001) \mathrm{mg} / \ell$, respectively. Total mortalities of fish and crabs within the affected areas were estimated at $6.75 \times 10^{4}$ individuals. Shellfish mortalities were high: for oysters, $20 \%$ in the gravel-cobble habitat and $29 \%$ in the boulder habitat and for clams, $66 \%$ in gravel-cobble habitat and $14 \%$ in the gravel-sand habitat. Latent mortality continued with time in the immediate vicinity of the spill and after ten days oyster mortality was estimated at $84 \%$. The unionized ammonia was almost completely dissipated within 15 days and the Department of Ecology estimated that the area would not suffer any long lasting effects on the environment and should recover rapidly. Shore crabs, for example, were moving back into the rocky area 15 days after the spill.

Measurements of subtoxic responses to antmonia have been restricted, for the most part, to freshwater organisms. Exposure of freshwater clams to ammonia results in inhibition of the ciliary beating rate and a reduction in the clam growth rate at concentrations of 0.08 to $0.20 \mathrm{mg} / \mathrm{l}$ anmonia nitrogen, respectively (Anderson 1978).

Exposure of freshwater carp to $4.9 \mathrm{mg} / \ell$ total ammonia results in subtoxic histopathological tissue necrosis (Fils 1963). Rainbow trout exposed to 0.033 $\mathrm{ppm} \mathrm{NH}_{3}-\mathrm{N}$ suffer pathological changes in gill and liver tissue (Smith and Piper 1975). The feeding rate of the brine shrimp Artemia is reduced to $1 / 3-1 / 2$ the normal rate at concentrations of "ammonia" greater than $1.8 \mathrm{mg} / \ell$ (Hanaoko 1977). 
Based on these observations, scenarios 1, 3 and 4 could result in varying levels of mortality to organisms in the spill area. Scenario 1 would likely result in only localized mortality or sublethal effects. Scenarios 3 and 4 would result in critical levels of ammonia and high mortality for most marine forms. Also because of the proximity of most bays or harbors to human habitation human exposure would also be a consideration.

If chlorine, which is commonly used as a biocide, also occurs in the area of the ammonia spill, toxic effects of the ammonia spill would be enhanced by formation of chloramines. Acute toxicities to lobster larvae are likely to occur at residual chloramine values one order of magnitude less than those for chlorine alone. In acute tests at $25^{\circ} \mathrm{C}$, significant mortalities were found for lobster larvae, killifish, winter flounder, and scup at chloramine residual values of $0.05,0.77,0.41$, and $0.32 \mathrm{mg} / \ell$, respectively. Respiratory stress was observed in lobster larvae at chloramine concentrations of less than 0.01 $\mathrm{mg} / \mathrm{e}$ (Ryther and Goldman 1975).

In conclusion, the biological impacts of the four spill scenarios range from slight through serious to critical. The overall ranking of the scenarios as to seriousness of impact of the hypothesized spill is based on the anticipated impacts to the various biota as well as judgment as to the value of the resource. For example, the waterway or ship canal is probably already degraded and does not therefore represent as important a biological or fishery resource as the large bay or harbor. Given the magnitude of impacts on the biota and the value of the resource, the ranking of the scenarios from sijght through serious to critical are:

- Scenario 2, an OTEC storage tank leak, would not likely result in organism mortality, but could have a slight impact by stimulating phytoplankton growth and causing changes in species composition, at least in the plankton, over an area greater than $5 \mathrm{~km}^{2}$.

- Scenario l, a collision or storm at an OTEC facility, could result in some acute mortality of marine life in a small area and some sublethal toxic responses. 
- Scenario 4, a tanker loading accident in a restricted waterway, would result in critical levels of ammonia in the water and mortality in most marine life. However, effects are restricted to a small area, which is probably already not important as a biological resource. However, human populations are likely to be present surrounding such an area and the hazard must, thus, be rated critical.

- Scenario 3, a tanker loading accident in a large harbor or bay, is undoubtedly the worst case in terms of impact on the marine biota or fishery resource. Acute mortalities can be expected for all fish and most invertebrates throughout a $5 \mathrm{~km}^{2}$ area. Ten days after the spill an area $100 \mathrm{~km}^{2}$ may still contain levels toxic to most marine life. Furthermore, most bays or harbors would be in proximity to human habitation and, in such cases, human exposure to the ammonia cloud would have to be considered as an additional hazard.

\subsubsection{Marine - Adequacy of Information and Research Needs}

Information on the effects of ammonia in the marine environment are limited. Table 5.8 summarizes the available literature on responses of marine biota to ammonia enrichment. Studies are needed on the toxicity of ammonia to the eggs and larval stages of marine organisms, on the sublethal effects of chronic low levels of ammonia and on the effects of chloramine compounds formed by the combination of chlorine biocides and ammonia. Presently, sufficient information does not exist to assess these effects.

\subsection{ASSESSMENT OF THE AMMONIA FIRE AND EXPLOSION HAZARDS}

The controversial question, whether ammonia vapors can burn or explode, is a very oid one and has been investigated many times over the last 170 years (White 1922). In 1809, Henry (Fruch and Doring 1931) had stated that mixtures of air and ammonia are not explosive but that they could be burned by the continuous action of an electrical spark. Only much later (1914) it was discovered by experiencing industrial accidents ${ }^{(a)}$ that explosions of ammonia/air

(a) These first accidents happened with mechanical refrigeration equipment. It may be interesting to know that up to the present time ammonia explosion accidents have practically been limited to this particular industry. 
TABLE 5.8. Responses of Marine Biota to Ammonia Enrichment

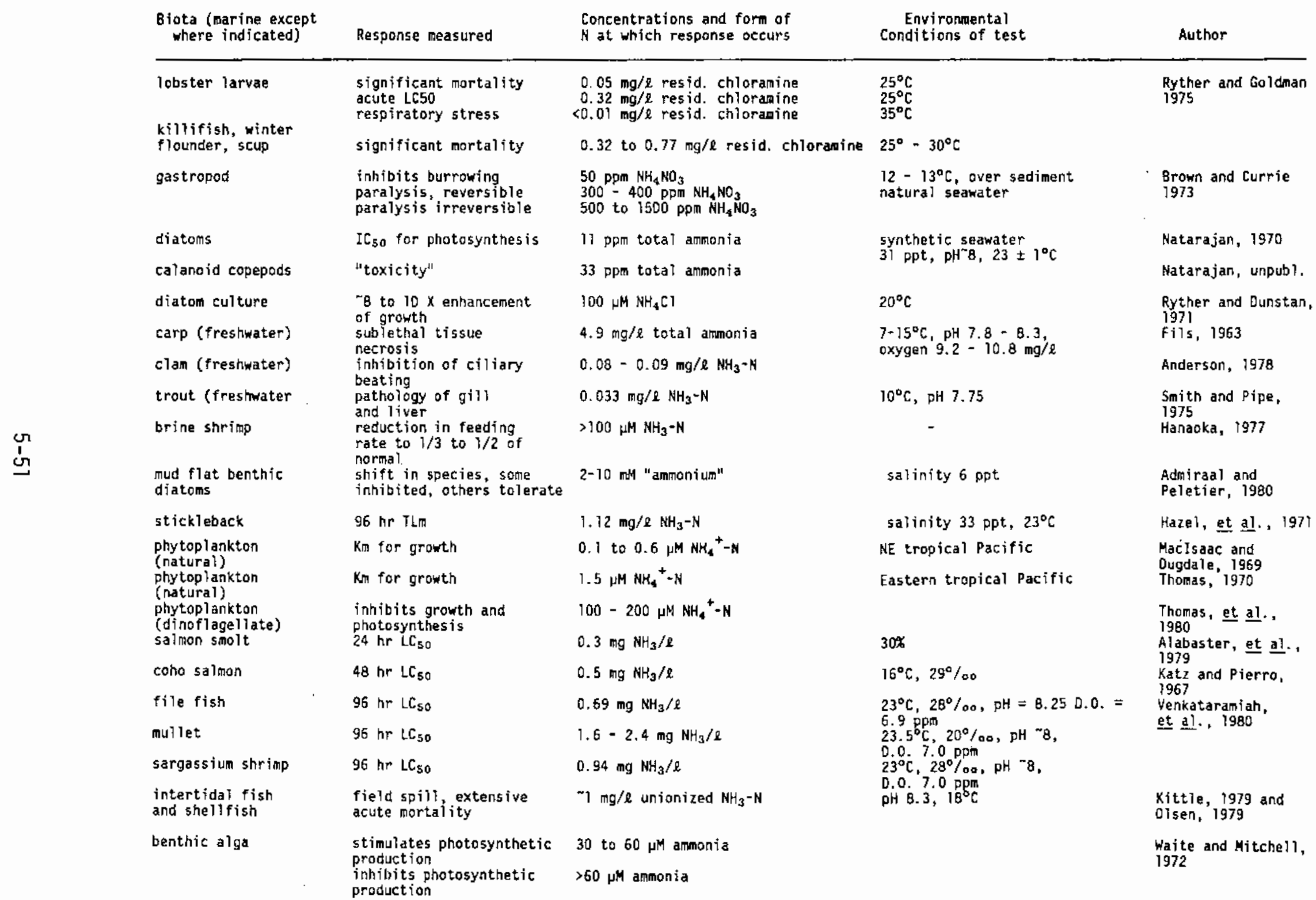


mixtures can indeed occur, and the $\mathrm{NH}_{3}$ flammability questions then became the subject of intensive and systematic investigations (Whilte 1923, Fruch and Doring 1931, Schliephake, et a1. 1930). Even eminent scientists such as M. Planck and $V$. Wartenburg (both Nobel prize winners) became involved in the controversy.

Obviously, there is no sharp distinction between flammable and nonflammable materials, and ammonia must be considered as a substance in the boundary area. Its ignition and subsequent deflagration depend heavily on prevailing circumstances. This can be explained by the following characteristics: Compared to common fuels, $\mathrm{NH}_{3}$ flammability in air (15-27\%) is very narrow $(27 / 15=1.8)$, and its lower flammability limit is very high, which marks it as a rather poor combustor; its ignition energy is at least an order of magnitude higher (Harris and McDermott 1977) than for normal fuels, which explains why it is hard to ignite; its flame propagation speed is quite low, which practically precludes detonation and, if ignited, maximum pressures are correspondingly low, which would mitigate any damage that might occur as the result of an explosion.

It might be somewhat surprising that, in spite of such poor combustion characteristics, ammonia can be successfully used in almost all types of combustion engines (Bomelburg and McNaughton 1980). But such use is possible only for carefully chosen operating conditions and, even then, ammonia remains inferior to the common hydrocarbon fuels.

Of the more than 500 incidents involving spills of anhydrous ammonia while in transportation in the U.S. during 1971-1980, only three resulted in fire or explosion (National Transportation Safety Board 1980). In the we11publicized Houston accident (1976) five people died and 150 were injured (Kaiser and Walker 1978, NTSB Accident Report 1977). However, the Houston accident involved a flameless explosion of the ammonia under pressure with no ensuing fire. Case histories have been reported on major ammonia incidents involving humans (Hardin 1974, McNaughton and Brenchley 1980). In all cases, injury or death was caused by the toxic properties of the ammonia. No $\mathrm{NH}_{3}$ fires were reported. Based on such information, it can be assumed that in more than $99 \%$ of ammonia incidents, no fires would be involved. Moreover, 
in those few accidents in which an ammonia fire was reported, no case was discovered in which humans were kilied or even seriously injured as a result of such a fire. In a separate study (Powell 1969), it has also been concluded that pure $\mathrm{NH}_{3}$ probably cannot be ignited by friction or impact resulting from violent vessel fractures. Such spontaneous ignitions occur with LNG and LPG, and it is assumed that if the Houston accident (NTSB Highway Accident Report 1977) had occurred with LPG instead of $\mathrm{NH}_{3}$ that most likely a fierce fire would have erupted.

The U.S. Department of Transportation has classified anhydrous ammonia as a "nonflanmable liquid." Although, strictly speaking, this is a misnomer, it is well justified, in view of our present knowledge and past experience. If ammonia is kept under pressure, e.g., in tank cars or in refrigeration systems, a rupture of containers or piping is, of course, a possibility, as it is in any compressed gas system. In cases involving such $\mathrm{NH}_{3}$ explosions, a relatively large amount of ammonia can flash upon depressurization and thus can generate a cloud of ammonia with a concentration that is well within the flammability limits. Thus, if a suitable ignition source is present, a "flash" fire could result which, in turn, could then ignite flammable materials nearby. Although such scenarios have a low probability, a few such accidents have happened (Hughes 1951). If the ammonia is contaminated with oil vapors (e.g., from the compressors), "foul gases" are mixed in with the ammonia. Such mixtures can be more easily ignited than pure $\mathrm{NH}_{3}$, as has been shown in recent tests (Kalkert and Schecker 1980).

As can be expected, the presence of water vapor in a combustible $\mathrm{NH}_{3} /$ air mixture reduces its flammability range significantly (CIarke and Wright 1955, DeCoursey et a1. 1962). If the water fraction exceeds 9 vol\%, ignition was found to be impossible at temperatures below $65^{\circ} \mathrm{C}$ (DeCoursey et al. 1962).

A thermodynamic analysis of ammonia spill fires, presented in Appendix $C$, is mainly based on a comparison with more familiar fuels, since a strict derivation from basic equations is too complex. That analysis considers the radiation from the flames back to the pool as being the overriding feature which determines the evaporation rate on the pool surface. By considering ammonia flame characteristics, compared with those for ethanol, it is then concluded that 
for ammonia this rate is insufficient for sustaining a continuous fire. (Ethanol pool fires burn quietly and appear to be sustaining just enough boiloff to barely keep going.)

Based on such indirect argumentation, it can indeed be assumed with practical certainty that $\mathrm{NH}_{3}$ pool fires cannot sustain themselves because the rate of boiloff is too low.

However, as it has been shown in LPG pool fire tests (Taylor et a]. 1980), only about one-half the heat of evaporation is supplied by radiation from the flames; the other half comes from the surroundings (soil, atmosphere, etc.) by conduction and convection. Since the analysis has entirely disregarded the latter part, its conclusions are not based on conservative assumptions and, thus, lose some of their otherwise convincing strength. In fact, it appears possible that under certain extreme conditions (e.g., when pouring $\mathrm{NH}_{3}$ onto molten steel) an ammonia pool fire could very well be sustained.

Generally, it appears that these analyses and conclusions again reinforce the contention that $\mathrm{NH}_{3}$ is a borderline fuel and that its burning characteristics depend very much on the prevailing circumstances. Therefore, in order to be certain that under ordinary conditions (e.g., when spilling liquid ammonia onto a road at $70^{\circ} \mathrm{F}$ ) no spill fire could sustain itself, a series of spill tests would be necessary.

The Phillips Petroleum Company (1965) conducted ignition tests on ammonia spills during the mid-1960s(a). These tests are very informative and stil1 provide the strongest evidence that $\mathrm{NH}_{3}$ spill fires are practically impossible under normal conditions.

In 1965 the Phillips Petroleum Company of Bartlesville, Oklahoma, carried out a series of small and large ammonia spill tests (up to 20 tons $\mathrm{NH}_{3}$ ) in diked areas (up to $22 \mathrm{ft} \times 22 \mathrm{ft}$ ). They attempted igniting the ammonia vapors with propane torches; this provded to be unsuccessful. Burning rags (soaked in fuel oils) thrown into the ammonia pool were promptly extinguished. It was

(a) The U.S. Coast Guard in currently conducting an ammonia spill test program at China Lake. However, the focus of this work is to determine the concentration and spreading pattern of ammonia. 
concluded, therefore (backed up by some crude measurements of $\mathrm{NH}_{3}$ vapor concentrations) that the vaporization of ammonia was too slow to generate concentrations in the vapor phase exceeding the low flammability limit (about $15 \%$ ) at the prevailing wind conditions. ${ }^{(a)}$ Surprisingly, the ammonia vapors could be ignited when water was sprayed into the ammonia pool. This was explained by increased evaporation and higher temperatures of the ensuing vapors, caused by the heat of reaction between the water and the ammonia. As the vapor temperatures are increased, the flamability limits are widened (Buckley and Husa 1962, J. Chemical and Engineering Data 1960, Zabertakis $1976)^{(b)}$. When the water spray into the pool was discontinued, the flames went out. This showed that an anmonia pool fire is not self-sustaining. It was also observed in these tests that in the initial stages of a spill the vapor generation is significantly higher than in the later stages, after a thermal equilibrium has essentially been reached. This seems to indicate that an initial deflagration (explosion) might still be possible if a large amount of $\mathrm{NH}_{3}$ were suddenly spilled and a suitable ignition source were present. However, no continuous fire is anticipated. Of course, such a brief flash fire would be more likely to occur if the ammonia is kept under pressure and above its normal boiling temperature.

This type of burning behavior of $\mathrm{NH}_{3}$ is clearly different from that of other 1 iquefied fuels (such as LNG and LPG). The difference can be traced mainly to the fact that ammonia/air mixtures are not normally flamable below $15 \%$, whereas LPG air mixtures are already flammable at $\sim 2 \%$. However, the warming effect of water is felt more for $\mathrm{LNH}_{3}$ than for liquid hydrocarbons, since only ammonia will react exothermally with water.

It was found also in the Phillips spill tests that the ground under the spill area initially heated up as the $\mathrm{NH}_{3}$ reacted with the water in the soil, thereby tending to increase the initial evaporation rate. On the other hand, the ammonia evaporating at the spill surface cooled off

(a) It is conceivable that, in very still air, the lower flammability limit could be reached. But such a condition would be hypothetical since the convection currents (due to density and temperature gradients above the poo1) cannot be suppressed, even in the complete absence of any wind.

(b) Whether this is an adequate explanation is doubtful, however. 
the surface layers of the spilled ammonia liquid down to $u-50^{\circ} \mathrm{F}$, thereby tending to decrease the evaporation rate. However, by the same effect, the $\mathrm{NH}_{3}$ /air mixture was also cooled off, thereby raising the lower flammability limit still higher.

Such effects have largely been ignored in analytical treatments of spilled liquefied fuels. (Admittedly, for liquid hydrocarbons the effect may be less pronounced, but is by no means absent.) Based on the results of their spill tests, the Phillips people warned against the use of water.

It would also be of interest to see whether flameless vapor explosions might occur when 1 iquefied ammonia is injected into the water, since it might become superheated, not just by heat transfer from the relatively warm water (as in the case of $L N G$ ), but also by the ensuing exothermic chemical reactions. A rough estimate indicates that in the case of anhydrous $\mathrm{NH}_{3}$ dissolution in ambient water, $3-4$ times as much energy is generated as in the case of pouring $L N G$ into water. This would indicate that $\mathrm{LNH}_{3}$ might be more susceptible to vapor explosions than LNG, if other influences could be neglected. (A much more thorough analysis is required for a more definitive statement on this point.)

\subsubsection{Conclusions}

The question of $\mathrm{NH}_{3}$ fires has always been controversial. Since ammonia is not easily combustible, its combustion behavior is affected significantly by many parameters. Explanations offered in the literature for sometimes unexpected behavior of antononia in spill and accident situations appear to be largely conjectural (Blanken 1980). The following can be said, however, with reasonable certainty:

- Amonia spill fires are practically impossible.

- Ammonia flash fires can occur. They are expected to be of short duration (seconds). However, they can ignite other combustible material nearby.

- Such flash fires may have the appearance of a relatively mild explosion, but they will not develop into a detonation. 
This indicates that the fire and explosion hazards of ammonia are of only minor gravity when compared to its toxicity hazards. They can also be considered much less serious, when compared with those of more prevalent fuels such as LNG, LPG, or gasoline.

\subsection{HUMAN HEALTH EFFECTS}

Two recent studies have focused on the health effects of ammonia (U.S. EPA 1977 and National Research Council 1979). This section draws heavily from these reports.

Ammonia is very water-soluble and thus is an irritant that most commonly affects the skin, eyes, mucous membrane of the upper respiratory tract and the lungs. When ingested, it has corrosive effects on the mouth, esophagus, and stomach. Findings in patients who die from acute toxic inhalation of ammonia fumes have revealed diffuse cerebral hemorrhage, in addition to effects on skin, eyes, and respiratory tract (Slot 1938).

The effects of ammonia on human health can result from accidental acute toxic exposure, from chronic exposure to low concentrations in the workplace or as an air pollutant and from endogenous accumulation in liver disease. The degree and type of problem or damage depends on the concentration, duration and type of exposure as well as the presence of diseases.

\subsubsection{Burns of the Eyes}

The most devastating burns of the eye are those caused by strong alkalis such as liquid ammonia and solutions of ammonia. These burns are corrosive, destroy the texture and substance of the occular tissue, and have a marked tendency for complications later.

Gaseous ammonia is slightly irritating to human eyes at concentrations of $140 \mathrm{ppm}$ and immediately irritating at $700 \mathrm{ppm}$ (Clinton 1948, Patty 1949). In humans, chronic exposure to ammonia gas in air causes the blood to collect excessively (called hyperemia) in the inner surface of the eye lids. A forceful blast of concentrated ammonia gas directed into the eyes causes severe ocular damage (Grant 1974). 
Ammonia is very soluble in water, combining to form amnonium hydroxide. This alkali is strongly dissociated and yields a large excess of hydroxyl ions. The $\mathrm{pH}$ depends on concentration and on the degree of dissociation. The amount of tissue damage is related to the $\mathrm{pH}$ or hydroxyl ion concentration.

The surface of the eyeball is not an effective barrier against liquid ammonia and ammonium hydroxide. The ammonium ion is highly soluble and quickly penetrates the cell barriers of the cornea; traces are detectable within five seconds and considerable ion concentration is present after 30 seconds (Siegrist 1920).

Within ten minutes of ammonia burn, the cornea becomes opaque and disintegration of cells occurs. If treatment is not immediate and vigorous, then further perforation of tissue occurs. When this occurs, vision is lost and only the presence of light and dark can be perceived.

Inmediate treatment consists of copious irrigation with water or saline solution. Because of the rapid penetration just described, the removal of ammonia must be prompt, probably within five to six seconds to reduce tissue damage (Siegrist 1920). Although immediate irrigation is beneficial, the efficiency of prolonged irrigation beyond a minute or so is questionable (Duke-Elder and Macfaui 1972, Lemp 1974).

Some other problems associated with exposure to ammonia are deformation of the eyelids and scarring of the tear ducts. Burned eyes therefore have decreased tear production (Lemp 1974).

\subsubsection{Effects on Skin}

Although odor is the first detectable sign of atmospheric ammonia, low concentrations of ammonia are irritating to the skin and thus provide an additional warning. Ammonia gas quickly dissolves on moist body surfaces and results in alkali burn; contact with liquid anhydrous ammonia also produces a burn by its freezing effect (He]mers, Top and Lnapp 1971; Highman 1978; Kass et a1. 1972; Levy et a1. 1964; Pattle, Burgess and Cullumbine 1956; Patty 1963; Walton 1973; White 1971). Contact with 1iquid anhydrous ammonia or ammonia gas under pressure results in second-degree burn, with formation of blisters that, if extensive, may be fatal. 
The relationship between response and ammonia concentration has not been well described. A concentration of $10,000 \mathrm{ppm}\left(7,000 \mathrm{mg} / \mathrm{m}^{3}\right)$ produces skin damage. The maximum concentration of vapor tolerated by the skin for more than a few seconds is $20,000 \mathrm{ppm}\left(14,000 \mathrm{mg} / \mathrm{m}^{3}\right.$ ) (Hygienic Guide Series 1971). One study indicates that $10,000 \mathrm{ppm}\left(7,000 \mathrm{mg} / \mathrm{m}^{3}\right)$ is mildly irritating to the $\operatorname{skin}, 20,000 \mathrm{ppm}\left(14,000 \mathrm{mg} / \mathrm{m}^{3}\right)$ causes increased irritation, and 30,000 $\mathrm{ppm}\left(21,000 \mathrm{mg} / \mathrm{m}^{3}\right)$ may produce blisters in a few minutes (Patty 1963). Therefore, skin should be protected in air if the concentration is over 10,000 ppm.

\subsubsection{Effects on Upper Respiratory Tract and Lungs}

Ammonia vapor has a sharp, irritating, pungent odor that acts as a warning of potentially dangerous exposure. The odor threshold concentration is as low as $0.7 \mathrm{ppm}\left(0.5 \mathrm{mg} / \mathrm{m}^{3}\right.$ ) for most sensitive people and as high as $50 \mathrm{ppm}$ (Sayfutdinov 1968; Sayfutdinov 1966; Sayfutdinov 1973; Fieldner, Katz and Kinney 1921;

Leonardow, Kendal and Barnard 1969). Ammonia is acceptable up to about $20 \mathrm{ppm}$ and beyond that people find it annoying. Chronic exposure to higher concentrations result in headache, nausea and reduced appetite (Nakatani and Sugani 1971).

Ammonia causes mild irritation, hoarseness, excess salivation, sneezing and coughing. More severe respiratory symptoms include abnormal excess accumulation of fluid (called edema) in the larynx and pulmonary areas; this can lead to asphyxiation. A concentration of $400 \mathrm{ppm}\left(280 \mathrm{mg} / \mathrm{m}^{3}\right)$ produces immediate throat irritation (Helmers, Top and Knapp 1971; Henderson and Haggard 1943), 1,700 ppm $\left(1,200 \mathrm{mg} / \mathrm{m}^{3}\right)$, cough $2,400 \mathrm{ppm}\left(1,700 \mathrm{mg} / \mathrm{m}^{3}\right)$, a threat to 1 ife after 30 minutes (Patty 1963), and 5,000-10,000 ppm $\left(3,500-7,000 \mathrm{mg} / \mathrm{m}^{3}\right)$, a high mortality rate (He1mers, Top and Knapp 1971).

Because ammonia is so water soluble, it is readily absorbed in the upper respiratory tract and thus the lungs are protected from the effects of exposure to low concentration of amonia (Boyd, MacLachlan and Perry 1943; Haggard 1924; Landahl and Herrmann 1950). The most cormon cause of death after acute exposure to anmonia is laryngeal and asphyxia or the development of pulmonary edema.

Immediate treatment consists of removal from exposure and ventilation with warm, humidified air or oxygen. If Taryngeal edema develops, then an emergency operation of the trachea is necessary to resume the passage of air to and from the lungs. 
There have been few studies on the events that follow acute toxic exposure to ammonia. Some of the survivors gradually recover their respiratory function over a period of one to six years (Finland, Davidson and Levenson 1946; Levy et al. 1964). In other cases, chronic airway obstruction gradually worsens over the next few years (Kass et a). 1972; Lepine and Soucy 1962; Walton 1974). In these latter cases, the changes can be attributed to other factors such as continued cigarette smoking.

There are two major ijmitations regarding the assessment of incidence and significance of late respiratory effects from actue toxic exposure to ammonia fumes: few patients have been studied and the pulmonary function tests used (such as vital and forced capacity) are relatively insensitive for the detection of early small airway obstruction. It is apparent from the available case reports that documented acute lower respiratory tract involvement does not necessarily lead to chronic respiratory tract disease.

\subsubsection{Air Quality Standards}

The current U.S. federal standard for exposure to ammonia is an 8-hour time-weighted average (TWA) of $50 \mathrm{ppm}\left(35 \mathrm{mg} / \mathrm{m}^{3}\right)$. This TWA concentration is for a 6- to 8-hour working day and 5 to 7 days per week.

The American Conference of Governmental Industrial Hygienists (ACGIH) recommends a maximum allowable concentration (MAC) of $100 \mathrm{ppm}\left(70 \mathrm{mg} / \mathrm{m}^{3}\right)$. The MAC is the average concentration that will not (except in cases of hypersensitivity) provoke any sign or symptoms of disease or poor physical condition. The MAC was later called the threshold limit value (TLV).

As a result of animal studies, it was found that cellular changes occurred in spleens, livers, and kidneys after chronic exposure to 140-200 ppm (100-140 $\left.\mathrm{mg} / \mathrm{m}^{3}\right)$ and direct toxic effects on isolated trachea after exposure at $100 \mathrm{ppm}$ $\left(70 \mathrm{mg} / \mathrm{m}^{3}\right)$. Based on these results, it was recommended that the TLV be reduced to $50 \mathrm{ppm}$ (American Conference of Governmental Industrial Hygienists 1966, American Conference of Governmental Industrial Hygienists 1963). This was done to specifically protect against respiratory irritation and to eliminate discomfort. 
A guide to short-term public limits (STPL) has been proposed (National Academy of Sciences 1972). The following concentrations were considered tolerable for the duration of the exposure: $20 \mathrm{ppm}\left(14 \mathrm{mg} / \mathrm{m}^{3}\right)$, ceiling for $10 \mathrm{~min}$ utes; $10 \mathrm{ppm}\left(7 \mathrm{mg} / \mathrm{m}^{3}\right)$, for 30 minutes; $10 \mathrm{ppm}$ for 60 minutes; and $5 \mathrm{ppm}$ as a TWA not to exceed ceiling limits, for $5 \mathrm{hr} /$ day, 3-4 days/month. Public energy limits (PEL) have also been defined: $100 \mathrm{ppm}\left(70 \mathrm{mg} / \mathrm{m}^{3}\right)$ for 10 minutes, $75 \mathrm{ppm}$ $\left(52 \mathrm{mg} / \mathrm{m}^{3}\right)$ for 30 minutes and $50 \mathrm{ppm}\left(35 \mathrm{mg} / \mathrm{m}^{3}\right)$ for 60 minutes (National Academy of Sciences 1972).

\subsubsection{Conclusions}

Accidental human exposure to ammonia vapors and anhydrous riquid is a serious health concern. Ammonia is very water-soluble and thus it commoniy affects the skin, eyes, mucous membrane of the upper respiratory tract and lungs. While low concentrations cause irritation, higher concentrations can cause permanent tissue damage and/or death.

Acute doses of ammonia disintegrate ocular cells, cause excessive amounts of mucous to accumulate in the throat and lungs, and burn the skin. The accumulation of fluid in the throat may become so severe that emergency surgery is required. There have been few studies on events that follow acute toxic exposure to amonia. While eye tissue damage is permanent, at least some patients seem to recover their respiratory capacity after one or two years.

Whereas airway obstruction may deveiop long after exposure, this is difficult to detect because the functional tests are quite insensitive to smal1 changes. In any event, acute lower respiratory tract exposure does not necessarily lead to chronic respiratory disease. 


\subsection{RELEASE PREVENTION AND CONTROL}

The purpose of this chapter is to focus on the current practices used by the industry to prevent ammonia releases and to control accidental spills. This overview of the current anmonia industry provides a basis for assessing the newer technological applications of ammonia as they exist today and may develop in the future.

Because of its toxicity, accidental discharges of armonia into the atmosphere must be avoided. However, anhydrous ammonia is not a cumulative poison. It has a distinctive pungent odor that, even at low concentration, is detectable by most people. Since ammonia is self-alarming, it serves as its own warning agent, so that no person will voluntarily remain in concentrations that are hazardous. Since ammonia gas is usually lighter than air, adequate ventilation is the best means of preventing accumulation. Experience has shown that ammonia is very hard to ignite (see Section 5.3) and under normal conditions is a stable compound. Lnder extremely limited conditions, ammonia can form ignitable mixtures with air or oxygen and thus should be considered hazardous.

Among 306 other materials, ammonia has been designated by Environmental Protection Agency (4D CFR 116) as a "hazardous" substance (human poison), and any environmental spil\} larger than 100 lb has to be promptly reported to federal authorities (usually EPA) within 24 hours (40 CFR 117).

\subsection{RELEASE PREVENTIDN}

The best way to avoid serious hazards as a result of handling ammonia is to prevent any occurrence of ammonia spills. This calls for a high degree of quality assurance in the design, construction, and operation of all equipment used for ammonia service. It also includes regular inspection of the equipment and proper training of the human operators.

The best assurance for avoiding accidents due to equipment failure or human error is to observe all rules and regulations for the construction and operation of ammonia-carrying components. Such rules are laid down in a wide 
variety of codes and standards, the most important of which will be discussed briefly below. This includes appropriate preventive maintenance on the equipment and observing proper safety practices in handling such equipment, and the ammonia itself. From a study of ammonia industry practices it can be concluded that such basic safety precautions are widely followed. This is probably the main reason why serious accidents involving ammonia have been relatively rare in the production industry. Regulations for the safe storage and handling of ammonia are the principal approach to release prevention and they are described below.

\subsubsection{Regulations for the Ammonia Industry}

Any particular technology is usually affected by a wide variety of codes and standards, which sometimes overlap each other. It also happens that certain aspects of that particular technology may be covered by obsolete requirements or may not be covered at a1]. Keeping the system of prevailing standards complete, consistent, and up-to-date requires a continuous effort on the part of the government and industry regulating agencies.

The ammonia technologies discussed in the previous chapters are controlled to various degrees by codes and standards of different origin. Whereas the conventional ammonia systems are controlled rather tightly, most of the new applications (presented in Chapter 3) are not yet covered by any special codes. However, by applying the basic intent of the existing ammonia codes to the new technologies, a fairly good coverage would already result. Obviously, numerous general engineering codes, e.g., American Socjety of Mechanical Engineers' Unfired Pressure Vessel Code, are applicable in all aspects of the ammonia technology as well and are, therefore, invoked frequently, even in the special ammonia standards.

The following brief survey will cover the existing rules, codes, and standards as they apply to the design, construction, location, installation, and operation of anhydrous ammonia systems. Wherever a particular system is not covered, or exempted from the discussed rules, it will be so noted. Since it is impossible, short of reproducing the entire standard verbatim, to list all requirements in detail, only a very brief general overview can be given here. 
The most important standard on equipment for anhydrous ammonia is the American Standards National Institute code ANSI K61.1 (1972 edition still valid). This standard has served as a guide (partly verbatim) for Occupational Safety and Health Administration standard 29 CFR 1910.111 (Storage and Handling of Anhydrous Ammonia), which was last amended on October 24, 1978. Since the 1atter is a government code, and is of more recent origin, it must be considered as the presently dominating standard. However, a new version of K61.l is expected for 1981 .

This set of standards pertains exclusively to "safety requirements for the storage and handling of anhydrous ammonia." It requires that all equipment used for such purposes be approved. This puts stringent requirements on the type of material, method of construction (e.g., welding procedures, etc), the operating limits, location, markings, safety relief devices, etc. In particular, piping, tubing, hose and fittings, have to meet specifications laid down in the code. It also requires that personnel employed to handle ammonia shall be trained in safe operating practices and be able to take proper action in the event of emergencies. All ammonia storage systems must have the following emergency equipment on hand: gas masks and breathing apparatus, protective clothing (including goggles and boots) and a shower or 50 gallons of clean water. This requirement applies in less stringent form also to mobile equipment, except farm applicator vehicles. The transfer of ammonia from one container to another is covered by a set of rules which, when conscientiously followed, would exclude any spillage. It postulates that containers must be filled only to a certain ratio (generally $56 \%$ ) specified in the code. Metering devices must be approved and calibrated. Transporting and handling (including loading and unloading) of tank cars is regulated by additional (DOT) regulations.

Storage containers are subject to different regulations, depending on whether they contain refrigerated or nonrefrigerated ammonia. For the latter category the design pressure is $250 \mathrm{psig}$, which would correspond to the vapor pressure of ammonia at $115^{\circ} \mathrm{F}$. The containers have to be equipped with a safety relief valve set at $250 \mathrm{psig}$ and a minimum specified discharge rate. In addition, such tanks must have a pressure gauge, an excess flow valve, a back-pressure 
check vaive, and a liquid level gauge. Installation, which can be above or below ground, is regulated by separate regulations. Hydrostatic testing is required in either case. Containers must be conspicuously marked as "anhydrous ammonia" and the owner must be identified. For refrigerated ammonia storage systems, codes are somewhat different, depending on whether the design pressure is higher or lower than 15 psig. Their construction is governed by American Petroleum Institute and American Society of Mechanical Engineer codes. Generally, the requirements are similar to those for nonrefrigerated storage. The tanks should be surrounded by dikes, high enough to hold the entire contents of the tanks. The refrigeration equipment for such tanks is also subject to specific code requirements.

Portable containers up to 1-ton capacity must be constructed according to DOT regulations. Their handling is regulated by ANSI K61.1 in considerable detai1. If ammonia tanks are mounted on trucks or trailers for transportation, their means of attachment are tightly regulated. So are appurtenances, piping, fittings, relief valves, etc., connected to such tanks. The vehicles carrying these tanks must also meet certain minimum safety requirements. If containers (up to 3000-gallon capacity) are mounted on farm wagons or farm equipment for field application, similar, though slightly less stringent, requirements are specified in the code.

The quality, size, and tolerances for hoses used in ammonia transfer are regulated to a considerabie extent. The hose must be subjected to a series of tests before it can be accepted and certified.

Even though the ANSI 61.1 standard appears to be comprehensive, it does not cover all conceivable conditions. Compressed Gas Association (CGA) publication (3977), which extensively quotes the ANSI standard, often goes into more detail and covers certain aspects not found in the ANSI standard, e.g., ruies concerning pipelines, barges, and tankers.

Barges and tankers for the transportation of ammonia must be especiaily designed, built, and approved by the U.S. Coast Guard for this service. Barges are 1 imited to inland waterways, tankers to ocean-going routes. Both require 
specially-equipped terminals for loading and unloading. Ammonia transported by water is generally refrigerated to $-33^{\circ} \mathrm{C}$. Barge capacity is limited to two tanks for a total of 2500 tons. Tankers have a maximum capacity of 25,000 tons. Both types of vessels are required to carry onboard refrigeration equipment for keeping the ammonia at $-33^{\circ} \mathrm{C}$. The barges and tankers must be inspected and requalified every 8 years. Loading and unloading of the vessels has to be performed according to Coast Guard regulations.

A1l pipeline operations in the U.S. are governed by the Natural Gas Pipeline Safety Act of 1968. This act was recently amended by the U.S. Congress (after extensive hearings) under Public Law 96-129 known as the "-pipeline Safety Act of 1979." Even though not specifically mentioned, pipelines carrying anhydrous ammonia would fall under the jurisdiction of this law, since Title 2 of the Act ${ }^{(a)}$ pertains to hazardous liquids which may, in the view of DOT, "pose an unreasonable risk to life and property when transported in pipeline facilities." This Act gives the Secretary of Transportation broad powers to enforce safe operational procedures in pipeline operations. A special Technical Hazardous Liquid Pipeline Safety Standards Comittee was established during 1980.

Under the 1968 and 1979 Acts, pipelines are specifically regulated by DOT, according to 49 CFR $195^{(b)}$ and, in the case of ammonia pipelines, are aljowed to carry only 1iquid (not gaseous) ammonia at ambient temperatures under pressure. Their maximum operating pressure is 1 imited to $500-1200$ psi for 6- to 8-in. pipe. The steels used for fabricating the pipe must conform with ANSI B31.4. Maximum throughput may reach 5,000 tons a day. Pumping stations and terminals for any ammonia pipeline are apparently not yet specifically covered by, the code, except for the general coverage extended by various codes to the components of the stations. Pipelines, originally built for petroleum products, may not be used for ammonia unless special permission is obtained from DOT. In the case of a serious accident, an immediate notice has to be given at a central telephone number and a written report has be submitted to DOT for each accident. An appropriate public education program has to be established by the pipeline

(a) Title 1 pertains to LNG only.

(b) This code covers transportation of any highly volatile liquid by pipelines, but is primarily intended for petroleum pipelines. It incorporates many other standards and specifications. 
carrier organizations so that in case of pipeline accidents, proper emergency procedures become known to the population living near pipeline installations.

\subsubsection{Safety Precautions for Amonionia Facilities}

Guides for appropriate safety $\mathrm{planning}$ in ammonia facilities have been compiled over the years by various organizations (Int. Inst. Anmonia Refrigeration 1977, Air Conditioning and Refrigeration Business 1978, Hale 1980). The supervisors of large ammonia plant storage facilities are generally well aware of their responsibility for assuring safe procedures in operating such facilities. This not only includes the protection of the mechanical equipment itself, but also the protection of the people working and living in the area. For this reason, all items of equipment are inspected periodically. Also, there is continuous upgrading of the operator training, and plans are drawn up for handling accidents and other emergencies. Such plans are usually quite detailed in that they specify the appropriate steps and the proper sequence (e.g., shutting off certain valves, pumps, etc.) to be taken in various types of emergencies.

A minimum amount of wel1-maintained safety equipment (such as protective clothing and breathing apparatus) is kept readily available for each person in the area. Safety drills are held frequently to familiarize the personnel with the emergency procedures and the proper handling of the safety equipment, since it is important that people act quickly and make no mistakes in case of an emergency.

A serious safety problem can arise if the vapor cloud from a major ammonia spill would drift into an adjacent inhabited area, because it is not always possible to locate an ammonia facility within a completely isolated region (Kletz 1980). Thus a quick alert of the people in the vicinity is very important. Whether adequate warning systems for such emergency situations al ready exist is quite doubtful. However, the technology (radio communication aided by microprocessors) is on hand to set up such systems, as demonstrated recently by the Dow Chemical Company at one of their major chlorine manufacturing plants (Melancon 1980). A practically identical system could apparently serve an ammonia installation equally well. It is suggested here that additional thought be given to such a possibility. 


\subsection{RELEASE CONTROL}

Major ammonia spills are considered serious accidents since ammonia usually evaporates rapidly and the spreading vapor cloud is a serious health hazard with even lethal consequences if concentrations exceed $27 \%$. For the case of an accidental ammonia spill, first aid equipment must be readily available. Employees handling ammonia must be educated on how to respond to the potential accident situations. The employer must have a written procedure describing actions to be taken in various types of emergency.

Warm liquid ammonia under pressure evaporates explosively if its containment experiences a major rupture. It can be assumed (depending on prevailing conditions) that roughly one-half of the ammonia is evaporated in this initial flash. Because the evaporation process is endothermic, the remaining liquid cools off rapidly, possibly well below its normal boiling point $\left(-33^{\circ} \mathrm{C}\right)$. This cooling will automaticaliy reduce the rate of further evaporation to a large degree.

If 1 iquefied ammonia $\left(-33^{\circ} \mathrm{C}\right)$ contained at atmospheric pressure spills into the open, there is much smaller initial evaporation flash. The evaporation rate will again rapidly decrease as the liquid ammonia cools down below its normal boiling point. Experimentally, liquid temperatures as low as $-60^{\circ} \mathrm{C}$ have been measured. Theoretically, under strictly adiabatic conditions, a temperature as $10 \mathrm{w}$ as $-71^{\circ} \mathrm{C}$ could be reached (Blanken 1980).

In actual situations, evaporation rate depends on the prevailing conditions, such as ambient temperature, wind speed, temperature and heat conductivity of the ground, depth of spilled ammonia, presence of water, e.g., rain. Because of the exothermal nature of hydration of ammonia with water, any contact of liquid anmonia with water will increase its evaporation rate. Thus, spills of ammonia into bodies of water could be much more hazardous than spills on land. For the same reason, it should not be attempted to "dilute" ammonia spills with water in the hope of reducing the vapor concentration. Just the opposite would be the case. The only useful role which water could play in reducing the hazardous conditions resulting from an ammonia spill would be to spray water into the developing ammonia cloud, but trying to avoid, at the same time, any water from reaching the liquid ammonia on the ground. 
Even though not yet specifically required by the code, ammonia storage tanks are cormonily surrounded by dikes, so that in case of a tank rupture the spilled ammonia is contained in a closely-limited area. Such an accident situation can fairly easily be kept under control by spraying a special foam onto the ammonia surface which then would reduce the ammonia evaporation rate by a factor of $u 3$ to 5 . This may be more than sufficient to keep the still-escaping vapor buoyant enough to make it rapidily rise at a rather steep angle instead of lingering at ground level. Tests have actually shown that the rate of evaporation can be reduced by proper foam application to such an extent that it would become practically harmless for humans, even if they would lean directly over the foam-covered ammonia (Norman and Dowell 1979). It would also be feasible to dispense the foam automatically from a suitably-placed foam storage container at the moment when the spill occurs. Such foam-dispensing systems have been installed in diked LNG storage facilities, and it would seem reasonable to require foam-dispersing systems for anhydrous storage also. It is important, however, that a nonaqueous foam be used for ammonia. Suitable foams are avaj1able in the U.S. (Clark 1979). With an amonia spill contained in a tight area and covered by foam, it would be quite straightforward to pump the ammonia into an empty storage vessel. 


\subsection{KNOWLEDGE GAPS AND RECOMMENDED R\&D}

The preceding chapters provide an overview of ammonia industry operations including production, distribution, storage, and consumer uses. Current knowledge of ammonia properties and release phenomena is summarized together with a review of release prevention and control practices. A1l of this supports the perspective that the ammonia industry is a mature industry supplying an essential material in a generally safe and reliable manner. A vast quantity of experience, technology and operational expertise has been developed in over 50 years of service. The combined influence of industry-generated standards and governmental regulations promotes safe and environmentally acceptable practices and tends to minimize the incidence and consequences of accidentai ammonia release.

Against this favorable background, ammonia is statistically involved each year in a few spectacular accidents that receive widespread news media coverage. It is also spilled in more numerous but smaller incidents that receive less publicity. The news media coverage emphasizes the casualties and the damage and potential hazards of these events. Therefore there is a public concern regarding current ammonia safety and environmental control practices in addition to the needs stemming from newer uses and applications. The assessments contained in Chapters 3 through 6 indicate that there are some notable gaps in knowledge and additional needs to further consider the release prevention and control practices. These indications suggest that additional information is needed as a basis for regulatory decision-making.

The DOE Liquefied Gaseous Fuels Safety and Environmental Control Assessment Program has the purpose of expanding the knowledge and data bases that support such decision-making activities. In the last four years the DOE Program has focused on LNG. This study was commissioned to assist the ESED in planning future R\&D in a Ammonia Subprogram. The study scope was broad enough, however, to include recommendations that relate to the R\&D activities of other agencies and the ammonia industry.

The following sections contain specific recommendations resulting from this assessment. Efforts are recommended that are appropriate for the DOE Subprogram and as R\&D by other agencies and the ammonia industry. 


\subsection{CURRENT AMMONIA USE SYSTEM}

It is recomimended that additional work be conducted to enhance the understanding of the causes of explosions (BLEVES) that occur in ammonia storage and transportation tanks. The research should focus on probable causes such as galvanic corrosion, stress corrosion cracking, improper maintenance and others. The research results would provide the basis for mitigation actions and improved codes and regulations. Since these problems are not unique to ammonia, the focus on ammonia should be done in the context of a broader study covering flammable and nonflammabie materials.

\subsubsection{Galvanic Corrosion}

The effects of galvanically coupled dissimilar metais in both liquid and vaporous ammonia should be studied and potential corrosion inhibitors should be tried out. Metal pairs to be included in such tests should include titanium coupled to steel, various copper-nickel alloys coupled to steel, aluminum and aluminum alloys coupled to steel, various stainless alloys coupled to steel etcetera. Tests should be conducted with and without welds and stress loads. Also, the potentially beneficial effect of aluminum oxide coatings on certain metals for reducing galvanic corrosion should be investigated.

\subsubsection{Stress Corrosion Cracking}

The stress corrosion cracking (SCC) resistence of certain commercial grades of steel, in the absence of corrosion inhibitors, should be considered. Since the water which is usually added to ammonia as an inhibitor can be lost in the evaporation/condensing cycles when anmonia is used as a working fluid, new inhibitors should be developed that are not affected by such cycles. The importance of oxygen in the SCC mechanism should be determined and hydrazine should be examined as a material useful to preventing SCC.

\subsubsection{Explosion Hazards}

The stress corrosion cracking (SCC) resistance of certain commercial grades of steel, in the absence of corrosion inhibitors, should be considered, since they can occur with other liquefied gases as well. In fact, such explosions occur less often in ammonia than other gases such as LPG and chlorine. No 
specific research program is recommended for ammonia but rather the results from such work for other liquefied gases should be applied to amnonia as well.

Although the question of $\mathrm{NH}_{3}$ fires has been controversial our conclusions are that ammonia spill fires are practically impossible. Ammonia flash fires can occur but they are expected to be of short duration (seconds). Therefore no $R \& D$ recomendations are presented for these areas.

\subsubsection{Accident Statistics}

A comprehensive data collection and analysis system should be developed for ammonia accident statistics. At the present time several special interest organizations and agencies collect certain types of information depending on the size of the spill and the extent of human injury. A common system would allow more accurate recording and retrieval of accident information and provide a sound data base for evaluating consequences as a function of many different parameters including occupation, type of industry, nature of injury, extent of injury, exposure conditions, type of accident, and others. Such an analysis would provide a method for identifying areas where improved safety and environmental control practices are required.

\subsubsection{Dispersion of Ammonia}

Additional research should be conducted to perfect the ability to describe the generation and dispersion of negatively buoyant ammonia plumes. Both pressurized and refrigerated ammonia spills have the potential to produce negatively buoyant plumes that linger and result in high concentrations of ammonia at ground level. Current models can estimate concentrations within a factor of about 10 whereas with additional research this could be improved to within a factor of 2 or 3 or better. The current tests being conducted at China Lake by the U.S. Coast Guard may provide some of this needed information.

Some specific recommendations to be considered for this work include:

1. Develop a more sophisticated three-dimensional turbulent mixing model that would provide more accurate dilution profiles for the pressurized release, 
2. Use carefully controlled experiments to quantify the variables controlling the degree of atomization of liquid ammonia during spills,

3. Study pressurized anmonia flow through a sharp-edged orifice under ambient conditions to determine what portion of the ammonia becomes an aerosol and what portion falls directly to the ground,

4. Conduct controlled experiments to collect data on wind evaporation of ammonia and use it to verify available evaporation models, and

5. Study spills to determine the partitioning ratios in water and the subsequent cloud characteristics.

\subsubsection{Ecological Effects}

In the evaluation of the effects of anmonia on aquatic and terrestrial organisms, several areas were identified where important information does not exist. Two important areas are 1) the determination of the life stages of plants and animals that are most sensitive to ammonia and 2) evaluation of the toxicity and sublethal effects on these organisms. For example, in the marine environment the toxicity and sublethal effects of ammonia to eggs and larvar stages of organisms needs to be determined because insufficient data exists with which to evaluate these effects. In addition research is needed into the effects of ammonia on community stability and resiliency as the result of a spill. Currently it is not known if spills of anmonia would cause irreversible changes to an ecological community or in what time frame the community could expect to recover from the effects of the spill. Expansion of data bases in these areas would help to refine and expand the evaluation of the effects of ammonia spilis.

\subsubsection{Health Effects}

In regard to human health effects from accidental exposure there are two areas needing additional work. First, more case studies are needed to more clearly define the long-term health problem associated with acute toxic exposures. Secondly, exposure time and concentration guidelines need to be developed for use in defining emergency procedures in the event of major spills in populated areas. 


\subsection{ANTICIPATED SAFETY PROBLEMS WITH NEW APPLICATIONS OF AMMONIA}

The following paragraphs discuss safety and environmental problems that might arise as a result of new applications. The key knowledge gaps are identified for each application and in some cases specific research recomendations are presented.

\subsubsection{Anmonia as a Fuel}

When using ammonia as a fuel in combustion engines the possibility of a liquid spill exists, for which the consequences have al ready been discussed. This could possibly represent a major hindrance in a widespread use of ammonia as automobile fuel. Even for a major car accident resulting in a fuel tank rupture, a fuel fire would not occur as easily as with gasoline. The rapid vaporization of the toxic ammonia would present a serious hazard, particularly in congested traffic situations and in densely populated areas. Fortunately, however, the quantities involved in such accidents would be rather small (maximum 20 gallons), so that unimpaired people could probably run away from the spill. Although it appears to be technically feasible to construct rupture-proof tanks or to reduce the leak rate significantly if a tank does rupture, there are no current plans to develop these solutions. Thus, if the use of ammonia as automobile fuel is seriously considered in the future, this will be the most serious safety problem to be resolved.

In some of the early tests for the U.S. Army's "Energy Depot" project, it was concluded that a substantial amount of $\mathrm{N}_{X}$ emissions would result from burning $\mathrm{NH}_{3}$ in combustion engines. In later investigations, this has been shown to be incorrect. In fact, if the combustion process is performed under proper conditions, ammonia appears to be one of the "cleanest" fuels available and with respect to $\mathrm{NO}_{x}$ it is ahead of gasoline, methane, propane, methanol, and even hydrogen.

Since the combustion of ammonia does not generate any $\mathrm{CO}_{2}$ either, it would not contribute to the wel1-publicized dangers of $\mathrm{CO}_{2}$-enrichment of the atmosphere ("greenhouse effect"). Overall, from an environmental pollution viewpoint, ammonia would be a highly desirable fuel (Graves and Hodgson 1975). 


\subsubsection{Ammonia in Binary Cycle Applications}

In binary cycle applications ammonia is contained under high pressure (up to $2500 \mathrm{psi}$ ) as a vapor and as a liquid. Obviously, it is possibie that leaks or even ruptures can occur in these systems (e.g., in the heat exchanger, in the pump, or in the piping, etc.) as they might occur in steam systems. However, since the corrosion behavior of ammonia vapor loops at high temperatures is not well known, such loops might involve some safety hazards that cannot be estimated very well at the present time.

It is therefore recomended that research be conducted into materials compatibility with $\mathrm{NH}_{3}$ at medium-to-high temperatures $\left(2300^{\circ} \mathrm{F}\right.$ to $\left.\sim 500^{\circ} \mathrm{F}\right)$, particularly in respect to stress corrosion cracking. Loop materials that are exposed to high pressures and temperatures and that also undergo temperature cycles could accumulate stresses superimposed on the stresses developed by the internal pressurization of the 10op. Since $\mathrm{NH}_{3}$ becomes increasingly dissociated into $\mathrm{H}_{2}$ and $\mathrm{N}_{2}$ with temperature, the possibility of hydrogen embrittlement and hydrogen permeation must also be considered as a potential safety problem. To protect against overpressure, safety valves are provided. They are supposed to discharge the ammonia through a stack into the atmosphere where it would dissipate gradually. The addition of ammonia to the atmosphere by man-made means is considered to have negligible effects only.

As in steam circuits, there is the possibility that a circulator or turbine might throw a blade, which then could result in a major leak. The problem of such leaks or ruptures has not been specifically discussed in the literature.

If a major break (rupture) in the loop, e.g., in the main pipe, would occur, the consequences of such an accident could be severe. If the break occurs inside a building, the building would probably be filled with a high concentration of ammonia vapor in a matter of seconds, since the vapor would discharge with supersonic speeds. Thus, there is the possibility that people in the building might not be able to escape in time. Because of the high pressure and relatively high temperature in the loop, most of the liquid $\mathrm{NH}_{3}$ portion would flash almost immediately, which would rapidly generate a large vapor 
cloud. There is also the possibility that the vapor cloud would explode and cause a flash fire if ignition sources are present. For this reason, all switches and lighting fixtures must be explosion-proof.

It must be realized, therefore, that the conditions in an ammonia power generating facility basically involve more serious hazards than those in a steam generating plant or those for merely keeping ammonia in storage or using it for refrigeration purposes. The amount of ammonia in the circuit of a large power station could easily amount to 2100 tons.

Since tube failures are quite common in steam generators of conventional and nuclear power plants, it must be expected that in corresponding ammonia vapor generators similar failures can also occur. In the case of the steam generators or heat exchangers using water as the heat transfer liquid, such problems are usually caused by corrosion and vibration. If ammonia were used instead of water, essentially the same causes would remain responsible for potential failures. As a consequence of such failures, ammonia could leak either into the primary loop (e.g., helium loop in the case of a gascooled nuclear reactor) or leak into the atmosphere. Apparently, no extensive failure analyses have been done for cases involving ammonia.

For the High Temperature Gas Reactor (HTGR) it can be surmised that if $\mathrm{NH}_{3}$ were to get into the helium circuit, it would inevitably enter the reactor itself where it would be heated up to $u 1500^{\circ} \mathrm{F}$ and would dissociate largely into $\mathrm{H}_{2}$ and $\mathrm{N}_{2}$. The $\mathrm{H}_{2}$ component could cause embrittlement of the steel containment and thus could potentially make the reactor unsafe for further operation. Even though the reactor is equipped with a helium purification system, it is doubtful whether such a system would be effective and fast enough in the case of a massive ammonia leak. Presently, these reactors are only in the study phase. Therefore, there is no danger of this type of accident happening in the foreseeable future.

When used in a bottoming cycle application, if ammonia leaks into the main water cycle, its immediate effect would be a change in the water chemistry (e.g., in the $\mathrm{pH}$ value) of this cycle, which in turn could cause long-term corrosion problems. Since, so far, the proper treatment of water in steam generator 
applications has been more art than science, it is hard to predict what the uitimate effect of ammonia contamination would be. It is likely that only practical experience will provide a reliable answer.

\subsubsection{Amonia in OTEC Systems}

Safety requirements and precautions for ammonia aboard OTEC plants have been found not to be more severe than for those existing within the ammonia manufacturing, fertilizing, and refrigeration industries. On the contrary, they might be less so since the armonia is only under moderate pressures (up to 150 psi, corresponding to warm sea water of less than $100^{\circ} \mathrm{F}$ ), and the total amount with in the closed loop is limited. Problems of inadvertent leakage can occur as a result of metal corrosion but do not seem to present a serious safety hazard.

Storage of large quantities of ammonia aboard should not generate any problems which would be different from those encountered on land-based facilities. In fact, a remote offshore facility appears to be fundamentally safer, just because of its remoteness from populated areas. For various technical, environmental, and economic resons it has been proposed that even common ammonia plants be buitt on barges or floating platforms. Even though the possibility of large spills (thousands of tons) of ammonia from storage containers aboard such floating manufacturing plants into the sea is very remote, the near-term (days) results of such an accident on the marine environment would be the killing of all fish and higher living organisms over a wide area; however, since in the long term (months or years) the amuionia has a fertilizing effect on plant life and zooplankton, the end result of an ammonia spill might even be beneficial.

\subsubsection{Ammonia in Refrigeration Technologies}

Ammonia has been used for refrigeration purposes for such a long time that there has been a substantial amount of experience with accidents in ammonia refrigeration plants. Of the explosive accidents that have occurred in such plants, most occurred in mechanical compressor plants, whereas absorption plants were hardly affected at a]1. As these accidents were reported in the press, it was usually implied that ammonia was the source of the explosion. However, 
ammonia, by itself, will hardly burn or ignite. What appears to have caused the explosions is the "foul" gas, which usually appears and collects in certain parts of an ammonia refrigeration system. The "foul" gas originates from a mixing and reaction of ammonia with the lubricating oil in the system. It contains some hydrogen and some hydrocarbons. It also appears possible that some therma dissociation of $\mathrm{NH}_{3}$ may occur in places of higher temperatures. It has been shown that in certain systems these foul gases are combustible but that it is safe to vent them into the open since only small amounts are involved. Moisture in the system seems to favor the generation of foul gas. As far as could be determined, nobody has ever tried to determine the exact chemical composition of the foul gas, which seems to be different with different installations.

Since in most compressors some mixing of lubrication oil with the ammonia is unavoidable, the compressor is usually followed by an oil separator unit, which returns the separated oil to the compressor. However, the (usually short) pipe connection between the compressor and the oil separator still represents a source for potential explosions. Just such an incident occurred in october 1979 in a refrigeration system of a Florida shrimp processing plant. The connecting pipe failed and the escaping vapor's high pressure anmonia-oil mixture hit the fluorescent lights on the ceiling and then ignited. The ensuing fire caused damage of about $\$ 10,000$, but no one was injured.

Present knowledge indicates that because ammonia is such a powerful solvent, any contact or mixing with certain organic materials may result in the development of highly combustible gases. It is, therefore, advisable to avoid any contact of the ammonia with these materials.

It is reconmended that a list be compiled for organic substances which should not be used in contact with ammonia. Laboratory tests will probably be required for the evaluation of the materials. The various conditions for generating "foul" gas should also be investigated in these tests because it is conceivable that, e.g., an oil mist, suspended in ammonia vapor, can form an explosive mixture, even if the oil is not soluble in $\mathrm{NH}_{3}$. 


\subsubsection{Arritonia Used for $\mathrm{NO}_{\mathrm{x}} \mathrm{x}$ Reduction}

In the most promising and furthest-developed method for removing $\mathrm{NO}_{\mathrm{x}}$ from boiler flue gases, $21 \mathrm{~mol} \mathrm{NH}_{3} / 1 \mathrm{~mol} \mathrm{NO}$ is consumed. Since $\mathrm{NO}_{\mathrm{x}}$ concentration in the exhaust is $2600 \mathrm{ppm}$ max. before treatment, the amount of $\mathrm{NH}_{3}$ required is reiatively low $\left(2 \mathrm{~kg} \mathrm{NH}\right.$ for $25000 \mathrm{~m}^{3}$ of exhaust gas). It cannot be expected that all $\mathrm{NH}_{3}$ will react in the process because mixing can never be perfect. Therefore, some excess ( $20 \%$ ) ammonia is introduced which would eventually be discharged unreacted into the atmosphere, unless special catalytic converters were installed which would reduce essentialiy all remaining $\mathrm{NH}_{3}$ to $\mathrm{N}_{2}$ and $\mathrm{H}_{2} \mathrm{O}$. Such converters, however, are expensive and are not deemed necessary from an environmental pollution standpoint. Because flue gases are still quite hot and are discharged through a stack, all ammionia contained therein will be quite buoyant and will rapidly rise to higher altitudes in the atmosphere without any possibility of lingering at ground level. Besides, the expected concentrations of $\mathrm{NH}_{3}$ in the stack gases are $2.100 \mathrm{ppm}$ and thus would not represent a health hazard, anyway.

A gradual increase of the ammonia level in the earth's atmosphere is not expected, even if all power plants were to be outfitted with such an $\mathrm{NO}_{x}$ reduction system, since there are other counteracting effects present (e.g., uptake of ammonia by plants, neutralization by acid rain, washout by any type of rain, etc.) which tend to maintain an equilibrium of the ammonia level in the atmosphere. Compared to natural sources of atmospheric ammonia the man-made ammonia contribution is small and is expected to remain so.

Obviously, the usual safety hazards connected with liquid ammonia are present in $\mathrm{NO}_{x}$ treatment facilities as well, but they are not considered to be more critical than at any other ammonia storage facility. It is, therefore, expected that existing codes and regulations for handling ammonia will be applied to any plants using $\mathrm{NO}_{x}$ treatment. It would also be advisable to install an $\mathrm{NH}_{3}$ monitoring device at the stack exit so that any deviation from the regular low ammonia discharge rate would be immediately detected. 


\subsubsection{Ammonia in Other Applications}

The use of amnonia for removing $\mathrm{SO}_{2}$ from flue gases does not seem to involve any basically different or new technological processes which potentially could result in environmental or safety problems.

The use of ammonia in the various methods of coal preparation is stili under active development, and no standard method has evolved yet. Therefore, a hazard assessment at this time is premature. Potentially, however, there exists the possibility that relatively large amounts of liquid ammonia could evaporate and escape into the open atmosphere if no adequate precautions are taken. It is recommended, therefore, that developments in this field be monitored in the future so that potential environmental and safety problems could be pointed out as early as possible.

The same arguments are applicable to any potential future use of ammonia in water-splitting schemes. 


\section{REFERENCES}

Admiraal, W. and H. Peletier. 1980. "Distribution of Diatom Species on an Estuarine Mud Flat and Experimental Analysis of the Selective Effect of Stress." J. Exp. Bio. Ecol 46(2/3):157-176.

Ahrendh, J. and H. D. Baehr. 1979. The Thermodynamic Properties of Anmonia. VOI-Forsch-Heft 596, (in German).

AHSRAE Handbook. 1980. "Refrigeration Systems Practices, Section III." In ASHRAE Handbook: Systems. American Society of Heating, Refrigerating, and Air Conditioning Engineering, New York, New York.

Air Conditioning and Refrigeration Business. 1978.

Alabaster, J. S. et a1. 1979. "The Effect of Dissolved Oxygen and Salinity on the Toxicity of Ammonia to Smolts of Salmon, Salmo salar." J. Fish. Biol. $15(6): 705-712$.

Aldrich, R. G. 1977. "Spontaneous Fracture of Coal." Fuel 56:345.

Alleman, R. T., B. M. Johnson and G. C. Smith. 1976. Ammonia as an Intermediate Heat Exchange Fluid for Dry-Cooled Towers. PNL-SA5997, Pacific Nor thwest Laboratory, Richland, Washington.

Anderson, K. B. 1978. Rapid Assessment of Water Quality Using the Fingernail Clam, Musculium transversum. Research Report, ITlinois University Water Resources Center.

Anhydrous Ammonia. 1977. Compressed Gas Association, 6th ed., New York, New York.

App1, M., K. Feind and $W$. Liebe. 1976. "Ammonia Shift Converter Failure." Ammonia Plant Safety 19:40-45.

Arnas, 0. A. 1978. "Dehumidification by Solar Energy." In Alternate Energy Sources, ed. T. N. Veziroglu, pp. 781-794. McGraw-Hi11, New York, New York.

Baker, C. R. and R. L. Shaner. 1978. "A Study of the Efficiency of Hydrogen Liquef action." Int. J. Hydrogen Energy. 3:321-334.

Ba11, W. L. 1970. "A Review of Atmospheric Ammonia Research Study." Ammonia Plant Safety. 12:1-7.

Barnett, E. and C. L. Wilson. 1960. Inorganic Chemistry. 2nd edition, p. 362 , J. Wiley \& Sons, New York, New York.

Barton, L. V. 1940. "Toxicity of Ammonia, Chiorine, Hydrogen Cyanide, Hydrogen Sulphide and Sulphur Dioxide Gases. IV. Seeds." Contrib Boyce Thompson Institute, 11:357-363. 
Bartz, J. A. et a1. 1976. Heat Rejection by Dry Cooling in Steam-Electric Power Stations. Report prepared by Union Carbide Corporation (LINDE) for EPRI.

Basson, P. W., J. T. Hardy and V. Lakkis. 1976. "Ecology of Marine Macroalgae in Relation to Pollution Along the Coast of Lebanon." Acta Adriatica 18(19):307-325.

Becker, C. D. and T. 0. Thatcher. 1973. Toxicity of Power Plant Chemicals to Aquatic Life. U.S. Atomic Energy Commission, WASH-T249, prepared by Pacific Northwest Laboratory, Richland, Washington.

Benedict, H. M. and W. H. Breen. 1955. "The Use of Weeds as a Means of Evaluating Vegetation Damage Caused by Air Pollution." Proceedings of the Third National Air Pollution Symposium. pp. 177-190, Pasadena, Calffornia.

Biederman, N. P. et al. 1978. Chemical, Electrochemical and Thermal Bridges for Transmission of OTEC Power. CONF-780236-2, National Technical Information Service, Springfield, Virginia.

BTanc-Feraud, P. and J. Fleury. 1978. "Armonia Binary Cycle: A Solution for Siting Power Plants at Totally Dry Sites." C\&M 34.

Blanken, J. M. 1980. "Behaviour of Ammonia in the Event of a Spillage." Anmonia Plant Safety 22:25-34.

Blouin, G. M. 1979. "Use of Ammonia in Agricuitural and Chemical Industries." Ammonia, Vol IV, pp. 81-184, Marcel Dekker Inc., New York, New York.

Boeltner, J. C., F. Gaillard-Cusin and H. James. 1978. "Attempt to Remove Nitric Oxide in Burnt Gases through Radical Interaction Kinetics." C. R. Hebd. Seances Acad. Sci., Ser. C, 287, No. 5:155-158. (in French).

Brennan, E. I. et al. 1962. "Ammonia Injury to Apples and Peaches in Storage." Plant Dis. Rep. 46:792-795.

Brown, A. C. and A. B. Currie. 1973. "Tolerance of Bulla digitalis (Prosobranchia) to Solutions of Ammonium Nitrate in Natural Sea Water." S. Afr. J. SCi. $69: 219-220$.

Brown, N. J. et a . 1979. Characterization Studies of the Selactine Reduction of $\mathrm{NO}$ by $\mathrm{NH}_{3}$. LBL-1D254, [awrence Berkeley Laboratory, University of California, Berkeley, California.

Bruggeman, A., L. Meynendonek and W. R. A. Goosens. 1978. "Elimination of $\mathrm{NO} X$ by Selectine Reduction with $\mathrm{NH}_{3}$." In Proceedings of the 15th DOE Nucl. Air Cleaning Conference, Vol I, pp. 6T4-625. U.S. Department of Energy, Washinton, D.C.

Buckley, W. and H. Husa. 1962. "Combustion Properties of Amonia." Chemical Engineering Progress, 58(2). 
Buivadas, L. J. 1980. "Coal to $\mathrm{NH}_{3} . "$ Presented at the 1980 AICHE Symposium on Ammonia Plant Safety.

Bureau of ACcident Investigation. 1969. Chicago, Burlington, and Quincy Railroad Company Train 64 and 824 Derailment and Collision with Tank Car ExpTosion, Crete Nebraska, February 18, 1969. NationaT Transportation Safety Board, Washington, D.C.

Bureau of Accident Investigation. 1973. Mid America Pipeline System Anhydrous Armonia Leak, Conway, Arkansas, December 6, 1973. PB-238 158, NationaT Transportation Safety Board, Washington, D.C.

Bureau of Accident Investigation. 1976a. Railroad Accident Report: Chicago and North Western Transportation Company, Freight Train Derailment and Col1ision, Glen Ellyn, Illinois, May 16, 1976. PB-267 939, NationaT Transportation Safety Board, Washington, D.C.

Bureau of Accident Investigation. 1976b. Highway Accident Report: Transport Company of Texas, Tractor - Semi-trailer (Tank) Collision with Bridge Column and Sudden Dispersal of Anhydrous Ammonia Cargo, I-6T0 at South Freeway, Houston, Texas, May 1T, 1976. PB-268 25T, National Transportation Safety Board, Washington, D.C.

Bureau of Accident Investigation. 1977. Railroad Accident Report: Louisville and Nashville Railroad Company Freight Train Derailment and Puncture of Anhydrous Ammonia Tank Cars at Pensacola, Florida, November 9, 1977. $\overline{\mathrm{PB}}-284$ 335, National Transportation Safety Board, Washington, D.C.

Bureau of Accident Investigation. 1979. Railroad Accident Report: Louisville and Nashville Railroad Company Freight Train Derailment and Puncture of Hazardous Materials Tank Cars, Crestview, Florida, Apri1 8, 1979. PB-301 165, National Transportation Safety Board, Washington, D.C.

Burkhart, J. A. and N. F. deGroot. 1975. An Analys is of Workers' Compensation Case Data in Agriculture. NTIS PB80-1939T5. Utah Biomedical Test Laboratory, Salt Lake City, Utah.

Burkhart, J. A., N. F. deGroot and L. B. Wolferson. 1970. Second Annual Report: on Occupational Illness and Injury Data in AgricuTture. NTIS PB80192636. Utah Biomedical Test Laboratory, Salt Lake City, Utah.

Burnett, T. A. and H. L. Faucett. 1979. Impact of Anmonia Utilization by NOx Flue Gas Treatment Processes. EPA-600/7-79-017, National Technical Information Service, Springfield, Virginia.

Campbel1, C. L. et al. 1958. "Affect of Certain Chemicals on the Flavor of Brewed Coffee." Food Resources, 23:575.

Carden, P. 0. 1977. "Energy Corradiation Using the Reversible Ammonia Reaction." Solar Energy 19:365-378. 
Carden, P. 0. and 0. M. Williams. 1978. "The Efficiencies of Thermochemical Energy Transfer." Int. J. Energy Res. 2:389-406.

Carmichae], A. D. 1979. Ocean Thermal Energy Conversion: A State-of-the-Art Study. EPRI-ER-1113-SR, Electric Power Research Institute, PaTo Alto, California.

Casazza, J. A. et al. 1975. "Does Hydrogen Have a Role in Future Energy Systems." Trans. 95th World Energy Conference, X:191-217.

Casey, G. B. 1975. "Rupture in Armonia Shift Conversion Unit." Ammonia Plant Safety 18:103-108.

Chajt, I. L. and G. Marchmont. 1978. Study Report for an $1100 \mathrm{MW}$ Power Plant Heat Rejection System Using Ammonia Dry Cooling Towers (Prepared for EPRI). Burns \& Roe, Richland, Washington.

Chan, M. and T. F. Yen. 1979. "Fracturing of 017 Shale by Ammonia." Presented at ACS Meeting, September, 1979.

Clark, W. 0. 1979. "Using Fire Foam on Ammonia Spills." Loss Prevention $13: 40-41$.

Clinch, J. M. 1978. "Major Factors in OTEC Power Cyc Te Design". In ATternative Energy Sources, ed. T. N. Veziroglu, pp. 1557-1569. McGraw-Hi7T, New York, New York.

Cohen, R. and E. J. Tschupp. 1978. "Analysis of Various OTEC Emissions." In Alternate Energy Sources, ed. L. Verziroglu, pp. 1483-1502.

Combs, S. K. 1978. An Experimenta? Study of Heat Transfer Enhancement for Anmonia Condensing on Vertical Tubes. ORNL 5356, Oak Ridge National Laboratory, 0ak Ridge, Tennessee.

Compressed Gas Association (CGA). 1977. Anhydrous Ammonia. 6th ed. Pamphlet G-2, New York, New York.

Corneil, H. G. and F. J. Hinzelmann. 1980. "Hydrocarbon for Future Refining." Hydroc. Proc. pp. 85-90.

Czuppon, T. A. and L. J. Buividas. 1979. "Which Feedstock for Ammonia?" Hydro. Proc. pp. 197-200.

Dao, K. et al. 1977a. Performance of an Experimental Solar-Driven Absorption Air Conditioner: AnuaT Report 197571976. LBL-591], Lawrence Berkeley Laboratory, University of California, Berkeley, California.

Dao, K. et al. 1977b. Performance of an Air-Cooled, Ammonia-Water Absorption Air Conditioner at Low Generator Temperatures. LBL-5224, Lawrence Berkeley Laboratory, University of California, BerkeTey, California. 
Dao, K. 1978a. A New Absorption Cycle: The Single-Effect Regenerative Absorption Refrigeration Cycle. LBL-6879, Lawrence Berkeley Laboratory, University of California, Berkeley, California.

Dao, K. 1978b. Conceptual Design of an Advanced Absorption Cycle: The Double-Effect Regenerative Absorption Refrigeration Cycle. LBL-8405, Lawrence Berkeley Laboratory, University of California, Berkeley, California.

Dao, K. et al. 1980. Development of Solar-Driven Absorption Air Conditioners and Heat Pumps. LBL-T077T, Lawrence Berkeley Laboratory, University of California, Berkeley, California.

Datta, R. S. and P. H. Howard. 1978. Characterization of the Chemical Comminution of Coal (Final Report). FE-2520-4.

Datta, R. S. et a1. 1976. Feasibility Study of Pre-Combustion Coal Cleaning Using Chemical Cominution (Final Report). FE-1777-4.

DeManche, J. M. et al. 1979. "The Rapid Response of the Marine Diatom Skeletonema costatum to Changes in External and Internal Nutrient Concentration." Mar. Biol. 53:323-333.

Dodd, K. T. and D. R. Gross. 1980. "Ammonia Inhalation Toxicity in Cats: A Study of Acute and Chronic Respiratory Dysfunction." Arch. Environ. Health $35(1): 6-14$.

Dugdale, R. C. 1967. "Nutrient Limitation in the Sea: Dynamics, Identification and Significance." Limnol and Oceanog. 12:685-695.

Dugdale, R. C. and J. J. Goering. 1967. "Uptake of New and Regenerated Forms of Nitrogen in Primary Productivity." Limnol and Oceanog. 12:196-206.

Dugger, G. L. and E. J. Francis. 1977. "Design of an Ocean Thermal Energy Plant-Ship to Produce Ammonia via Hydrogen." Int. J. Hydr. Energy 2:237-249.

Dugger, G. L. et a1. 1977. "Experiments on and Design of Low-Cost Aluminum Heat Exchangers for OTEC Plant Ships." In Proceedings of the 4th Annual Conference on OTEC, pp. vi-iii-123.

Dugger, G. L., E. J. Franc is and W. H. Avery. 1978. "Technical and Economic Feasibility of Ocean Thermal Energy Conversion." Solar Energy 20:259-274.

Eisenstadt, M. et al. 1959. Solar Air Conditioning With an Antmonia-Water Absorption Refrigeration System. ASME Paper 59-A-276, American Society of MechanicaT Engineers.

Eitzen, T. S. et a1. 1979. Characterization of N0x Removal Through Ammonia Addition. LBL-8049, Lawrence Berkeley Laboratory, University of California, Berkeley, California. 
Elliott, D. E. and H. C. Fischer. 197l. "Open-Cycle Ammonia Refrigeration." ASHRAE J.:55-60.

Energy Research and Technology. 1979. "Power Generating Ocean Platform." Energy Resource \& Tech. 1(2):5.

Eyster, C. 1964. "Micronutrient Requirements for Green Plants, Especially Algae." Algae and Man, ed. D. J. Jackson, pp. 86-119, Plenum Press, New York, New York.

Farber, E. A. et a1. 1966. "Operation and Performance of the University of Florida Solar Air-Conditioning System." Solar Energy 10(2):91-95.

Federal Register. 39, No. 125, Storage and Handling of Anhydrous Ammonia. OSHA, 1910.111.

Fenimore, C. P. 1980. "Destruction of $\mathrm{NO}$ by $\mathrm{NH}_{3}$ in Lean Burnt Gas." Comb. and Flame $37: 245-250$.

Fils, J. 1963. "Anatomicohistopathological Changes Induced in carp (Cyprinus carpio L.) by Ammonia Water. Part II. Effects of Subtoxic Concentrations." Actra Hydrobiol. 10:225-238.

Fleury, J. 1978. Economic Study of a PWR 1300 MW Power Station With a Water Vapor and Ammonia Binary CycTe.

Fogg, G. E. 1966. Algae Cultures and Phytoplankton Ecology. University of Wisconsin Press, Madison, Wisconsin.

Frank-Kamenetzky, D. 1939. "Calculation of Thermal Explosion Limits." ACTA Physicochimica U.R.S.S. 10(3).

Ganic, E. H. and J. Wu. 1979. Comparative Study of Working Fluids for OTEC Power Plants. ANL/OTEC-TM-1, Argonne National Laboratory, Argonne, Illínois.

Ganic, E. N. and J. W'u. 1980. "On the Selection of Working Fiuids for OTEC Power Plants." Energy Conv. \& Mgmt. 20:9-22.

Graves, R. L. and J. W. Hodgson. 1975. "Emissions from an Ammonia-Fueled Spark Ignition Engine." ASME paper 75-Wn/DGP-2.

Gregory, D. P. and R. B. Rosenberg. 1973. "Synthetic Fuels for Transportation and National Energy Needs." SAE paper 730520.

Griffiths, R. F. 1977. Critical Review of the USCG Report by Raj et al. (1974) on Spil1s of Liquid Anhydrous Ammonia onto Water with an A]ternative Assessment of the Experjmental Results. UKAEA Report SRD R GT.

Griffiths, R. F. and G. D. Kaiser. 1979. The Accjdental Release of Anhydrous Ammonia to the Atmosphere - A Systematic Study of Factors Influencing Cloud Density and Dispersion. UKAEA Report SRD R 154. 
Gro11, M. et a1. 1978. "Development of an Axial Groove Aluminum/Ammonia Liquid Trap Heat Pipe Thermal Diode." In Proceedings of the 3rd International Heat Pipe Conference, 78-418. American Institute of Aeronautics and Astronautics, New York, New York.

Haar, L. and J. S. Gallagher. 1978. "Thermodynamic Properties of Anmonia." J. Phys. Chem. Ref. Data $7(3): 635-792$.

Haas, W. R, et al. 1979. "Thermochemical Energy Storage System and Heat Pump." In Proceedings of Conference on Solar Energy and Solar Options, pp. $473--487$.

Hack, $W$. et a1. 1978. "Reaction Rates of $\mathrm{NH}_{2}$ Radicals with $\mathrm{NO}, \mathrm{NO}_{2}, \mathrm{C}_{2} \mathrm{H}_{4}$ and other Hydrocarbons." In Proceedings of 17th Symp. on Combustion,

pp. 505-513.

Haddock, S. R. and R. J. WIlliams. 1978. The Density of an Ammonia Cloud in the Early Stages of Atmospheric Dispersion." SRP R. 103, United Kingdom Energy Authority, Culcheth, Warrington, UK.

Hafezzadah, H. et al. 1977. "Preliminary Analysis of the Effects of Sea Water Leakage on the Performance of the Ammonia Cycle." In Proceedings of the 4 th Annual Conference on OTEC, pp. viii-3-35.

Hale, C. C. 1980. "Armonia Storage Terminals Safety Program." Ammonia Plant Safety 22:35-53.

Hampson, 8. L. 1977. "Relationship Between Total Ammonia and Free Ammonia in Terrestrial and 0cean Waters." J. duConseil. 37:117-122.

Hanoaka, H. 1977. "Harmful Effect of Armonia Growth of the Brine Shrimp Artemia salina and inhibition of Ammonia Accumulation with an Alga Chorella." Bu17. Plankton Soc. Japan 24(2):99-107.

Hardy, J. T. and Z. Jubayli. 1976. "Phytoplankton Standing Crop and Sewage Nutrient Enrichment Along the Central Coast of Lebanon." Environ. Pollut. $11: 195-202$.

Harsh, K. M. 1978. "Toxicity Modification of an Anhydrous Ammonia Spill." In Proceedings from the National Conference on the Control of Hazardous Material SpilTs, pp. T48-T5T. U.S. EnvironmentaT Protection Agency, Washington, D. $\bar{C}$.

Harvey, R. A. et al. 1979. Open-cycle MHD System Analysis. EPRI AF-1230, Electric Power Research Institute, Palo Alto, California.

Haynes, B. S. 1977. "Reaction of Ammonia and Nitric 0xide in the Burnt Gases of Fue 1-Rich Hydroc arbon-Air Flames." Comb. Flame 28:81-89.

Hazel, C. R. et al. 1971. "Sensitivity of Striped Bass and Stickleback to Amonia in Relation to Temperature and Salinity." California Fish and Game Department 57:138-153. 
Heck, W. W. et a1. 1970. "Other Phytotoxic Pollutants." Recognition of Air Pollution Injury to Vegetation: A Pictoral Atlas, pp. FT-F24, ed. J. S. Jacobsen and A. C. HilT.

Hesse, G., and P. R. Augustine. 1980. "Wyodak: A Milestone in Dry Cooling." Power Eng. 84(8):pp. 66-69.

Hilado, C. J. et al. 1978. "Effect of Individual Gaseous Toxicants on Mice." Proc. West Pharmocol. Soc. 21:159-160.

Hoddart and William. 1978 and 1979.

Howard, P. H. and R. S. Datta. 1977. "Chemical Cominution: A Process for Liberating the Mineral Matter from Coal." ACS Symp. Ser. 64:58-68.

Howard, P. H. et a1. 1977. "Chemical Fracture of Coal and Sulfur Liberation." Fuel $56: 346$.

Howerton, M. T. 1978. A Thermochemical Energy Storage System and Heat Pump. IECEC 789152, American Institute of Chemical Engineers, New York, New York.

Huang, B. J. and T. Y. Chang. 1978. "Design Analysis of Ammonia-Water Absorption Refrigeration Systems. (Inter. Socjety Energy Conversion Engineering Conference). IECEC 789378, American Institute of Chemical Engineers, New York, New York.

Iizuka, T. and J. H. Lunsford. 1978. "Active Intermediates in the Reduction of Nitric Oxide by Ammonia over a CoY Zeolite." J. Am. Chem. Soc. 100(19): $6106-6110$.

Inhofer, W. A. 1969. "Ammonia Transport via Pipeline." Safety in Air and Ammonia Plants, 11:40-45, AICHE.

Isabel1, J. R. 1976. "Failure in Ammonia Plant Transfer Line." Ammonia Plant Safety 19:144-147.

Int. Inst. Ammonia Refrigeration. 1977.

Jaeger, F. A. and C. A. Ha11. 1980. "Ammoniated Sa1t Heat Pump/Thermal Storage System." Paper presented at Int. Seminar on Thermochemical Energy Storage, Stockholm, January 7, 1980.

Jaeger, F. A. 1980. "Thermal Storage for Solar Cooling Using Paired Anmoniated Sait Reactions." In Proceedings of DOE Contractors' Review Meeting on Active Solar Heating and Cooling, pp. 11-26-27, U.S. Department of Energy, Washington, D.C.

Kaiser, G. D. and B. C. Walker. 1978. "Releases of Anhydrous Ammonia from Pressurized Containers--The Importance of Denser-than-Air Mixtures." Atm. Envir. 12:2289-2300. 
Kamogawa, H. 1980. "OTEC Research in Japan." Energy 5:481-492.

Kanury, M. 1977. Introduction to Combustion Phenomena. ISBN:0-677-02690-0, Gorden and Breach Science Publishers.

Kaskan, W. E. and D. E. Hughes. 1973. "Mechanism of Decay of Armonia in Flame Gases from $\mathrm{NH}_{3} / \mathrm{O}_{2}$ Flames." Comb. Flame 20:381-388.

Katzer, J. R. 1975. "Kinetics of $\mathrm{NO}$ Reduction by $\mathrm{NH}_{3}$ over Supported Pt and the Effect of $\mathrm{SO}_{2}$." In The Catalytic Chemistry of Nitrogen Oxides, eds. R. L. K1imisch and J. G. Larson, pp. T33-T65. PTenum Press, New York, New York.

Katz, M. and R. A. Pierro. 1967. Estimates of the Acute Toxicity of AmmoniaUrea Plant Wastes to Coho Salmon, Oncorhynchus kisutch. Final Report, Fish Res. Institute, University of Washington, Seatt 1 , Washington.

Keller, D. V. and C. D. Smith. 1976. "Spontaneous Fracture of Coal." Fuel $55: 273-280$.

Kiorsky, J. R. et al. 1979. "A New Zeolite Catalyst for Selective Catalytic Reduction of $\mathrm{NO} x$ with $\mathrm{NH}_{3}$." Presented at the 3rd International Symposium, Inst. of Chem. Engrs. Contr. of Sulphur and Other Gaseous Emissions, United Kingdom.

Kittle, L. 1979. Anhydrous Anmonia Spi11, Hood Canal. Internal Memorandum, Washington State Department of Ecology, OTympia, Washington.

Kletz, T. A. 1980. "Plant Layout and Location: Methods for Taking Hazardous Occurrences into Account." Loss Prevention 13:147-153.

Konopka, A. et a1. 1977. "Alternative Forms of Energy Transmission from OTEC Plants." In Proceedings of the 4 th Annual Conference on OTEC, Pp. III-47-56.

KTussman, W. G. et al. 1970. "Utilization of Anhydrous Ammonia in Fisheries Management." Proceedings of the 23rd Annual Conference Southeastern Assoc. Game Fish Commer., pp. 512-519.

Konopka, A. et al. 1976. Energy Transmission from Ocean Thermal Energy Conversion Plants. IECEC 769164, Intersoc Tety Energy Conversion Engineering Conference, American Institute of Chemical Engineers, New York, New York.

Kostors, C. H., and S. P. Vincent. 1979. OTEC Armonia Turbine Design Study. IECEC 799026, Intersociety Energy Conversion Engineering Conference, American Institute of Chemical Engineers, New York, New York.

Lamp, T. R. 1978. "Development of a Heat Pipe Assembly for a Gas-Fired Commercial Tilting Brazier." In Proceedings of the 3rd International Heat Pipe Conference, 78-399. American Institute of Aeronautics and Astronautics, New York, New York. 
Lavi, A. 1980. "Ocean Thermal Energy Conversion: A General Introduction." Energy 5:469-480.

LeBlanc et a1. 1979. "Armonia." Encyclopedia of Chemical Technology, ed. Kirk-0thmer, Vol. 2, pp. 470-516, 3rd ed., J. Wiley, New York, New York.

Lewis, L. G. and N. F. Sather. 1979. OTEC Performance Tests of the CarnegieMellon University Vertical Fluted Tube Condenser. ANL/OTEC-PS-4, Argonne National Laboratory, Argonne, Illinois.

Lipman, M. 1979. "Save: Condense $\mathrm{NH}_{3}$ with R12." Hydrocarb. Process $58(1): 153-156$.

Lichtenberg, W. H. 1971. "Overflow of an Ammonia Storage Tank." Ammonia Plant Safety 19:59-61.

Lloyd, R. 1981. "The Toxicity of Ammonia to Rainbow Trout (Salmo gairdnerii Richardson)." J. Exper. Biol. 38:447-455.

Lonsdale, H. 1974. "Ammonia Tank Failure - South Africa." Ammonia Plant Safety 17:126-131.

Longwe11, P. n.d. Calculation of Critical Temperature and Time-to-Explosion for Propellants and Explosives. NAWtPS Report 7646.

Lorenz, J. J. et a1. 1979. OTEC Performance Test of the Carnegie-Melion University Vertical Fluted-Tube Evaporator. ANL/0TEC-PS-5, Argonne National Laboratory, Argonne, Illinois.

Lyon, R. D. 1979. "Thermal DeNOX: How it Works." In Hydrocarb. Proc. $58(10): 109-112$.

Lyon, R. K. and D. Benn. 1978. "Kinetics of the $\mathrm{NO}-\mathrm{NH}_{3}-\mathrm{O}_{2}$ Reaction." In Proceedings of 17th Symp. on Combustion, pp. 601-610.

MacArthur, J. G. 1971. "Ammonia Storage Tank Repair." Ammonia Plant Safety $14: 1-5$.

MacIsaac, J. J. and R. C. Dugdale. 1969. "The Kinetics of Nitrate and Ammonia Uptake by Natural Populations of Marine Phytoplankton." Deep-Sea Research $16: 45-57$.

Mansoori, G. A. and V. Pate1. 1979. "Thermodynamic Basis for the Choice of Working Fluids for Solar Absorption Cooling Systems." Solar Energy 22:483-491.

Marzo, L. and L. Fernandez. 1980. "Destroy NOX Catalytically." Hydroc. Process 59(2):87-89.

Matida, M., Y. Nishiyama and Y. Tami. 1977. "Liquid Anmonia Treatment of a Bituminous Coal." Fuel 56:177-180. 
Matida, M., Y. Nishiyama and Y. Tami. 1978a. "Effects of Liquid Ammonia Treatment on Gasification with Hydrogen." Fuel 57:559-561.

Matida, M., Y. Nishiyama and Y. Tami. 1978b. "Swelling Behaviour of a Single Coal Particle." Fuel 57:562-564.

Matida, M., Y. Nishiyama and Y. Tami. 1979a. "Reactivity of Coals Treated with Liquid Ammonia." Fue] 58:366-370.

Matida, M., Y. Nishiyama and Y. Tami. 1979b. "Properties of Coals Treated with Liquid Ammonia." Fuel 58:609-613.

Matida, M., Y. Nishiyama and Y. Tami. 1979c. "Catalytic Steam Gasification at Atmospheric Pressure." Fue] 58:614-618.

Matsuda, S. et al. 1980. "Selective Catalytic Reduction of Nitrogen Oxides with Ammonia in Presence of Sulfur Trioxide Deposition of Amstonium Bisulfate." Paper presented at 73rd Annual Meeting of Air Pollution Control Association, June 22-27, 1980.

McCallan, S. E. A. and C. Setterstron. 1940. "Toxicity of Ammonia, Chlorine, Hydrogen Cyanide, Hydrogen Sulphide and Sulphur Dioxide Gases I. General Methods and Correlations." Contrib. Boyce Thompson Institute 11:325-330.

McCallan, S. E. A. and F. R. Weeden. 1940. "Toxicity of Antmonia, Chlorine, Hydrogen Cyanide, Hydrogen Sulphide and Sulphur Dioxide Gases II. Fungi and Bacteria." Contrib. Boyce Thompson Institute 11:331-342.

McDonald, C. F. and D. L. Vrable. 1976. "Component Design Considerations for as Turbine MTGR-Waste-Heat Power Plants." IECEC 769032, American Institute of Chemical Engineers, New York, New York.

McDonaid, C. F. and K. Vepa. 1977. "Ammonia Turbomachinery Design Considerations for the Direct Cycle Nuclear Gas Turbine Waste Heat Power Plant." Paper 77-GT-75, American Society of Mechanical Engineers.

McGowan, J. G. 1979. Continued Evaluation of Compact Heat Exchangers for OTEC Evaluation. Co0-4238-14.

Mckee, J. E. and H. W. Wolf. 1971. Water Quality Criteria. California State Water Resources Control Board, Pub. 3-A, Sacramento, CaTifornia.

McNaughton, D. J. and C. M. Berkowitz. 1979. "Overview of U.S. Research Activities in the Dispersion of Dense Gases." Presented at Symposium Schwere Gase, Frankfurt, Germany.

Melancon, C. L. 1980. "Improving Emergency Control and Response Systems." Loss Prevention 13:43-47. 
Meyer, C. A. and F. K. Fischer. 1962. "Working Fluids for Power Generation of the Future." In Proceedings of the Anerican Power Conference, 24, pp. $371-381$.

Miller, J. A. et a1. 1979. A Theoretical Model for the Selective Reduction of Nitric Oxide by Anmonia. SAND 79-8256, Sandia National Laboratory, Atbuquerque, New Mexíco.

Miller, J. A. et al. 1980. A Chemical Kinetic Model for the Selective Reduction of Nitric Oxide by Ammonia. SAND 80-8635, Sandia National Laboratory, ATbuquerque, New Mexico.

Mizumoto, M. et a1. 1979. "Effects of Coexisting Gases on the Catalytic Reduction of $\mathrm{NO}$ with $\mathrm{NH}_{3}$ over $\mathrm{Cu}(\mathrm{II}) \mathrm{NaY} . "$ J. Catal 59:319-324.

Munze1, W. 0. 1978. "Compatibility Tests of Various Heat Pipe Working Fluids and Structural Materials at Different Temperatures." In Proceedings of the 3rd International Heat Pipe Conference, 78-398. American Institute of Aeronautics and Astronautics, New York, New York.

Murphy, R. W. and H. W. Hoffman. 1979. Condensation on Evaporation Heat Transfer with Low-Boiling Temperature Fluids. CONF-790539-1, National Technical Information Service, Springfield, Virginia.

Murray, T. M., and K. C. Bordoloi. 1978. "A Progress Report on the University of Louisville Dual Solar Energy." In Alternate Energy Sources, ed.

T. N. Veziroglu, pp. 923-928. McGraw-Hill, New York, New York.

Muzio, L. J., J. K. Arand and K. L. Maloney. 1978. Noncatalyt ic NOx Removal with Ammonia. EPRI Report FP-735, Electric Power Research Institute, Paio Alto, California.

National Academy of Sciences (NAS). 1969. Eutrophication: Causes, Consequences, Correctives. National Academy of Science Press, Washington, D.C.

Natarajan, K. V. 1970. "Toxicity of Ammonia to Marine Diatoms." J. Wat. Poll. Cont. Fed. 42(5):R184-R190.

National Research Council. 1979. Ammonia. Committee on Medical and Biologica $\}$ Effects of Environmental Pollutants, University Park Press, Baltimore, Maryland.

National Transportation Safety Board (NTSB). 1971. Railroad Accident Report Chicago, Burlington, and Quincy Railroad Company Train 64 and Train 824 Derailment and Collision with Tank Car Explosion, Crete, Nebraska, February 18, 1979. Report No. NTSB-RAR-71-2, Washington, D.C.

National Transportation Safety Board (NTSB). 1974. Pipeline Accident Report Mid America Pipeline System Anhydrous Ammonia Leak, Conway, Kansas, December 6, 1973. Report No. NTSB-PAR-74-6, washington, D.C. 
Nissen, D. A. 1979. The Physical Properties of $\mathrm{NH}_{4} \mathrm{Cl}$ ] $\mathrm{NH}_{3}$. SAND 79-8049, Sandia National Laboratory, Albuquerque, New Mexico.

Norman, E. C. and H. A. Dowe11. 1979. "Using Aqueous Foams to Lessen Vaporization from Hazardous Chemical Spi11s." Loss Prevention 13:27-34.

Noyes, R. 1967. "Ammonia and Synthesis Gas." Chem. Proc. Manager 26.

Partridge, L. J. 1976. "Coal-Based Ammonia Plant Operation." CEP pp. 133-137.

Okubo, A. 1971. "Horizontal and Vertical Mixing in the Sea." Impingenent of Man on the Oceans, pp. 89-168, ed. D. W. Hood, Wiley-Interscience, New York, New York.

01 lendorf, S. 1978. "Heat Pipes in Space and on Earth." In Proceedings of the 3rd International Heat Pipe Conference, 78-439. American Institute of Aeronautics and Astronautics, New York, New York.

01 sen, S. 1979. Anhydrous Amonia Spill observations. August 9 through September 5, 1979. Internal Memorandum, Washington State Department of Fisheries, Point Whitney Laboratory, Brinnon, Washington.

Pebworth, L. A. 1976. "Catastrophic Failure in Process Lines." Ammonia Plant Safety 19:148-150.

Power Generating Cooling Systems. 1975. A Closed Loop Ammonia Dry Cooling System and an Evaporative Water Cooling System. Pacific Northwest Laboratory, Richtand, Washington.

Pratt, D. R. 1976. Compatibility of Ammonia with Candidate Dry Cooling System Materials. BNWL-1992, Pacific Northwest Laboratory, Richland, Washington.

Pratt, D. T. and E. S. Starkman. 1969. "High-Temperature Kinetics of AmmoniaAir Combustion." Twelfth Symposium (International) on Combustion, The Combustion Institute.

Raj, P. K. and J. H. Hagopion. 1974. "Hazards Presented by the Release of Anhydrous Ammonia on Water." Proceedings of the National Conference on the Control of Hazardous Material Spills, American Society of Chemical Engineers.

Raj, P. K. and R. C. Reid. 1978. "Fate of Liquid Ammonia Spilled onto Water." Environ. Sci. Technol. 12(13):1422-1425.

Raj, P. K., J. Hogopian and A. S. Kalelkar. 1974. Prediction of Hazards in Spills of Anhydrous Ammonia in Water. Report No. AD-779-400, for the U.S. Coast Guard, Arthur D. Little, Cambridge, Massachusetts. 
Reed, J. H. 1970. Prevention of Accidents in the Transportation of Hazardous Materials. Publications Section, National Transportation Safety Board, Washington, D.C.

Resplondy, A. 1969. "Etude Experimentale des Proprietes de 1'Ammonia." Chim., Ind. - Gen., Chim. 102:691-702.

Roose, T. R., R. K. Hanson and C. H. Kruger. 1978. "Decomposition of NO in the Presence of Ammonia." In Proceedings of 11th Int. Symposium on Shock Tubes and Wares. University of Washington Press, Seattle, Washington.

Roose, T. R., R. K. Hanson and C. H. Kruger. 1979. "Therma] Decomposition of $\mathrm{NH}_{3}$ in Shock Waves." Presented at 12th Int. Shock Tube Symposium, July, 1979, Jerusalem.

Ryther, J. H. and W. H. Dunstan. 1971. "Nitrogen, Phosphorus and Eutrophication in the Coastal Marine Environments." Science 171:1008-1013.

Ryther, J. H. and J. C. Goidman. 1975. Combined Toxicity of Chiorine, Ammonium and Temperature on Marine Plankton. U.S. ERDA AT(TI-1)-2532, Washington, D.C.

Sazski, E. W. and P. C. Owzarski. 1977. "Compatibility Studies for the Ammonia-Titanium-Seawater System as Related to Ocean Thermal Energy Conversion." In Proceedings of the 4th Annual Conference on OTEC, pp. vii-46-53.

Sabin, C. M. and H. F. Poppendick. 1979. "Ammonia Vaporization and Condensation Investigations Related to OTEC Heat Exchangers." In Proceedings of the 6th OTEC Conference, pp. 11.9.1-5.

Schrieber, C. F., W. D. Grimes and W. F. McI Thenny. 1979. Inter leakage of Ammonia in OTEC Exchangers: Effects on Corrosion and Scate Formation. ANL/0TEC-BCM-002, Argonne National Laboratory, Argonne, IIlinois.

Schuster, J. R., D. L. Vrable and J. P. Huntsinger. 1976. "Binary Plant Cycles Studies for the Gas Turbine HTGR." Paper 76-GT-39, American Soc iety of Mechanical Engineers.

Scott, W. D. and D. Lamb. 1970. "Two Solid Compounds Which Decompose into a Common Vapor: Anhydrous Reactions of Ammonia and Sulfur Dioxide." $\mathrm{J}$. Am. Chem. Soc. 92:3943-3946.

Selyama, T. et a1. 1979. "Catalytic Reduction of $\mathrm{ND}$ with $\mathrm{NH}_{3}$ over Cu( II)NaY." Ind. Eng. Chem. Prod. Res. Dev. 18:279-283.

Shale, C. C. 1973. "Ammonia Injection: A Route to Clean Stacks." Adv. in Chem. 127:195-205.

Shale, C. C., D. G. Simpson and P. S. Lewis. 1971. "Removal of Sulfur and Nitrogen 0xides from Stock Gases by Ammonia." In Chem. Eng. Prog. Sym., $115(67): 52-58$. 
Sherman, J. L. 1970. "Storage of Anhydrous Armonia in a Mined Cavern." Ammonia Plant Safety 12:8-10, CEP Tech. Manual of AIChE.

Slack, A. V. and G. R. James, eds. 1974-1979. Ammonia. Vols. I, II, III, IV, Marcel Dekker Inc. New York, New York.

Slusarek, Z. M. 1969. "The Economic Feasibility of the Steam - Ammonia Power Cycle." PB184331.

Smith, C. E. and R. G. Piper. 1975. "Lesions Assocjated with Chronic Exposure to Ammonia." The Pathology of Fishes, pp. 497-514, eds. W. E. Rebelin and G. Migaki, University of Wisconsin Press, Madison, Wisconsin.

Spear, M. 1980. "European Petrochemicals Edge Away from Naphtha." Process. Eng. pp. 69-70.

SRI Internationa1. 1980. Directory of Chemical Producers United States.

Steigelmann, W. H., R. G. Seth and G. P. Wachtell. 1972. "Binary-cycle Power Plants Using Air-cooled Condensing Systems." In Proceedings of the American Power Conference, pp. 521-530.

Stokes, K. J. 1979. "Compression Systems for Armonia Plants." CEP. pp. 88-91.

Talib, A. et a1. 1979. "Hydrogen and Alternative Means of Energy Delivery from OTEC Plants." Hydrogen for Energy Distribution. Institute for Gas Technology.

Tamai, Y. et a1. 1978. "Catalytic Gasification of Coals Pretreated with Liquid Ammonia." ATternate Energy Sources pp. 3075-3085.

Taslakian, M. J. and J. T. Hardy. 1976. "Sewage Nutrient Enrichment and Phytoplankton Ecology Along the Central Coast of Lebanon." Mar. Biol. 38:315-325.

Teen, C. L. 1968. "Thermal Radiation Properties of Gases." Advances in Heat Transfer 5:253.

Temple, P. J. et at. 1979. "Toxic Effects of Ammonia on Vegetation in Ontario, Canada." Environ. Pollut. 20(4):297-302.

Tennessee Valley Authority. 1979. Symposium on Ammonia from Coal. Bulletin Y-143, Muscle Shoals, Alabama.

Thomas, T. R. and D. T. Pence. 1974. "Reduction of NOx with Ammonia over Zeolite Catalyst." In Proceedings of the 67th Annual Meeting of Air Pollution Control Association, Paper No. 75-258. 
Thomas, W. H. 1970. "Effect of Amonium and Nitrate Concentration on Chlorophyl1 Increases in Natural Tropical Pacific PTankton Populations." Limnol. and Oceanog. 15:386-394.

Thomas, W. H. and A. J. Carsola. 1980. "Ammonium Input to the Sea via Large Sewage Outfalls: I. Tracing Sewage in Southern California Waters." Mar. Environ. Res. 3(4):277-289.

Tock, R. W., K. C. Hoover and G. J. Faust. 1979. "Removal by Transformation to Solid Crystals of $\mathrm{NH}_{3}$ Complexes." In Control of Emissions from Stationary Combustion Sources Pollution Detection and Behavior in the Atmosphere. AICHE Symposium Series 188, Vol. 75, pp. 62-82, American Institute of Chemical Engineers, New York, New York.

Todo, N. et al. 1974. "Reductive Removal of Nitrogen Oxides from Waste Gases," German Patent 2,411,888.

Tokarz, R. D. et aT. 1978. Comparative Cost Study of Four Wet/Dry Cooling Concepts That Use Ammonia as the Intermediate Heat Exchange Fluid. PNL-2661, Pacific Northwest Laboratory, Richland, Washington.

Trimbie, L. C. and R. L. Potash. 1980. "Design and Construction of an OTEC Test Plant." J. Sol. Energy Eng. 102(1):41-46.

TWR Systems and Energy. 1976. Ocean Thermal Energy Conversion: Test Facilities Study Vol. I, II, III. TID278I5.

U.S. Department of Commerce. 1979. Bureau of Census, Statistical Abstract of the United States. U.S. Government Printing Office.

U.S. Department of Transportation (DOT). 1973. Hazardous Materials Incident Report 3110085. Hazardous Materials Incidence Reporting System, office of Hazardous Materials Operations, Washington, D.C.

U.S. Department of Transportation (D0T). 1976a. Hazardous Materials Incident Report 6D60028. Hazardous Materials Incidence Reporting System, Office of Hazardous Materials Operations, Washington, D.C.

U.S.Department of Transportation (DOT). 1976b. Hazardous Materials Incident Report 6050911. Hazardous Materials Incidence Reporting System, Office of Hazardous Materials Operations, Washington, D.C.

U.S.Department of Transportation (DOT). 1976c. Hazardous Materials Incident Report 6060004. Hazardous Materials Incidence Reporting System, Office of Hazardous Materials Operations, washington, D.C.

U.S.Department of Transportation (DOT). 1976d. Hazardous Materials Incident Report 6040588. Hazardous Materials Incidence Reporting System, Office of Hazardous Materials Operations, Washington, D.C. 
U.S. Environmental Protection Agency (EPA). 1977. Ammonia. EPA-600/1-77-054, Office of Research and Development, Health Effects Research Laboratory, Research Triangle Park, North Carolina.

U.S. Federal Water Pollution Control Administration (FWPCA). 1968. Water Quality Criteria. Report to the National Technical Advisory Committee to the Secretary of the Interior, Washington, D.C.

Vasilier, L. L. 1978. "Application of Heat Pipes for Freezing Grounds." In Proceedings of the 3rd International Heat Pipe Conference, 78-400. American Institute of Aeronautics and Astronautics, New York, New York.

Venkataramiah, A. et al. 1980. Studies on the Toxicity of OTEC PTant Components on Marine Animals from the Gulf of Mexico. Annual Report to U.S. Department of Energy, Gulf Coast Research Laboratory, Ocean Springs, Mississippi.

Waite, T. and R. Mitche11. 1972. "The Effect of Nutrient Fertilization on the Benthic Alga Ulva lactuca." Botanica Marina 15:15]-156.

Waters, E. D. et al. 1975. "The Application of Heat Pipes to the Trans-Alaska Pipeline." IECEC Paper 759218.

Wentworth, W. E. et al. 1979. Development of Operational Chemical Cycles for the Storage of Energy. SAND 79-8208, Sandia National Laboratory, Albuquerque, New Mexico.

Whitefield, M. 1978. "The Hydrolysis of Ammonium Ions in Sea Water: Experimental Confirmation of Predicted Constant at One Atmosphere Pressure." J. Mar. Biol. Assoc. U.K. 58(3):781-786.

,

Wiebe R. 1934. "The Solubitity of Hydrogen in Liquid Ammonia." J. Chem. Soc.. $56: 2357-2360$.

Wilbur, P. J. and C. E. Mitche11. 1975. "Solar Absorption Air Conditioning Alternatives." Solar Energy 17:193-199.

Williams, D. A. and J. B. Tiedemann. 1974. A Heat Pump Powered by Natural Thermal Gradients. IECEC Paper 749041, American Institute of Chemical Engineers, New York, New York.

Williams, D. A. et al. 1957. Interim Heat Absorption Cooling Systems with Solar Regeneration. ASME Paper 57-A-260, American Society of Mechanical Engineers.

Williams, G. P. 1978. "Causes of Amonia Plant Shutdowns." Amonia Safety. $20: 123-130$.

Williams, 0. M. and P. 0. Carden. 1979a. "Energy Storage Efficiency for the Ammonia/Mydrogen-Nitrogen Thermochemical Energy Transfer System." Int. J. Energy Res. 3:29-40. 
Williams, 0. M. and P. 0. Carden. 1979b. "Amonia Dissociation for Solar Thermochemical Absorbers." Int. J. Energy Res. 3:129-142.

Williams, 0. M. 1980. "Design and Cost Analys is for an Anmonia-Based Solar Thermochemical Cavity Absorber." Solar Energy 24:255-263.

Williamson, W. B. and 3. H. Lunsford. 1976. "Nitric Dxide Reduction Over CU(II)Y Zeolites." 3. Phys. Chem. 80:2664-2671.

Willingham, W. T. 1976. Ammonia Toxicity. EPA-908/3-76-001, Control Technology Branch, Water Division, V.S. Environmental Protection Agency, Region VIII, Denver, Colorado.

Wise, H. 1975. "The Ammonia Route to N0x Conversion in Auto Exhaust Cataiysis." In The Catalytic Chemistry of Nitrogen 0xides, eds. R. L. K? imisch and J. G. Larson, pp. 235-246. PTenum Press, New York, New York.

Wood, B. 1969-1970. "Alternative Fluids for Power Generation." In Proceedings of the Institute of Mechanical Engineers, 184(40):713-740.

Woodhu11, A. S., M. C. Hu and G. A. Englesson. 1978. Conceptual Designs and Cost Estimates of Ammonia Dry/Wet Cooling Systems. Prepared by United Engineers for Pacific Northwest Laboratory, Richland, Washington.

Zaioudek, F. R. et a1. 1976. A Study of the Comparative Costs of Fire Wet/Dry Cooling Tower Concepts. BNWL-2T22, Pacific Northwest Laboratory, Richland, Washington.

Zaloudek, F. R. et al. 1978. Conceptual Design Study - Advanced Concepts Test (ACT) Facility. PNL-2715, Pacific Northwest Laboratory, Richland, Washington. 


\section{ANNOTATED BIBLIOGRAPHY}

Alleman, R. T. B. M. Johnson, and G. C. Smith. 1976. Ammonia as an Intermediate Heat Exchange Fluid for Dry-Cooled Turners. PNL-SA-5997, Pacific Northwest Laboratory, Richland, Washington.

Exhaust steam from the last stage of the power turbine is condensed by boiling ammonia in a special condenser. The ammonia vapor is then transferred to a dry cooling tower where it is recondensed and the waste heat rejected to the atmosphere. The advantages of such a scheme over standard water-oniy systems are elucidated.

Anderson, H. C. et a?. 1961. "Catalytic Treatment of Nitric Acid Plant Tail Gas." Ind. Eng. Chem. 53(3):199-204.

In laboratory tests it was demonstrated that ammonia over a Pt cataiyst removes $\mathrm{NO}_{x}$ selectively from tail gases of nitric acid plants. This process was considered preferable over processes using natural gas or other fuel gases. A patent (U.S. 1,233,712 of 5/9/60) was granted on the process, superseding an earlier U.S. patent dated $3 / 18 / 24$.

Anderson, J. H. 1977. Compact Heat Exchangers for Sea Thermal Power Plants. TID 28151.

The objective of the program is to develop suitable heat exchangers for use with ammonia and sea water. Practical construction techniques are evaluated which would permit low-cost manufacturing, since OTEC heat exchangers wou?d have to be very large by present standards.

Arnas, 0. A. 1978. "Dehumidification by Solar Energy." In Alternate Energy Sources, ed. T. N. Veziroglu, pp. 781-794. McGraw-Hill, New York, New York.

Solar refrigeration of moist air by absorption type coolers is more advantageous when solar energy is used. The two commonly used systems are the ammonia/water and the water/lithium bromide types. It is argued that the latter is more cost-efficient.

Ba11, W. L. 1970. "A Review of Atmospheric Armonia Research Study." Ammonia Plant Safety. 12:1-7.

An overview is given on the anmonia safety research sponsored by the Ammonia Storage Committee of the Compressed Gas Association, Inc. This committee, in turn, is supported financially by a group of 38 domestic and overseas companies involved in large-scale use or manufacture of armonia. 
Banks, R. 1978. "Armonia Output Increased by Hydrogen Recovery." Ammonia Plant Safety, 20:79-84.

Because of the steep increase in energy costs it is no longer justifiable to burn purge gas containing hydrogen. Cryogenic hydrogen recovery units are, therefore, installed now in ammonia plants.

Barber, J. C. 1978. "Ammonia Losses in Production and Agricultural Use." Ammonia Plant Safety, 20:5-10.

The production of ammonia and its use in making fertilizers involve no large anmonia losses. Ammonia emissions from industrial plants apparently cause no significant air pollution or industrial hygiene problems. Almost all of the $6 \mathrm{ppb}$ of $\mathrm{NH}_{3}$ contained in the atmosphere is generated by natural biological processes. Industrial processes contribute less than $0.1 \%$ of this amount.

Bartz, J. A. et a1. 1976. Heat Rejection by Dry Cooling in Steam-Electric Power Stations. Report prepared by Union Carbide Corp. (LINDE) for EPRI.

A phase-change heat-rejection system using anhydrous ammonia as the working fluid is technically feasible for electric power generating stations. Considerable savings in capital and operating costs would result from such a scheme when compared with conventional dry cooling tower operations.

Benedict, B. A. 1978. "Analytical Models for Toxic Spills." Proceedings of the Conference on Control of Hazardous Material Spills, pp. 439-443.

Analytical models can, with proper care, predict the behavior and movement of a toxic spill. However, the physical system must be well understood to enable a good prediction. The paper briefly reviews the literature on the subject. Ammonia is not treated specifically.

Biederman, N. P., et al. 1978. Chemical, Electrochemical and Thermal Bridges for Transmission of OTEC Power. CONF-780236-2, National Technical Information Service, Springfield, Virginia.

The economics of various ways of transmitting OTEC-generated power from the off-shore facilities to land-based consumers are evaluated. It is concluded that various nonelectric schemes (such as ammonia generation) are more economical than electric transmission by cable. However, the underlying technical assumptions are rather tentative.

Blare-Feraud, P., and J. Fleurg. 1978. "Ammonia Binary Cycle: A Solution for Siting Power Plants at Totaily Dry Sites.." C\&M 34.

The advantages of using ammonia as an intermediate heat transfer fluid in the binary cooling cycle of a power plant are shown by a 
detailed analysis. Plans for a pilot plant demonstration are outlined. Start-up service of this plant is expected for the end of 1981.

Blanken, J. M. 1978. "Pitfalls in Handling Ammonia." Ammonia Plant Safety, $20: 32-36$.

It is shown that most amonia incidents are caused by carelessness or inexperience. A number of such incidents are cited. All of them could have been avoided. All of them could have happened with any liquefied gas.

Blouin, G. M. 1979. "Use of Armonia in Agricultural and Chemical Industries." Anmonia, Vol IV, pp. 81-184, Marcel Dekker Inc., New York, New York.

A survey is given on the many applications and uses of ammonia in the fertilizer industry and as base material for a myriad of products in the chenical industry. Miscellaneous other applications are also briefly described.

Boeltner, J. C., F. Gaillard-Cusin, and H. James. 1978. "Attempt to Remove Nitric Oxide in Burnt Gases through Radical Interaction Kinetics." C. R. Hebd. Seances Acad. Sci., Ser. C, 287, No. 5:155-158. (in French).

The removal of NO in combustion gases $c$ an be achieved through the addition of ammonia. It is postulated that an interaction of transient species of $\mathrm{CO}$ with $\mathrm{NH}_{3}$ will lead to an $\mathrm{NH}$ radical formation. The latter wil] then react with $N_{0}$ to forr. $N_{2}$.

Breed, C. E. and G. E. Hollinden. 1976. "Pilot Plant Study of the Ammonia Absorption-Ammonium Bisulfate Regeneration Process." Power Generation: Air Pollution Monitoring and Control. eds. K. E. Noll and W. T. Devis, pp. 359-378. Ann Arbor Science Publ. Inc.

Ammoniacal solutions are used for absorption of $\mathrm{SO}_{2}$ from plant flue gases. Subsequently, the absorbing solution is regenerated yielding $\mathrm{SO}_{2}$ gas, which can be used for fertilizer production. The operation of a TVA pilot plant based on this process is described.

Brizzolara, R. T. 1951. "Is Ammonia the Case of Refrigeration P1ant Explosions?" Refr. Eng. 59:1077-1079, 1126-1134.

The author explains that explosions occurring in ammonia refrigeration plants generaliy are not caused bv ammonia vapors but most likely by compressed air/oil vapor mixtures. It is known that ammonia is not easily ignited unless it is dissociated to some degree into hydrogen and nitrogen.

Brown, N. J., et al. 1979. Characterization Studies of the Selective Reduction of $\mathrm{NO}$ by $\mathrm{NH}_{3}$. LBL-10254, Lawrence Berkeley Laboratory, University of California, Berkeley, California. 
In a laboratory scale combustion tunnel the characteristics of the NO abatement by $\mathrm{NH}_{3}$ have been studjed. It was found that the effectiveness of the removal process depends very much on the equivalence ratio of the combustion reactants. It rises as stoichiometric conditions are approached from the lean side and is very sensitive at near stoichiometric conditions. Under fuel rich conditions ammonia addition is practically ineffective for No remova?.

Bruggeman, A., L. Meynendonek, and W. R. A. Goosens. 1978. "Elimination of $\mathrm{NO}_{\mathrm{X}}$ by Selective Reduction with $\mathrm{NH}_{3} . "$ In Proceedings of the 15th DOE Nucl. Air Cleaning Conference, Vol I, pp. 6T4-625. U.S. Department of Energy, Washinton, D.C.

It was shown in laboratory experiments that the nitrogen oxides which are generated during the dissolution of the fuel in nuclear reprocessing plants can be partially removed by an ammonia treatment. But since excess $\mathrm{NH}_{3}$ cannot be tolerated ejther, its catalytic destruction by the oxygen of the air was also demonstrated. Tests on a larger scale in a pilot plant are under preparation.

Buivadas, L. J. 1980. "Coal to $\mathrm{NH}_{3}$." Presented at the 1980 AICHE Symposium on Ammonia Plant Safety.

An overview is given on the various coal gasification schemes suitable for use in anmonia manufacturing. It is predicted that coal will be competitive with natural gas by 1985 for economic energy poiticy reasons.

Bureau of Labor Statistics. 1978. Occupational Injuries and Illnesses, Oregon. Washington, D.C.

This is the standard annual publication based on Workmen's Compensation data submitted to the bureau by those states participating in the Supplementary Data System. Contains tables of the various tabulations of the data which classify injury and iliness. Reports do not contain ammonia as a specific source of injury or contain individual case reports.

There is a similar report available for each state participating.

Bureau of Labor Statistics. 1980. Supplementary Data System Microdata Files User's Guide, 1978-1979. NTIS PB80-149S82. Washington, D.C.

This is the guide to the data files containing occupational injury and illness characteristics derived from the workers' compensation reports of participating states. It includes a description of the data system definitions of the data items and lists of the codes and titles used. 
Burnett, T. A., and H. L. Faucett. 1979. Impact of Anmonia Utilization by NOx. Flue Gas Treatment Processes. EPA-600/7-79-01], NationaT Technical Information Service, Springfield, Virginia.

Based on a 1977 outlook, the additional ammonia requirements for the 1984-2000 period have been estimated which would arise from the use of $\mathrm{NH}_{3}$ for $\mathrm{NO}_{x}$ flue gas treatment. Even though future $\mathrm{NH}_{3}$ consumption could dramatically increase for such purposes, it is likely that the requirements can be met by an expanding ammonia industry, as long as natural gas (and later coal) remains readily available.

Carden, P. 0. 1977. "Energy Corradiation Using the Reversible Ammonia Reaction." Solar Energy 19:365-378.

The reversible chemical reaction $2 \mathrm{NH}_{3}+\mathrm{N}_{2}+3 \mathrm{H}_{2}$ is proposed for the transfer and storage of solar energy. The endothermic forward reaction occurs in the solar collector whereas the exothermic reverse reaction is used for energy recovery.

Carden, P. 0., and 0. M. Williams. 1978. "The Efficiencies of Thermochemical Energy Transfer." Int. J. Energy Res. 2:389-406.

The paper presents a general thermodynamic study of systems involving thermochemical energy transfer. In particular, the efficiencies for the ammonia/hydrogen-nitrogen system are calculated. Storage efficiencies generally exceed $90 \%$, and work recovery efficiencies of about $50 \%$ can be achieved.

Carmichae1, A. D. 1979. Ocean Thermal Energy Conversion: A State-of-the-Art Study. EPRI-ER-1113-SR, Electric Power Research Institute, Palo Alto, California.

Ammonia is the preferred working fluid for a closed cycle OTEC plant mainly because it allows the use of reasonably-sized equipment. Open cycle plants would require huge turbines, which are well beyond the present state-of-the-art.

Chait, I. L. and G. Marchmont. 1978. Study Report for an $1100 \mathrm{MW}$ Power Plant Heat Rejection System Using Anmonia Dry Cooling Towers (Prepared for EPRI). Burns \& Roe, Richland, Washington.

It is shown that the capital cost for an ammonia heat rejection system for an $1100 \mathrm{mWe}$ plant corresponds to $\$ 162 / \mathrm{kW}$. This compares with a cost of about $\$ 25 / \mathrm{kW}$ for a standard water cooling system, incorporating wet cooling towers. (Mid' 77 cost figures).

Chan, M., and T. F. Yen. 1979. "Fracturing of 0 il Shale by Ammonia." Presented at ACS Meeting, September, 1979. 
Experimental results are reported on the treatment of certain oil shales with ammonia. Fracture was observed similar to that which occurs in coal.

Clark, W. D. 1976. "Using Fire Foam on Anmonia Spilis." Ammonia Plant Safety, 18:40-41.

It was demonstrated that a special type of foam (tradenamed: Komet Extrackt S), which is free of water, is well-suited for reducing the evaporation rate of anmonia spilis. An expansion ratio of 75 was found to be most suitable, since still lighter foams were frequently blown away in the tests.

Clinch, J. M. 1978. "Major Factors in OTEC Power Cycle Design". In Alternative Energy Sources, ed. T. N. Veziroglu, pp. 1557-1565. McGraw-Hil1, New York, New York.

The general requirements for the major components of OTEC plants are discussed for the case that ammonia is chosen as the working fluic. The heat exchangers are clearly the most important items, both in terms of performance and cost. It is suggested that a thorough test program be undertaken to evaiuate various designs before a fuil-size plant is being built.

Cockshaft, J. E. 1976. "Antmonia Absorption Refrigeration Process for Low Grade Waste Heat Recovery." CONF-7608122, pp. 92-96.

A new process is described using an ammonia absorption refrigeration cycle. Energy for the process is supplied as low grade waste heat available from methane product gas after recompression. Design features and the economics show considerable capital and operating cost savings.

Cohen, R., and E. J. Tschupp. 1978. "Analysis of Various OTEC Emissions." In Alternate Energy Sources, ed. L. Verziroglu, pp. 1483-1502.

The market potential for OTEC has been identified as being electricity and energy intensive products such as anmonia or aluminum. It has been projected that OTEC derived ammonia could fall within the range of costs of ammonia produced from fossil fuels by the year 2000 .

Combs, G. A. 1980. "Improving Efficiency in an $1750 \mathrm{t} / \mathrm{d} /$ Anunonia Plant." Paper presented at the 25th Symposium on Safety in Ammonia Plants.

In order to save feedstock and/or fuel, an existing armonia plant has been retrofitted with a cryogenic hydrogen recovery unit.

Combs, S. K. 1978. An Experimental Study of Heat Transfer Enhancement for Ammonia Condensing on Vertical Tubes. ORNL 5356, Oak Ridge National Laboratory, Oak Ridge, Tennessee. 
The heat transfer performance of single vertical tubes with anmonia condensing on the outside was determined experimentally. It was found that by adding external flutes to the tubes, the condensing heat transfer coefficient could be increased up to seven times.

Corneil, H. G. and F. J. Hinzelmann. 1980. "Hydrocarbon for Future Refining." Hydroc. Proc. pp. 85-90.

Hydrogen needs are forecast to the year 2000. This current manufacturing cost for hydrogen by steam reforming is quoted as $\$ 6.12 / \mathrm{MM}$ Btu. Hydrogen sources other than gas and oil are likely to be more costly.

Czuppon, T. A. and L. J. Buividas. 1979. "Which Feedstock for Ammonia?" Hydro. Proc. pp. 197-200.

The most economical feedstock currently is natural gas, followed by naphtha, fuel oil, and coal--in that order. For new amonia plants a number of energy-saving devices are proposed.

Dao, K., et a1. 1977a. Performance of an Experimental Solar-Driven Absorption Air Conditioner: Annual Report 1975/1976. LBL-5911, Lawrence Berkeley Laboratory, University of California, Berkeley, California.

A nominal 3 ton, continuous operation, heat actuated, $\mathrm{NH}_{3} / \mathrm{H}_{2} \mathrm{O}$ type water chiller has been fabricated by modification of a commercia? gas-fired unit. Twenty-two experimental runs were made with operations found to be very stable. A numerical analysis of the thermodynamic cycle agree with the test results within $\pm 5 \%$.

Dao, K., et a1. 1977b. Performance of an Air-Cooled, Ammonia-Water Absorption Air Conditioner at Low Generator Temperatures. LBL 5224, Lawrence Berkeley Laboratory, University of California, Berkeley, California.

It has been demonstrated experimentally that it is technically feasible to use the ammonia-water absorption cycle for cooiing with a heat source temperature below $200^{\circ} \mathrm{F}$ and a heat sink temperature (using air cooling) below $110^{\circ} \mathrm{F}$.

Dao, K. 1978(a). A New Absorption Cycle: The Single-Effect Regenerative Absorption Refrigeration CycTe. LBL 6879, Lawrence Berkeley Laboratory, University of California, Berkeley, California.

The new cycle has a higher coefficient of performance (COP), and thc "cut-off" input temperature is much lower than in the basic cycle. This is shown specifically for the ammonia/water cycle.

Dao, K. 1978(b). Conceptual Design of an Advanced Absorption Cycle: The Double-Effect Regenerative Absorption Refrigeration Cycle. LBL 8405, Lawrence Berkeley Laboratory, University of California, Berkeley, California. 
The analysis for an advanced absorption refrigeration cycle is presented with aqua-ammonia mixtures as the working fluid. Referred to as the double-effect regenerative absorption cycle, it improves the performance of the conventional single-effect cycle. However, it appears to be mechanically much more complex.

Dao, K. et al. 1979. Development of Solar-Driven Ammonia-Water Absorption Air Conditioners and Heat Pumps. LBL 9630, pp. 15-18.

The paper gives design details for the new $\mathrm{NH}_{3} / \mathrm{H}_{2} \mathrm{O}$ absorption air conditioner. It has a cooling capacity of 3 tons minimum with a coefficient of performance exceeding 0.65 .

Dao, K., et al. 1980. Development of Solar-Driven Absorption Air Conditioners and Heat Pumps. LBL-10771, Lawrence Berkeley Laboratory, University of California, Berkeley, California.

It has been experimentally demonstrated that the conventional singleeffect ammonia-water absorption cycle can be used (with minor modifications) for solar cooling. The design and fabrication of an actual solar energy ammonia-water absorption air conditioner has been completed.

Dalta, R. S., and P. H. Howard. 1978. Characterization of the Chemical Comminution of Coal (Final Report). FE-2520-4.

Experimental results are reported which describe the factors influencing the rate and degree of fragmentation of coal when exposed to ammonia. The superior ability of chemical cominution by $\mathrm{NH}_{3}$ to liberate pyritic sulfur and ash, without excessive size reduction, has been demonstrated.

Dalta, R. S., et al. 1976. Feasibility Study of Pre-Combustion Coal Cieaning Using Chemical Comminution (Fina? Report). FE-1777-4.

Chemical comminution by ammonia is able to liberate more pyrite and a comparable amount of ash than mechanical crushing to the same size consist.

Day, B. F. 1978. "Armonia Transportation Accident Report." Ammonia Plant Safety, 20:30-31.

The piercing of an ammonia rail tank car in the derailment of a freight train is described. A second accident involved a tractorsemi-trailer (tank filled with liquid ammonia), which overturned and fell from a highway bridge. In both cases, the ammonia was spilled.

Deegan, D. C. and B. E. Wilde. 1973. "Stress Corrosion Cracking Behaviour of ASTM A517 Grade F Steel in Liquid Ammonia Environments." Corrosion, $29: 310-315$. 
Test results confirm previous research findings that (1) uncontaminated ammonia does not cause cracking; (2) air contamination in ammonia causes cracking; and (3) $0.2 \%$ water addition inhibits cracking in air-contaminated ammonia. Hydrogen embrittlement is not involved in the cracking mechanism.

"Direct Ammonia Refrigeration System Saves Energy and Expenses for Winery." Food Eng. 50(9): 175 .

By eliminating the intermediate glycol cooling loop and using ammonia directly under boiling conditions, the efficiency of the refrigeration system can be markedly increased. Overall power savings are said to reach $35 \%$.

Dugger, G. L. et al. 1975. "Floating Ocean Thermal Power Plants and Potential Products." J. Hydronautics, 9(4):129-141.

It is shown that ammonia production at sea aboard an DTEC plant looks economicaliy competitive.

Dugger, G. L., and E. J. Francis. 1977. "Design of an Ocean Thermal Energy Plant-Ship to Produce Ammonia via Hydrogen." Int. J. Hydr. Energy 2:231-249.

A baseline design has been developed for a $100 \mathrm{MW}$ OTEC plant-ship that would produce 313 tons per day of ammonia. It is judged that ammonia would be producible at competitive cost $(\$ 96 / \mathrm{t}$ in 7975 dollars) by the sixth and subsequent plant-ships based on an extrapolated $500 \mathrm{MW}_{\mathrm{e}}$ size.

Dugger, G. L., et a1. 1977. "Experiments on and Design of Low-Cost Aluminum Heat Exchangers for OTEC Plant Ships." In Proceedings of the 4th Annual Conference on OTEC, Pp. vi-iii-i23.

To minimize the cost of the large OTEC heat exchangers, simple twophase-flow units made of large-diameter aluminum tubes (ammonia inside, sea water outside) have been designed for integration with a simple, barge-type, reinforced concrete hull. The underlying analysis is presented. Model tests in a two-phase amonia flow loop are described. Test results are discussed in the light of two-phase flow theory.

Dugger, G. L., E. J. Francis, and W. H. Avery. 1978. "Technical and Economic Feasibility of Ocean Thermal Enerjgy Conversion." Solar Energy 20:259-274.

Thermodynamically, ammonia is by far the most attractive working fluid for OTEC power plants. Besides, it is proposed using the OTEC generated power to produce ammonia aboard and to pipe it ashore as a liquid. The economic advantages of such an approach are outlined. The superiority of ammonia as a hydrogen carrier, when compared with liquefied hydrogen, is also pointed out. 
Dunifon, H. E. and P. C. Campbel1. 1980. "Inspection and Repair of a Urea Reactor and an Ammonia Receiver." Paper presented at the 25th Symposium on Safety in Ammonia Plants.

Severe cracking was found across a weld of an ammonia receiver. It was concluded that this was a case of stress corrosion cracking caused by air-contaminated amonia in a nonstress relieved drum.

Eggers, P. E. 1972. Design, Fabrication, and Evaluation of the Extruded Heat Pipe with Ammonia Working Fiuid. Battelle Columbus Laboratories, Columbus, ohio.

The characteristics of a $7 \mathrm{ft}$ long, 0.5 in diam. heat pipe with a heat transport capacity of up to 5900 watt-inches are briefly described.

Eisenstadt, M., et a1. 1959. Solar Air Conditioning With an Ammonia-Water Absorption Refrigeration System. ASME Paper 59-A-276, American Society of Mechanical Engineers.

It has been demonstrated by tests that ammonia and water constitute a particularly advantageous combination for absorption refrigeration systems with solar regeneration. The possibility of operating such a system also on a continuous bas is is pointed out.

Eitzen, T. S., et a1. 1979. Characterization of NOx Removal Through Ammonia Addition. LBL 8849 , Lawrence Berkeley Laboratory, University of California, Berkeley, California.

Experimental results for selective $\mathrm{NO}_{x}$ reduction by $\mathrm{NH}_{3}$ injection are obtained in a combustion tunnel. Test parameters are varied over a wide span. Measured reductions range from 13 to 74 percent.

Elliott, D. E., and H. C. Fischer. 1971. "Open-Cycle Ammonia Refrigeration." ASHRAE J.:55-60.

Commercial grade anhydrous ammonia is used for mobile refrigeration units on a once-through basis. Before discharge to the atmosphere, the vaporized amonia is dissociated and combusted to nitrogen and water. Capital and upkeep costs are quite low whereas operating costs are rather high.

Energy Research and Technology. 1979. "Power Generating Ocean Platform". Energy Resource \& Tech. $1,2: 5$.

A $50 \mathrm{~kW}$ mini-OTEC power plant will begin operating off Hawai in 1979. Ammonia will be used as a closed cycle working fluid. It is vaporized by warm (surface) ocean water and condensed by cold (deep) ocean water. 
Farber, E. A., et al. 1966. "Operation and Performance of the University of Florida Solar Air-Conditioning System." Solar Energy, 10(2):91-95.

A continuous absorption refrigeration system is described which uses ammonia and water as the working fluids and operates by heat applied from flat-place solar absorbers. Performance has been tested at the University of Florida. Peak cooling capacity was found to be 3.7 tons of refrigeration.

Farinola, G. and V. Langana. 1979. "Why Barge-Mount Ammonia/Urea Plants?" Hydroc arb. Process. 58(9):202-206.

The advantages of building ammonia plants on barges are outlined. Apart from safety, barge-mounted plants are more cost-effective.

Feind, K. 1975. "Reducing Vapor Loss in Ammonia Tank Spills." Ammonia Plant Safety, 17:114-118.

Experiments have shown that aqueous foams are rapidly destroyed when supplied to an ammonia spill because the water contained in the foam reacts with the ammonia. It is, therefore, recommended that other light materials, such as plastic films or polystyrene spheres, be used to reduce the open surface area of the spill.

Fenimore, C. P. 1980. "Destruction of $\mathrm{NO}$ by $\mathrm{NH}_{3}$ in Lean Burnt Gas." Comb. and Flame $37: 245-250$.

Experiments are described which demonstrate the influence of temperature on the thermal DeNO $\mathrm{x}$ process. The process works best between 1100 and $1300 \mathrm{~K}$. It is thought to be an equilibrium between two competing processes: $\mathrm{NH}_{2}+\mathrm{NO} \rightarrow \mathrm{N}_{2}+\mathrm{H}_{2} \mathrm{O}$ and $\mathrm{NH}_{2}+\mathrm{OH}+\ldots+\mathrm{NO}+\ldots$. (The $\mathrm{NH}_{2}$ radical is formed by $\mathrm{NH}_{3}+\mathrm{OH} \rightarrow \mathrm{NH}_{2}+\mathrm{H}_{2} \mathrm{O}$ ). At low enough temperatures the process becomes inefficient, presumably because active $\mathrm{NH}_{2}$ radical is formed too slowly. It fails at high temperatures $\left(>1300 \mathrm{~K}\right.$ ) because $\mathrm{NH}_{2}$ is consumed without destroying a comparable amount of $\mathrm{NO}$.

Fletcher, W. J., J. B. Liljedahl and R. C. Rund. 1974. Analys is of Anhydrous Ammonia Accidents for Preventive Measures. Report published by ASAE.

Reports an analysis by the National Safety Council of detailed accidents reports received at the Indiana State Chemists' office and Purdue University. Contains reconmendations to reduce the incidence and seriousness of ammonia releases.

Fleury, J. 1978. Economic Study of a PWR 1300 MW Power Station With a Water Vapor and Ammonia Binary Cycle.

It is shown that a steam/ammonia binary cycle power plant operates more economically than a regular steam plant. However, its original 
capital cost is higher. The saturated ammonia vapor drives an expansion turbine and is then condensed back to the liquid phase in a dry cooling tower.

Freitag, W., and M. W. Packbier. 1978. "Solving Nitric Acid Plant Pollution Problems." Ammonia Plant Safety, 20:11-16.

BASF operates two large nitric acid piants in which the tail gases are treated by selectively reaucing $\mathrm{NO}_{\mathrm{x}}$ with ammonia over a $\mathrm{V}_{2} \mathrm{O}_{5}$ catalyst.

Ganic, E. H. and J. Wu. 1979. Comparative Study of Working Fluids for OTEC Power Plants. ANL/OTEC-TM-1, Argonne National Laboratory, Argonne, Illinois.

of the three fluids (ammonia, propane, freon 114) investigated, armonia is the best choice for minimizing heat exchanger size, which has a significant influence on overall systems cost. The most attractive characteristic of ammonia as an OTEC working fluid is its relatively high thermal conductivity.

Ganic, E. N., and J. Wu. 1980. "On the Selection of Working Fluids for OTEC Power Plants." Energy Coriv. \& Mgmt. 20:9-22.

An analytic comparison between ammonia, propane, and Freon-114 has shown that ammonia is generally the superior working fluid, mainly because of its relatively high thermal conductivity. Its main disadvantages are its toxicity and corrosion probiems with certain alloys, particularly copper-alloys.

Gustin, R. E. and D. A. Novacek. 1979. "Armonia Storage Vent Accident." Ammonia Plant Safety, 21:80-81.

A refrigeration compressor trip-out released ammonia from the release valves on top of the storage tank. The ammonia vapors were then ignited by the fiare on the same tank. There was only minor damage. For future prevention of such an accident the flare was relocated to be well away from the relief valves.

Haas, W. R. et al. 1979. "Thermochemical Energy Storage System and Heat Pump." In Proceedings of Conference on Solar Energy and Solar Options, pp. $473--48 \overline{7}$.

The results of experimental investigations of using ammoniated salts as energy storage media in process heating and in solar space heating and cooling applications are reported. The investigated topics include: material compatibility and corrosion testing, reaction rate testing, cyclic testing, and reactor design and operation studies.

Hack, W. et al. 1978. "Reaction Rates of $\mathrm{NH}_{2}$ Radicals with $\mathrm{NO}, \mathrm{NO}_{2}, \mathrm{C}_{2} \mathrm{H}_{2}$, $\mathrm{C}_{2} \mathrm{H}_{4}$ and other Hydrocarbons." In Proceedings of $17 \mathrm{th}$ Symp. on Combustion, pp. 505-513. 
Since the reactions of $\mathrm{NH}_{2}$ radicals with $\mathrm{NO}_{x}$ are of primary importance for the reduction of $\mathrm{NO}_{\mathrm{x}}$ in combustion exhaust gases, their kinetics have been experimentally investigated. The pertinent rate constants were determined for a temperature range of $209<T<505 \mathrm{~K}$.

Hafezzadah, $H$. et a 1. 1977. "Preliminary Analysis of the Effects of Sea Water Leakage on the Performance of the Ammonia Cycle." In Proceedings of the 4 th Annual Conference on OTEC, pp. viii-31-35.

Water leakage into an amonia cycle can have disturbing effects on cycle performance because the dew point is strongly influenced by the water content. Various ways are suggested to overcome this problem. More R\&D is needed.

Hale, C. C. 1979. "Refrigerated Ammonia Storage: Design and Practice." Ammonia Plant Safety, 21:61-68.

The paper contains the result of a survey on the design and operating practices for large refrigerated ammonia storage tanks. Safety features are stressed. No serious spill accident in the operation of these tanks has ever occurred.

Harvey, R. A. et al. 1979. Open-cycle MHD System Analysis. EPRI AF-1230, Electric Power Research Instítute, Palo Alto, California.

Because of high operating temperatures the $\mathrm{NO}_{\mathrm{x}}$ production in $\mathrm{MHO}$ burners is exceptionally high. Ammonia injection into the exhaust has been selected as the best (and possibly only) method available for controlling $\mathrm{NO}_{x}$ emissions from future MHD plants.

Haynes, B. S. 1977. "Reaction of Ammonia and Nitric Oxide in the Burnt Gases of Fuel-Rich Hydrocarbon-Air Flames." Comb. Flame 28:81-89.

A multiplicity of reactions between $\mathrm{NH}_{j}(i=0,1,2,3)$ and $\mathrm{NO}$ is possible for which the reaction rates depend very much on temperature and also on the presence of other species, such as hydrocarbons and $\mathrm{OH}$ radicals. A full understanding of the reaction mechanisms has not been achieved yet. The subject matter is of practical importance for the $\mathrm{NO}_{\mathrm{x}}$ reduction with ammonia in flue gases.

Heller, F. J. 1980. "Ansnonia Tank Car Safety." Paper presented at the AICHE Symposium on Ammonia Plant Safety.

An overview is given on accidents and their prevention involving rail tank cars carrying ammonia. Codes and inspection procedures are briefly outlined. The overall safety record has been improving steadily over the years and $c$ an now be considered relatively good.

Helmers, S. R., W. H. McConnel, Jr. and L. W. Knapp. 1971. "Ammonia Mishaps in Agriculture." Agricultural Engineering, 52(3):118-120. 
This paper presents four case histories of anhydrous ammonia releases to illustrate potential health hazards.

Hendersen, G. L. "Appendix F: Application of Industry Practices to the Design of an Ammonia Phase-Change Heat Transport Process Pilot Plant." Conceptual Design Study - Advanced Concepts Test (ACT) Facility. PNL-2715, Pacific Northwest Laboratory, Richland, Washington.

Recommendations are given for using ammonia as an intermediate heat transport fluid in a dry/wet cooling tower concept. Standard safety and maintenance rules are listed for using anhydrous ammonia in such a process.

Hendricks, N. A. 1979. "Safety Wall Systems for Ammonia Storage Protection." Ammonia PIant Safety, 21:69-72.

Various types of prestressed cylindrical concrete walls are described by which ammonia or LPG storage tanks can be enclosed. Such safety walls supposedly provide better protection than dikes in cases of major spills.

Hesse, G., and P. R. Augustine. 1980. "Wyodak: A Milestone in Dry Cooling." Power Eng. 84(8): pp. 66-69.

The world's largest air-cooled steam condenser, now operating at the $330 \mathrm{MW}$ Wyodak Station, has demonstrated the technical and economic feasibility of using dry cooling in modern fossil-fired power plants in water-short areas.

Howard, P. H., and R. S. Datta. 1977. "Chemical Comminution: A Process for Liberating the Mineral Matter from Coal." ACS Symp. Ser. 64:58-68.

Ammonia can be used to fracture coal and to liberate mineral matter. This process is very competitive with other processes currently being considered for production of clean coal.

Howard, P. H., et a1. 1977. "Chemical Fracture of Coal and Sulfur Liberation." Fuel 56:346.

The results of Keller and Smith's paper (see above) are critically evaluated.

Howerton, M. T. 1978. A Thermochemica] Energy Storage System and Heat Pump. IECEC 789152, American Institute of Chemical Engineers, New York, New York.

The concept of a thermochemical energy storage system is described which is based on the reversible reactions of certain ammoniated salts. By pairing any two of such reactions, an energy storage system and a reversible heat pump can be devised. The working fluid cycled between the high temperature and low temperature reactors is 
always gaseous ammonia. Analytical studies and bench scale experiments have demonstrated the feasibility of the concept.

Huang, B. J., and T. Y. Chang. 1978. "Design Analysis of Ammonia-water Absorption Refrigeration Systems. (Later Society Energy Conversion Engineering Conference). IECEC 789378, American Institute of Chemical Engineers, New York, New York.

A rigorous system analysis for an ammonia-water absorption refrigeration system is presented. The following five independent design variables are considered: generator temperature, condenser temperature, evaporator temperture, ammonia concentration of the strong solution, and the reflux ratio.

Hughes, T. R. 3951. "Mysterious Amnonia Explosions." Refrig. Eng. $59: 859-862$.

It is argued that fires or explosions occurring in connection with ammonia spills are not the result of ammonia combustion, but of other gases ("foul gases") mixed with the ammonia vapors. Such accidents have occurred mainly in industries where refrigeration by ammonia is merely an auxiliary to the main business.

Hutchings, J. et al. 1972. "Stress Corrosion of Steels in Anhydrous Amnonia." Ammonia Plant Safety, AICHE, 14:102-108.

Occurrence of stress corrosion cracking of steel vessels containing ammonia has been rather common. However, the phenomenon is stili little understood and new, extensive tests are planned.

I izuka, T., and J. H. Lunaford. 1978. "Active Intermediates in the Reduction of Nitric Oxide by Ammonia over a CoY zeolite." J. Am. Chem. Soc. 100(19): $6106-6110$.

Laboratory studies have been conducted to determine the kinetics of the reduction of $\mathrm{NO}$ by $\mathrm{NH}_{3}$ using a CoY zeolite as a catalyst. It was found that the reaction is different from the better known cuy zeolite reaction since its order is $<0.5$, which is considered to be an advantage. The nighest reaction rates are obtained at $85^{\circ} \mathrm{C}$.

Int. Institute Anmonia Refrigeration. 1977. "A Suggested Guide: Recommended Procedures in Event of Ammonia Spills." Bu11. 106.

The severity and frequency of ammonia spills can be much reduced by proper maintenance and design of the systems. Safety instructions and drills for the operating personnel are very important. Cleanup procedures are described.

Iwako, H., and S. Ando. 1979. "Mineral $0 i l$ Emilsion Fuels With a Low Nitrogenoxide Generation Potential." Japan patent 79-39, 406. 
Fuel emulsions are prepared continuously by mixing a mineral oil (e.g., a heavy hydrocarbon oil) with $5-30 \% \mathrm{H}_{2} \mathrm{O}$ and $\mathrm{NH}_{3}$ in an amount more than the molar amount of $\mathrm{NO}_{x}$ formed during the combustion of the oil. Aq. $\mathrm{NH}_{3}$ droplets in the fue 1 reduce the combustion rate and promote complete combustion at a lower temperature. $\mathrm{NO}_{\mathrm{x}}$ formation is reduced to a level such that additional processing of the fuel to remove $N$ is not required.

Jaeger, F. A., and C. A. Hall. 1980. "Ammoniated Salt Heat Pump/Thermal Storage System." Paper presented at Int. Seminar on Thermochemical Energy Storage, Stockho $1 \mathrm{~m}, 1 / 7 / 80$.

A trade-off study comparing the energy storage characteristics of several combinations of solid and liquid ammoniates has revealed that a liquid ammoniate coupled with pure anhydrous ammonia is the most cost-effective system.

Jaeger, F. A. 1980. "Thermal Storage for Solar Cooling Using Paired Armoniated Salt Reactions." In Proceedings of DOE Contractors' Review Meeting on Active Solar Heating and Cooling, pp. 17-26-27. U.S. Oepartment of Energy, Washington, D.C.

Testing with a 5000 Btu capacity system has revealed that the use of liquid ammoniates (e.g., $\mathrm{NH}_{4} \cdot \mathrm{Cl} \cdot \mathrm{nNH}_{3}$ ) allows much higher heat transfer rates than a soijd ammoniate. Compatibility of liquid ammoniates with suitable materials has been investigated. A large system $(600,000$ Btu storage capacity) has been designed.

Johnston, A. M. 1980. "Amonia/Water Absorption Cycles with Relatively High Generator Temperatures." Solar Energy, 25:243-254.

It is shown analytically that performance of solar air conditioning, refrigeration, and heat pump systems can be improved by utilizing single or double-stage ammonia/water absorption cycles in connection with evacuated solar collectors in the temperature range of $100-200^{\circ} \mathrm{C}$.

Jones, 0. A. and B. E. Wilde. 1977. "Corrosion Performance of Some Metals and Alloys in Liquid Ammonia." Corrosion, 33:46-50.

Coupons of various metals were exposed for periods of $T$ and 8 months in an autoclave filled with liquid ammonia at room temperature. Very Tow weight losses, and often weight gains, were experienced, indicating that most metals and their alloys are fairly inert in liquid ammonia with respect to general corrosion.

Jones, D. A., C. D. Kim and B. E. Wilde. 1977. "The Electrochemistry and Mechanism of Stress Corrosion Cracking of Constructional Steels in Liquid Ammonia." Corrosion, 33:52-55. 
Electrochemical polarization measurements were performed on constructional alloy steel to elucidate the operative corrosion mechanism in pure ammonia and also in ammonia contaminated with species of industrial importance. Based on the results, a model for stress corrosion cracking of steel in ammonia is presented.

Kaiser, G. D. and B. C. Walker. 1978. "Releases of Anhydrous Ammonia from Pressurized Containers--The Importance of Denser-than-Air Mixtures." Atm. Envir. 12:2289-2300.

A very tentative and simplistic model for the dispersion of ammonia vapor after a major spill is presented. The validity of the model is questionable. Quantitative test on anmonia spills are non-existent but are required for the proper development of a valid model.

Kamogawa, H. 1980. "OTEC Research in Japan." Energy 5:481-492.

The R\&D work on OTEC in Japan has taken a course similar to that in the U.S.A. Consequently, as a result of an evaluation of potential working fluids it was found that amonia would be the most suitable fluid for closed OTEC systems.

Kaskan, H. E., and D. E. Hughes. 1973. "Mechanism of Decay of Ammonia in Flame Gases from $\mathrm{NH}_{3} / \mathrm{O}_{2}$ Flames." Comb. Flame 20:381-388.

Whereas the $\mathrm{H}_{2} / \mathrm{O}_{2} \mathrm{fl}$ ame involves 6 kinetically important species, the $\mathrm{NH}_{3} / \mathrm{O}_{2}$ flame involves 12 . The $\mathrm{H}_{2} / \mathrm{O}_{2}$ reaction is relatively the most simple one and is almost completely understood. The ammonia/ oxygen reaction is the next one in complexity and is fairly we 11 understood. It $c$ an be considered as a stepping stone towards the understanding of the highly compiex hydrocarbon/oxygen reactions and the reactions in which ammonia is used to reduce the $\mathrm{NO}_{\mathrm{x}}$ content of flue gases.

Katzen, J. R. 1975. "Kinetics of $\mathrm{NO}$ Reduction by $\mathrm{NH}_{3}$ over Supported $\mathrm{Pt}$ and the Effect of $\mathrm{SO}_{2} . "$ In The Catalytic Chemistry of Nitrogen Oxides, eds. R. L. Klimisch and J. G. Larson, pp. 133-165. PTenum Press, New York, New York.

Using a selective reducing agent, such as ammonia, to reduce NO in the presence of oxygen eliminates both the large reductant consumption and heat generation problems. Pt-catalysts don't seem to be much affected by the presence of $\mathrm{SO}_{2}$. The kinetics of the reactions are explored and tentatively explained.

Keller, D. V., and C. D. Smith. 1976. "Spontaneous Fracture of Coai." Fuel $55: 273-280$. 
Experimental and analytical work is described which investigates the disintegration of coal when exposed to ammonia. The resulting particle size could be fairly well predicted by an analytical model specifically developed for this purpose.

Kim, C. D. et a1. 1975. "Stress Corrosion Cracking of Line-Pipe Steels in Anhydrous Ammonia." Corrosion, 31:255-26i.

Tests have showl that $0.2 \%$ water in $\mathrm{NH}_{3}$ is completely effective in preventing stress corrosion cracking in ERW pipe with strength ievels up to those specified for API grade $x-50$ suitable for ammonia pipe lines. Without the water present any of the steels tested were susceptible to cracking when the amonia was contaminated with air.

Kiorsky, J. R. et al. 1979. "A New Zeolite Catalyst for Selective Catalytic Reduction of $\mathrm{NO}_{\mathrm{x}}$ with $\mathrm{NH}_{3}$." Presented at the 3rd International Symposium, Inst. of Chem. Engns. Contr. of Sulphur and Other Gaseous Emissions, U.K.

Research on selective catalytic reduction of nitrogen oxides with ammonia is discussed. A new catalyst has been tested which shows very high activity under moderate operating conditions. Effects of operating temperatures, ammonia concentration, and gas velocity on the catalytic performance are assessed.

Kiyomiya, M., and M. Kawai. 1979. "The Effectiveness of Laterite as a Catalyst for the Reduction of $\mathrm{NO}$ with $\mathrm{NH}_{3}$ " Atm. Envir. 13:559-561.

It has been shown experimentally that laterite can be an inexpensive and nontoxic catalyst for the removal of $\mathrm{NO}_{\mathrm{x}}$ from combustion gases with the use of ammonia vapors. The influences of $\mathrm{O}_{2}, \mathrm{H}_{2} \mathrm{O}$, and $\mathrm{SO}_{2}$ on the effectiveness of the catalyst are not yet fully understood.

Konopka, A. et a). 1976. Energy Transmission from Ocean Thermal Energy Conversion Plants. IECEC 76, $\overline{9164}$, American Institute of Chemical Engineers, New York, New York.

Besides hydrogen, ammonia has been considered as a potential energy carrier from the off-shore OTEC plant to the energy market. The paper presents technical and economic trade-offs among the various options.

Konopka, A. et a]. 1977. "Aiternative Forms of Energy Transmission from OTEC Plants." In Proceedings of the 4th Annual Conference on OTEC, pp. III-47-56.

The paper compares the transmission of OTEC-derived chemical and electrical energy in terms of technical fozsibility and economic preference. Anong the nine chemical energy carriers considered, liquid ammonia appears to be the best overall choice. 
Kostors, C. H., and S. P. Vincent. 1979. OTEC Ammonia Turbine Design Study. IECEC (Inter Society Energy Conversion Engineering Conference) 799026, Ameri can Institute of Chemical Engineers, New York, New York.

Based on state-of-the-art hardware, an ammonia turbine for OTEC operations has been conceptually designed. Since the turbine has to handle very large flow volumes at relatively low temperature and pressure differentials, its size becomes quite large. For the design case of $15 \mathrm{MW}$ e the total weight would exceed 90 tons.

Lari, A. 1980. "Ocean Thermal Energy Conversion: A General Introduction." Energy 5:469-480.

The OTEC concept is discussed with emphasis on the closed Rankine cycle using ammonia as the working fluid. Economically, the concept is most attractive for the island market, which is heavily dependent on imported oil. For the U.S. mainland the economic viability is still questionable because of the remaining technical uncertainties. Development and demonstration projects are, therefore, an urgent requirement.

Lefrois, R. T. 1979. "Solar Energy Heat Utilization." U.S. Patent 4, 169,499.

Solar energy is used to dissociate ammonium-carbamate (=urea reacteo with water) into $\mathrm{CO}_{2}, \mathrm{NH}_{3}$, and $\mathrm{H}_{2} \mathrm{O}$. Heat is recovered by recombining these substances. The entire system operates at temperatures of less thar $250^{\circ} \mathrm{C}$.

"Lesson in Safety: what to Do About Anmonia Spills." 1978. Air Cond. \& Kefr. Business, pp. 82-84.

Helpful suggestions are given to prevent the occurrence of armonia spills and to minimize accident damage in case a spill does occur.

Lewandowski, G. A. 1980. Rankine Bottoming Cycle Safety Analysis. DOE/ET15445, Department of Energy, Washington, D.C.

Three organic working fluids (Fluorinol 85, Freon 11, and Toluene) have been evaluated for their environmentl safety impact. Specific precautions have been suggested for plants which use such fluids.

Lewis, J. L. 1980. "A Philosophy for Energy Reduction while Maintaining Reliability in Modern Ammonia Plants." Paper presented at the 25 th Symposium on Ammonia Plant Safety.

Various techniques for reducing the energy requirements of anmonia plants are discussed, based on a computer model for the overall plant operation. Three major changes in the conventional plant design are suggested as a result of the analysis. 
Lewis, L. G., and N. F. Sather. 1979. OTEC Performance Tests of the CarnegieMelion University Vertical Fluted Tube Condenser. ANL/OTEC-PS-4, Argonne National Laboratory, Argonne, ITTinois.

Current federai development plans call for closed-cycle OTEC plants that use ammonia in a Rankine power cycle. The paper presents test results on a fluted tube ammonia condenser, obtained at the OTEC heat exchanger test facility at ANL. The condenser performed in a stable and repeatable manner without any operational problems.

Lipman, M. 1979. "Save: Condense $\mathrm{NH}_{3}$ into R12." Hydrocarb. Process $58(1): 153-156$.

It is possible to add capacity and to improve efficiency in an existing ammonia refrigeration system at lowest cost by condensing against a primary fluorocarbon refrigerant.

Locklin, D. W. et a]. 1980. "Fireside Additive Trials in Utility Boilers-Overview of an EPRI Study." Combustion, 2:26-33.

Ammonia has proved effective as an additive in coal-firing for flyash conditioning. Electrical resistivity of flyash is reduced, thus making precipitation more effective.

Loginow, A. W. 1976. "Detection and Diagnosis of Stress Corrosion Crack ing in Armmonia Tanks." Mat. Perf. pp. 33-38.

Details are given of recent DOT regulations concerning fabrication, testing, and inspection for vehicle tank transporting anhydrous ammonia. The regulations provide for post-weld heat treatment, wet fluorescent and magnetic particle inspection, plus hydrostatic testing every 5 years.

Lorenz, J. J. et al. 1979. OTEC Performance Test of the Carnegie-Mellon University Vertical Fluted-Tube Evaporator. ANL/0TEC-PS-5, Argonne National Laboratory, Argonne, Illinois.

The CM-U amonia evaporator for the closed cycle OTEC plant has been tested in the OTEC heat exchanger test facility at ANL. The test results were very stable and reproducible, with the quality of the ammonia vapor exceeding 99.9\%. Other types of ammonia evaporators will also be tested at the same facility.

Ludwigsen, P. B. and H. Anup. 1976. "Stress Corrosion Cracking of Mild Stee] in Ammonia Vapor Above Liquid Ammonia." Corrosion, 32:430-432.

Tests have shown that stress corrosion cracking can be prevented by heating the steel exposed to the ammonia vapor to $1^{\circ}$ to $2^{\circ} \mathrm{C}$ above the 
temperature of the liquid. An addition of $0.2 \%$ water to the anhydrous ammonia does not prevent stress corrosion cracking of the steel in the vapor space, if the steel is cooled and ammonia can condense on it.

Lyle, F. F. and R. T. Hi11. 1978. "SCC Susceptibility of High Strength Steels in Liquid Ammonia at Low Temperatures." Corrosion, 34:349-354.

Tests were conducted to investigate the SCC susceptibility of various high strength steels in low temperature liquid or vaporous ammonia. Conditions prevailing on the ammonia pipeline in the Soviet Union during the winter were to be duplicated. Results showed that, under the postulated conditions, certain steels are SCC susceptible, whereas others are not.

Lyon, R. D. 1979. "Thermal DeN0 $\mathrm{x}$ : How it Works." In Hydrocarb. Proc. $58(10): 109-112$.

By injecting small amounts of ammonia into the flue gas, its $\mathrm{NO}_{\mathrm{x}}$ content can be reduced by about 50\%. Such a scheme is indicated where air pollution problems are quite severe, such as in Japan and Southern California.

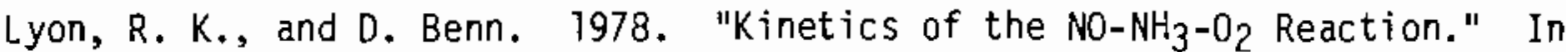
Proceedings of 17th Symp. on Combustion, pp. 601-610.

Using $\mathrm{He}$ as a carrier gas the kinetics of the $\mathrm{NO}-\mathrm{NH}_{3}-\mathrm{O}_{2}$ reaction were experimentally investigated. It was found that oxidation of $\mathrm{NH}_{3}$ to form $\mathrm{NO}$ occurs concurrently with reduction of $\mathrm{NO}$ by $\mathrm{NH}_{3}$. Thus, the NO concentration tends toward an equilibrium state. It was also found that the $\mathrm{NH}_{3}$ concentration must be small, compared with the $0_{2}$ concentration, in order to reduce NO effectively up to $100 \%$. The concentration of $\mathrm{NH}_{3}$ needed to cause inefficiency was found to increase with increasing oxygen content and increasing temperature. A free radical reaction mechanism explaining the experimental results has been proposed.

Lyon, R. K., and J. P. Longwe11. 1976. "Selective Non-catalytic Reduction of $\mathrm{NO}_{X}$ by $\mathrm{NH}_{3} \cdot "$ EPRI-SR39, paper IIB.

At $1700^{\circ}$ to $1800^{\circ} \mathrm{F}$ nitric oxide is reduced by ammonia and oxygen. The reaction products are nitrogen and water. In the presence of hydrogen (or natural gas) the reaction occurs at lower temperatures. A $70 \%$ denox was demonstrated without undesirable side effects.

Lyon, R. K. 1975. "Method for the Reduction of the Concentration of NO in Combustion Effluents Using Armonia." U.S. Patent 3,900,554.

The method of reducing the NO contained in exhaust gases with ammonia vapor and oxygen at a temperature from $1300^{\circ}$ to $2000^{\circ} \mathrm{F}$ is the subject of a patent assigned to Exxon. 
Maclean, D. L. 1980. "Energy-Saving Modifications in Armonia Plants." CEP, pp. 98-104.

Described energy savings devices include an air heater to improve heat efficiency of the reformer, a revised surface condenser, and a hydrogen recovery system from the synthesis loop purge gas.

Mansoori, G. A., and V. Patel. 1979. "Thermodynamic Bas is for the Choice of Working Fluids for Solar Absorption Cooling Systems." Solar Energy 22:483-491.

The thernodynamic properties of the refrigerants and absorbents determine the performance of the cooling system. On a theoretical basis three combinations of refrigerants/absorbents $\left(\mathrm{NH}_{3}+\mathrm{H}_{2} \mathrm{O}\right.$, $\mathrm{NH}_{3}+\mathrm{NaSCN}$ and $\mathrm{H}_{2} \mathrm{O}+\mathrm{LiBr}$ ) are evaluated for optimum results. The $\mathrm{NH}_{3}+\mathrm{H}_{2} \mathrm{O}$ combination is the most versatile, whereas the $\mathrm{H}_{2} \mathrm{O}+[\mathrm{iBr}$ combination is preferable for very hot climates.

Marzo, L., and L. Fernandez. 1980. "Oestroy N0x Catalytically." Hydroc. Process $59(2): 87-89$. ,

The $\mathrm{NO}_{x}$ content of the tail gases from nitric acid manufacturing plants can be substantially reduced by selective or non-selective catalytic abatement. Only reactions with ammonia as a selective agent are of practical significance. Catalysts can be made of noble metals or certain metaliic oxides. The process has been tested in a pilot plant and is now being installed in a large commercial plant in Spain.

Matsuda, 5. et a1. 1980. "Selective Catalytic Reduction of Nitrogen 0xides with Ammonia in Presence of Sulfur Trioxide Deposition of Ammonium Bisulfate." Paper presented at 73rd Annual Meeting of Air Pollution Control Association, June 22-27, 1980.

$\mathrm{TiO}_{2}$-based catalysts show a high activity, selectivity, and resistance to $\mathrm{SO}_{\mathrm{x}}$ poisoning over a temperature range of $200-\sim 450^{\circ} \mathrm{C}$. For NOx removal from flue gases they have been widely used in Japan. By the end of 1979 several tens of commercial plants have been constructed there which use this type of $\mathrm{NO}_{\mathrm{x}}$ removal process.

MCDonald, C. F., and D. L. Urable. "Component Design Considerations for Gas Turbine HTGR-Waste-Heat Power PTants." IECEC 769032, American Institute of Chemical Engineers, New York, New York.

Anmonia was found to be the most effective working fluid because of good heat transfer properties, high effective specific heat and high vapor pressure at $40^{\circ} \mathrm{C}$. Ammonia pumps, condensers, heat exchangers and turbines are described. 
McDonald, C. F. and K. Vepa. 1977. "Ammonia Turbomachinery Design Considerations for the Direct Cycle Nuclear Gas Turbine Waste Heat Power Plant."

Paper 77-GT-75, American Society of Mechanical Engineers.

The analytical and conceptual design studies for a $450 \mathrm{MW}(\mathrm{e})$ ammonia turbine are presented. An eight-stage, double-flow, axial turbine for an inlet temperature of $25^{\circ} \mathrm{C}$ has been selected. Low aerodynamic loading and the absence of moisture are believed to result in a $290 \%$ efficiency and an operational life of 30 years. The turbines are intended for the ammonia bottoming cycle of a gas turbine type high temperature, gas cooled reactor.

McGowan, J. G. 1979. Continued Evaluation of Compact Heat Exchangers for OTEC Evaluation. Co0-4238-14.

An analytical and experimental evaluation of the performance characteristics of compact heat exchangers, using ammonia as the working fluid, has been carried out over the entire range of OTEC operating conditions.

McHale, C. E. 1979. Ammonia Condenser Tube Test. Union Carbide Corporation (LINDE).

The heat transfer coefficients for condensing ammonia vapor within the tubes of a cooling tower are determined experimentally. The optimum slope of the finned tubes for obtaining most efficient heat transfer is also determined.

McLaughiin, T. J. 1978. "Appendix E: Environmental Impact Assessment for a Facility for the Study and Demonstration of a Dry/Wet Cooling Tower Concept with Ammonia Phase-Change Heat Transport System." Conceputal Design St:idy Advanced Concepts Test (ACT) Facility. PNL-2715, PaCific Northwest Laboratory, Richland, Washington.

The environmental impact of performing the experiment is small compared to the advantage of obtaining data concerning ammonia as a heat transfer agent. Since a closed piping system is used, ammonia releases to the atmosphere are practically nil except for occasional purging of the system.

Medard, L. 1970. "Rupture of an Ammonia Road Tanker." Ammonia Plant Safety, $12: 17-18$.

A tank car filled with 19 tons of ammonia exploded at the unloading stations. Five persons were overcome by the toxic fumes and died. No fire erupted. The accident was caused by stress corrosion cracking.

Meyer, C. A., and F. K. Fischer. 1962. "Working Fluids for Power Generation of the Future." In Proceedings of the American Power Conference, 24, pp. $371-381$. 
It is shown that ammonia represents a better working fluid for bottoming cycles than water, since its vapor pressure at low temperature is much higher. This results in considerable size reduction in the low pressure turbines.

Miller, J. A. et a1. 1979. A Theoretical Model for the Selective Reduction of Nitric Oxide by Ammonia. Sand 79-8256, Sandia National Laboratory, Albuquerque, New Mexico.

The reduction of $\mathrm{NO}$ in exhaust gases by reaction with $\mathrm{NH}_{3}$ is calculated as a function of gas temperature with the aid of a newlydeveloped mathematical computer program. Agreement with test data is satisfactory between 1050K and 1350K.

Miller, J. A. et al. 1980. A Chenical Kinetic Model for the Selective Reduction of Nitric 0xide by Ammonia. Sand 80-8635, Sandia National Laboratory, ATbuquerque, New Mexico.

The reaction between ammonia and $N 0$ in the presence of oxygen is explained on a quantitative basis. $\mathrm{NH}_{2}$ (amidogen) plays a crucial role in the reaction mechanism. NO removal takes place only within a limited temperature range (from about 1000 to $1500 \mathrm{~K}$ ). Required reaction times are in the order of $10^{-1} \mathrm{sec}$.

Misawa, T. "The Corrosion Fatigue and Stress Corrosion Cracking of a-Brass in Amoniacal Solutions." Corrosion Sci. 18:199-216.

The effects of $\mathrm{pH}$ on the fatigue life and on the fatigue crack propagation and the nature of cracking were investigated for $\alpha$-brass in ammoniacal solutions with a pH range of 4.3-9.8. The results showed that transgranular cracking predominated in alkaline solutions and intergranular cracking in neutral and acidic solutions.

Mizumoto, M. et aI. 1979. "Effects of Coexisting Gases on the Catalytic Reduction of NO with $\mathrm{NH}_{3}$ over Cu(II) NaY." J. Catal 59:319-324.

The co-existing gases $\left(\mathrm{H}_{2} \mathrm{O}, \mathrm{SO}_{2}, \mathrm{O}_{2}\right)$ have a significant effect on the $\mathrm{NO}-\mathrm{NH}_{3}$ reaction over zeolite ( $\mathrm{Cu}$ II NaY). It has been shown that $\mathrm{H}_{2} \mathrm{O}$ competes with $\mathrm{NO}$ in the adsorption to $\mathrm{Cu}$ (II) ions of the zeolite catalyst and, therefore, lowers the rate of NO reduction. Oxygen has a very favorabie influence, whereas the presence of $\mathrm{SO}_{2}$ tends to inhibit the catalytic activity. The NO reduction increases with temperature up to about $300^{\circ} \mathrm{C}$, where it is practically complete. The overall reaction in the presence of oxygen is believed to be:

$$
\mathrm{NO}+\mathrm{NH}_{3}+\frac{3}{4} \mathrm{O}_{2}=\mathrm{N}_{2}+3 / 2 \mathrm{H}_{2} \mathrm{O}
$$

Murphy, R. W., and H. W. Hoffman. 1979. Condensation on Evaporation Heat Transfer with Low-Boiling Temperature Fluids. CoNF-790539-T, National Technical Information Service, Springfield, Virginia. 
A brief progress report is given on ORNL tests involving antmonia as the working fluid in OTEC condenser and evaporator configurations. Emphasis has been on heat transfer enhancement by modifying the heat transfer surfaces, e.g., on fluted tubes.

Murray, T. M., and K. C. Bordoloi. 1978. "A Progress Report on the University of Louisville Oual Solar Energy." In Alternate Energy Sources, ed.

T. N. Veziroglu, pp. 923-928. McGraw-Hill, New York, New York.

An anmonia-water absorption air conditioning system is being developed. Its performance is to be compared with that of a commercial 3 ton lithiumbromide absorption air conditioner. Both will be solar powered.

Muzio, L. J., J. K. Arand, and K. L. Maloney. 1978. Noncatalytic NOx Removal with Ammonia. EPRI Report FP-735, Electric Power Research Institute, Palo Alto, Californịa.

In coal-fired power plant experiments about $65 \%$ reductions in No were obtained at an ammonia injection rate of 1 mole $\mathrm{NH}_{3} /$ mole $\mathrm{NO}$. The peak reductions occurred in a temperature range from $1700^{\circ} \mathrm{F}$ to about $1850^{\circ} \mathrm{F}$, depending on the type of coal. The simultaneous addition of small quantities of hydrogen increased the NO reductions further and at the same time decreased ammonia emissions.

Naruse, Y. et al. 1980. "Oeactivation of Iron Oxide Catalysts During $\mathrm{NO}_{\mathrm{X}}$ Reduction with $\mathrm{NH}_{3}$ in Flue Gases." Ind. Eng. Chem. Res. Oev. 19:62-65.

It has been shown in laboratory tests that $50_{x}$ and certain dust components (in particular, K) in flue gases will cause catalyst deactivation when iron oxides are used for $\mathrm{NO}_{x}$ reduction with ammonia.

Naruse, Y. et a). 1980. "Properties and Performance of Various Iron 0xide Catalysts for NO Reduction with NH3." Ind. Eng. Chem. Res. Dev. 19:57-61.

An iron oxide catalyst, obtained from a byproduct in steel plants, can be used as an inexpensive catalyst for reduction of $\mathrm{NO}_{x}$ with ammonia under atmospheric pressure at temperatures between $250^{\circ}$ and $400^{\circ} \mathrm{C}$. Most other catalysts which have been suggested for this process are relatively expensive.

National Safety Counci1. 1979. Farm/Ranch Standardized Accident Survey--An 18-State Report.

This report presents the best compilation of farm accident data available. It allows comparison of chemical accidents to other sources of injury. 
National Transportation Safety Board. 1979. Special Investigation Report Survival in Hazardous Materials Transportation Accidents. Bureau of Technology, Washington, D.C.

The Safety Board investigated the survival actions of the victims in the 1976 Houston ammonia tank truck accident. These actions were analyzed with respect to the DOT mandated safeguards for reducing casualties in hazardous materials accidents.

Niess, J. 1979. "Particulate Removal from $\mathrm{NO}_{\mathrm{X}}$ Abatement Off-Gas in a Nitric Acid Plant." Ammonia Plant Safety, 21:171-172.

When ammonia is used for $\mathrm{NO}_{x}$ removal in tail gases from nitric acid plants, ammonia nitrate is formed in very small particies. Such particles can cause plugging problems and are, therefore, collected by suitable mechanical filters.

Nissen, D. A. 1979. The Physical Properties of $\mathrm{NH}_{4}-\mathrm{Cl}-\mathrm{NH}_{3}$. SAND 79-8049, Sandia National Laboratory, Albuquerque, New Mexico.

The compound $\mathrm{NH}_{4} \mathrm{Cl} \cdot 3 \mathrm{NH}_{3}$ is one of the most attractive candidates for use in thermochemical heat pump/storage systems. The physical properties of this ammoniate have been measured and are presented in the paper.

Norman, E. C. and H. A. Dowe11. 1979. "Using Aqueous Foams to Lessen Vaporization from Hazardous Chemical Spills." Loss Prevention 13:27-34.

A special foam, based on synthetic surfactants, has been developed by National Foal Systems, Inc., for use on ammonia spills. Tests have shown that it is still more effective than the previously available foam, Komet Extrackt $S$.

Noyes, R. 1967. "Armonia and Synthesis Gas." Chem. Proc. Manager 26.

A thorough description is given of the various methods of producing ammonia from different feedstocks.

Partridge, L. J. 1976. "Coal-Based Ammonia Plant Operation." CEP pp. $133-137$.

A large ammonia plant based on the Koppers-Totzek low pressure, high temperature, coal gasification process is described. This plant has been operating since 1974 in South Africa.

Patterson, L. B. 1979. "Ammonia Separator Accident." Ammonia Plant Safety, $21: 95-99$.

In 1970 a major explosion occurred in an ammonia plant, most likely caused by leaking syn-gas from the ammonia separator. The incident 
shows that hydrogen under high pressure poses a far more serious safety problem in an ammonia plant than the ammonia itself.

Phelps, E. H. 1972. "Stress Corrosion Cracking in Ammonia." Ammonia Plant Safety, AIChE, 14:109-111.

New evidence from additional tests shows that the 1961 suggestion of $0.2 \%$ water addition to ammonia is indeed a valid method to prevent stress corrosion cracking. However, the purity of the ammonia and the type of steel and its history have an as-yet-unknown influence on the reliability of the method.

Phillips, B. R. 1979. "Failure at the Inlet Nozzle Weldment of an Ammonia Synthesis Converter." Ammonia Plant Safety, 21:21-28.

The failure was attributed to hydrogen embrittlement. The ensuing fire was caused also by hydrogen. Escaping ammonia was merely a secondary effect. No injuries occurred in this accident.

Poore, R. E. and J. C. Stover. 1980. "Efficient Operation of $\mathrm{NH}_{3}$ Plant at Reduced Rates." Paper presented at the 25th Symposium on Safety in Ammonia Plants.

With gas costing now about $\$ 2.50 / M M B t u$, it amounts to more than $70 \%$ of the total plant operating cost. By reducing production rate, better use can be made of the gas. This is due to an increase in heat exchange area and catalyst volume per unit of throughput, resulting in a lower pressure drop for the process flow.

Power Generating Cooling Systems. 1975. A Closed Loop Anmonia Dry Cooling System and an Evaporative Water Cooling System. Seattle, Washington.

The performance characteristics and systems components costs for an evaporative water cooling system and an amonia dry cooling system are presented. The projected average operating costs for the evaporative water cooling system are $13.7 \mathrm{mills} / \mathrm{kWh}$ and $10.4 \mathrm{mills} / \mathrm{kwh}$ for the ammonia system.

Pratt, D. R. 1976. Compatibility of Ammonid with Candidate Dry Cooling System Materials. $\overline{B N W L-1992, ~ P a c ~ i f ~ i c ~ N o r t h w e s t ~ L a b o r a t o r y, ~ R i c h i a n d, ~}$ Washington.

The report concludes that aluminum, carbon steel and stainless steel are suitable candidate materials for use in the cooling cycle of a power plant with an ammonia heat rejection system. Corrosion of these materials in high purity anhydrous ammonia is pirzicically negligible.

Quakenbush, V. C. et al. 1979. Chemical Comminution--An Improved Route to Clean Coal. EPA-600/7-79-098a. 
Raw coal is contacted with $\mathrm{NH}_{3}$ in a reactor system at moderate pressures and temperatures. This disrupts the natural bonding forces acting across the internal boundaries of the coal structure where the pyritic $S$ and ash deposits are located. Such chemical comminution in combination with conventional coal separation processes offers a promising alternative to mechanical crushing for coal cleaning.

Raj, P. K. and J. H. Hagopion. 1974. "Hazards Presented by the Release of Anhydrous Ammonia on Water." Proceedings of the National Conference on the Control of Hazardous Materia] SpiTls, American Society of Chemical Engineers.

A simple mathematical model is described, permitting the prediction of the vapor spread from a massive release of liquid ammonia on water. Experimental spills of ammonia on water were performed, but no quantitative comparison with the theoretical predictions were made.

Reed, J. 0. 1979. "Storage and Handling of Ammonia." in Ammonia, Vol IV, pp. 3-50, Marce 1 Dekker, New York, New York.

The various aspects of storing ammonia are discussed. Both pressurized storage at ambient temperatures and unpressurized storage at $-33^{\circ} \mathrm{C}$ are considered, as well as storage at intermediate conditions. Auxiliary equipment for operating a storage facility is described.

Robertson, D. E. et al. 1978. "Chemical Characterization of Gases and Volatile Heavy Metals in Geothermal Effluents." Trans. Geoth. Res. Council, $2: 579-582$.

By measurements taken at various geothermal sites it has been shown that ammonia is a ubiquitious contaminant in geothermal effluents. It shows up in the brine as well as in the steam condensate and the noncondensable gases. It is usually discharged directly to the environment, apparently without much harm.

Roose, T. R., R. K. Hanson, and C. H. Kruger. 1978. "Decomposition of N0 in the Presence of Ammonia." In Proceedings of 1lth Int. Symposjum on Shock Tubes and Wares. University of Washington Press, Seattle, Washington.

From shock tube experiments it is believed that the primary reaction of $\mathrm{NO}$ removal by ammonia is: $\mathrm{NH}+\mathrm{NO} \rightarrow \mathrm{N}_{2} \mathrm{O}+\mathrm{H}$ with a rate constant of $9 \times 10^{9} \mathrm{~T}^{0.75} \mathrm{~cm}^{3} / \mathrm{mole}-\mathrm{sec}$.

Roose, T. R., R. K. Hanson, and C. H. Kruger. 1979. "Thermal Decomposition of $\mathrm{NH}_{3}$ in Shock Waves." Presented at 12th Int. Shock Tube Symposium, JuTy, 1979, Jervsalem.

Rate constants for the thermal decomposition of ammonia into $\mathrm{NH}_{2}, \mathrm{NH}$, and $\mathrm{H}$ have been determined in shock tube experiments. 
Rubin, A. M. and R. N. Lyon. 1977. "Hazards and Materials Compatibility of Ammonia for Power Plant Applications." ASME paper 77-RC-4.

A general review is presented on the materials compatibility, thermal stability, safety and handiing, storage, and shipping of ammonia. The potential use of armonia as a power plant working fluid and a heat-transport agent is discussed.

Saaski, E. W., and P. C. Owzarski. 1977. "Compatibility Studies for the Ammonia-Titanium-Seawater System as Related to Ocean Thermal Energy Conversion", In Proceedings of the 4th Annual Conference on OTEC, pp. vii-46-53.

Slow tensile strain experiments until failure of titanium rods have been carried out in pure liquid ammonia, ammonia-water (0.025-1.0\%), and ammonia-seawater $(0.065-1 \%)$ mixtures. Results indicate that strain-corrosion-cracking ( $\mathrm{SCC}$ ) can occur, but no single mechanism seems to explain all observed SCC phenomena.

Sabin, C. M., and H. F. Poppendick. 1979. "Ammonia Vaporization and Condensation Investigations Related to OTEC Heat Exchangers." In Proceedings of the 6th OTEC Conference, Pp. 11.9.7-5.

The heat transfer conductances of liquid armonia films evaporating over horizontal round tubes and over tubes with modified surfaces were experimentally investigated. It was found that certain surface modifications improved heat transfer.

Sandru, U. and F. Chiriac. 1977. "Transfer of Heat of Vaporization of Ammonia in Flows Through Horizontal Pipes Under Conditions of a Low Vapor Concentration." Revista de Chemie, 28(1):26-32 (in Romanian).

The theory of two-phase nucleate boiling is applied to anmonia in horizontal pipe flow. Various correlations, published in the pertinent literature, are critically evaluated for their appicability. Measurements are described to verify and/or modify the correlations.

Schrieber, C. F., W. D. Grimes, and W. F. McIl henny. 1979. Interleakage of Armonia in OTEC Exchangers: Effects on Corrosion and Scale Formation. ANL/0TEC-BCM-002, Argonne National Laboratory, Argonne, ITlinois.

The influence of water-ammonia mixtures on proposed OTEC heat exchanger materials has been examined at environmental conditions simulating an OTEC plant exposure. Results have indicated that CP titanium will give best performance, followed by pre-treated aluminum alloy 5052 .

Schuster, J. R., D. L. Urable, and J. P. Huntsinger. 1976. "Binary Plant Cycles Studies for the Gas Turbine HTGR." Paper 76-GT-39, American Soc iety of Mechanical Engineers. 
A supercritical Rankine cycle employing ammonia as the working fiuid is proposed for the secondary power cycle of a Gas Turbine High Temperature Gas Cooled Reactor. A description of the preliminary design of such a plant is given.

Scott, W. D., and D. Lamb. 1970. "Two Solid Compounds Which Decompose into a Common Vapor: Anhydrous Reactions of Ammonia and Sulfur Dioxide." J.Am. Chem. Soc. 92:3943-3946.

The paper describes results from 1 aboratory experiments which suggest that anhydrous (vapor) reactions between $\mathrm{NH}_{3}$ and $\mathrm{SD}_{2}$ produce an unusual and complex system containing compounds in the solid state in equilibrium with the vapor phase. For a 1:l stoichiometric ratio the equilibrium is given by $\mathrm{NH}_{3} \cdot \mathrm{SO}_{2} \rightleftarrows \mathrm{NH}_{3}+\mathrm{SO}_{2}$; however, other stoichiometric ratios have also been observed.

Selyama, T., et a1. 1979. "Catalytic Reduction of $\mathrm{NO}$ with $\mathrm{NH}_{3}$ over Cu(II)NaY." Ind. Eng. Chem. Prod. Res. Dev. 18:279-283.

The effect of a zeolite catalyst for the reduction process of NO with ammonia is investigated. The efficiency of NO reduction is above $90 \%$ for temperatures $>120^{\circ} \mathrm{C}$, if a small amount $(21 \%)$ of free oxygen is present. End products of the process are $\mathrm{N}_{2}, \mathrm{H}_{2} \mathrm{O}$, and $\mathrm{N}_{2} \mathrm{O}$.

Shale, C. C. 1973. "Ammonia Injection: A Route to Clean Stocks." Adv. in Chem. Ser. No. 127:195-205.

Laboratory tests have demonstrated essentially complete removal of $\mathrm{SO}_{2}$ from mixed gases by injecting ammonia vapor and steam. The precipitation of the resulting salt particles yields a low-grade fertilizer (mainly ammonium sulfite). The regeneration of ammonia from this product is another option. The remaining $\mathrm{SO}_{2}$ fraction in the combustion gases is less than $100 \mathrm{ppm}$. The process chemistry for pilot scale operation is described in the article.

Shale, C. C., D. G. Simpson, and P. S. Lewis. 1971. "Removal of Sulfur and Nitrogen Oxides from Stock Gases by Ammonia." In Chem. Eng. Prog. Sym., Ser. 115, 67, pp. 52-58.

The paper presents results of laboratory-scale experiments under selected conditions whereby sulfur and nitrogen oxides react with ammonia in the presence of water vapor. Finely divided ammonium salts are produced which dissolve in the liquid water that appears when the gas is cooled below its dew point. Theory is presented to explain the results obtained from the experiments. A conceptual design is outlined for a plant that would make use of the new process.

Silver, J. A. et al. 1980. Homogeneous Production and Removal of NOx from Combustion Gases. Prog. Rpt. ARI-RP-52. 
Experimental and theoretical studies are underway to describe in a quantitative way the various chemical reactions which occur when ammonia is used for removal of $\mathrm{NO}_{x}$ from combustion exhaust streams.

Silver, J. A. et a 1. N.d. Homogeneous Production and Removal of NO $x$ from Combustion Exhaust Gases. 7th Quarterly Report. ARI-RP-55.

A chemical model of the $\mathrm{N} O \mathrm{x}$ chemistry has been developed which includes 54 reactions. Although not yet complete, the reaction set clearly indicates the key reaction to be $\mathrm{NH}_{2}+\mathrm{NO}$.

Simonis, P. and J. L. Bouhy. 1978. "Use of Solar Energy for Refrigeration With a Water-Ammonia Absorption Machine." Sci. Tech. Froid. 3:235-242.

Experimental results obained with a small, solar-driven absorption refrigerator have demonstrated the technical feasibility of the concept. The dynamic behavior of the total system has been theoretically analyzed.

Slack, A. V. and G. R. James, eds. 1974-1979. Anmonia. Vols. I, II, III, IV, Marce I Dekker Inc. New York, New York.

An extensive monograph on the technology of ammonia manufacture is contained in volumes I, II, and III. The contents of voiume IV deal with handling, storage, and shipping of ammonia and with its final use in the agricultural and chemical industries. Energy-related applications are not covered.

Slusarek, Z. M. 1969. "The Economic Feasibility of the Steam - Ammonia Power Cycle." PB184331.

Binary steam-ammonia power plants are shown to be economically attractive, expecially for sites located in arid regions close to minable coal resources. An overall binary cycle efficiency of $41.8 \%$ is predicted. The paper presents technical details on binary cycle thermodynamics, the ammonia turbine and heat exchanger, and on the dry cooling tower.

Srisukh, S. and T. R. Rehm. 1976. Anmonia from Coal. IECEC paper 769042.

The conceptual design of a process plant which produces liquid ammonia from coal is described. Such a plant is not only technically feasible but also profitaile.

Ste ige Imann, W. H., R. G. Seth, and G. P. Wachtell. 1972. "Binary-cycle Power Plants Using Air-cooled Condensing Systems." In Proceedings of the American Power Conference, pp. 521-530. 
The choice of working fluids and the optimum cycle configuration for binary-cycle power plants with dry cooling towers are discussed. It appears that the use of ammonia would lead to the most economical design of such a system.

Stokes, K. U. 1979. "Compression Systems for Ammonia Plants." CEP. pp. $88-91$.

Gas turbine driven centrifugal compressors are the most efficient and cost-effective compression systems for modern ammonia plants. However, they still require about $20 \%$ of the total energy used to produce ammonia.

Swann, D. R., and G. D. Drisse1. 1980. Feasibility of Retrofitting Catalytic Postcombustion NO $\times$ Controls on an $80 \mathrm{MW}$ Coal-Fired Utility Boiler. EPRI CS-1372.

Two Japanese processes of catalyticaliy reducing $\mathrm{ND}_{x}$ with the aid of ammonia are now considered technically and economically superior to other $\mathrm{NO}_{\mathrm{x}}$ removal schemes. Thus, they were chosen for a design study to retrofit an existing $80 \mathrm{MW}$ power plant with such a system. The specifications, derived from this study, formed the bas is for an RFQ from selected manufacturers.

Takahashi, A., and T. Takeyama. 1977. "Combustion of Fuel 0ils." Japan patent $79-13,510$.

By adding ammonia downstream of the oil burner, the $\mathrm{NO}_{x}$ produced by the combustion can be reduced.

Talib, A. et a1. 1979. "Hydrogen and Alternative Means of Energy Delivery from OTEC Plants." Hydrogen for Energy Distribution. Institute for Gas Technology.

The production and transportation costs and overall energy efficiency of the chemical energy carriers (hydrogen and ammonia) are estimated. The capital and operating costs and efficiencies of converting the delivered hydrogen and ammonia into electricity are also discussed.

Tandy, T. F. 1980. "Rupture of an Anhydrous Ammonia Rail Car." Paper presented at the AIChE Symposium on Ammonia Plant Safety.

A "super jumbo" tank car exploded while being filled at the loading facility. The two people who were operating the facility were killed instantly. No other injuries resulted. No fire erupted. The accident was probably caused by a gouge which the car had sustained in a previous derailment. New periodic inspection procedures for tank cars are proposed.

Tee 1, R. B. 1979. Stress-Corrosion Cracking of Steels in Ammonia: A Survey. ANL /OTEC-BCM-002, pp. 256-278. 
Carbon steel and certain other steels can be subject to stresscorrosion cracking in air-contaminated dry ammonia. Such corrosion is generally inhibited when water or hydrazine is present in the amount of 0.1 to $0.2 \%$ (wt). Little is known of galvanic effects in ammonia between steel and more noble metals.

Tennessee Valley Authority. 1979. Symposium on Ammonia from Coal. Bulletin Y-143, Muscle Shoals, Alabama.

About 30 papers were presented at this symposium describing the various aspects of producing ammonia from coal in the United States.

Thomas, T. R., and D. T. Pence. 1974. "Reduction of NOx with Ammonia over Zeolite Catalyst." In Proceedings of the 67th Annual Meeting of Air Pollution Control Association, Paper No. 75-258.

The catalytic effect of Zeolon-900 (a synthetic modernite produced by Norton Chemical Company) on the reaction efficiency of $\mathrm{NO}$ and $\mathrm{NH}_{3}$ has been investigated. It was found that on a laboratory scale the $\mathrm{NO}_{x}$ abatement was $>95 \%$, even in the presence of $\mathrm{H}_{2} \mathrm{O}, \mathrm{CO}_{2}, \mathrm{O}_{2}$, and $\mathrm{SO}_{2}$. Since the catalyst is not poisoned by $\mathrm{SO}_{2}$, a simitiar process may be effective to reduce both $\mathrm{NO}_{x}$ and $\mathrm{SO}_{2}$ in a single bed.

Tielroy, J. and W. F. VanWeenen. 1980. "New Concept Ammonia with Higher Efficiency." Paper presented at the 25th Symposium on Amonia Plant Safety.

By combining the PSA purification process for hydrogen production and a Rankine cycle for power recovery, a new type of ammonia plant is proposed, which is claimed to operate at higher efficiency than conventional plants.

Tock, R. W., K. C. Hoover, and G. J. Faust. 1979. "Removal by Transformation to Solid Crystals of $\mathrm{NH}_{3}$ Complexes." In Control of Emissions from Stationary Combustion Sources Pollution Detection and Behavior in the Atmosphere. AIChE Symposium Series 188, VoT. 75, pp. 62-82, American Institute of Chemical Engineers, New York, New York.

Reaction of $\mathrm{SO}_{2}$, contained in the stack gases of power plants, with ammonia vapors results in the formation of solid sulfites and sulfates. The study shows that it would require about 34 tons $\mathrm{NH}_{3} /$ day to convert 64 tons $\mathrm{SO}_{2}$ /day (typical for a $100 \mathrm{MW}$ power plant). It is emphasized that the cost of $\mathrm{SO}_{2}$ removal by any process, including this one, is going to be quite large.

Todo, N. et al. 1974. "Reductive Removal of Nitrogen Oxides from Waste Gases," German Patent 2,411,888.

A catalyst (comprising active $\mathrm{Al}_{2} \mathrm{O}_{3}$, CuO or $\mathrm{FeO}$ and $\mathrm{Cr}_{2} \mathrm{O}_{3}$ ) is useful to speed up the reduction of NO by ammonia in the temperature range from 200 to $450^{\circ} \mathrm{C}$. The catalyst is said to be insensitive to $\mathrm{SO}_{2}$ poisoning. 
Tokarz, R. D. et al. 1978. Comparative Cost Study of Four Wet/Dry Cooling Concepts That Use Ammonia as the Intermediate Heat Exchange Fluid. PRL-2661, Pacific Northwest Laboratory, RichTand, Washington.

The four cooling concepts principally studied in this report utilize anmonia liquid-vapor phase change to transfer heat from the steam turbine outlet to the cooling towers. The results indicate that such anmonia systems are potentially more cost-effective than the more standard water cooling systems using integrated wet/dry cooling towers.

Trimble, L. C., and R. L. Potash. 1980. "Design and Construction of an OTEC Test Plant." J. Sol. Energy Eng. 102(1):41-46.

In the mini-OTEC project energy conversion efficiency will be tested for a closed-loop concept with $\mathrm{NH}_{3}$ as the working fluid.

Truscott, J. M. and J. G. Livingstone. 1978. "Safety in Ammonia Plants and Related Facilities." Ammonia Plant Safety, 20:153-155.

Inspection of tanks for ammonia storage at atmospheric pressure and $-33^{\circ} \mathrm{C}$ revealed no stress corrosion cracking, whereas it was present in tanks operating pressurized at ambient temperatures. Trace amounts (above $10 \mathrm{ppm}$ ) of $\mathrm{O}_{2}$ in the $\mathrm{NH}_{3}$ are believed to be responsible by the authors for the occurrence of SCC.

TWR Systems and Energy. 1976. Ocean Thermal Energy Conversion: Test Facilities Study Vol. I, II, III. TI027815.

An integrated test program for OTEC is developed. Ammonia is considered to be the working fluid and is also considered as a potential energy storage and transfer medium.

VanGrieken, K. A. 1975. "Experience with Stress Corrosion Cracking in Ammonia Spheres." Ammonia Plant Safety, AIChE, 17.

The addition of $0.2 \%$ water to the liquid ammonia and the purging of oxygen is helpful to reduce stress corrosion cracking. Use of fracture mechanics test specimen and regular checks on oxygen concentration in the ammonia are recomended for preventive maintenance.

Wakabayashi, T. 1978. "New Pollutant Treating Process for Armonia PTants." Ammonia Plant Safety, 20:17-21.

Ammonia stripped from plant condensates is utilized as the reducing agent in the selective reduction of $\mathrm{NO}_{\mathrm{x}}$ contained in the flue gases of the same anmonia plant.

Wallace, D. P. 1979. "Atmospheric Emissions and Control." Ammonia Plant Safety, 21:51-56. 
Potential hazards are considered for the release of amonia from a safety relief valve. In such cases the vented ammonia vapors are to be flared. However, ignition may not always be guaranteed to occur. So $f$ ar, no accidents of this $k$ ind have been reported.

Waters, E. D. et al. 1975. "The Application of Heat Pipes to the Trans-Alaska Pipeline." IECEC Paper 759218.

Ammonia heat pipes are used in the vertical support members on the above-ground portion of the Alaska pipeline to remove heat from the permafrost during the winter months without auxiliary power or external control devices. This will aid in permafrost degradation during the summer.

Watt, T. 1979. "Little Aid Seen for Ammonia Industry." 0i] \& Gas Journal, $77: 36-38$.

A vast expansion of the ammonia manufacturing capacity was initiated in the late 1960s, when energy costs were still very low. However, when the new plants came on stream in the mid-1970s, the price for $0 i 1$ and gas had escalated. This caused a marked reduction in the growth of the ammonia consumption. Nevertheless, it is forecast that, over the long run, significantly more ammonia will be needed as fertilizer in order to provide food for a rapidly increasing world population.

Wentworth, W. E. et al. 1979. Development of Operational Chemical Cycles for the Storage of Energy. SAND 79-8208, Sandia Nationa 7 Laboratory, A1buquerque, New Mexico.

The thermal decomposition of $\mathrm{NH}_{4} \mathrm{HSO}_{4}$ into ammonia, water, and sulfur-trioxide is being investigated for the energy storage step, and the reverse recombination reaction for the energy regeneration step.

West, E. J. et a1. 1978. "Life Support System for Ammonia Plant Work." Ammonia Plant Safety, 20:140-143.

A life support system made by Bendix provides breathing air to workers operating in atmospheres that will not support life. In ammonia plants it is used for loading catalysts in the synthesis converters.

Widmer, M. and J. Mascarel10. 1976. "Binary Ammonia Cycles." Collect. Dir. Etud. Electr. Fr. 27:147-167.

The feasibility of a binary $\mathrm{H}_{2} \mathrm{O} / \mathrm{NH}_{3}$ cycle is demonstrated using direct ammonia condensing in a dry atmospheric cooling tower. Such a scheme is planned to be used in France with new nuclear power stations. 
Wilbur, P. J., and C. E. Mitche11. 1975. "Solar Absorption Air Conditioning Alternatives." Solar Energy 17:193-199.

The anmonia/water and the water/lithium-bromide types of absorption air conditioners are compared on an analytical basis. It is concluded that on balance the advantages of the lithium-bromide version slightly outweigh those of the ammonia type. If refrigerant storage is included in the cycle, the ammonia-water system may become preferable.

Williams, D. A., and J. B. Tiedemann. 1974. A Heat Pump Powered by Natural Thermal Gradients. IECEC Paper 749041, American Institute of Chemical Engineers, New York, New York.

A three-step aqua-ammonia absorption system is described which operates between sea water and cold air. With a large water storage pond, such a system can provide year-round heating by solar energy, even in subarctic regions.

Williams, D. A. et a1. 1957. Interim Heat Absorption Cooling Systems with Solar Regeneration. ASME Paper 57-A-260, American Society of Mechanical Engineers.

A very simple intermittent cooling system of the ammonia/water type is described which uses solar energy for regeneration. It is estimated that a practical system can be operated for 22 hours/day in the refrigeration mode and that it $c$ an be regenerated within 2 hours, if solar energy is available. If not, another form of energy (e.g., gas or electricity) can be used instead.

Williams, G. P. 1978. "Causes of Ammonia Plant Shutdowns." Ammonia Plant Safety, 20:123-13D.

Shutdowns caused by the synthesis loop (which contains $\mathrm{NH}_{3}$ ) amount to less than $10 \%$ of all shutdowns. Small leaks are the primary cause for shutdowns. The syn-gas compressor is the single most troublesome of all components.

Williams, 0. M., and P. 0. Carden. 1979a. "Energy Storage Efficiency for the Amonia/Hydrogen-Nitrogen Thermochemical Energy Transfer System." Int. J. Energy Res. 3:29-40.

It is shown that energy storage efficiencies for the endothermic ammonia/hydrogen-nitrogen reaction can exceed $90 \%$. The validity of the analytical determination is verified by experimental data.

Williams, 0. M., and P. 0. Carden. 1979b. "Amemonia Dissociation for Solar Thermochemical Absorbers." Int. J. Energy Res. 3:129-142.

It appears that the catalyst is the critical item which would determine the economic value of the concept. 
Williams, 0. M. 1980. "Design and Cost Analysis for an Ammonia-Based Solar Thermochemical Cavity Absorber." Solar Energy 24:255-263.

It is shown that a solar thermochemical cavity absorber, based on the ammonia dissociation reaction, has the potential for being mass-produced at a cost of about $\$ 10 / \mathrm{m}^{2}$. The design and operating parameters of a $10 \mathrm{~m}^{2}$ parabolic absorber have been calculated and are listed in the paper.

Williamson, W. B., and J. H. Lunsford. 1976. "Nitric Oxide Reduction Over Cu(II)Y Zeolites." J. Phys. Chem. 80:2664-2671.

Laboratory tests have shown that the $\left[\mathrm{Cu}\left(\mathrm{NH}_{3}\right)_{4}\right]^{\text {t+ }}$ complex formed in a Y-type zeolite is an active catalyst for the reduction of No by ammonia. Rate maximum was determined at $110^{\circ} \mathrm{C}$. Details of the reaction kinetics were explored.

Wise, H. 1975. "The Ammonia Route to $\mathrm{NO}_{x}$ Conversion in Auto Exhaust Catalysis." In The Catalytic Chemistry of Nitrogen Oxides, eds. R. L. Klimisch and J. G. Larson, pp. 235-246. Plenum Press, New York, New York.

Since previously used catalytic $\mathrm{NO}_{\mathrm{x}}$ reduction methods have not been fully satisfactory, the $\mathrm{NH}_{3}$ route as a possible alternate approach to auto-exhaust control is considered in some detail. A fully satisfactory explanation of the complete reaction mechanism is not yet available, however, because of insufficient information regarding the chemical kinetics of the intermediate reactions.

Wood, B. 1969-1970. "Alternative Fluids for Power Generation." In Proceedings of the Institute of Mechanical Engineers, 184(40):713-740.

The characteristics of various working fluids (besides water) are discussed in detail. Ammonia is one of the more promising types, particularly for bottoming cycles in connection with regular steam plants. Size reduction for the low pressure turbines is considered the main advantage.

Woodhu 11, A. S., M. C. Hu, and G. A. Englesson. 1978. Conceptual Designs and Cost Estimates of Ammonia Dry/wet Cooling Systems. Prepared by United Engineers for Pacific Northwest Laboratory, Richland, Washington.

Conceptual designs and capital cost estimates have been prepared for two different ammonia cooling systems, each sized for a $1000 \mathrm{MW}(\mathrm{e})$ fossil power plant. The two systems are an all-dry system and a deluge wet/dry system, which are estimated at $\$ 102$ and $\$ 87 \mathrm{million}$, respectively (July 1978 prices).

Yoshida, S, et a]. 1979. "Surface Oxygen Species as Active Species in the Reduction of Nitrogen 0xide by Ammonia over Copper Vanadate." Ind. Eng. Chem. Prod. Res. Dev. 18:283-288. 
Copper vanadate can be an active catalyst for $\mathrm{NO}$ reduction by $\mathrm{NH}_{3}$ at low temperatures $\left(2150^{\circ} \mathrm{C}\right)$. The mechanism of this process involves the adsorption of $\mathrm{NO}, \mathrm{NH}_{3}$, and $\mathrm{O}_{2}$ on the surface of the CuV, with oxygen playing the major role in the chemical exchange reactions.

Youn, K. C. 1979. "NH3-Pt Process Promises NOx Control." Hydroc. Process. $58(2): 117-121$.

Tests have shown that ammonia with a platinum catalyst is the most efficient combination for removing $\mathrm{NO}_{x}$ from flue gases. The expected costs for installing and operating such a system are said to be small.

Zaloudek, F. R. et a]. 1976. A Study of the Comparative Costs of Five Wet/Dry Cooling Tower Concepts. BNWL-2122, Pacific Northwest Laboratory, Richland, Washington.

The costs of five alternative wet/dry power plant heat rejection concepts were estimated. One of these concepts consisted of a deluge augmentation cooling tower with an intermediate ammonia evaporationcondensation loop. This concept showed the lowest capitalized operating cost.

Zaloudek, F. R. et a1. 1978. Conceptual Design Study - Advanced Concepts Test (ACT) Facility. PNL-2715, Pacific Northwest Laboratory, Richland, Washington.

The design concept for a test facility is described for demonstrating the use of ammonia as a heat transport fluid in a wet/dry cooling tower. This facility is now under construction near Bakersfield, CA as an addition to an existing coal-fired power plant. 


\section{APPENDIX A}

ACCIDENTAL SPILLS AND HUMAN EXPOSURE 


\section{ACCIDENTAL SPILLS AND HUMAN EXPOSURE}

Accidental spills of ammonia occur in production, storage, transportation and use. This section includes descriptions of some of these spills as they have been reported in the literature.

\section{PRODUCTION}

In November 1975, a metal failure in a high-temperature shift conversion unit occurred at the BASF A. G. plant in Rotterdam. The accident happened during restart of the 1,000-ton/day plant. The metal failure was at a weld in the converter vessel and was caused by "hydrogen cracking." The plant was shut down before any serious leakage of process gas occurred. (Appl, Feind and Lidbe 1976).

In May 1975 a tee in the primary-to-secondary reformer transfer line at Nipak's ammonia plant in Texas ruptured suddenly and violently. The 320-t/day plant was shut down and there were no injuries. The precise cause for the failure was not determined. However, it was theorized that severe erosion of the part contributed to its failure (Isabel1 1976).

In January 1976, carbonic accid corrosion caused a 12-inch process gas line to fail catastrophically at the Farmland Industries, Inc. plant in Kansas. The gas ignited (natural gas, not ammonia) and the shock wave was felt six miles away. A crowd of curious spectators soon gathered. The flash fire was quickly extinguished and no one was hurt. After shutdown, the carbon steel pipe was checked and found to be only $75 \%$ of its original thickness. During cooling of the process gas the carbon dioxide forms carbonic acid that attacks the carbon steel pipe. Stainless steel pipe was used as a replacement (Pebworth 1976).

In 1974, an explosion and fire occurred at the Irish Nitrogen Ltd. plant in Arklow, Ireland. The ammonia shift conversion unit ruptured and the cause was found to be corrosion. No one was injured and the damage was confined mainly to the conversion unit (Casey 1975). 
STORAGE

At the Hills Chemicals, Inc. plant in Early, Iowa, a new 40,000 t low-pressure storage tank was being filled when it was noted that ammonia vapor was coming from under the insulation drain. Corrosion was occurring on the galvanized conduit mounted on the foundation, and the concrete was spalling in areas near ammonia vent points. The tank was emptied, the pinhole leaks repaired and then put into service. The numerous pinholes were attributed to the construction and testing activities conducted on the tank bottom during the cold winter months (Lichtenberg 1971).

In 1970, $160 \mathrm{t}$ of ammonia were spilled at Gulf's refrigerated ammonia storage in Blair, Nebraska. The tank was being filled from barges and the high-level alarm and shutdown system failed to operate. As a result the ammonia spilled and the cloud spread over the surrounding area. No residences in town were evacuated but school children were sent home and several farm residences were evacuated after being alerted by the county sheriff through a loudspeaker from a low.flying plane. Three firemen were treated for fume inhalation but no serious injuries occurred (MacArthur 1971).

In 1973, a 50-t pressure-storage tank in Nata?, South Africa failed, and an estimated $30 \mathrm{t}$ of anhydrous ammonia was released. The failure resulted from a brittle fracture. The ammonia caused the deaths of 18 people. 0ne employee, $45 \mathrm{~m}$ from the tank, was killed outright by the blast; ejght were killed by gas while attempting to escape and three others died within a few days as a direct result of having been gassed. Outside the plant fence, four people died immediately, and two others died several days later. Another 65 required hospital treatment and an unknown number were treated by private doctors (Lonsdale 1974).

TRANSPORTATION

During the period 1971-1975, 239 incidents $^{(a)}$ involving transportation accidents with anhydrous anmonia were reported to the U.S. Department of

(a) Data from Office of Hazardous Materials Operations, U.S. Department of Transportation, Washington, DC. 
Transportation. From 1971 to April 1977, there were 61 incidents that caused injury or death related to the handling or transportation of anhydrous ammonia (NRC 1979).

Quantities too small to be measured (due to pressure release before a safetyvalve shutoff caused by defective or accidentally ruptured fitting valves or by closures of the container) are the predominant cause of injuries during transportation of anhydrous or aqua ammonia. Usually, hospitalization is not required and the injured, having received exposure sufficient to cause eye irritation, minor skin burns, or fume inhalation, are released after treatment.

A number of accidents involving the transportation of anhydrous ammonia have resulted in injuries and death from exposure to it. Some incidents involved transfer of the product at storage facilities or transportation by truck, train, and pipeline.

In 1977 , a hose failed while transferring ammonia from a truck to a $76-\mathrm{m}^{3}$ storage tank at a farm chemical service station in Cedarville, Ohio. Water was sprayed on the hose to reduce the evaporation of ammonia; the water subsequently ran into a nearby creek. Several peat moss dams were built downstream to block the water, to lower and buffer the stream $\mathrm{pH}$, and to absorb ammonia. Hydrochloric acid was then added to the stream to neutralize the effect of the ammonia. The chemicals killed all stream life within $13 \mathrm{~km}$ of the spill; however, the hydrochloric acid neutralization and peat moss dams did reduce the impact. An afterthe-fact study concluded that quicker action could have saved more of the stream and that a dam could have been built to prevent the water from going into the creek (Harsh 1978).

In 1976, during the unloading of a tractor-trailer at a bulk storage plant, a 2-in. (5-cm) liquid transfer hose burst. The failure of the safety devices to shut down resulted in the discharge of $5,500 \mathrm{gal}(14.2 \mathrm{t})$ of anhydrous ammonia. Nine townspeople were treated for inhalation of the fumes and released. Two persons who assisted in the rescue had to be hospitalized because of exposure to the fumes (U.S. DOT 1976a).

In another incident, involving the unloading of a tank-truck in 1971 in Indiana, the driver had completed unloading, had bled off the pressure, and had 
disconnected the hoses and laid them on the ground. While capping the unloading pipe, he accidentally opened the valve for the unloading line, allowing the anhydrous ammonia between this valve and the safety valve to escape. He was not wearing safety clothing. He ran to a water tank and placed his head and shoulders in the water. By the time a witness ran to him, he was limp; he never regained consciousness (U.S. DOT 1973).

In 1973, a cylinder used in servicing air-conditioning equipment and containing 2.2 gal $(5.7 \mathrm{~kg})$ was being transported in the cargo space of a half-ton van truck. The cylinder ruptured (for unknown reasons) as the truck was moving at approximately $60 \mathrm{mph}$ on a freeway in Industry, California. The driver stopped the truck, opened the door, and fell out. Although attended by the highway patrol and a fire rescue squad, he died either at the scene or on the way to the hospital (U.S. DOT 1973).

A catastrophic accident involving a truck occurred in May 1976 in Houston, Texas, when the semitrailer, containing 7,509 gal (19.3 t) of anhydrous asmonia, overturned due to the lateral surge of the liquid and excessive speed of the truck on a curve of a freeway overpass, and plunged $15 \mathrm{ft}$ to the freeway below. The truck's tank exploded, and the explosion split one of the overpass support columns. A 100-ft-high cloud of ammonia developed. Rescue was hampered by the absence of wind under the overpass, which prevented the dispersion of the gas; the danger persisted for approximately $21 / 2 \mathrm{~h}$. Five deaths and 178 injuries were caused by inhalation of the ammonia fumes (U.S. DOT 1976b).

An accident involving two trains occurred in Glen Ellyn, Illinois, in May 1976. It was caused by a faulty outside rail of a curved track that did not comply with federal track safety standards. The locomotive and 27 cars of a freight train overturned, owing to the lateral force on the faulty track. When a second train traveling in the same direction on an adjacent track collided with the derailed train, a tank car in the second train ruptured, releasing $20,000 \mathrm{gal}$. (51.5 t) of anhydrous ammonia. The accident occurred in the early morning, and 3,000 residents were evacuated and kept away for more than $16 \mathrm{~h}$. There were no deaths, and the injuries suffered by 15 people were not serious (U.S. DOT 1976c). 
Some 8,800 gal. (22.7 t) of anhydrous ammonia leaked from the tank car of a train over approximately a mile of track in Reese, Michigan, in April 1976. The accident occurred when a train unloaded one of its cars into the track where the tank car was being unloaded. The cars coupled, and the conductor pulled the cutting lever and signaled the engineer; however, the cars failed to uncouple, and the discharge pipes on the tank car were pulled away, pulling the hoses apart. Local residents were notified to evacuate, and only two people were injured (U.S. DOT 1976d).

In February 1979, a catastrophic train accident occurred in Crete, Nebraska. A train derailed on a curve, and the derailed cars struck cars standing on a siding; a tank car was fractured by the impact and released 29,200 gal. (75.2 t) of anhyrous ammonia. At $6: 30 \mathrm{a} . \mathrm{m}$. , when the accident occurred, the temperature was $4^{\circ} \mathrm{F}\left(-15.6^{\circ} \mathrm{C}\right)$, and there was ground fog, with thin scattered clouds at $12,000 \mathrm{ft}$ and no wind. A temperature inversion had occurred in the area. Several houses close to the railroad were damaged by flying parts from derailed cars and from the burst tank car. Those houses quickly filled with ammonia gas, forcing the residents to abandon them and try to escape. Several residents of other houses smelled the gas, left their homes, and sought shelter. Any person who ventured into the vapor cloud without adequate protection was either killed or seriously injured. Five people were killed immediately by amnonia, another died later, and 53 were injured (28 of them seriously)(NTSB 1971).

The anhydrous ammonia pipeline of the Mid America Pipeline Company (MAPCO) ruptured at Conway, Kansas, in December 1973, releasing 89,800 gal. (231.1 t) of anhydrous ammonia into the atmosphere. The accident was caused by excessive pressure due to the failure of a remote-controlled valve to open when the station at Borger, Texas, began pumping. Pumping was stopped after 9,660 gal. $(24.9 \mathrm{t})$ of anhydrous ammonia had been pumped into the line, and the indicator light on the console in Tulsa, Oklahoma, still showed that the valve had not opened. The $8-i n .(20.3-\mathrm{cm})$ pipeline had ruptured under an initial pressure of at least $1,200 \mathrm{psig}\left(8,275 \mathrm{kN} / \mathrm{m}^{2}\right)$. At the time of the accident, the ground was covered with snow, ice, and sleet. The temperature was near $20^{\circ} \mathrm{F}\left(-7^{\circ} \mathrm{C}\right)$, the sky was clear, and the wind was at $5-10 \mathrm{mph}$. The injured were the drivers 
of two trucks in U.S. Highway 56, within a half-mile $(0.8 \mathrm{~km})$ of the ruptured Tine; they were hospitalized because of ammonia burns to the eyes, nose, throat, and lungs. The ammonia vapor was visible a half-mile from the leak, and invisible but very irritating to the eyes, nose, and throat for another 3.5 miles $(5.6 \mathrm{~km})$. Beyond that point, ammonia order was detectable for another 4 miles $(6.4 \mathrm{~km})$, but did not irritate the eyes, nose, or throat (NTSB 1974).

According to U.S. Coast Guard records from 1971 to mid-1977 few accidents or spills involving ammonia-carrying vessels have occurred. The incidents on record involved tank barges, rather than ships, and involved mostly spills from leaky fittings, valves, or hoses during transfer. During this period, the only catastrophic accident occurred in October 1974. A barge containing 9,000 tons $(8,160 \mathrm{t})$ of anhydrous ammonia and 4,500 tons $(4,080 \mathrm{t})$ of bulk urea broke from the towline during a storm and grounded and sank off Kekur Peninsula, Baranof Island, Alaska. The entire cargo of anhydrous ammonia and urea escaped to the marine environment and the atmosphere. There was no exposure of humans. Some musse1s and starfish died, and approximately a square mile $\left(2.6 \mathrm{~km}^{2}\right)$ of forest in the immediate vicinity was laid waste by anmonia fumes.

$\underline{\text { USE }}$

Reports involving the overturn of nurse tanks on the highway or involving other vehicles can be found in newspapers and police records, but usually indicate a small envelope of danger with few injuries, in most instances involving only the driver or people engaged in rescue or cleanup. Statistics on such accidents appear to be unobtainable.

In agricultural areas, local doctors are seeing the results of on-the-farm exposure of farmers to ammonia. Reports of accidental exposure to a minimal envelope of danger (a spray of liquid, ruptured hose, leaky valve, etc.) have involved loss of eyesight, respiratory problems, and skin burns.

A 40-year-old employee of an anhydrous ammonia distributing company was injured while transferring liquid from a rail car to a nurse tank. The employee was standing on the side walkway of the rail car. The nurse tank filled more 
rapidly than expected; before the employee realized how full it was, the safety relief valve emitted a spray of amtonia. (This valve is designed to prevent the tank from being overfilled--it relieves at $85 \%$ of capacity--and ensures that there is space for the anhydrous ammonia to expand when the temperature rises, without bursting the tank.) The victim, standing about $6 \mathrm{ft}$ above the valve, was sprayed on the face and chest. He immediately jumped to the ground and began to wash his face in a water tank that was on the premises for such emergencies. He was taken to a local hospital, but quickly transferred to a larger hospital. Facial burns were not extremely serious, and both eyes were unaffected; but pulmonary edema and pneumonitis reulting from inhalation developed quickly, with inflammation and edema of the upper airways. A tracheostomy was performed, and aspiration was necessary. Treatment included pressuized oxygen, aminophyliine, and several antibiotics. Recovery was gradual, and the patient was discharged after 11 days in the hospital. There was no residual lung damage (U.S. EPA 1977).

A 17-year-old farm boy who applied fertilizer for a commercial concern was injured during transfer of aqua ammonia (25\% in water). He and his employer were installing a new transfer pump when the accident occurred. With the new pump in place, they started to move the liquid from the nurse tank to the applicator tank. One hose had not been tightened sufficiently and began to leak. Without shutting off the machine, the boy grasped the hose and began to rotate it to make a tight connection. As he did so, the opposite end of the hose flipped out of the applicator tank and sprayed him with several gallons of aqua ammonia. Knocked down but not panicking, he scrambled to his tractor and use his jug of water to wash his eyes. He then ran 70 yards to a nearby creek and immersed himself, but he did not remove his ammonia-soaked clothing. He noted some tightness of his throat during the first few minutes after the accident. He was driven home by his employer, removed his clothing, and rested. He soon noticed, however, that he had received burns to the buttocks from contact with his clothing during the 2-mile ride home. Taken to a local hospital, the victim was treated for a second-degree burns and recovered completely within a few days. No eye injury was sustained (U.S. EPA 1977).

A 36-year-old manager of an anhydrous ammonia retail operation was injured in a farmer's field to which he had been summoned because of improperly functioning 
equipment. The farmer was using a 1,000-gal (3.8- $\left.\mathrm{m}^{3}\right)$ nurse tank connected by direct supply to a seven-row tool bar applicator. Anhydrous ammonia runs from the nurse tank through a hose and quick-coupling device to a flow regulator on the tool bar and from there out through the individual knives into the ground. The coupling device had been leaking, so the manager installed a new one. When the device was tested, by opening the liquid-out valve at the supply tank and permitting ammonia to pass through the hose, leakage occurred again. The man closed the liquid-out valve and attempted to make a tighter connection by jiggling the coupler. The coupler flew apart, and the man was sprayed in the face with anhydrous ammonia that had remained under pressure in the portion of the hose between the coupler and flow regulator. Immediate blepharospasm prevented him from seeing clearly as he got away from the escaping ammonia stream. The farmer who was with him at the time took him to the rear of the nurse tank and helped him pour a 5-gal emergency water supply over his face. He washed with water from a Thermos bottle while being driven 25 miles to a doctor's office, where his eyes were irrigated for several minutes. During the washing, the victim concentrated on the left side of his face, believing that only that part had been affected. His right eye, which in fact had also been sprayed, was thus somewhat neglected and sustained the greater damage, with resulting irritative conjunctivitis and superficial corneal ulceration. Second-degree facial burns were also sustained, and palpebraj edema of the left eye developed of such magnitude as to swell the eye shut several times during the following week. Recovery took a week, and there were no known sequelae (U.S. EPA 1977). Supplementa] Accident Case Histories

The following accident descriptions are presented to supplement those available in previously published reports. The National Research Council report Ammonia (1979) gives details specifically on transportation and agricultural accidents. The AIChE publication "Ammonia Plant Safety and Related Facilities" has reported on some in-plant injury accidents. The accidents described give some feeling for the variety of ways an individual can be exposed to ammonia hazards: 
1. Disabling work injuries involving ammonia systems on cold storage rooms. Data are from a brief summary report provided by the California Department of Industrial Relations, Division of Labor Statistics and Research (1975).

- An engineer at a meat packing house was checking anmonia lines. He opened a valve and ammonia squirted on his right upper leg. He sustained first and second degree burns on his thigh.

- A cleanup man at the meat warehouse for a retail food chain was cleaning the beef cooler when an ammonia leak occurred. He was overcome by fumes.

- A refrigeration mechanic at a frozen food plant was removing a strainer and all the anmonia not purged out of the line sprayed him on the face and chest.

- A plant man at a dairy products distribution center was checking the head pressure in the ammonia system. As he turned the valve, ammonia leaked out and was inhaled into his lungs.

- A creamery maintenance man was repairing an ammonia valve. The bottom blew out and liquid anmonia shot out, burning his hand.

- While adding ammonia to the annomia system, an operating engineer at a food manufacturing plant got ammonia in his right eye. The fill line was not empty when he disconnected it.

- An order filler at a milk plant was filling orders. While in the cold box refrigeration unit, he breathed in ammonia vapors. His lungs were irritated.

- An engineer at a food producing plant was working on the ammonia line when the line broke, spraying him in both eyes. He also inhaled ammonia fumes.

2. A partial list of accepted disabling claims having ammonia as the source of injury for Oregon in 1978. Data are taken from individual worker's compensation data provided by the Oregon Workers' Compensation Department. 
- A tank truck driver was killed when he was overcome by the gas cloud following the rupture of an unloading hose.

- A maintenance worker on a salmon ranch was cleaning the oil trap on a thermal valve at the refrigeration system. Pressure had not been adequately bled off and liquid ammonia was blown into his eyes.

- A clerk for an engineering firm suffered an allergic reaction from the long term exposure to ammonia associated with blueprint machine operation.

- A field hand was burned on the arm by a splash of liquid ammonia when he slipped while rewinding the service hose from a fertilizer applicator.

- A hotel dishwasher suffered burns to his eyes when the ammonia he was pouring into a mop bucket splashed into his face.

- A cold storage operator for a fresh fruit and vegetable processer suffered disabling injury to his lungs and chest from continual exposure to ammonia plant odors and fumes.

- An induction heater operator at a metal extrusion plant inhaled ammonia fumes while assisting in the rescue of coworkers following an ammonia truck unloading accident.

- A night superintendent for a refrigerated lumber warehouse was exposed to ammonia fumes during his routine inspection rounds. An equipment malfunction had caused a compressor room to fill with ammonia vapors. The worker's eyes and lungs were injured after he opened the compressor room door.

- A plant supervisor was removing trash from the attic above a cannery freezer. Another employee, aiding in the cleanup, lost control of a forklift and crashed into the freezer wall. The collision broke a pipe on the high pressure ammonia receiver, thus causing the room to fill rapidly with ammonia vapors. The supervisor suffered burns to eyes and throat while escaping from the room. 
- A meat cutter for a retail grocer was treated for lung irritation and breathing difficulty after exposure to ammonia cleaning solution fumes.

- A maintenance worker at a food processing plant was treated for bronchitis and other respiratory problems. The illness was diagnosed as being related to the long term exposure of the worker to ammonia fumes.

3. Summary of anhydrous ammonia related accidents

These nine case histories represent all the ammonia accidents reported in the National Safety Council Farm Accident Survey (1979). The data are from surveys conducted in 18 states over one-year periods. The cases account for approximately one-quarter of a percent of the total work injuries reported.

- Oregon - March, Friday, 8 a.m. - A son, in the 25 to 44 age category, received severe injury to the eye while filling an anhydrous ammonia tank prior to applying it to a field of corn stalks. The accident was a result of the failure of equipment (hoses, valves or nozzles). Failure to check equipment and damaged safety equipment were indicated as causes.

- Oregon - February, Tuesday, 8 a.m. - A husband, in the 45 to 64 age category, received burns to multiple areas of the body while filling a tank prior to application. Failure of equipment combined with failure of the operator to use protective equipment were cited as the cause.

- Nebraska - April, Friday, 9 a.m. - A husband, in the 45 to 64 age category, received a severe eye injury while applying $\mathrm{NH}_{3}$ during field work. Equipment failure combined with failure to use protective equipment were cited as the cause.

- Oklahoma - October, Tuesday, 7 a.m. - A husband, age unknown, received severe injury to the genital area of the body while filling the tank prior to application. Equipment failure and disregard of safety instructions were cited as the cause. 
- Iowa - November, Wednesday, 5 p.m. - A husband, in the 25 to 44 age category, suffered a severe injury of the eye as the result of leaking container. The individual, a bystander, was unaware of the hazardous condition.

- Iowa - November, Wednesday, 11 a.m. - A part-time employee, in the 25 to 44 age category, suffered a slight injury to multiple parts of the body while doing field work. The injury was caused by a gas from a leaking container. Operator failed to use proper protective equipment.

- Iowa - May, Thursday, 9 a.m. - A son, in the 15 to 24 age category, was doing field work when he was burned on the arm from the chemical as the result of leaking container. Improper cleaning procedures were indicated as the cause.

- Kansas - April, Thursday, 3 p.m. - A husband, in the 45 to 64 age category, received a slight burn on the arm while doing field work. He was applying $\mathrm{NH}_{3}$ when equipment failed. The operator was unaware of the hazardous condition.

- Kansas - April, Monday, 3 p.m. - A husband, in the 45 to 64 age category, was involved in a severe burn to multiple parts of the body. He was filling a tank prior to application. No cause was identified. 


\section{APPENDIX B}

ADIABATIC MIXING OF NH (LIQUID) AND AIR 
APPENDIX B

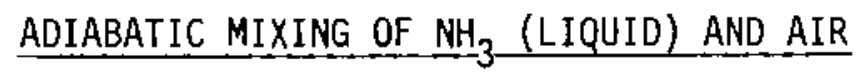

This appendix provides details of the calculations supporting Section 5.1.3. Section B. 1 gives the reader the sample calculations and model details used in the cold spill scenario, and Section B. 2 gives the sample calculations and model details for the isentropic pressurized spill scenario.

For the thermodynamic properties of air and ammonia, the excellent reference of Raznjevic was used (Kuzman Raznjevic, "Handbook of Thermodynamic Tables and Charts," Hemisphere Publishing Company, 1976). Air and $\mathrm{NH}_{3}$ vapor were occasionally assumed to behave as ideal gases for calculation of the density of mixtures of air and $\mathrm{NH}_{3}$ vapor. This assumption will be noted where it is used.

\section{B. 1 THE COLD SPILL}

The cold spill is defined as the spill of $-33^{\circ} \mathrm{C}$ liquid ammonia at 1 atm vapor pressure into the environment. The spill can be divided into two regimes: the adiabatic evaporation of $\mathrm{NH}_{3}$ into air where the heat of evaporation is received from the air, and the non-adiabatic evaporation of $\mathrm{NH}_{3}$ where the heat is received from sources other than the air (e.g., the ground). All real spills are a combination of the two regimes. In calculations for the scenarios, each spill is divided into adiabatic and non-adiabatic parts as presented below.

\section{B.1.1 Adiabatic Calculations}

The perfectly adiabatic spill is one where the ground is a perfect insulator and the ammonia pool at $t=0$ is at $T_{1}=-33^{\circ} \mathrm{C}$ and 1 atm vapor pressure. In the process of receiving heat from the air, the liquid $\mathrm{NH}_{3}$ cools to a steady state temperature $T_{2}$. The sensible heat in the ammonia $C_{p}\left(T_{1}-T_{2}\right)$ also causes evaporation of a certain fraction $(X)$ of the initial spill. The ammonia vaporized by the sensible heat can be theoretically vaporized as pure $\mathrm{NH}_{3}$ vapor at 1 atm and $-33^{\circ} \mathrm{C}$. A heat balance at $\mathrm{T}_{2}$ with the air and a pressure balance requirement at $\mathrm{T}_{2}$ will provide the $\mathrm{wt} \% \mathrm{NH}_{3}$ in the air at equilibrium (saturated). The necessary equations are: 


$$
\begin{aligned}
& p\left(\mathrm{NH}_{3}\right)+p(\text { air })=1 \text { atm } \\
& C_{p}(\text { air })\left(T_{\text {air }}-T_{2}\right) y_{a}=\Delta H_{v} y_{n}
\end{aligned}
$$

where:

and

$$
\begin{aligned}
& \mathrm{p}\left(\mathrm{NH}_{3}\right) \text { is the vapor pressure vs } \mathrm{T} \text { curve for } \mathrm{NH}_{3} \\
& C_{p} \text { (air) = heat capacity of air } \\
& \mathrm{T}_{\text {air }}=\text { initial air temperature } \\
& \Delta H_{v}=\text { heat of vaporization of } \mathrm{NH}_{3} \text { at } \mathrm{T}_{2} \\
& y_{a}=1 \text { bs dry air at } T_{a i r} \text { required to vaporize } y_{n} \text { lbs of } \\
& \mathrm{NH}_{3} \text { at } \mathrm{T}_{2} \\
& v=y_{n} / \rho_{n} \\
& P(\text { Air })=\left(y_{a} / 29\right) R T_{2} / V \text { (ideal gas behavior for air) }
\end{aligned}
$$

where: $\quad \rho_{n}=$ density of pure $\mathrm{NH}_{3}$ vapor in equilibrium with liquid $\mathrm{NH}_{3}$ at $\mathrm{T}_{2}$

$V=$ volume of $\mathrm{y}_{n}$ lbs saturated $\mathrm{NH}_{3}$ vapor at $\mathrm{T}_{2}$

$R=$ gas constant.

Equations B.3 and B.4 can be substituted into B.1 and the resulting equations along with $B .2$ can be solved by trial and error using the data for $\mathrm{p}\left(\mathrm{NH}_{3}\right), \rho$. For $T_{a i r}=298^{\circ} \mathrm{K}$ and $y_{n}=100$ grams, the unknowns $y_{a}$ and $T_{a}$ are $y_{a}=6.59$ grams and $T_{2}=202.5^{\circ} \mathrm{K}=-70.7^{\circ} \mathrm{C}$. Then the weight fraction of $\mathrm{NH}_{3}$ is $\mathrm{X}=6.59$ / $(100+6.59)=0.0624$ and the mole fraction of $\mathrm{NH}_{3}$ is $(6.24 / 17) /[6.24 / 17+$ $94.76 / 29]=0.102$. The density of the mixture at $-70.7^{\circ} \mathrm{C}$ is

$$
\rho_{\mathrm{m}}=[17(.102)+29(1-.102)] /[82.06(2.205)]=1.67 \times 10^{-3} \mathrm{~g} / \mathrm{cm}^{3}
$$

where: molecular weight of $\mathrm{NH}_{3}=17$

$$
\begin{aligned}
& \text { molecular weight of air }=29 \\
& R=82.06 \mathrm{~cm}^{3} \text { atm } /\left(\mathrm{g} \text { mole }{ }^{\circ} \mathrm{K}\right)
\end{aligned}
$$


Since we now know $\mathrm{T}_{2}$, the quantity of $\mathrm{NH}_{3}$ evaporated from the $\mathrm{NH}_{3}$ sensible heat can be calculated. We assume that 100 grams of 1 iquid $\mathrm{NH}_{3}$ at $-33^{\circ} \mathrm{C}$ produces $\mathrm{z}$ grams of vapor at $-33^{\circ} \mathrm{C}$ and $100-z$ grams of liquid at $-70.7^{\circ} \mathrm{C}$. The energy balance is

$$
\begin{aligned}
z \Delta H_{v}\left(-33^{\circ} \mathrm{C}\right)= & (100-\mathrm{z})\left[\mathrm{H}_{\ell}\left(-33^{\circ} \mathrm{C}\right)-\mathrm{H}_{\ell}\left(-70.7^{\circ} \mathrm{C}\right)\right] \\
\Delta H_{v}\left(-33^{\circ} \mathrm{C}\right)= & 326.57 \mathrm{gcal} / \mathrm{g}, \text { heat of vaporization of } \\
& 1 \text { iquid } \mathrm{NH}_{3} \text { at }-33^{\circ} \mathrm{C} \\
\mathrm{H}_{\ell}\left(-33^{\circ} \mathrm{C}\right)= & 64.21 \mathrm{gcal} / \mathrm{g}, 1 \text { iquid } \mathrm{NH}_{3} \text { enthalpy at }-33 \mathrm{C} \\
\mathrm{H}_{\ell}\left(-70.7^{\circ} \mathrm{C}\right)= & 25.2 \mathrm{gca} 1 / \mathrm{g}, \text { liquid } \mathrm{NH}_{3} \text { enthalpy at }-70.7^{\circ} \mathrm{C} .
\end{aligned}
$$

From these values, $z=10.67$; therefore, while the ammonia pool is cooling down, the initial cloud is buoyant pure $\mathrm{NH}_{3}$ vapor which gradually becomes more dense until the final steady state vapor-air mixture is as above. This can be modeled in two parts. The $\mathrm{NH}_{3}$ sensible heat can produce 1) a buoyant cloud of $9.05 \mathrm{x}$ $10^{-4} \mathrm{~g} / \mathrm{cm}^{3}$ at $-33^{\circ} \mathrm{C}$ of $10.67 \%$ of the initial spill and 2) a dense cloud of $89.33 \%$ of the initial spill at $-70.7 \%$ and $\rho=1.67 \times 10^{-3} \mathrm{~g} / \mathrm{cm}^{3}$ containing 6.24 weight $\% \mathrm{NH}_{3}$. These two clouds can be combined into one cloud at $-70.2^{\circ} \mathrm{C}$ $\left(203^{\circ} \mathrm{K}\right.$ ) and $\rho=7.66 \mathrm{~g} / \mathrm{cm}^{3}$ and $7.0 \mathrm{wt} \%$ (11.36 mole $\%$ ) $\mathrm{NH}_{3}$ using appropriate heat capacities.

\section{B.1.2 Adiabatic Evaporation Rates}

With the evaporating insulated pool established at about $-70^{\circ} \mathrm{F}$, estimating the evaporation rate is the next step in the scenario description. For this calculation, the work of Ball (1969) is used. Figure B.l gives evaporation rates as a function of wind speed and temperature and square pool diameter. For the scenario of a 40 ton spil1 a 100-ft x 100-ft square pool would evaporate at about $2 \times 10^{4} \mathrm{lb} / \mathrm{hr}$ according to Figure B.1. Thus, an 88,000 1b (40 ton) spill would evaporate in 4.4 hours.

\section{B.1.3 Non-Adiabatic Calculations}

The purpose of the non-adiabatic calculations is to determine how much heat from sources other than the air can be used to evaporate the ammonia and still maintain a nonbuoyant cloud. To do this, a set of calculations at different fractions of non-adiabatic heat was carried out. The end result is Figure 5.3, 


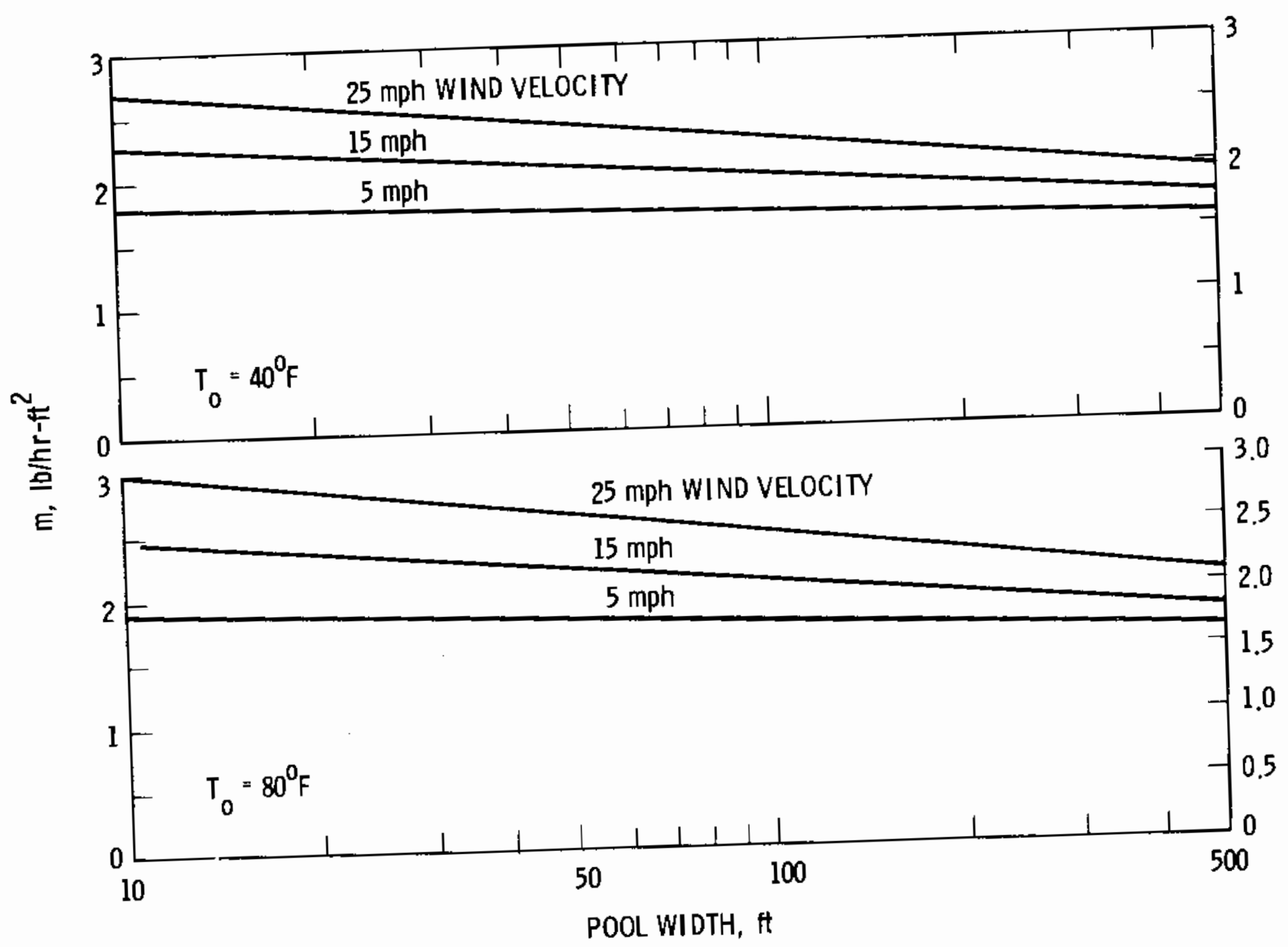

FIGURE B.1. Steady-state Evaporation Rates for Square Liquid Pools (Ba11 1979) 
showing the density, temperature and ammonia concentration of the saturated $\mathrm{NH}_{3}$-air mixture as a function of the fraction of non-adiabatic heat applied. There are two points easily established. Zero percent non-adiabatic heat produces the $-70^{\circ} \mathrm{C}$ saturated cloud of density $1.66 \mathrm{~kg} / \mathrm{m}^{3}$ with $7.0 \mathrm{wt} \% \mathrm{NH}_{3}$. On the other end of the scale, 100\% non-adiabatic heat gives a buoyant cloud of $100 \%$ $\mathrm{NH}_{3}$ at $-33^{\circ} \mathrm{C}$ and density of $0.905 \mathrm{~kg} / \mathrm{m}^{3}$. The following example shows how these values are calculated for points between 0 and 100\% non-adiabatic heat. Two relationships are needed to calculate the two unknowns in the process of adiabatic plus non-adiabatic evaporation. The starting point is one g-mole of dry air (the adiabatic heat source) at $25^{\circ} \mathrm{C}, 1 \mathrm{~atm}$, plus a specified amount of non-adiabatic heat, $q$, and $n$ g-moles liquid $\mathrm{NH}_{3}$ at $-33^{\circ} \mathrm{C}, 1$ atm that evaporate forming $n+1$ moles of $\mathrm{NH}_{3}$ saturated air at $T_{2}$. The heat balance is

$$
q+29(1) C P_{a}\left(25-T_{2}\right)+17 n C p_{n}\left(-33-T_{2}\right)=17 n \Delta H_{v}\left(-33^{\circ} \mathrm{C}\right)
$$

where $n C p_{n}\left(-33-T_{2}\right)$ is the heat given off by the $\mathrm{NH}_{3}$ vapor of heat capacity $C p_{n}$. In the case where $q=29 C_{p_{a}}\left(25-T_{2}\right)$, the non-adiabatic heat (the $50 \%$ non-adiabatic heat point in Figure 5.3), Equation $B .6$ becomes:

$$
2(6.97)\left(25-T_{2}\right)+n(8.364)\left(-33-T_{2}\right)=17 n(326.57)
$$

in units of gram calories. If we solve for $n$ at two points $\left(T_{2}\right)$ and calculate each $n$ and $n+1$ then the line $n /(n+1)$ vs $T_{2}$ intersects the vapor pressure curve $p$ (atm) vs $T_{2}$ at the correct $T_{2}$. For example:

$$
\begin{aligned}
& T_{2}=-50^{\circ} \mathrm{C}, \mathrm{n}=0.193, \mathrm{n} /(\mathrm{n}+1)=0.162 \\
& T_{2}=-70^{\circ} \mathrm{C}, \mathrm{n}=0.245, \mathrm{n} /(\mathrm{n}+1)=0.197
\end{aligned}
$$

On the plot of $p(a \mathrm{tm})$ vs $T_{2}$, Figure B.2, the line between the two points $n /(n+1)=0.197, T_{2}=-70^{\circ} \mathrm{C}$ and $n /(n+1)=0.162, T_{2}=-50^{\circ} \mathrm{C}$ intersects the $p$ versus $T_{2}$ curve at $T_{2}=-62.3^{\circ} \mathrm{C}$ and $p=n /(+1)=0.185$. The corresponding density of the saturated gas at $-62.3^{\circ} \mathrm{C}$ is 


$$
\rho=\frac{(1-.185)(29)}{82.06(62.3+273.2)}+0.187 \times 10^{-3}=1.553 \times 10^{-3} \mathrm{~g} / \mathrm{cc} .
$$

Similarly for other points, the coefficient of $6.97\left(25-T_{2}\right)$ in equation B.7 changes. For example, for $75 \%$ non-adiabatic heat, the coefficient is 4 and for $90 \%$, the coefficient is 10 . Thus the remaining points of Figure B.2 are computed.

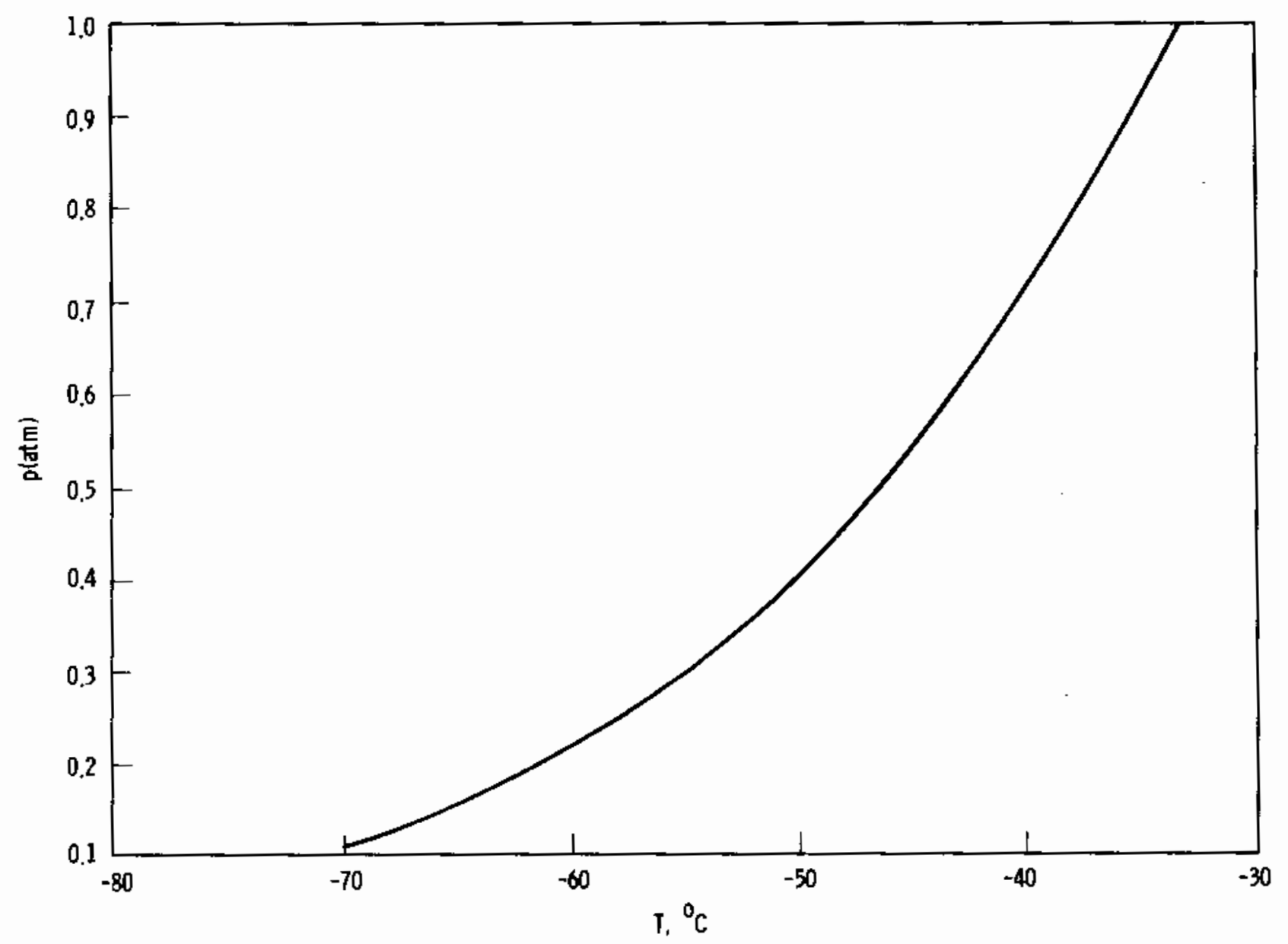

FIGURE B.2. Vapor Pressure of Liquid Ammonia 


\section{B.2 THE PRESSURIZED SPILL}

For the purposes of this report, we have considered the pressurized storage of ammonia to be ambient temperature storage of liquid ammonia with no partial refrigeration. The exact condition chosen for calculations is $25^{\circ} \mathrm{C}(9.9$ atm vapor pressure) and the surrounding air is dry at $1 \mathrm{~atm}, 25^{\circ} \mathrm{C}$. The pressurized spill is assumed to be a jet of the liquid $\mathrm{NH}_{3}$ produced by isentropic flow through a break in the storage system wall or piping. Since the adiabatic mixing with air spans the range of a mass of vapor and droplets to a dense invisible vapor-in-air cloud, the presence of droplets early in the mixing contribute significantly to the fluid properties (i.e., density, temperature and composition). These properties have been calculated in Section B.2.1. Following this, the isentropic blowdown cloud dimensions and properties are calculated from analogies to a 3-dimensional circular jet in Section B.2.2.

\section{B.2.1 Calculation of $\mathrm{NH}_{3}$ Air Mist Properties}

The first step in these calculations is to find the $\mathrm{NH}_{3}$ partition fraction of vapor formed during isentropic blowdown. This is done on T-S (TemperatureEntropy) and or H-S (Enthaipy-Entropy) diagrams for ammonia (Hougen, et al. 1960). A constant entropy 1 ine lets one immediately read the conditions at $-33^{\circ} \mathrm{C}, 1$ atm which is $83 \%$ liquid and $17 \%$ vapor. The enthalpy change results in an exist velocity of $282 \mathrm{~m} / \mathrm{sec}$. (a) The momentum of the blowdown is assumed to cause intimate mixing of ambient air and the $83 \%$ liquid/17\% vapor jet. With the presence of droplets during early stages of the mixing, the method described in Section B.1.1 is not sufficient.

The procedure used to include liquid droplets in equilibrium with the vaporin-air mixture is as follows. Starting with $100 \mathrm{~g} \mathrm{NH}_{3}\left(-33^{\circ} \mathrm{C}, 83 \mathrm{~g}\right.$ liquid, $17 \mathrm{~g}$ vapor), mix $Z$ grams of dry air at $25^{\circ} \mathrm{C}$ ( $Z$ is chosen), calculate the density,

(a) This velocity is the maximum by isentropic expansion based on the initial conditions of $25^{\circ} \mathrm{C}$ and 9.9 atmospheres. During a real blowdown, $1 \%$ of the liquid $\mathrm{NH}_{3}$ would have to evaporate to fill the vessel. In reality the average available energy for blowdown is reduced to the equivalent of the $\mathrm{NH}_{3}$ being at $22.4^{\circ} \mathrm{C}$ and 9.13 atmos. The reduction in velocity is insignificant, and any heat transfer from the ambient air to the liquid in the tank via the tank walls tends to restore the liquid to $25^{\circ} \mathrm{C}$ and 9.9 atmospheres. 
temperature $T_{2}$ and composition ( $y$ grams new vapor) of the mixture. An energy balance gives

$$
\begin{aligned}
& \text { y } \Delta H_{v}\left(-33^{\circ} \mathrm{C}\right)+(17+y) \int_{-33}^{T_{2}} C p\left(\mathrm{NH}_{3} \text { vapor }\right) d T+\int_{-33}^{T_{2}} \mathrm{Cp}\left(\mathrm{NH}_{3} \text { liq. }\right) d T \\
& =-2 \int_{25}^{T_{2}} C p \text { (air) dT. }
\end{aligned}
$$

With constant heat capacities, this becomes

y $\Delta_{v}\left(-33^{\circ} \mathrm{C}\right)+(17+y) \mathrm{Cp}\left(\mathrm{NH}_{3}\right.$ vapor $)\left(\mathrm{T}_{2}+33\right)=-\mathrm{Z}\left(\mathrm{T}_{2}-25\right) \mathrm{Cp}$ (air).

The following values were used:

$$
\begin{aligned}
& \mathrm{Cp}\left(\mathrm{NH}_{3} \text { vapor }\right)=0.492 \mathrm{gcal} / \mathrm{g}^{\circ} \mathrm{C} \\
& \mathrm{Cp}\left(\mathrm{NH}_{3} \text { liq }\right)=1.11 \mathrm{gcal} / \mathrm{g}^{\circ} \mathrm{C} \\
& \mathrm{Cp}(\text { air })=0.2403 \mathrm{gcal} / \mathrm{g}^{\circ} \mathrm{C} \\
& \Delta H_{v}\left(-33^{\circ} \mathrm{C}\right)=326.57 \mathrm{gcal} / \mathrm{g} .
\end{aligned}
$$

The pressure balance $p\left(\mathrm{NH}_{3}\right.$ vapor $)+p(a i r)=1$ atm can be written as mole fraction of $\mathrm{NH}_{3}$ vapor, $\mathrm{MF}\left(\mathrm{NH}_{3}\right)$ :

Equation B.9 then becomes

$$
\operatorname{MF}\left(\mathrm{NH}_{3}\right)=\left[\frac{(y+17)}{17}\right]\left[\frac{(y+17)}{17}+\frac{z}{29}\right] \text {. }
$$

$$
y+17=\frac{-0.2403 Z\left(T_{2}-25\right)-111\left(T_{2}+33\right)+5551.7}{326.57-0.618\left(T_{2}+33\right)}
$$

Procedure for the following example:

Pick $Z=100$, calculate $y+17$ at $T_{2}=-35,-40,-45,-55^{\circ} \mathrm{C}$. 


$$
\text { At } \begin{array}{rlrl}
\mathrm{T}_{2} & =-35^{\circ} \mathrm{C} & \mathrm{y}+17=22.01, & \operatorname{MF}\left(\mathrm{NH}_{3}\right)=0.273 \\
\mathrm{~T}_{2}=-40 & y+17=23.85, & \operatorname{MF}\left(\mathrm{NH}_{3}\right)=0.289 \\
\mathrm{~T}_{2}=-45 & \mathrm{y}+17=25.65, & \operatorname{MF}\left(\mathrm{NH}_{3}\right)=0.304 \\
\mathrm{~T}_{2}=-55 & \mathrm{y}+17=29.15, & \operatorname{MF}\left(\mathrm{NH}_{3}\right)=0.332
\end{array}
$$

The values of $\mathrm{MF}\left(\mathrm{NH}_{3}\right)$ versus $\mathrm{T}_{2}$ are plotted on the curve $\mathrm{p}\left(\mathrm{NH}_{3}\right)$ in atm. versus $T_{2} i n^{\circ} \mathrm{C}$. The intersection is the correct value of $\operatorname{MF}\left(\mathrm{NH}_{3}\right)$ at $\mathrm{T}_{2}$. Here $\mathrm{T}_{2}=$ $-53.5^{\circ} \mathrm{C}$ and $\mathrm{y}+17=28.63$. Thus, $\mathrm{y}=11.63$ grams of $\mathrm{NH}_{3}$ droplets were evaporated in the mixing of 100 grams of dry air with 100 grams of $\mathrm{NH}_{3}$ (83\% liquid, $17 \%$ vapor at $-33^{\circ} \mathrm{C}$ ) to make a new saturated mixture of 28.63 grams $\mathrm{NH}_{3}$ vapor at $-33^{\circ} \mathrm{C}$ ) to 71.37 grams liquid droplets and 100 grams of air, all at $-53.5^{\circ} \mathrm{C}$, $1 \mathrm{~atm}$ pressure. The corresponding density of this mixture is

$$
\rho_{2}=(100+z) \frac{17+y}{\rho_{\mathrm{NH}_{3}} \text { (vapor) }}+\frac{83+\mathrm{y}}{\rho_{\mathrm{NH}_{3}} \text { (liquid) }}, \mathrm{g} / \mathrm{cm}^{3}
$$

$\rho_{\mathrm{NH}_{3}}$ (vapor) = density of saturated $\mathrm{NH}_{3}$ vapor at $-53.5^{\circ} \mathrm{C}, \mathrm{g} / \mathrm{cm}^{3}$

$\rho_{\mathrm{NH}_{3}}$ (1iquid) $=$ density of liquid $\mathrm{NH}_{3}$ at $-53.5^{\circ} \mathrm{C}, \mathrm{g} / \mathrm{cm}^{3}$

The values of $\rho_{\mathrm{NH}_{3}}$ (vapor) and $\rho_{\mathrm{NH}_{3}}$ (liquid) were obtained by interpolation of values in Raznjevic (1976). Here

$$
\rho_{2}=(100+100) \frac{28.63}{3.041 \times 10^{-4}}+\frac{71.37}{0.7067}=2.122 \times 10^{-3} \mathrm{~g} / \mathrm{cm}^{3} .
$$

This process is repeated for more choices of $z$. Finally, a plot of the properties $(\rho, t)$ can be made as a function of composition such as air $/ \mathrm{NH}_{3}$ mass ratio, plotted in Figures $B .3$ and B.4.

\section{B.2.2 Isentropic Blowdown Plume Description}

This section discusses the use of the properties of 2-0 and 3-D turbulent jets to calculate the velocity and concentration profiles in the isentropic blowdown during adiabatic mixing with air. The only reference used is 




FIGURE B.3. Cloud Density and Temperature for Adiabatic Mixing of Dry Air at $25^{\circ} \mathrm{C}, 1$ atm and $\mathrm{Pure} \mathrm{NH}_{3}$ (83\% Liquid Drops, $17 \%$ Vapor) at $-33^{\circ} \mathrm{C}$. Region of No Liquid $\mathrm{NH}_{3}$ Drops 


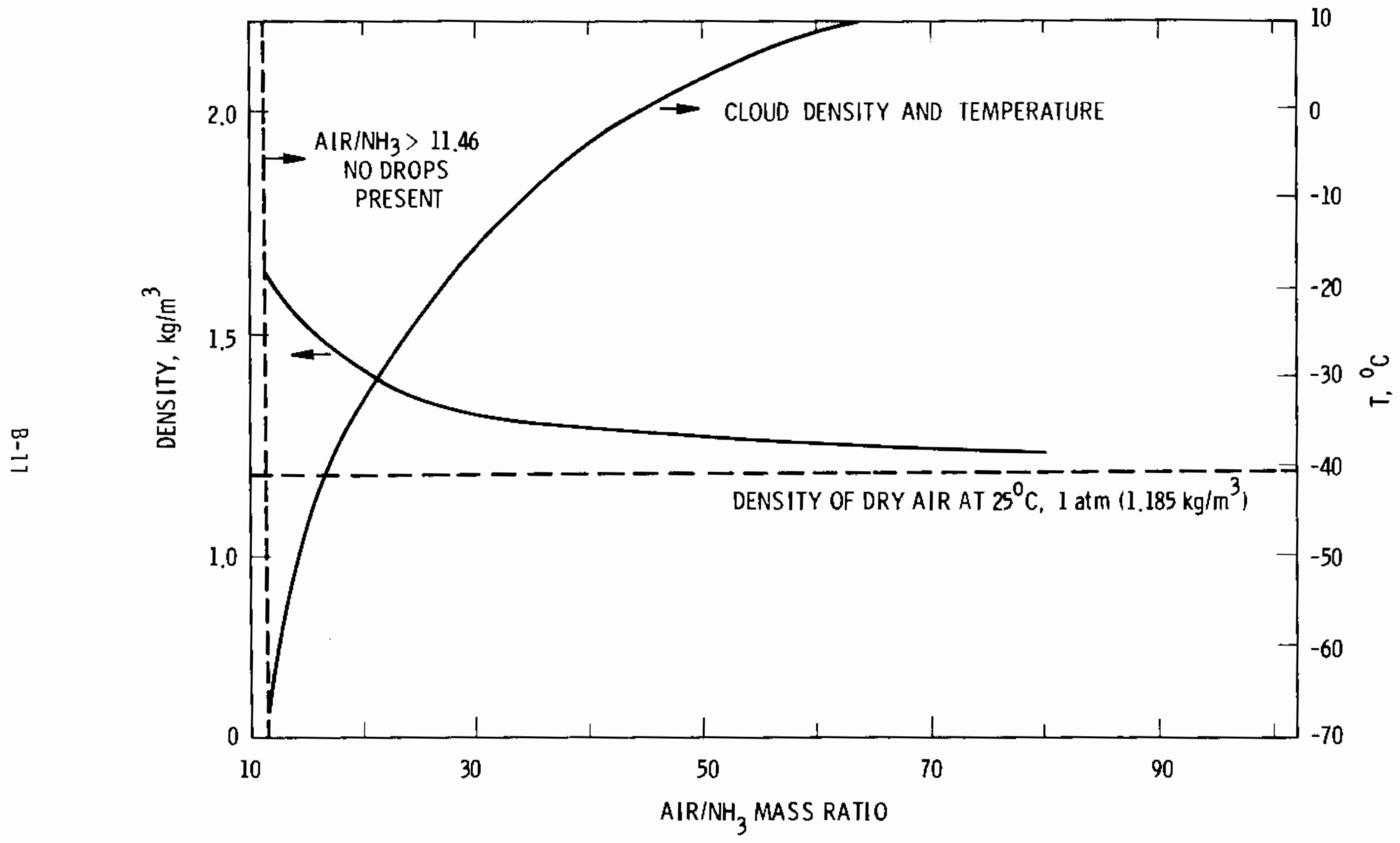

FIGURE B.4. Cloud Density and Temperature for Adiabatic Mixing of Dry Air at $25^{\circ} \mathrm{C}$, 1 atm and $\mathrm{Pure}_{3}$ ( $83 \%$ Liquid Drops, $17 \%$ Vapor) at $-33^{\circ} \mathrm{C}$. Region of $\mathrm{No}^{2} \mathrm{Liquid} \mathrm{NH}_{3}$ Drops 
Schlichting (1968). The details of the algebra and calculus used here is kept to a minimum. The blowdown as a jet of momentum issuing from a circutar hole in space is described as a three-dimensional jet. The momentum profile of the turbulent 3-D jet becomes our model. For mixing, the 2-D turbulent jet is our model wherein the mixing of the jet at centerline velocity Umax and temperature at Tmax into a fluid at $T=0$ is

$$
\frac{U}{U \max }=\left(\frac{T}{T \max }\right)^{2}
$$

We assume that this relationship holds for the 3-D jet and for concentration $C$ as wel1, i.e.,

$$
\frac{U}{U \max }=\left(\frac{c}{C \max }\right)^{2}
$$

where no density or other fluid properties change during the mixing. This is obviously not the case here, but a correction is made for this later in this section.

The 3-D circular jet velocity profile in the jet direction $(x)$ is described

where $\quad n=\frac{1}{4} \varepsilon_{0}\left(\frac{3 K}{\pi}\right) \frac{y}{x}=15.174 \frac{y}{x}$

$$
U=U_{\max } /\left(1+\frac{1}{4} n^{2}\right)
$$

$$
\begin{aligned}
K & =\text { kinematic momentum (constant). } \\
\varepsilon_{0} & =0.00161 \sqrt{K}
\end{aligned}
$$

Since momentum is conserved,

$$
K=2 \pi \int_{0}^{\infty} u^{2} y d y
$$


Likewise is the initial jet mass velocity in $\left(\mathrm{NH}_{3}\right.$ here)

$$
\dot{m}=\int_{0}^{\infty} C i U 2 \pi y d y=2 \pi C_{\max } U_{\max } \int_{0}^{\infty} y\left[\frac{1}{1+\alpha y^{2}}\right]^{3} d y
$$

The integration of $\mathrm{B} .16$ gives

$$
\dot{\mathrm{m}}=4 \pi \varepsilon_{0} \times C_{\max }
$$

From $\mathrm{B} .13$ then, the concentration of $\mathrm{NH}_{3}$ at any point $x, y$ is

$$
c=c_{\max } /\left(1+\frac{1}{4} n^{2}\right), c_{\max }=\frac{\dot{m}}{4 \pi \varepsilon_{0} x}
$$

and $x$ velocity $U=u_{m}^{\prime} /\left(1+\frac{1}{4} n^{2}\right)^{2}$

where $U_{m}^{\prime}=\frac{3 K}{8 \pi \varepsilon_{0} x}\left(\frac{\rho_{0}}{\rho}\right)^{\frac{t_{2}}{2}}$.

which includes a density change correction along the centerline of the form $\rho_{0}^{2} U_{0}^{2}=\rho^{2} U^{2}$ which satisfies an $x$-momentum balance along the centerline.

The procedure for calculating velocity and concentration profiles is as follows:

a. Define break dimensions and storage quantity.

$y_{0}=$ break radius (circular orifice)

$M_{0}=$ mass of antonia

$V_{0}=$ volume of liquid anmonia.

b. Carculate blowdown time, $t_{b}$

$t_{b}=v_{0} /\left(\pi y_{0}^{2} U_{\ell}\right)$

$U_{\ell}=$ iiquid equivalent velocity $=\frac{\rho_{0}}{\rho_{\ell}} U_{0}$

$p_{0}=2$-phase density $\left(5.33 \mathrm{~kg} / \mathrm{m}^{3}\right.$ here $)$

$\rho_{\ell}=1$ iquid density $\left(602.8 \mathrm{~kg} / \mathrm{m}^{3}\right.$ here $)$

$U_{0}=$ isentropic maximum velocity, $282 \mathrm{~m} / \mathrm{sec}$ 
c. Calculate $K, \varepsilon_{0}, \dot{m}=\rho_{0} U_{0} \pi y_{0}^{2}$.

d. Calculate concentration profile from B. 18 which gives the following equation for the isopycnic lines (constant concentration, $\rho_{\mathrm{NH}_{3}}$ )

$$
\begin{aligned}
& y=\frac{x}{15.174}\left[4\left(\frac{C_{\max }}{\rho_{\mathrm{NH}_{3}}}-1\right)\right]^{1 / 2}, \\
& C_{\max }=\frac{\dot{m}}{4 \pi \varepsilon_{0} x} .
\end{aligned}
$$

e. Relate $\rho_{\mathrm{NH}_{3}}$ to $\rho$ to calculate velocities from B.19.

f. Calculate $\int_{0}^{x^{*}} \frac{d x}{U m}=t^{*}$ by trial and error unti] $t^{*}=t_{b}$ and then $x^{\star}=x_{b}$, the approximate length of the cloud at the end of blowdown.

g. The maximum $y$ value for each $\rho_{\mathrm{NH}_{3}}$ is at

$$
x=\frac{\dot{m}}{8 \pi \varepsilon_{0} \rho_{\mathrm{NH}_{3}}} .
$$

h. The cloud volume at $t_{b}$ is (obtained by integration)

$$
\begin{aligned}
v_{c} & =a\left(b x_{b}^{2} / 2-x_{b}^{3} / 3\right) \\
a & =4 \pi /(15.174\rangle^{2} \\
b & =\dot{m} / 4 \varepsilon_{0} \rho_{N_{3}}\left(x_{b}\right) .
\end{aligned}
$$

i. Normalize all concentration profiles by the factor

$$
\left[\frac{M_{0}}{\dot{m} x_{b}^{2}(15.174)^{2} 4 \varepsilon_{0}}\right] .
$$


This latter factor was 0.511 for the case illustrated in Section 5.1.4.2. The assumptions of this application of 2-D and 3-D jets result in a mas balance error of about a factor of 2 . 



\section{APPENDIX C}

AN ANALYTICAL EXAMINATION OF THE FIRE AND EXPLOSION HAZARDS OF AMMONIA 


\section{APPENDIX C}

\section{AN ANALYTICAL EXAMINATION OF THE FIRE AND EXPLOSION HAZARDS OF AMMONIA}

This appendix uses basic chemical thermodynamic principles to evaluate the combustibility, ignition characteristics and flame stability of ammonia. The properties of ammonia as a fuel are compared to ethanol because it is a fuel with well-known characteristics. Finally, the pool burning characteristics of amonia are evaluated to determine the likelihood of flames or explosions in the event of a spill in the presence of an ignition source.

\section{C.1 AMMONIA COMBUSTION}

The combustion of armonia in air, carried to completion, may be written as:

$$
\begin{aligned}
& (4 \phi) \mathrm{NH}_{3}+3\left(\mathrm{O}_{2}+3.76 \mathrm{~N}_{2}\right) \text { reactants } \rightarrow 6 y \mathrm{H}_{2} \mathrm{O}+(3[3.76]+2 y) \mathrm{N}_{2}+ \\
& 3(1-y) \mathrm{O}_{2}+4(\phi-y) \mathrm{NH}_{3} \text { products. }
\end{aligned}
$$

The equivalence ratio, $\phi$, determines the amount of fuel relative to the oxidant available. If the equivalence ratio equals unity, all available fuel and oxygen are consumed. If it is greater than unity, the oxygen present is insufficient to burn all of the fuel. Therefore, some fuel is left in the product side of the reaction. If the coefficient, $\phi$, is less than unity, the amount of fuel is insufficient to burn all of the oxidant. Subsequently, the combustion products contain oxygen. In the above reaction, nitrogen, $\mathrm{N}_{2}$, is assumed to be inert and appears in the same amount on either side of the equation. In summary,

$$
\begin{aligned}
& \phi<1+\text { fuel-lean } \\
& \phi=1+\text { stoichiometric } \\
& \phi>1+\text { fuel-rich. }
\end{aligned}
$$


The function $y$ appearing in Equation (C. 1 ) is actually a function of $\phi$ and is given as shown in Figure C.1. Examination of this equation indicates that this function prevents the appearance of fuel or oxidant on the products side of a fuel-lean or fuel-rich combustion, respectively.

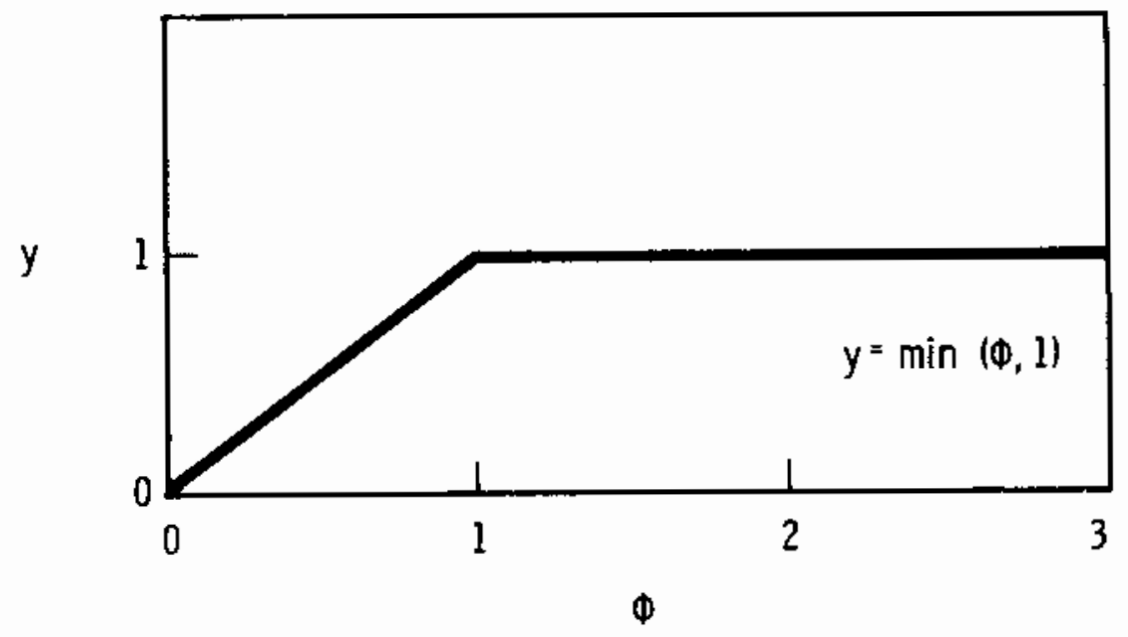

FIGURE C. . . Graph of the $y(\phi)$ Function

\section{C.1.1 First Law Analysis}

For the purposes of this analysis, the changes in kinetic and potential energy across the flame zone (designated as the zone in which the temperature and combustion products attain their final value) are assumed to be negligible. The first law then may be expressed as:

$$
H_{r}=H_{p}
$$

that is, the enthalpy of the reactants equals the enthalpy of the products. The total enthalpy on either side of Equation (C.3) is a sum of the individual enthalpies, $H_{i}$, defined as:

$$
H_{i}=n_{i}\left(h_{f}^{0}+\Delta h\right)_{i}
$$


where

$$
\begin{aligned}
n_{i} & =\text { number of moles of species, } i . \\
h_{f}{ }^{0} & =\text { enthalpy of formation of species, } i .
\end{aligned}
$$

and

$\Delta \bar{h}_{i}=\int_{T_{0}}^{T} c_{p} d T=$ the sensible enthalpy change of species, $i$.

Thus, Equation (C.3) may be expressed as:

$$
\sum_{i=r} N_{i}\left(\hbar_{f}^{0}+\Delta \bar{h}\right)_{i}=\sum_{j=p} n_{j}\left(\hbar_{f}^{0}+\Delta \hbar\right)_{j} .
$$

The heats of formation, $\bar{h}_{\mathrm{f}}{ }^{0}$, of pure substances in their natural state $\left(\mathrm{N}_{2}, \mathrm{O}_{2}\right.$ in this problem) at a standard temperature, $T_{0}\left(=298.15^{\circ} \mathrm{K}\right.$ in JANAF tables $)$, are taken as zero. The enthalpy of formation, $\bar{h}_{f}{ }^{0}$, for the $\mathrm{NH}_{3}$ and $\mathrm{H}_{2} \mathrm{O}$ is the enthalpy required to form these species from standard state elements such as $\mathrm{H}_{2}$ and $\mathrm{N}_{2}$ at $\mathrm{T}_{0}$, the standard state temperature. Table $\mathrm{C} .1$ gives the heats

\begin{tabular}{|c|c|c|}
\hline as & $\mathrm{h}_{f}{ }^{0} \frac{\mathrm{kcal}}{\mathrm{mol}}$ & $c_{p}-\frac{c a l}{g-m o l}-o_{k}^{(a)}$ \\
\hline & 0.00 & $9.3355-122.56 \theta[-3 / 2]+256.38 \theta[-2]$ \\
\hline & 0.00 & $8.9465+.0048044 \theta[3 / 2]-42.679 \theta[-3 / 2]$ \\
\hline & -57.79 & $34.190-43.868 \theta[1 / 4]+19.778 \theta[1 / 2]$ \\
\hline & -10.97 & $6.086+.8812 \theta-.001506 \theta[2]$ \\
\hline
\end{tabular}
of formation and specific heats of the species involved.

TABLE C.1. Heats of Formation and Specific Heats

(a) $A \theta[B]$ should be read $A \theta^{B}$.

The sensible enthalpy change may be obtained by inserting the specific heat, $c_{p}$, for each gas into Equation (C.4d) and integrating from the standard state to the desired temperature. The integration is performed using the transformation:

$$
d T=100 d \theta
$$

and the resulting functions are listed in Table C.2. 
TABLE C.2. Sensible Enthalpy Functions

\begin{tabular}{|c|c|}
\hline & $\Delta \hbar_{j}\left[\frac{c a l}{g-\text { mol }}\right]$ \\
\hline & $-9483.09+933.55 \theta+24512.0 \theta[-1 / 2]-25638.0 \theta[-1]$ \\
\hline & $-5714.88+894.65 \theta+.192176 \theta[5 / 2]+8535.8 \theta[-1 / 2]$ \\
\hline & $-2839.49+3419.0 \theta+3509.44 \theta[5 / 4]+1318.53 \theta[3 / 2]$ \\
\hline & $-2192.90+608.6 \theta+44.06 \theta[2]-.502 \theta[3]$ \\
\hline
\end{tabular}

Equation (C.5) now reduces to:

$$
\begin{aligned}
& 4 \phi\left(-10.97 \frac{\mathrm{kcal}}{\mathrm{mol}}\right)-6 y\left(-57.8 \frac{\mathrm{kcal}}{\mathrm{mol}}\right)-(\phi-y)\left(-10.97 \frac{\mathrm{kal}}{\mathrm{moT}}\right)= \\
& 6 y \Delta \hbar_{\mathrm{H}_{2} \mathrm{O}}+(3[3.76]+2 y) \Delta \hbar_{\mathrm{N}_{2}}+3(1-y) \Delta \mathrm{h}_{\mathrm{O}_{2}}+4(\phi-y) \Delta \mathrm{h}_{\mathrm{NH}_{3}} .
\end{aligned}
$$

Using the quantities tabulated in Tables C.1 and C.2, Equation (C.7) is solved iterativeiy, by trial and error, for various values of the equivalence ratio, $\phi$. The value of temperature for which Equation (C.7) becomes an equality is known as the "adiabatic flame temperature" (AFT) and it is one of the most fundamental parameters of combustion theory. It should be noted that Equation (C.7) tacitiy assumes that the spilled ammonia has mixed with the surrounding air at the given equivalence ratio, $\phi$, and the reference state temperature, $T_{0}$, before combustion is initiated. ${ }^{(a)}$ A plot of the adiabatic flame temperature as a function of $\phi$ is shown below in Figure C.2. The data values used for these plots are given below in Table C.3.

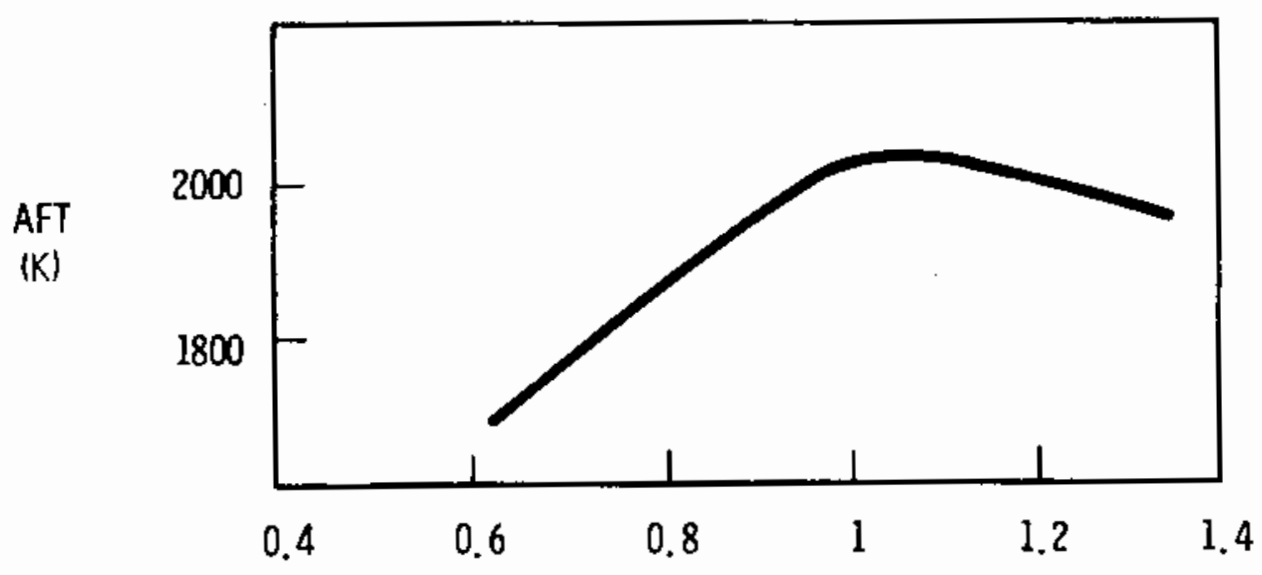

FIGURE C.2. AFT Versus Equivalence Ratio

(a) This implies that the AFT calculated here will probably be high. 
TABLE C.3. Adiabatic Flame Temperature (AFT) in ${ }^{\circ} \mathrm{K}$ Versus Equivalence Ratio, $\phi$ (Amnonia Combustion in Air)

$$
\begin{array}{clllllllll}
\phi & .63 & .7 & .8 & .9 & 1.0 & 1.1 & 1.2 & 1.3 & 1.383 \\
\text { AFT } & 1638 & 1737 & 1872 & 1996 & 2109 & 2058 & 2009 & 1963 & 1925
\end{array}
$$

\section{C.1.2 Flammability Limits}

The limits of the abscissa $(\phi=.63$ and 1.383$)$ in Figure $C .2$ are not arbitratily chosen but represent the equivalence ratio which corresponds to the upper and lower flammability limits (UFL and LFL, respectively). By using Amagat's principle, ${ }^{(a)}$ the volume fraction of ammonia, $\frac{\mathrm{NH}_{3}}{\mathrm{~V}_{\mathrm{T}}}$, at the initial

$$
\frac{V_{\mathrm{NH}_{3}}}{V_{T}}=\frac{{ }^{n_{N H}}}{n_{T}}=\frac{P_{N_{3}}}{P_{T}}=\frac{4 \phi}{4 \phi+3+11.28} \text { (total moles in mixture) }
$$

The flammability limits of ammonia in air are given below in volume fractions:

$$
\begin{aligned}
& \mathrm{LFL}=15 \% \mathrm{NH}_{3}=.15 \text { (volume fraction) } \\
& \mathrm{UFL}=28 \% \mathrm{NH}_{3}=.28 \text { (volume fraction) }
\end{aligned}
$$

These equations may be substituted into the LHS of Equation (C.3), which is then solved for $\phi$. The resulting values for the LFL and UFL are those expressed above.

\section{C.1.3 Chemical Kinetics of the Ammonia-Air Reaction}

The expression for the rate of change of ammonia concentration may be expressed by a global Arrhenius reaction rate given by Equation (C.2):

$$
\dot{W}_{f}^{\prime \prime \prime}=-\frac{d}{d t}\left[\mathrm{NH}_{3}\right]=10^{B} \exp (-E / R T)\left[\mathrm{NH}_{3}\right]^{f}\left[\mathrm{O}_{2}\right]^{\mathrm{n}-\mathrm{f}}\left(\frac{\mathrm{mol}}{\mathrm{cm}^{3}-\mathrm{sec}}\right)
$$

(a) Simply stated, Amagat's principle is that a gas (A) occupying a container with another gas (B) may be considered as occupying its own volume, $V_{A}$, according to $\frac{P_{A}}{P_{T}}=\frac{V_{A}}{V_{T}}=\frac{n_{A}}{n_{T}}$. 
where

$$
\begin{array}{ll}
B=13.63 & \pm .22 \\
E=34.77 \mathrm{kcal} / \mathrm{mol} & \pm 1.65 \\
f=.75 & \pm .12 \\
n=1.95 & \pm .11 .
\end{array}
$$

This expression was obtained from experimental data obtained for the pressure range:

$$
\frac{1}{2} \operatorname{atm}<\mathrm{P}_{T}<1 \mathrm{~atm} .
$$

\section{C.1.4 Laminar Flame Theory}

Mallard and Le Chatelier first studied the propagation of a laminar flame through aquiescent media. Based upon their phenomenological reasoning, they arrived at the following expression for the flame speed (defined as the velocity of the flame front with respect to the unburnt gas in front of the flame):

$$
U_{0} \sim\left(\frac{k}{\rho c_{p}}[R R]\right)^{\frac{1}{2}}
$$

where $R R$ is the reaction rate. Glassman (1977) raises the question whether more complex theories tell any more. The problem was put on firmer mathematica] grounds by the Russian School of Combustion (Semenov, Veldovich, and others), who analyzed the flame structure with a singly dimensional coordinate system moving with the flame. The analysis consisted of the one-dimensional conservation of mass, species, and energy. They demonstrated that the reactant species and energy equations could be cast in identical form if:

$$
D \rho=k / c_{p}
$$

Therefore, one equation could be used to completely analyze the system. Needless to say, the energy equation was the most fruitful one to solve.

The one-dimensional energy equation for a reacting system is

$$
\frac{d}{d x}\left(k \frac{d T}{d x}\right)-\dot{m}^{\prime \prime} c_{p} \frac{d T}{d x}+\dot{W}_{f}^{\prime \prime \prime} \Delta H=0 .
$$


The flame is divided into two zones, a pre-heat zone in which the heat generation term is zero and a quasi-isothermal reaction zone in which the convection term is nearly zero. This equation is then solved for both regions. Figure C.3 is a schematic of the flame structure.

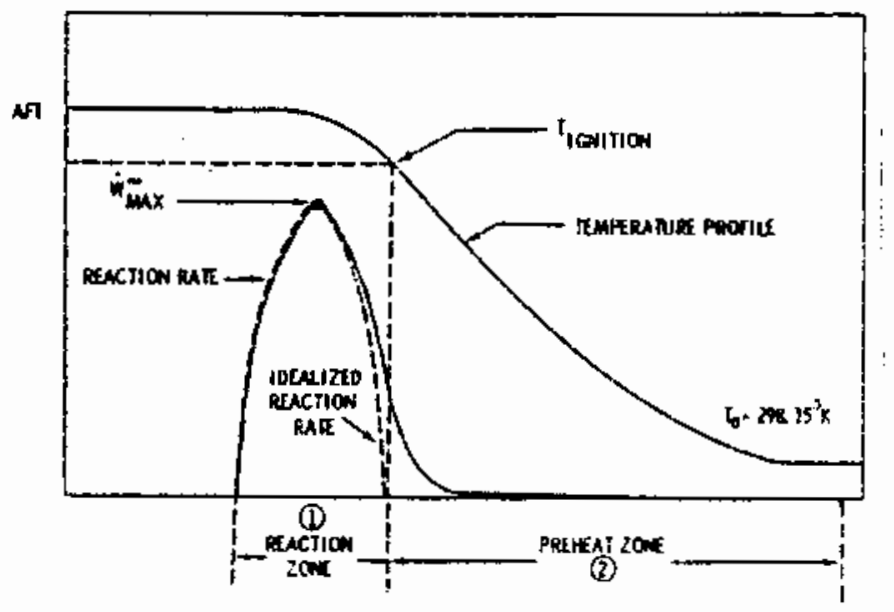

FIGURE C.3. Therma] Flame Structure

\section{C.1.5 Preheat Zone Analys is}

By neglecting any heat release in the pre-heat zone, Equation (C.14) may be rewritten as:

$$
\frac{d}{d x}\left(k \frac{d T}{d x}\right)-\dot{m}^{\prime \prime} c_{p} \frac{d T}{d x}=0
$$

Integrating once with respect to $x$ yields $(a)$ :

$$
k \frac{d T}{d x}=\dot{m}^{\prime \prime} c_{p} T+c
$$

where $C$ is the unknown constant of the integration. Evaluating Equation (C.16) at the cold boundary, $x=\infty$, where the temperature gradient is zero, results in:

$$
c=-\dot{m}^{\prime \prime} c_{p}^{\top} 0 .
$$

(a) This analysis assumed constant specific heat, $c_{p}$. 
The application of Equation (C.16) at the ignition edge of the reaction zone leads to the expression for the thermal heat flux at the interface of the two zones:

$$
\left.\left.k\right|_{T_{i}} \frac{d T}{d x}\right|_{1,0}=\dot{m} " c_{p}\left(T_{i}-T_{0}\right) .
$$

\section{C.1.6 Reaction Zone Analys is}

The main problem in solving Equation (C.14) is that the heat production term is extremely nonlinear and temperature-dependent (compare to Equation C.10). Figure C. 3 shows the typical flame structure present when Arrhenius-type reaction rates are present. The fuel reaction rate does not become significant until the fuel-air mixture has been heated to near a somewhat arbitrary ignition temperature, $T_{i}$. At this point, the reaction takes off, producing a lot of energy, which sustains the flame. The reaction rate peaks somewhere behind the flame front and falls rapidiy to zero as the reactants (ammonia and air, in this case) are depleted.

Because the heat generation rates and conduction heat transfer are changing rapidly in this region while the temperature profile changes little, the convection term in Equation (C.14) can be ignored. Because the reaction zone is nearly isothermal, the thermal conductivity may be considered constant for the analysis of this region. Equation (C.14) may then be expressed as:

$$
\frac{d^{2} T}{d x^{2}}+\frac{\Delta H \dot{w}_{f}^{\prime \prime \prime}}{k_{1}}=0
$$

Multiplying Equation (C.19) by the temperature gradient and rearranging yields:

$$
\frac{d T}{d x}\left(\frac{d^{2} T}{d x^{2}}\right)=\frac{d}{d x}\left[\frac{1 / 2}{2}\left(\frac{d T}{d x}\right)^{2}\right]=-\frac{\Delta H \dot{W}_{f}^{\prime \prime \prime}}{k_{1}}\left(\frac{d T}{d x}\right) .
$$

Upon integration from the ignition temperature, $T_{i}$, to the adiabatic flame temperature, AFT, Equation (C.20) becomes:

$$
\left(\frac{d T}{d x}\right)_{-\infty}^{2}-\left(\frac{d T}{d x}\right)_{2,0}^{2}=\frac{-2 \Delta H}{k_{1}} \int_{T_{i}}^{A F T} \int_{f}^{\prime \prime \prime \prime} d T
$$


and, therefore,

$$
\left.\frac{d T}{d x}\right|_{2,0}=\left[\left.\frac{2 \Delta H}{k_{2}} T_{i} f_{f}^{A F T}\right|^{\prime \prime \prime \prime} d T\right]^{\frac{1}{2}} .
$$

For zero order reactions (i.e., reactions not dependent on the concentration of either reactant) the integral can be evaluated exactly. Since $n$ and $f$ in Equation ( $C .10)$ are nonzero, the reaction rate depends on the temperature, and the local concentration of ammonia and air. Equation (C.22) is, therefore, not directly integrable.

\section{C.1.7 Flame Speed and Thickness}

The speed of flame propagation with respect to the unburnt gases ahead of it may be obtained by equating the temperature gradients between zones 1 and 2 . The flame velocity, $u_{0}$, and density of the unburned cloud, $\rho_{0}$, are related to $\dot{m}^{\prime \prime}$ in Equation (C.18) by the relation:

$$
\dot{m}^{\prime \prime}=\rho_{0} u_{0} \text {. }
$$

Solving for the flame speed yields:

$$
u_{0}=\left[\frac{2 \Delta H k}{\rho_{0}^{2} C^{2}\left(T_{f}-T_{s}\right)^{2}} T_{0}^{\rho_{f}} \dot{W}_{f}^{\prime \prime \prime} d T\right]^{\frac{1}{2}} .
$$

Notice that the range of integration has been enlarged $T_{i} \rightarrow T_{f}$ to $T_{0} \rightarrow T_{f}$ on the assumption that 7 ittle reaction occurs between the initial temperature, $T_{0}$, and the ignition temperature, $T_{i}$. The temperature difference in the denominator should contain $T_{i}$, but this was replaced by the adiabatic flame temperature, $T_{f}$, on the assumption that reaction occurs mainly near the ignition temperature. Thus, the unknown ignition temperature, $T_{i}$, has been eliminated from the calculation.

The flame thickness is somewhat arbitrarily defined as the zone in which the temperature rises from the ambient temperature, $T_{0}$, to the ignition temperature, $T_{i}$. Typicaliy, the reaction zone is much smaller than the preheat zone 
in a flame, and its thickness is not included in the flame thickness. This may not be the case for ammonia combustion because the kinetics are much slower. A calculation of the thickness of the reaction zone would require a complex analysis for little benefit.

Equation ( $C .15$ ) can be integrated directly by using an integrating factor to yield:

$$
\frac{d T}{d x}=c_{1} \exp \left[\frac{\dot{m} c_{p} x}{k}\right]
$$

which can be further integrated to

$$
\frac{T-T_{0}}{T_{f}-T_{0}}=\exp \left[\frac{\dot{m} c_{p} x}{k}\right] .
$$

The argument of the exponential clearly governs the "decay rate" of the flame. The flame thickness may be arbitrarily defined as the value of the abscissa, $x$, which makes the exponent in Equation (C.26) equal to -2 , namely:

$$
\delta_{f}=\frac{2 k}{\rho_{0}\left|u_{0}\right| c_{p}}=\frac{2 \alpha_{0}}{\mid u_{0} T} \text {. }
$$

Thus, the faster the flame speed, the thinner the flame zone.

A method is now needed to determine the heat production terms in Equation (C.24).

The heat liberated per mole of ammonia burned may be calculated from Equation (C.7). This heat liberated goes into the sensible enthalpy change of the product's species, such as water vapor. Dividing Equation (C.7) by the number of moles of fuel $(4 \phi)$ while neglecting the sensible enthalpy terms, $\Delta h_{i}$, yields:

$$
\Delta \mathrm{H}_{\mathrm{NH}_{3}}=\frac{4 \phi}{4 \phi}(-10.97)-\frac{6 y}{4 \phi}(-57.7) \frac{-4(\phi-y)}{4 \phi}(-10.97)
$$

(heat liberated per mol of $\mathrm{NH}_{3}$ ) 
or, upon rearranging,

$$
\Delta \mathrm{NH}_{3}=\frac{y}{\phi}(75.58)\left(\frac{\mathrm{kca}]}{\mathrm{mol} \text { of } \mathrm{NH}_{3}}\right) .
$$

The expression for the average combustion rate of the ammonia in Equation (C.24) must now be estimated. Equation (C.24) cannot be integrated directly since the molal concentration and Arrhenius form depend on temperature and thermodynamic history of the combustion process. Attempts to determine this numerically were not justified on the grounds that the increased accuracy. was not worth the expenditure of time and money. Therefore, a conservative estimate was made for the quantity.

The maximum possible combustion rate of the ammonia would occur at the highest possible flame temperature (i.e., the adiabatic flame temperature) for the mixture under combustion. The average fuel combustion rate used in Equation (C.24) must certainly be below this value. Thus, the flame speed calculated in this manner is conservative (i.e., higher flame speeds will be predicted than if a more rigorous calculation were made) in three ways:

- The reaction is assumed to go to completion (very unlikely under accident conditions).

- The initial mixture of ammonia and air is assumed to be perfectly mixed at equivalence ratio, $\phi$, at $77^{\circ} \mathrm{F}\left(298.15^{\circ} \mathrm{K}\right),{ }^{(a)}$ resulting in a higher adiabatic flame temperature.

- Depletion of reactants must cause a decrease in the rate of their combustion eventualiy.

Examination of Figure C.3 suggests another possible method for estimating the heat release. The actual reaction rate curve (solid line) can be approximated by half a sinusoid, originating at $x=D$, apexing at the maximum reaction rate, $\dot{W}_{\text {max }}^{\prime \prime \prime}$, as calculated before, and falling off to zero as the reaction

(a) In reality, the mixture will be colder, since the spilled ammonia boils at $-28^{\circ} \mathrm{F}\left(-33.3^{\circ} \mathrm{C}\right)$. 
terminates. This method probably underestimates the integral in Equation (C.24) because it neglects all reaction prior to the ignition point, $x=0$. Thus, these two methods should "bracket" the actual reaction rate:

$$
\frac{2}{\pi^{\prime}} \dot{W}_{\max }^{\prime \prime \prime}<\frac{1}{\left(T_{f}-T_{0}\right)} f_{T_{0}}^{T_{f}} \dot{W}_{f}^{\prime \prime \prime} \mathrm{dT}<\dot{W}_{\max }^{\prime \prime \prime} .
$$

\section{1.8 Results}

The flame speed, $u_{0}$, calculated from Equation (c.24) and Inequality (C.30), using the upper and lower reaction rates, is shown in Figure C.4 for ammonia concentrations between the lower and upper flammability limits. The tabulated values of these quantities are listed in Table C.4.

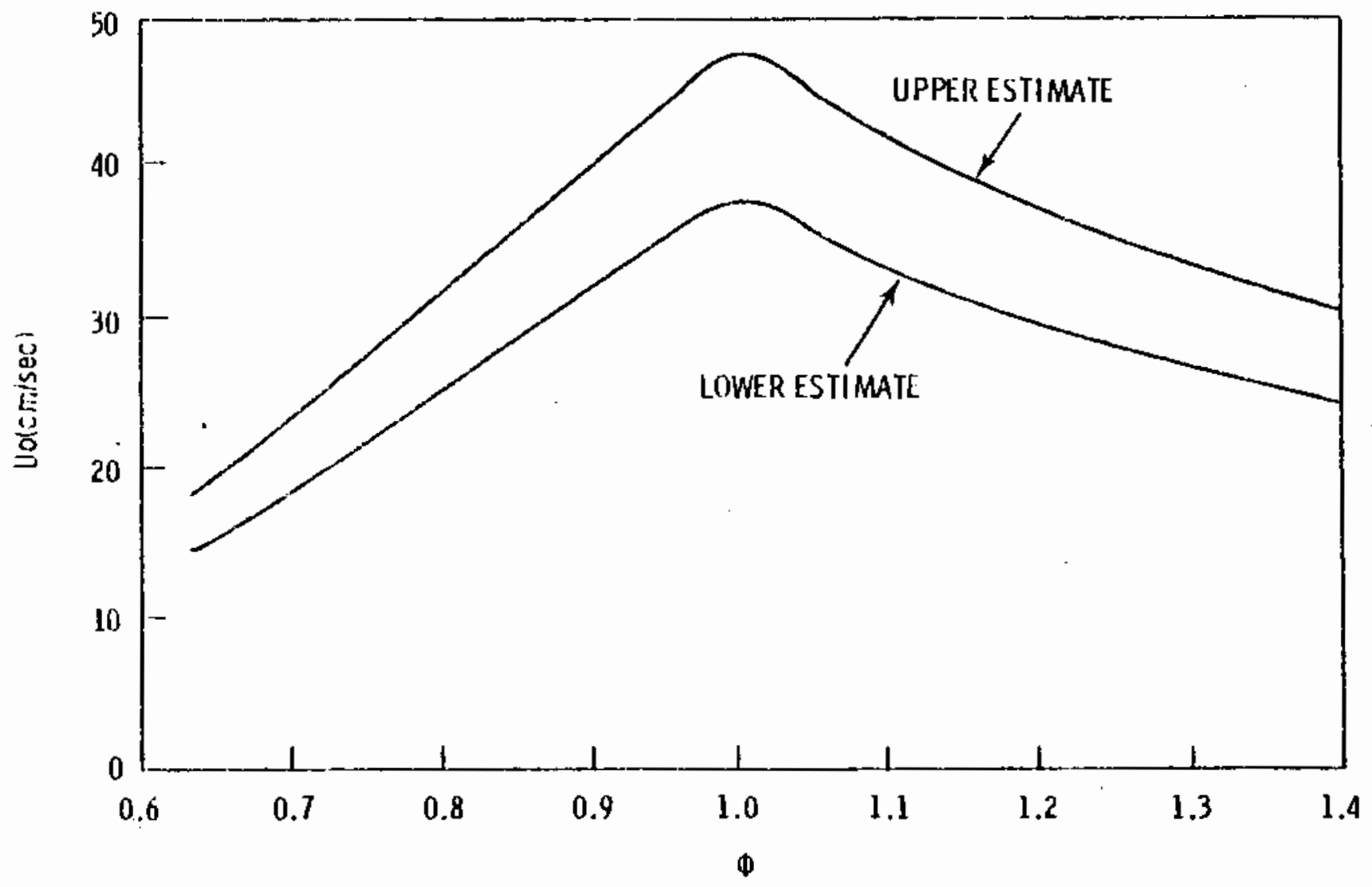

FIGURE C.4. Flame Velocities in Anmonia Versus $\phi$ 
TABLE C.4. Upper and Lower Flame Speeds Versus Equivalence Ratio

$\begin{array}{cccc}\Phi & \begin{array}{c}u_{0} \\ \text { (Upper) } \\ \text { (cm/sec) }\end{array} & & \begin{array}{c}u_{0} \\ \left(\begin{array}{c}\text { Lower) } \\ \text { (cm/sec) }\end{array}\right.\end{array} \\ .63 & 18.6 & & 14.9 \\ .70 & 23.9 & & 19.1 \\ .80 & 31.7 & & 25.4 \\ .90 & 39.5 & 31.6 \\ 1.00 & 47.1 & 37.7 \\ 1.10 & 41.9 & 33.5 \\ 1.20 & 37.4 & 29.9 \\ 1.30 & 33.5 & 26.8 \\ 1.38 & 30.4 & 24.3\end{array}$

\section{C.1.9 Conclusions}

These values are well within physically accepted limits. Thus, it seems probable that flames will propagate in ammonia-air mixtures.

\section{C.2 IGNITION CHARACTERISTICS}

Ignition temperatures of ammonia-air systems are widely available (Kanury 1977; Inhofer 1969; Buckley and Husa 1962). Most were obtained in different ways and, consequentiy, have different values. Most agree that ammonia is fairly difficult to ignite. This chapter attempts to theoretically demonstrate the reason for this. A comparison of the ignitability of other, better known combustibles with that of ammonia is then presented.

\section{C.2.1 Critical Temperature Theory}

This report shall look at the ammonia ignition problem using the concept of "critical temperature." The critical temperature concept requires some explanation. Given a slab, cylinder, or sphere, a stationary combustible mixture of gases having a characteristic dimension, a, at what temperature can the outer surface be maintained without burning? This problem was first studied by Frank-Kamenetzky (1939). Longwell (n.d.) expanded on this theory, which will be used in this analysis. 
The transient energy equation for this system may be expressed as:

$$
\rho c \frac{\partial T}{\partial t}=k \nabla^{2} T+\rho Q Z \exp (-E / R T)
$$

Longwe11 sought solutions to Equations (C.3I) which allowed the energy conducted by diffusion from the gas to the outside wall to just equal the energy generated in the gas. Thus, the second and third terms of Equation (c.31) balance, and consequently the first term, transient energy storage, is zero. The highest wall temperature, $T_{C}$, at which this can occur is defined as the critical temperature.

Therefore, if a steady-state solution exists, it must satisfy the equation:

$$
\lambda\left[\frac{d^{2} T}{d r^{2}}+\frac{n}{r} \frac{d T}{d r}\right]=-\rho Q Z \exp (-E / R T)
$$

where

$$
\begin{aligned}
& n=0 \rightarrow \text { slab geometry } \\
& n=1 \rightarrow \text { cylindrical geometry } \\
& n=2 \rightarrow \text { spherical geometry. }
\end{aligned}
$$

Manipulating the argument of the exponential term yields:

if

$$
\frac{E}{R\left(T_{c}-T_{c}+T\right)}=\frac{E}{R T_{c}}\left(\frac{1}{1+\frac{-T_{c}+T}{T_{c}}}\right) \approx \frac{E}{R T_{c}}\left(1+\frac{T-T_{c}}{T_{c}}\right)
$$

$$
\left.\frac{T-T_{C}}{T_{C}} \ll\right]
$$

Inequality (C.33b) will usually be met for most gases because the heat generation rate small enough to prevent thermal runaway (or ignition) would also, of necessity, be too small to support a substantial temperature gradient across the body of gas. Equation ( $\mathrm{C} .32$ ) may be nondimensionalized according to:

$$
\begin{gathered}
\bar{r} \equiv r / a \\
\theta \equiv \frac{E}{\mathrm{RT}_{\mathrm{C}}{ }^{2}}\left(T-\mathrm{T}_{\mathrm{c}}\right)
\end{gathered}
$$


and

$$
\delta \equiv \frac{\rho Q Z}{k} \frac{E}{R T_{C}^{2}} a^{2} \exp \left(-E / R T_{C}\right) .
$$

This transformed energy equation now becomes:

$$
\frac{d^{2} \theta}{d \bar{r}^{2}}+\frac{n}{\bar{r}} \frac{d \theta}{d \bar{r}}=\delta \exp \theta .
$$

Frank-Kamenetzky (1939) determined, for constant temperature boundary conditions, that the parameter, $\delta$, would have the following values, depending upon geometry:

$$
\begin{aligned}
& \delta=.88 \text { (s lab geometry) } \\
& \delta=2.00 \text { (cylindrical geometry) } \\
& \delta=3.32 \text { (spherical geometry). }
\end{aligned}
$$

Therefore, to find the critical temperature, a simple insertion of the proper parameter, $\delta$, for the particular geometry under consideration, into Equation (C.34c) yields' ctranscendental equation for the critical temperature:

$$
T_{C}=\frac{E}{2.303 R \log \left[\frac{E a^{2} \dot{W}^{\prime \prime \prime} \Delta H \exp \left[+E / R T_{C}\right]}{\lambda R T_{C}{ }^{2} \delta}\right]} \text {. }
$$

Equation (C.37) could not be solved explicitly for the critical temperature, $T_{C}$, and an iterative process was implemented. An initial temperature was guessed and the right-hand side of Equation (C.37) was calculated. This new value for the critical temperature was resubstituted into the right-hand side of Equation (C.37). The process continued until both sides of Equation (C.37) were essentially equal. This method converged quickly to the correct value of $T_{C}$, the critical temperature.

The heat generation term in Equation (C.31) is obtained by equating:

$$
\rho Q Z \exp [-E / R T]=\Delta H_{t} \dot{W}_{f}^{\prime \prime \prime}
$$

where the fuel combustion rate, $\dot{W}_{f}^{u t}$, and heat of combustion, $\Delta H_{f}$, are given by Equations (C.10) and (C.4a), respectively. 


\section{C.2.2 Results of Critical Temperature Theory}

The critical temperatures for several different critical dimensions are shown below in Figure $C .5$ for planar, cylindrical, and spherical geometries. Tabulated values are given in Table C.5 immediately below. Also shown are some ignition temperatures for other combustibles (Kanury 1977).

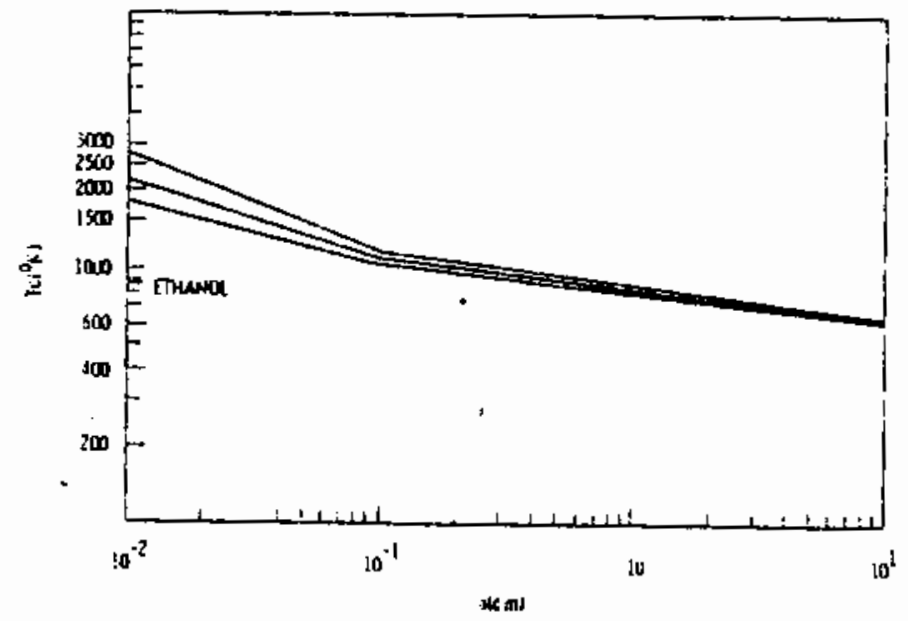

FIGURE C.5. Critica1 Temperature Versus Size (Three Geometries)

TABLE C.5. Critical Temperature for Various Sizes and Geometries

\begin{tabular}{|c|c|c|c|}
\hline $\begin{array}{c}a \\
(\mathrm{~cm})\end{array}$ & $\begin{array}{r}51 a b \\
\delta=.88 \\
\end{array}$ & $\begin{array}{c}\text { Cyl inder } \\
2.00 \\
\end{array}$ & $\begin{array}{c}\text { Sphere } \\
3.32\end{array}$ \\
\hline .01 & 1780.8 & 2187.8 & 2732.4 \\
\hline . 10 & 1019.7 & 1094.7 & 1146.9 \\
\hline .50 & 814.75 & 875.5 & 886.6 \\
\hline 1.0 & 752.5 & 788.0 & 811.9 \\
\hline 2.0 & 700.2 & 730.2 & 750.2 \\
\hline 5.0 & 642.2 & 666.8 & 683.1 \\
\hline 10.0 & 604.9 & 626.4 & 640.5 \\
\hline
\end{tabular}

Even stoichiometric mixtures of air and ammonia are quite stable, compared to other combustibles. The temperature of combustion for amnonia is given as $1050^{\circ} \mathrm{K}$ (Kanury 1977), $1109^{\circ} \mathrm{K}$ (Buckley and Husa 1962) and $1310^{\circ} \mathrm{K}$ (Inhofer 1969). 
The conditions under which these studies were performed are unavailable but seem to bear out the results of this analysis. Out of 55 fuels listed, ammonia had the highest ignition temperature. Such a comparison is not completely valid since the 1 ist was compiled from a number of sources, which presumably all used somewhat different apparati.

\section{C.2.3 Conclusions}

While ammonia flames will propagate at atmospheric pressure the preceding analys is and experimental evidence from Inhofer (1969), Kanury (1977), and Buckley and Husa (1962) all suggest that it is extremely difficult to ignite, even under stoichiometric conditions.

The critical temperature, $T_{c}$, calculated above for various geometries and scales, is the theoretical maximum temperature at which a container of stoichiometric air-ammonia can be maintained without runaway temperature which would correspond to ignition. The chemical kinetics and thermodynamic data used in this analysis (Pratt and Starkman 1969) indicate that a low heat of combustion and a slow reaction rate are the main reasons for this behavior. Therefore, from the ignition characteristics viewpoint, ammonia has been demonstrated analytically and experimentally to be among the safest of fuels, even in the presence of air.

\section{C.3 POOL BURNING CHARACTERISTICS OF AMMONIA}

The ignition and pre-mixed flame propagation characteristics of ammoniafueled fires have been discussed. Presumably, after a vapor cloud of ammonia above a pool has been ignited and has burned the cloud, a steady-state pool fire should follow.

This chapter studies the mechanisms of energy feedback from thermal radiation and the boiloff of the liquid fuel underneath. (a) Because quantitative values of radiant heat fluxes and boiloff rates contain iittle meaning, it is instructive to compare these quantities between two fuels, ammonia and one whose burning properties are more familiar such as ethanol.

(a) Heat transfer by conduction and convection to the pool surface is ignored in this work. 
A fundamental analysis of the pool fire characteristics of amonia would require a complex analys is of the conservation equations (mass, momentum, energy, species, turbulent kinetic energy, etc.), including the modeling of thermal radiation and chemical kinetics. Such an analysis is beyond the scope of this work. However, some assessment of the pool burning characteristics of ammonia relative to other, more common combustibles is necessary.

Kanury (1977) lists the relevant thermophysical properties for 55 combustibles. The properties listed which are most relevant to pool fire burning characteristics are:

- boiling temperature $(P=1 \mathrm{~atm})$

- heat of vaporization (joules/gm)

- heat of combustion (joules/gm).

Not 1 isted are the thermal radiation properties of the fuels, a transport mechanism extremely important to the pool fire problem. This availability of properties for most fuels (Kanury [1977] inciudes armonia, but only briefly) suggests a possible strategy for assessing the burning properties of anmonia. Inspection of the 55 materials (Xanury 1977) shows that some combustibles are not as flammable as others in various respects (ignition, flame propagation velocity, etc.). Identification of these properties, which lead to poor pool fire combustion characteristics, allows a selection of a prototype fuel to be made which is a poor burner in the pool fire mode. This fuel can then be compared to ammonia in the pool-fire burning mode and an assessment of the relative flanmability can be made.

The single most important aspect of pool fires is the interaction between the pool and the flame above. The energy feedback from the flame (by conduction, convection and thermal radiation) to the pool determines the rate of fuel boiloff. The amount of fuel boiled off is thus dependent on the flame properties (particularly thermal radiation) and the heat of vaporization of the fuel $h_{f g}$. A large heat of vaporization will result in lower boiloff rates, given the same energy input to the pool. The difference in temperature between the pool and the flame above it is governed largely by the heat of combustion, $\bar{h}_{R P}$, of the fuel. Low heats of combustion would tend to result in low fuel boiloff rates 
and, hence, less vigorous combustion. The boiling temperature of the fuel is not considered to be a critical parameter because the absolute temperature difference between pool and flame is most important in determining boiloff rate, particularly if the fuel is at saturation temperature. Thus, a combustible with poor pool burning characteristics would have a low heat of combustion, $h_{R P}$, and a high heat of vaporization, $h_{f g}$. Kanury (1977) lists ethanol, $\mathrm{C}_{2} \mathrm{H}_{5} \mathrm{OH}$, as having the lowest heat of combustion and highest heat of vaporization of 55 combustible fuels listed, excluding ethanol and ammonia. (Ammonia has a larger heat of vaporization, $h_{f g}$, but other properties such as heat of combustion are not 1 isted.)

The following sections detemine the burning properties of ethanol and ammonia by determining the radiation properties of the flame above the pool for each substance. This flame is assumed to be hemispherical (at least initialiy) and consists of the combustion products of stoichiometric ethanol or ammonia and air mixtures. (a) The radius of the cloud is from $.1 \mathrm{~m}$ to $10 \mathrm{~m}$, a size representative of most small spills. The radiation heat transfer to the pool in the center of the hemisphere is calculated (along with the flame emissivity) and compared for both fuels. The boiloff rate for each fuel is also calculated, and conclusions can be drawn from arguments based on the heat of combustion for both fuels.

\section{C.3.1 Radiative Properties of Ammonia and Ethanol Flames}

The radiative properties of combustion gases depend upon the molecular structure of the gases and the presence of soot in the flame. Ammonia $\left(\mathrm{NH}_{3}\right)$ contains no carbon and soot formation is impossible. Ethanol $\left(\mathrm{C}_{2} \mathrm{H}_{5} \mathrm{OH}\right)$ flames can contain soot, which adds to the radiative emission of the flame. This analysis will neglect the radiation from soot particles in ethanol flames since no general theory of soot formation is available. Therefore, the radiant emission calculated for ethanol flames will be less than or equal to the actual emission for such flames. Thus, this calculation of thermal radiation is a conservative calculation as far as ethanol is concerned. The molecular radiation

(a) The actual geometry is somewhat unimportant, as the fuels, ammonia and ethanol, are being compared on a relative basis. Therefore, any geometry would probably serve for this comparison. 
is caused by vibrational-rotational transitions in the combustion gases $\left\langle\mathrm{H}_{2} \mathrm{O}\right.$ for ammonia, $\mathrm{H}_{2} \mathrm{O}$ and $\mathrm{CO}_{2}$ for ethanol) and occurs only in narrow spectral regions known as bands.

The emission from a hemisphere of gas, radius L (homogeneous, uniform temperature), to the "center" of the hemisphere for a single wavelength, $\lambda$ (or rather, wave number, $n$ ) is given by:

$$
E_{\eta, g}=\left[1-\exp \left(-a_{\eta} L\right)\right]
$$

where $a_{\eta}$ is the spectral absorption coefficient (a). The emission for a "band" of radiation for a gas is obtained by integrating Equation (C.39) over the bandwidth, $\Delta W$. This value is known as the "equivalent" bandwidth, $\bar{A}^{(a)}$ given by Teen (1968):

$$
\bar{A} \equiv \Delta W^{f}\left[1-\exp \left(-a_{n} L\right)\right] d_{n} .
$$

The emission for a single band, $j$, for a gas, $i$, is given by:

$$
q_{R, i, j}=\bar{A}_{i, j} e_{\eta_{j}, b} \text {. }
$$

The total heat flux for all the bands in a gas is given by: $(b)$

$$
q_{R, j}=\sum_{j} q_{R, i, j}=\sum_{j} \vec{A}_{i, j} e_{\eta_{j}, b} .
$$

The total heat flux is, therefore, the sum over all gases and bands:

$$
q_{R}=\sum_{i} q_{R, i}=\sum_{i} \sum_{j} \bar{A}_{i, j} e_{\eta_{j}, b} .
$$

(a) The quantity $\bar{A}$ depends only on the thermodynamic state $(T, T, \rho)$ and the path length, L. Teen (1968) contains the formula for these quantities for various gases and bands.

(b) $e_{\eta_{j}, b, i}$ is the black body function evaluated at the band center wavenumber $n_{j}$ 
Ethanol combustion products contain $\mathrm{CO}_{2}$ and $\mathrm{H}_{2} \mathrm{O}$ vapor ( $\mathrm{N}_{2}$ does not radiate) while ammonia combustion products contain $\mathrm{H}_{2} \mathrm{O}$ as the principal radiator. Table C.6 gives the temperature and pressure at which the radiative emissions were calculated for each set of combustion products.

Figure C. 6 shows the thermal emissions of the combustion products of ethanol and ammonia for various radius $L$. Notice that the ethanol products emit more thermal radiation than the ammonia products, even though the soot radiation possible from the ethanol flame is left out. Table C.7 contains the tabulated values used in making Figure C.6.

The emissivity may also be calculated for a mixture of combustion products in the following manner:

$$
\varepsilon_{g}=\frac{\sum_{j \sum j} \bar{A}_{i, j} e^{n_{j, b}}}{\sigma T^{4}}
$$

These values are also presented in Table C.7.

\section{C.3.2 Boiloff Rates}

The thermal radiation from the cloud of combustion products incident on the fuel pool may be assumed to be absorbed totally if the emission and reflection on the pool surface are neglected. For a boiloff rate, $\dot{m}$, due totally to radiation, $\dot{q}_{R}$, incident from the cloud:

TABLE C.6. Properties for Thermal Radiation Calculation

\begin{tabular}{ccc} 
Property & Ethanol (a) & Anmonia \\
\cline { 1 - 1 } & .1842 & .3112 \\
${ }_{\mathrm{H}_{2} \mathrm{O}}$ & .1228 & -- \\
${ }_{\mathrm{T}}^{\mathrm{CO}} \mathrm{H}_{2}$ & $2000^{\circ} \mathrm{K}$ & $2000^{\circ} \mathrm{K}$ \\
$\mathrm{P}_{\mathrm{T}}$ & $1 \mathrm{~atm}$ & $1 \mathrm{~atm}$ \\
$\mathrm{~L}$ & $.1-10 \mathrm{~m}$ & $.1-10 \mathrm{~m}$
\end{tabular}

(a) Section C. 6 contains material relevant to the combustion thermodynamics of ethanol. 


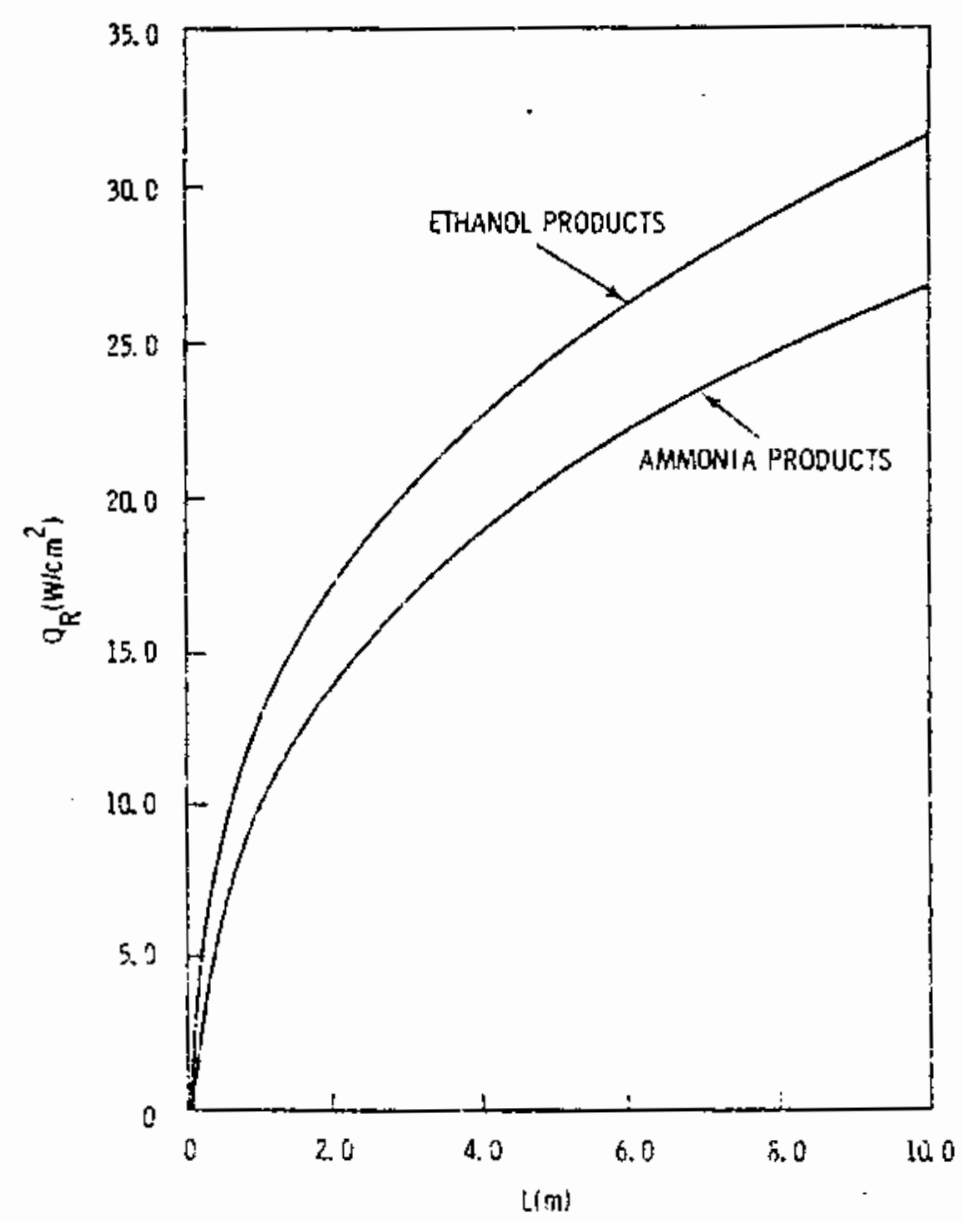

FIGURE C.6. Thermal Radiation from Ethanol and Armonia Combustion Incident on the Base of a Hemispherical Cloud Versus Radius, L, of the Hemispherical cloud

TABLE C.7. Radiation Emissivity and Boiloff Versus Radius of Cloud, L

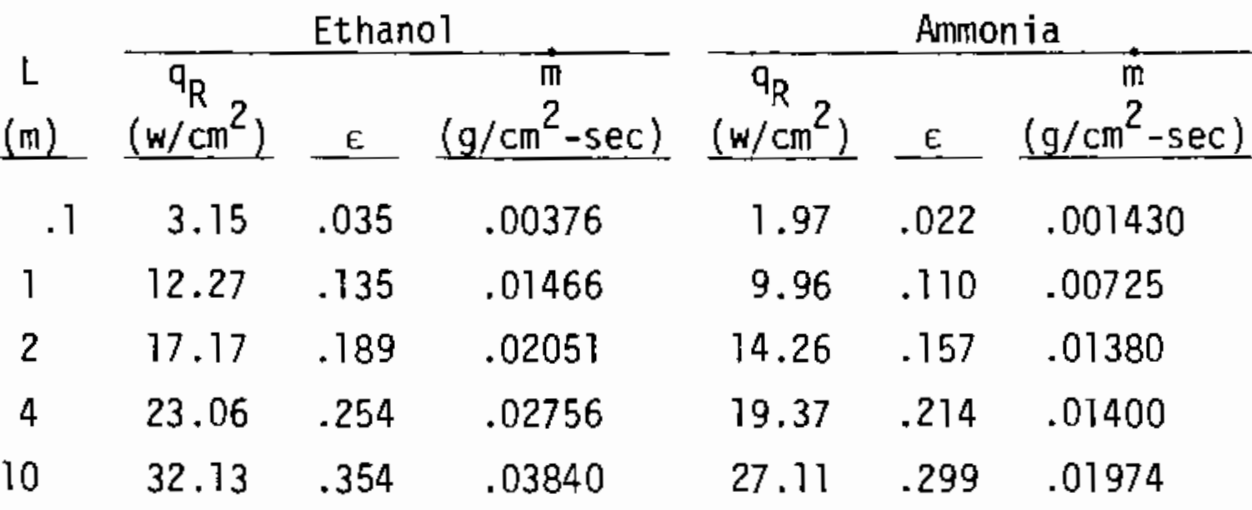




$$
\dot{q}_{R}=\dot{m}\left[h_{f g}+c_{p}\left(T_{b}-T_{p}\right)\right]
$$

where $T_{p}$ is the pool temperature and $T_{b}$ the boiling temperature of the pool. If the pool is assumed to be at saturation:

$$
\dot{q}_{R}=\dot{m} h_{f g} \cdot
$$

This formula was used to calculate the boiloff rates for ethanol and ammonia and are tabulated in Table C.7. These results are presented graphically in Figure C.7. Note that the boiloff for the ammonia is significanly lower than that for ethanol because of the smaller radiation input and the larger heat of vaporization for the ammonia.

\section{C.3.3 Heat of Combustion $\left(h_{R P}\right)$}

The heat of combustion of ethanol (Kanury 1977) is given as:

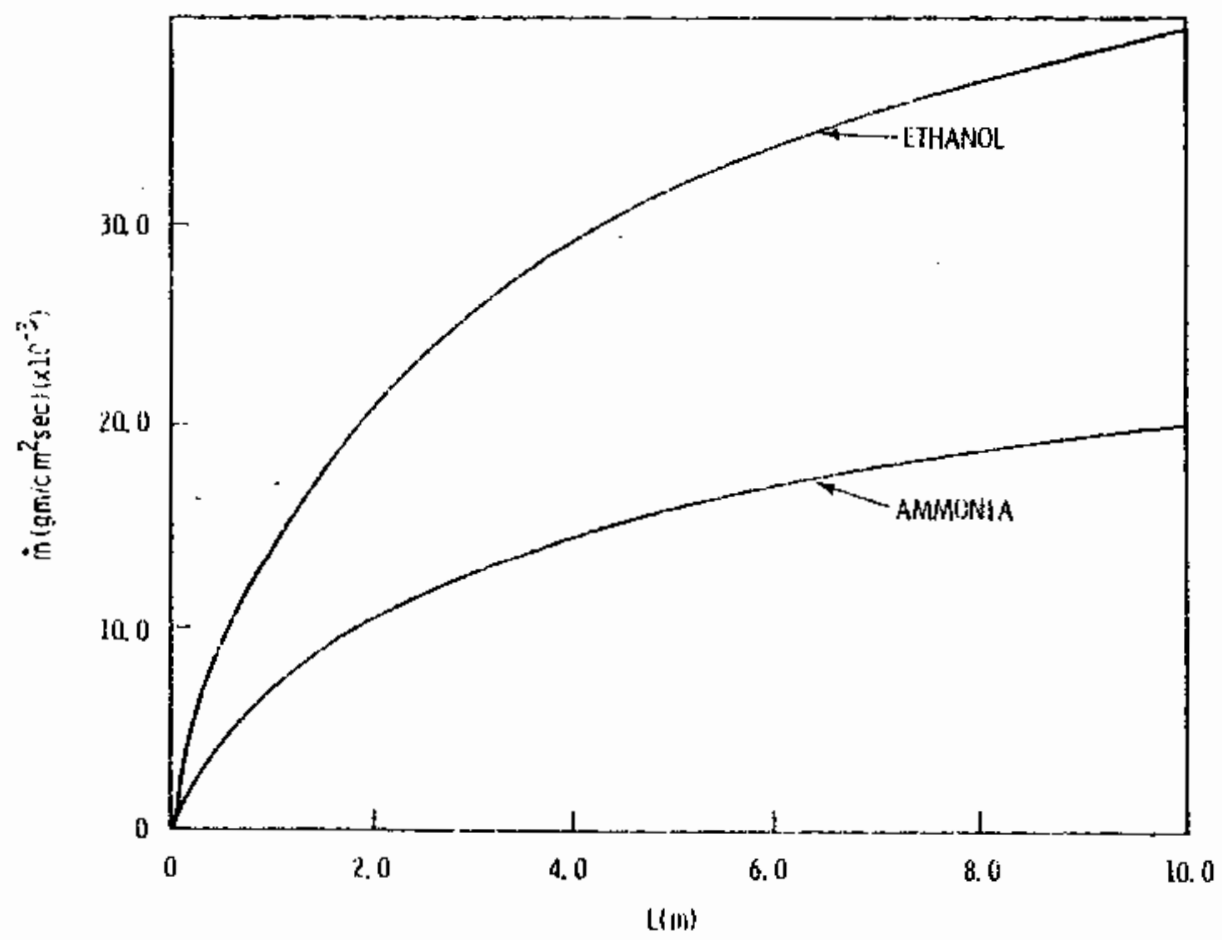

FIGURE C.7. Boiloff Rates for Ethanol and Ammonia Versus Cloud Diameter 


$$
h_{\mathrm{RP}}=6.40 \mathrm{kcal} / \mathrm{g} \text { of fuel }
$$

on a mass basis. Section C.1.7 gives the heat of combustion for stoichiometric ammonia on a molar basis as $75.6 \mathrm{kcal} / \mathrm{mol}$, which converts to:

$$
\bar{h}_{\mathrm{RP}}=75.6 \frac{\mathrm{kcal}}{\mathrm{mol}} / \frac{17 \mathrm{~g}}{\mathrm{~mol}}=4.45 \mathrm{kcal} / \mathrm{g} \text { of fuel. }
$$

Note that this value is $30 \%$ smaller than the heat of combustion for ethanol.

\section{C.3.4 0iscussion of Pool Fire Characteristics of Ammonia}

The burning properties of ethanol have been widely experienced. Even relatively large pools burn quietly and with a blue, almost invisible flame. This lack of vigor in the pool burning process for ethanol is almost certainly due to $i$ ts low heat of combustion and high heat of vaporization. Therefore, the fact that ammonia has a lower heat of combustion and a higher heat of vaporization naturally implies that ammonia is less likely to burn in a stable manner in this situation.

Figure $C .6$ reveals that the radiation emitted by both combustion gases is nearly equal. (a) Figure $C .7$ reveals that the mass transfer from the ammonia induced by radiation is only .5 (50\%) of that leaving the ethanol in mass per unit area and time. Furthermore, Section C.3.3 shows that the mass leaving the ammonia pool has only .7 (70\%) of the energy release potential of the ethanol. Thus, the ammonia pool fire only has $\left(\frac{7}{10} \times \frac{5}{10}=\right) 35 \%$ as much energy going into the flame as the ethanol fire. Thus, since the pool burning mode of ethanol is tenuous, it seems unlikely that ammonia would burn steadily in this mode at all. Also, because ammonia has such narrow flammability limits ( 15 to $27 \%$ ), mixing above the pool fire would also serve to disperse the fuel to below the LFL so that combustion would be rendered difficult, if not possible. The demonstration of this speculation is beyond the scope of this study.

In summary, the following physical parameters are thought to make pool burning of ammonia less likely than ethanol and perhaps even impossible:

(a) The radiation bands given by Teen (1968) are probably only within $\pm 10 \%$ accuracy. 
- low radiation heat transfer to fuel pool caused by the absence of soot

- high heat of vaporization

- low heat of combustion

- narrow flammability limits.

\section{C.3.5 Conclusions}

It is the conclusion of this theoretical study concerning the combustion characteristics of ammonia that

- Ammonia vapor is extremely difficult to ignite at atmospheric pressure, compared to most other combustibles

- Upon ignition of an ammonia-air mixture, the flame front will spread slowly, compared to most other fuels

- Pool fire burning of ammonia is improbable since the reaction lacks the energy necessary to sustain the boiloff rate at a suitable value.

\section{C.4 COMPOSITION AND PROPERTIES OF AMMONIA-AIR SYSTEMS}

A determination of various flame parameters for an anmonia-air flame requires a knowledge of the thermophysical properties of the individual species and the mixture as a whole. The properties necessary to this study are:

- Molar Composition

- Density and Mass Fraction

- Thermar Conductivity

- Specific Heat.

\section{C.4.1 Molar Composition}

The evaluation of Equation (C.10) requires that the concentration of ammonia and oxygen in moles per cubic centimeter be known for the various values of the equivalence ratio and adiabatic flame temperature. The mol fraction of a species, $Y_{i}$, is defined as the number of moles of species $i$ per total number of moles of all species comprising the mixture. The mol fraction for ammonia, nitrogen, and oxygen in the reactants are from Equation (C.1):

$$
\mathrm{Y}_{\mathrm{NH}_{3}}=\frac{4 \phi}{4 \phi+14.28}
$$




$$
\begin{aligned}
& Y_{0_{2}}=\frac{3}{4 \phi+14.28} \\
& Y_{N_{2}}=\frac{11.28}{4 \phi+14.28} .
\end{aligned}
$$

By definition

$$
\sum_{i} Y_{i}=1 .
$$

The partial pressure of an ideal gas is given by:

$$
P_{i}=Y_{i} P_{T} .
$$

The moles of gas per unit volume can, therefore, be calculated as:

where

$$
\frac{n_{i}}{V}=\frac{P_{i}}{\overline{R T}}=\frac{Y_{i} P_{T}}{\bar{R} T}
$$

$$
\left(\bar{R}=.082054 \frac{a^{a t m}-1}{g-m o 1-{ }^{\circ} K}\right)
$$

and where the answer is in $g$-moles of species $i / 1 i t e r$. To convert it to $\mathrm{g}$-moles $/ \mathrm{cm}^{3}$, simply divide Equation (C.54) by 1000.

\section{C.4.2 Density and Mass Fraction}

The density of ammonia-air mixtures may be calculated by converting molar density into mass density according to the formula:

$$
\text { l g-mol of species } j=M W_{i} \text { in grams }
$$

and, therefore,

$$
p_{i}=10^{-3} \times \frac{Y_{i} P_{T}}{\bar{R}_{T}}\left(\mathrm{~g} / \mathrm{cm}^{3}\right) .
$$

The mass fraction of species $i$ in the mixture is:

$$
x_{i}=\rho_{j} / \rho .
$$


The mass fraction $x_{i}$ and the mol fraction $Y_{i}$ are related according to:

$$
Y_{i}=\left(x_{i} / M w_{i}\right) /\left(\Sigma x_{i} / M w_{i}\right) .
$$

\section{C.4.3 Thermal Conductivity}

At a temperature of $293^{\circ} \mathrm{K}$, the thermal conductivity of pure ammonia and air differ by only about $10 \%$ (Kanury 1977). Because the mol fraction of ammonia in the flanmable region $(.63<\phi<1.38)$ is always less than .2 , little error will result if the reactants are assumed to have the thermal conductivity of pure air (Kanury 1977):

$$
\kappa=\kappa_{0}\left(T / T_{\text {ref }}\right)^{n}
$$

where

$$
\begin{aligned}
\kappa_{0} & =5.83 \times 10^{-5}\left(\mathrm{cal} / \mathrm{cm}-\mathrm{sec}-{ }^{\circ} \mathrm{K}\right) \\
\mathrm{T}_{\text {ref }} & =273.0\left({ }^{\circ} \mathrm{K}\right) \\
\mathrm{n} & =.94 .
\end{aligned}
$$

\section{C.4.4 Specific Heat}

The specific heat of individual species in the reactants and products is listed in Table C.l. However, a method of obtaining a specific heat for the mixture of gases is necessary. The specific heat of the mixture is obtained as a weighted average of the specific heat of the individual species. The mass fraction is used as the the weighting factor.

$$
c_{p}=\sum_{i} X_{i} p_{i}
$$

\section{C.4.5 Amtronia Flashing}

An immediate problem relating to the ammonia fire problem is that of ammonia flashing. Upon rupture of an ammonia container, part flashes over to vapor and part remains a liquid, but at a lower temperature. Typically, most ammonia containers are not refrigerated and are at or near ambient temperature conditions. The pressure is the saturation pressure of the ammonia at this temperature. 


\section{C.5 THERMODYNAMICS OF AMMONIA}

The initial enthalpy $H_{j}$ of ammonia in volume $V_{j}$ (equal to the volume of the original container) is the sum of the liquid and vapor components (subscripts, $f$ and $g$, respectively):

$$
H_{i}=v_{i}\left\{\left(1-\alpha_{i}\right) \rho_{f, i} h_{f, i}+\alpha_{i} \rho_{g, i} h_{g, i}\right\} \text {. }
$$

From thermodynamic tables for ammonia: ${ }^{(a)}$

$$
\begin{aligned}
& h_{f, i}=120.5 \mathrm{Btu} / 1 \mathrm{bm} \\
& h_{g, i}=629.1 \mathrm{Btu} / 1 \mathrm{bm} \\
& \rho_{f, i}=37.99 \mathrm{ibm} / \mathrm{ft}^{3} \\
& \rho_{g, i}=0.431 \mathrm{bm} / \mathrm{ft}^{3} .
\end{aligned}
$$

After rupture, the system pressure becomes atmospheric and the temperature of the system drops to some value to be determined. If the system is considered adiabatic, then enthalpy is constant and:

$$
H_{i}=H_{0} \text {. }
$$

Thermodynamic data on ammonia (i.e., the saturation curve) determine the new state of the system (at $P=14.7$ psi) as:

$$
\begin{aligned}
& h_{f, 0}=12.7 \mathrm{Btu} / \mathrm{ibm} \\
& h_{g, 0}=602.1 \mathrm{Btu} / \mathrm{lbm} \\
& \rho_{f, 0}=42.481 \mathrm{bm} / \mathrm{ft}^{3} \\
& \rho_{g, 0}=.05531 \mathrm{brn} / \mathrm{ft}^{3} .
\end{aligned}
$$

The final system enthalpy also consists of liquid and vapor components:

$$
H_{0}=v_{0}\left\{\left(1-\alpha_{0} \rho_{f, 0} h_{f, 0}+\alpha_{0} \rho_{g, 0} h_{g, 0}\right\}\right. \text {. }
$$

Initially, $v_{i}$ and $\alpha_{i}$ are given in the problem definition. The equality of Equations (C.61) and (C.63) allow the final volume, $v_{0}$, and void fraction,

(a) The ambient temperature is assumed to be $\sim 70^{\circ} \mathrm{F}$. 
$\alpha_{0}$, to be determined. However, the quality of the above equation yields only one equation for the two unknowns, $\alpha_{0}$ and $V_{0}$. Therefore, another equation is needed and the principle of conservation of mass applies.

If the liquid and vapor amonia is considered as being surrounded by an adiabatic and an impermeable, perfectly deformable membrane, the mass within such a system must be conserved:

$$
m_{i}=m_{0}=v_{0}\left\{\left(1-\alpha_{0}\right) \rho_{f, 0}+\alpha_{0} \rho_{g, 0}\right\} \text {. }
$$

Solving Equation (C.64) for the final volume, $v_{0}$, and substitution into Equation (C.63) yields:

$$
H_{0}=\frac{m_{i}\left\{\left(1-\alpha_{0}\right) \rho_{f, 0} h_{f, 0}+\alpha_{0} \rho_{g, 0} h_{g, 0}\right\}}{\left\{\left(1-\alpha_{0}\right) \rho_{f, 0}+\alpha_{0} \rho_{g, 0}\right\}} .
$$

The only unknown quantity in Equation (c.65) is the final void fraction, $\alpha_{0}$.

Rearranging, the final void fraction is expressible as:

$$
\alpha_{0}=\frac{\rho_{f, 0}\left(H o / m_{i}-h_{f, 0}\right)}{\left\{\left(H_{0} / m_{i}-h_{f, 0}\right) \rho_{f, 0}-\left(H_{0} / m_{j}-h_{g, 0}\right) \rho_{g, 0}\right\}} .
$$

The final volume, $v_{0}$, is then obtained from Equation (C.64). From this analysis it was determined that $26.9 \%$ of liquid ammonia stored at $70^{\circ} \mathrm{F}$ would flash into vapor at 14.7 psig, ambient pressure.

\section{C.6 THERMODYNAMICS OF ETHANOL COMBUSTION}

In Section C.3.1, a comparison is made between the combustion of ethanol and anhydrous ammonia in the liquid state. This section is a compitation of the chemistry and thermodynamics necessary to make that comparison.

\section{C.6.1 Stoichiometry}

Only stoichiometric mixtures of ethanol vapors and air are used in this comparison. Therefore, the overall reaction, assuming that it goes to completion, may be expressed as: 


$$
\mathrm{C}_{2} \mathrm{H}_{5} \mathrm{OH}+3\left(\mathrm{O}_{2}+3.76 \mathrm{~N}_{2}\right) \rightarrow 3 \mathrm{H}_{2} \mathrm{O}+2 \mathrm{CO}_{2}+3\left(3.76 \mathrm{~N}_{2}\right) .
$$

The mole fractions of the water vapor and carbon dioxide in the products are thus:

$$
\begin{aligned}
& \mathrm{Y}_{\mathrm{H}_{2} \mathrm{O}}=\frac{3}{3+2+11.28}=.1843 \\
& \mathrm{Y}_{\mathrm{CO}_{2}}=\frac{2}{3+2+11.28}=.1228 .
\end{aligned}
$$

Thus, the molal density may be expressed as:

where

$$
\begin{aligned}
{\left[\mathrm{H}_{2} \mathrm{O}\right] } & \left.=\frac{{ }_{\mathrm{H}_{2} \mathrm{O}}{ }^{P_{T}}}{\overline{\mathrm{R}} \mathrm{T}_{\mathrm{O}}} \text { [moles } / \mathrm{cm}^{3}\right] \\
{\left[\mathrm{CO}_{2}\right] } & \left.=\frac{{ }^{\mathrm{CO}_{2}} \mathrm{P}_{\mathrm{T}}}{\overline{\mathrm{R}} \mathrm{T}_{\mathrm{O}}} \text { [moles } / \mathrm{cm}^{3}\right] \\
\overline{\mathrm{R}} & =82.054 \frac{\text { atm }-\mathrm{cm}^{3}}{\mathrm{~mol}-{ }^{\circ} \mathrm{K}} .
\end{aligned}
$$

The density of each is obtained from:

and

$$
\begin{aligned}
\rho_{\mathrm{H}_{2} \mathrm{O}} & =\frac{{ }_{\mathrm{H}_{2} \mathrm{O}}{ }^{P_{T}}{ }^{M W_{\mathrm{H}_{2} \mathrm{O}}}}{\overline{\mathrm{R}} \mathrm{T}_{\mathrm{O}}}\left(\mathrm{g} / \mathrm{cm}^{3}\right) \\
{ }^{3} \mathrm{CO}_{2} & =\frac{{ }^{Y} \mathrm{CO}_{2}{ }^{P_{\mathrm{T}}}{ }^{M W_{\mathrm{CO}_{2}}}}{\overline{\mathrm{R}} \mathrm{T}_{\mathrm{O}}}\left(\mathrm{g} / \mathrm{cm}^{3}\right) .
\end{aligned}
$$

\section{C.6.2 Heat of Formation}

The heat of formation of a substance must be known to calculate the adiabatic flame temperature, AFT. This quantity was calculated knowing the heat of combustion of the reaction, $h_{\mathrm{RP}}$. The formula is given as:

$$
\bar{h}_{R P}=\sum_{i} v_{i} \bar{h}_{j}-\sum_{j} v_{j} \bar{h}_{j}=-295.0 \frac{\mathrm{kcal}}{\text { mot of } \mathrm{C}_{2} \mathrm{H}_{5} \overline{\mathrm{OH}}}
$$




$$
\begin{aligned}
& i=\text { products } \\
& j=\text { reactants } \\
& \left(\nu_{i} \text { are stoichiometric coefficients }\right)
\end{aligned}
$$

where

$$
\bar{h}_{i}=\bar{h}_{f, i}^{0}+\Delta \bar{h}_{i}
$$

at standard conditions $\left(298.15^{\circ} \mathrm{K}\right.$ usually), the sensible enthalpy change, $\Delta \overline{\mathrm{h}}_{i}$, is zero. The heats of formation of pure substances, such as $\mathrm{N}_{2}$, are also zero. Therefore, the heats of formation for ethanol may be obtained as:

$$
\bar{h}_{R P}=3 \bar{h}_{f, H_{2} O}^{0}+2 \bar{h}_{f, C_{2} H_{5} O H}^{0} .
$$

Thus, the heat of formation of ethanol is found to be:

$$
\overline{\mathrm{h}}_{\mathrm{f}, \mathrm{C}_{2} \mathrm{H}_{5} \mathrm{OH}}^{\mathrm{OH}}=-66.1 \mathrm{kcal} / \mathrm{mol} \text {. }
$$

\section{C.6.3 Adiabatic Flame Temperature of Ethanol}

If the heat of combustion goes entirely into the sensible enthalpy change of the products (i.e., and adiabatic system), the following equality holds:

$$
\begin{gathered}
h_{R P}=3 \Delta \bar{h}_{H_{2} O}+2 \Delta \bar{h}_{C_{2}}+11.28 \Delta \bar{h}_{N_{2}} \\
\approx \Delta T\left(3 \bar{c}_{p}, H_{2} O+2 \bar{c}_{p}, C O_{2}+11.28 \bar{c}_{p}, N_{2}\right)
\end{gathered}
$$

where an average specific heat, $\vec{c}_{p}$, has been used for all species. Use of tabulated specific heats and a linearly-interpolating eyeball results in the adiabatic flame temperature rise of:

$$
\Delta \mathrm{T}=1687^{\circ} \mathrm{K}
$$

or

$$
\mathrm{T}_{\mathrm{f}} \approx 298^{\circ} \mathrm{K}+1687^{\circ} \mathrm{K}=1985^{\circ} \mathrm{K} .
$$

This temperature is comparable to that of stoichiometric ammonia $\left(2109^{\circ} \mathrm{K}\right)$. 


\section{C.6.4 Heat of Evaporation}

The heat of evaporation, $h_{f g}$, of ethanol is (Kanury 1977):

$$
\mathrm{h}_{\mathrm{fg}_{\mathrm{g}}, \mathrm{C}_{2} \mathrm{H}_{5} \mathrm{OH}}=4.74 \mathrm{kcal} / 9 \text {. }
$$

Any heat flux to a pool of ethanol may be related to the boiloff rate and enthalpy change in the liquid phase by:

$$
q^{\prime \prime \prime}=\dot{m}^{\prime \prime \prime}\left[h_{f g}, C_{2} H_{5} O H+c_{p, 1}\left(T_{j}-T_{B}\right)\right]
$$

where the boiling temperature for ethanol is given as (Kanury 1977):

$$
\mathrm{T}_{\mathrm{B}}=538^{\circ} \mathrm{K}
$$


APPENDIX D

ENVIRONMENTAL IMPACT RATING TABLES 


\section{1 RATING THE HAZARDS FOR FRESHWATER SPILL SCENARIOS}

Expected impacts generated by each of the freshwater spil1 scenarios were rated in terms of potential hazards. The relative hazards index defines the degree of risk caused by spills of $\mathrm{NH}_{3}$ in freshwater environments. The index is based on three assessments of risk (R) for each spill scenario:

$R_{1}$ - potential impact,

$R_{2}$ - potential holistic significance to the environment, and

$R_{3}$ - technical uncertainty or need for more information.

For every spill scenario, each of the $R_{1}, R_{2}$ and $R_{3}$ was rated on a scale of risk defined as:

$$
\begin{aligned}
& 0=\text { no risk (no impact) } \\
& 1=\text { detectable risk (1ight impact) }, \\
& 2=\text { significant risk (medium impact), and } \\
& 3=\text { serious risk (heavy impact) } .
\end{aligned}
$$

The relative hazards index (I) was then obtained by summing the risk assessments (R);

$$
I=R_{i=1}^{3} R_{i}
$$

This provided a rating scale of 0 to 9 and allowed for three general interpretations of I:

$$
\begin{aligned}
& I=0 \text { to } 3 \text { - nonexisting or minor hazard, } \\
& I=3 \text { to } 6 \text { - moderate hazard, and } \\
& I=6 \text { to } 9 \text { - serious hazard. }
\end{aligned}
$$

Numerical impact assessments for the eight scenarios are recorded in the scenario rating tables (Tables D. $1-8$ ). Each table relates the major categories 
of biota with their natural activities as a matrix for judging impact. At each matrix location the three risk-assessment decisions were scored on the 0-3 scale. Those ratings appear in each assessment column as:

$$
R_{T}+R_{2}+R_{3}=I .
$$




\section{TABLE D.1. Hazards Ratings for Scenario 1}

SCENARIO 1:

A BARGE COLLISION ON A LARGE LAKE SPILLING 600 TONS OF $\mathrm{NH}_{3}$ INSTANTANEOUSLY AND PRODUCING CONCENTRATIONS OF 0.007 TO $0.5 \mathrm{mg} / \mathrm{L}$ IN THE UPPER $1 \mathrm{~m}^{\mathrm{a}}$ ASSESSMENT MATRICES THAT ARE NOT APPLICABLE TO THIS SCENARIO ARE NOTED AS "NA".

\begin{tabular}{|c|c|c|c|c|c|}
\hline COMMUNITY & POPULATION & $\begin{array}{l}\text { SURViVAL } \\
\text { (ecute } \\
\text { toxicity) }\end{array}$ & $\begin{array}{l}\text { NUTAITION } \\
\text { (eutro- } \\
\text { phication) }\end{array}$ & $\begin{array}{l}\text { PRODUCTIVITY } \\
\text { (growth and } \\
\text { reproduction) }\end{array}$ & $\begin{array}{c}\text { STABILITY } \\
\text { (community } \\
\text { structure) }\end{array}$ \\
\hline \multirow[t]{6}{*}{ BENTHIC: } & BACTERIA & $000=0$ & $000=0$ & $000=0$ & $100=1$ \\
\hline & ALGAE & $000=0$ & $100=1$ & $100=1$ & \\
\hline & MACROPHYTES & $000=0$ & $100=1$ & $100=1$ & \\
\hline & PAOTOZOANS & $000=0$ & $000=0$ & $000=0$ & \\
\hline & HIGHER INVERTEBRATES & $000=0$ & NA & $000=0$ & \\
\hline & VERTEBRATES & $000=0$ & NA & $000=0$ & \\
\hline \multirow[t]{4}{*}{ PLANKTONIC: } & BACTERIA & $000=0$ & $110=2$ & $110=2$ & $100=1$ \\
\hline & ALGAE & $1+0=2$ & $110=2$ & $110=2$ & \\
\hline & PROTOZOANS & $110=2$ & $110=2$ & $110=2$ & \\
\hline & HIGHER INVERTEBRATES & $110=2$ & NA & $000=0$ & \\
\hline \multirow[t]{3}{*}{ NEKTONIC: } & SUAFACE & $110=2$ & NA & $110=2$ & $100=1$ \\
\hline & PROFUNDAL & $000=0$ & NA & $000=0$ & \\
\hline & MIGRATORY & $000=0$ & NA & $000=0$ & \\
\hline CIVILIZEO: & HUMAN (HEALTH) & $000=0$ & NA & $000=0$ & $000=0$ \\
\hline
\end{tabular}

a 600 TONS $\left(5.4 \times 10^{8} \theta\right)$ OF $\mathrm{NH}_{3}$ ARE SPILLED INSTANTANEOUSLY INTO A LARGE LAKE AND MIXED TO A DEPTH OF $1 \mathrm{~m}$. THE ESTIMATED BOUNDARY CONCENTRATIONS OF $\mathrm{NH}_{3}$ IN THIS TOP LAYEA OF WATER ARE 0.007 TO $0.5 \mathrm{mg} / \mathrm{L}$.

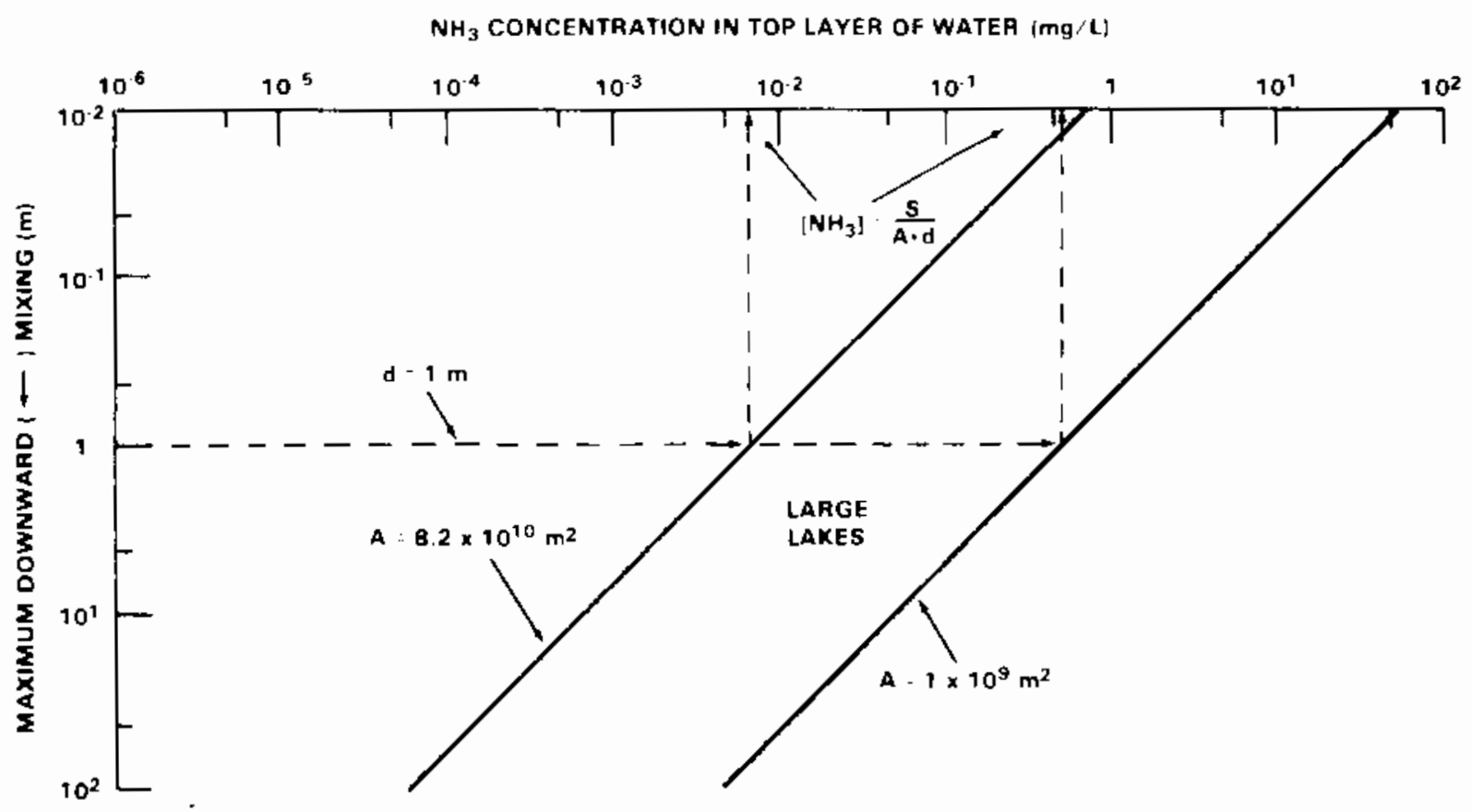




\section{TABLE D.2. Hazards Ratings for Scenario 2}

SCENARIO 2:

A BARGE COLLISION ON A LARGE RIVEF SPILLING 600 TONS OF NH, OVEA A PEAIOD OF 1 HOUR AND PRODUCING CONCENTRATIONS OF 5 TO $100 \mathrm{mg} / \mathrm{L}$ DOWNSTPEAM.a ASSESSMENT

MATRICES THAT ARE NOT APPLICABLE TO THIS SCENARIO ARE NOTED AS "NA".

BENTHIC:

ALGAE
MACROPHYTES
PROTOZOANS
HIGHER INVERTEBHATES
VERTEBAATES

PLANKTONIC:

\section{BACTERIA}

ALGAE

PROTOZOANS

HIGHER INVERTEQRATES

$\begin{array}{ll}\text { NEKTONIC: } & \text { SURFACE } \\ & \text { PROFUNDAL } \\ & \text { MIGPAIORY }\end{array}$

CIVILIZED: HUMAN (HEALTH)

\begin{tabular}{|c|c|c|c|}
\hline $\begin{array}{l}\text { SURVIVAL } \\
\text { lacuto } \\
\text { toxicityl }\end{array}$ & $\begin{array}{l}\text { NUTRITION } \\
\text { (eutro- } \\
\text { phication) }\end{array}$ & $\begin{array}{l}\text { PAODUCTIVITY } \\
\text { igrowh and } \\
\text { reproduction) }\end{array}$ & $\begin{array}{c}\text { STABILITY } \\
\text { (community } \\
\text { structure) }\end{array}$ \\
\hline
\end{tabular}

\begin{tabular}{|c|c|c|}
\hline $211=4$ & $000=0$ & $211=4$ \\
\hline $221=5$ & $000=0$ & $221=5$ \\
\hline $11=4$ & $000=0$ & $1=3$ \\
\hline $321=6$ & $000=0$ & $1=4$ \\
\hline $21=6$ & NA & $322=7$ \\
\hline $21=6$ & NA & $322=$ \\
\hline
\end{tabular}

$211=4$

$211=4$

$311=5$

$000=0$

$111=3$

$000=0 \quad 111=3$

$000=0 \quad 211=4$

NA $\quad 211=4$

\begin{tabular}{|c|c|c|c|}
\hline $320=5$ & NA & $221=5$ & $322=7$ \\
\hline $320 \cdot 5$ & NA & $221=5$ & \\
\hline $330=6$ & NA & $331=7$ & \\
\hline$=0$ & NA & $000=0$ & $000=0$ \\
\hline
\end{tabular}

GOO TONS $\left(5.4 \times 10^{8} \mathrm{~g}\right)$ OF $\mathrm{NH}_{3}$ ARE SPILled INTO A LARGE RIVER OVEA A PERIOD OF 1 hOUA. THE ESTIMATED BOUNDARY CONCENTRATIONS OF $\mathrm{NH}_{3}$ IN DOWNSTREAM WATER ARE 5 TO $100 \mathrm{mg} / \mathrm{L}$.

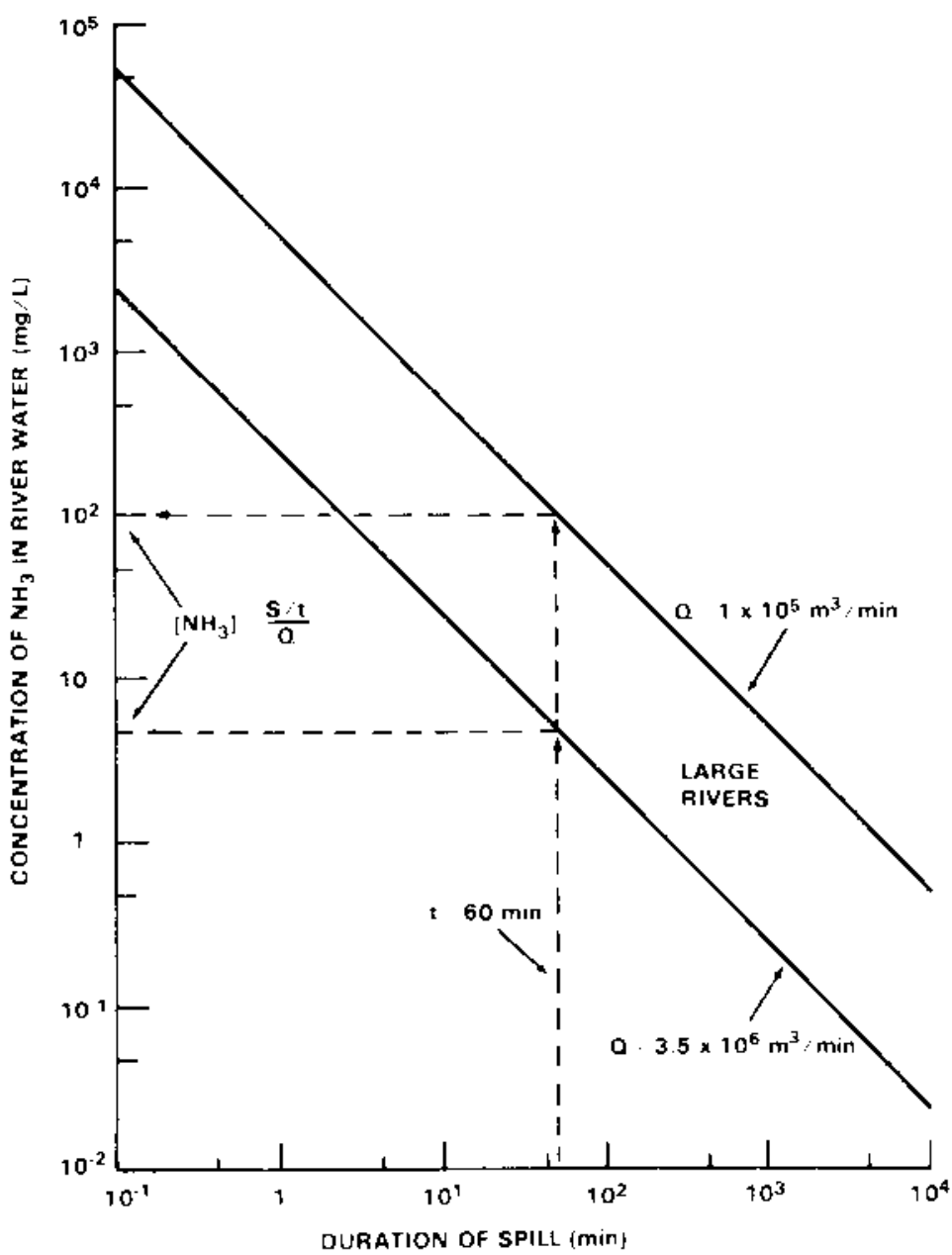




\section{IABLE D.3. Hazards Ratings for Scenario 3}

SCENARIO 3:

A RAILROAD CAR (NORMAL SIZE) ACCIDENT SPILLS 20 TONS OF NH 3 INSTANTANEOUSLY INTO A MEDIUM-SIZED LAKE, PRODUCING CONCENTRATIONS OF 0.02 TO $2 \mathrm{mg} / \mathrm{L}$ IN THE UPPER $1 \mathrm{~m}$. ASSESSMENT MATRICES THAT ARE NOT APPLICABLE TO THIS SCENARIO ARE NOTED AS "NA".

\begin{tabular}{|c|c|c|c|c|c|}
\hline COMMUNITY & POPULATION & $\begin{array}{c}\text { SURVIVAL } \\
\text { (acute } \\
\text { toxicity) }\end{array}$ & $\begin{array}{c}\text { NUTRITION } \\
\text { (eutro- } \\
\text { phication) }\end{array}$ & $\begin{array}{l}\text { PRODUCTIVITY } \\
\text { (growth and } \\
\text { reproduction) }\end{array}$ & $\begin{array}{c}\text { STABILITY } \\
\text { (community } \\
\text { structure) }\end{array}$ \\
\hline \multirow[t]{6}{*}{ BENTHIC: } & BACTERIA & $000=0$ & $100=1$ & $100=1$ & $112=4$ \\
\hline & ALGAE & $000=0$ & $111=3$ & $111=3$ & \\
\hline & MACADPHYTES & $000=0$ & $111=3$ & $111=3$ & \\
\hline & PROTOZOANS & $100=1$ & $100=1$ & $100=1$ & \\
\hline & HIGHER INVERTEBRATES & $110=2$ & NA & $110=2$ & \\
\hline & VERTEBRATES & $110=2$ & NA & $110=2$ & \\
\hline \multirow[t]{4}{*}{ PLANKTONIC: } & BACTERIA & $000=0$ & $221=5$ & $211=4$ & $222=6$ \\
\hline & ALGAE & $000=0$ & $331=7$ & $331=7$ & \\
\hline & PROTOZOANS & $000=0$ & $221=5$ & $111=3$ & \\
\hline & HIGHER INVERTEBAATES & $100=1$ & NA & $100=1$ & \\
\hline \multirow[t]{3}{*}{ NEKTONIC: } & SURFACE & $211=4$ & NA & $222=6$ & $222=6$ \\
\hline & PROFUNDAL & $000=0$ & NA & $222=6$ & \\
\hline & MIGRATORY & $110=2$ & NA & $222=6$ & \\
\hline CIVILIZED: & HUMAN (HEALTH) & $000=0$ & NA & $000=0$ & $000=0$ \\
\hline
\end{tabular}

${ }^{9} 20$ TONS $\left(1.8 \times 10^{7} \mathrm{~g}\right)$ OF $\mathrm{NH}_{3}$ ARE SPILLED INSTANTANEOUSLY INTO A MEDIUM-SIZED LAKE AND MIXED TO A DEPTH OF $1 \mathrm{~m}$. THE ESTIMATED BOUNDARY CONCENTRATIONS OF $\mathrm{NH}_{3}$ IN THIS TOP LAYER OF WATER ARE $0.02 \mathrm{TO} 2 \mathrm{mg} / \mathrm{L}$.

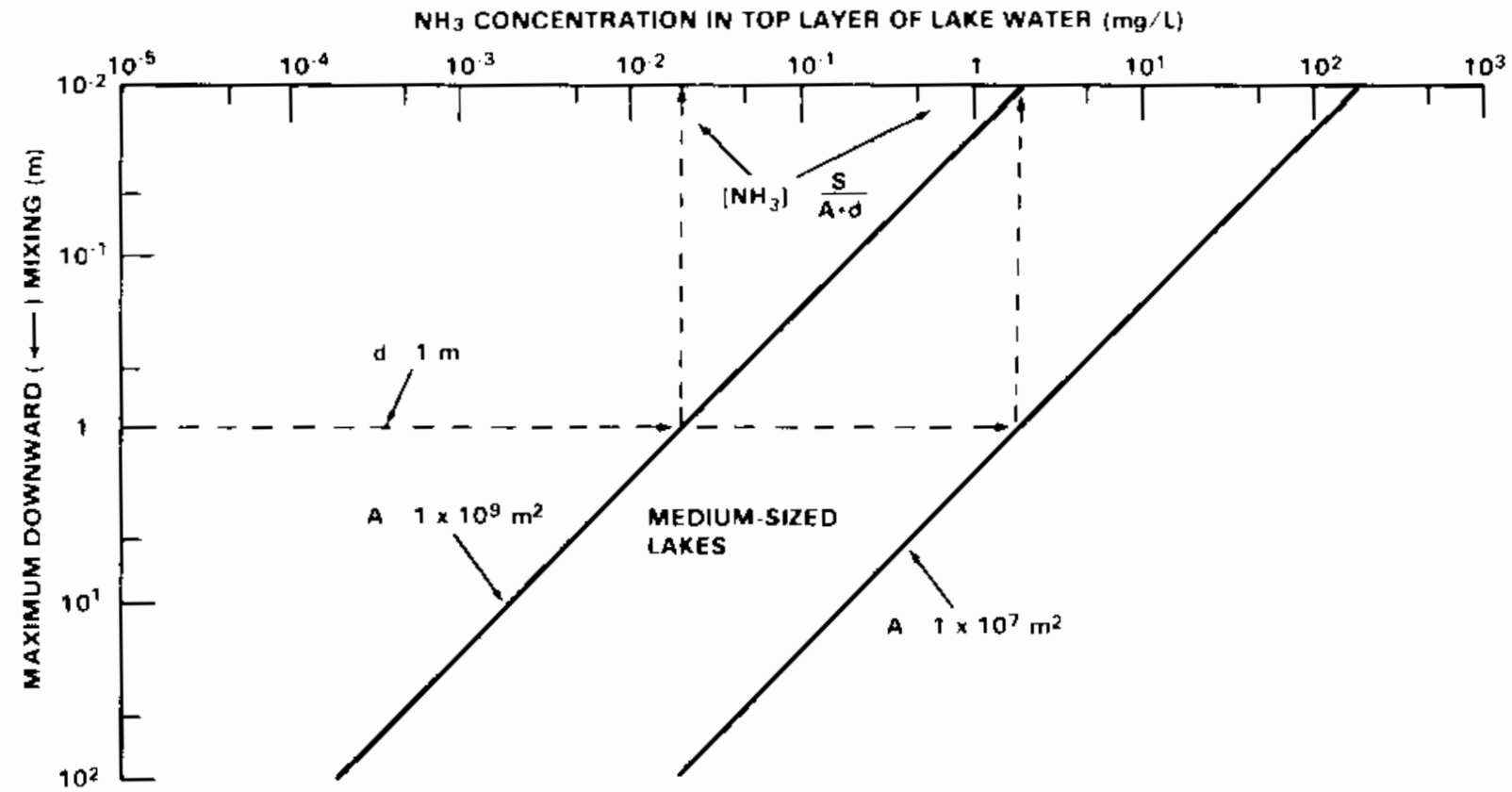




\section{TABLE 0.4. Hazards Ratings for Scenario 4}

SCENARIO 4:

A RAILROAD CAR (JUMBO SIZE) ACCIDENT SPILLS 60 TONS OF NH 3 INSTANT ANEOUSLY INTO A MEDIUM-SIZED LAKE, PRODUCING CONCENTRATIONS OF $0.05 \mathrm{TO} 5 \mathrm{mg} / \mathrm{L}$ IN THE UPPER $1 \mathrm{~m}^{a}$ ASSESSMENT MATRICES THAT ARE NOT APPLICABLE TO THIS SCENARIO ARE NOTED AS "NA".

\begin{tabular}{|c|c|c|c|c|c|}
\hline COMMUNITY & POPULATION & $\begin{array}{c}\text { SURVIVAL } \\
\text { (acute } \\
\text { toxicity) }\end{array}$ & $\begin{array}{c}\text { NUTRITION } \\
\text { (eutro- } \\
\text { phication) }\end{array}$ & $\begin{array}{l}\text { PRODUCTIVITY } \\
\text { (growth and } \\
\text { reproduction) }\end{array}$ & $\begin{array}{c}\text { STABILITY } \\
\text { (community } \\
\text { structure) }\end{array}$ \\
\hline \multirow[t]{6}{*}{ BENTHIC: } & BACTERIA & $000=0$ & $100=1$ & $100=1$ & $112=4$ \\
\hline & ALGAE & $000=0$ & $111=3$ & $111=3$ & \\
\hline & MACROPHYTES & $000=0$ & $111=3$ & $111=3$ & \\
\hline & PROTOZOANS & $100=1$ & $100=1$ & $100=1$ & \\
\hline & HIGHER INVERTEBRATES & $110=2$ & NA & $1+0=2$ & \\
\hline & VERTEBRATES & $110=2$ & NA & $110=2$ & \\
\hline \multirow[t]{4}{*}{ PLANKTONIC: } & BACTERIA & $000=0$ & $221=5$ & $211=4$ & $222=6$ \\
\hline & ALGAE & $000=0$ & $331=7$ & $331=7$ & \\
\hline & PAOTDZOANS & $000=0$ & $221=5$ & $111=3$ & \\
\hline & HIGHER INVERTEBRATES & $100=1$ & NA & $100=1$ & \\
\hline \multirow[t]{3}{*}{ NEKTONIC: } & SURFACE & $211=4$ & NA & $222=6$ & $222=6$ \\
\hline & PROFUNDAL & $000=0$ & NA & $222=6$ & \\
\hline & MIGRATORY & $110=2$ & NA & $222=6$ & \\
\hline CIVILIZED: & HUMAN (HEALTH) & $000=0$ & NA & $000=0$ & $000=0$ \\
\hline
\end{tabular}

$\mathrm{NH}_{3}$ CONCENTRATION IN TOP LAYER OF LAKE WATER img $/$ L)

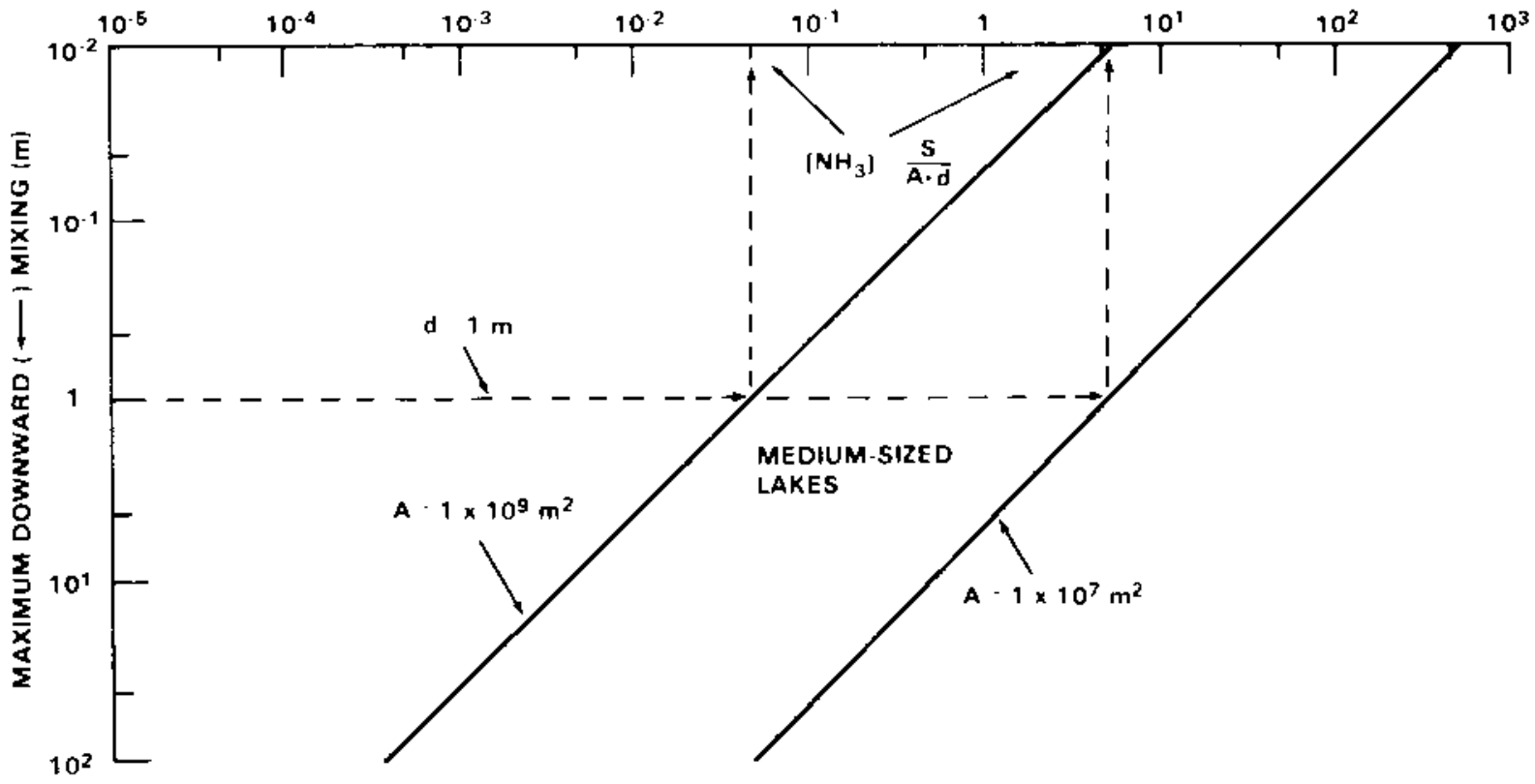




\section{IABLE 0.5. Hazards Ratings for Scenario 5}

SCENARIO 5:

A RAILROAD CAR (NORMAL SIZE) ACCIDENT SPILLS 2OTONS OF NH, INTO A MEOIUM-SIZED RIVER OVEA A PERIOD OF 1 HOUR. PRODUCING CONCENTRATIONS OF 3 TO $300 \mathrm{mg} / \mathrm{L}$ DOWNSTAEAM." ASSESSMENT MATRICES THAT ARE NOT APPLICABLE TO THIS SCENARIO ARE NOTED AE "NA"

\begin{tabular}{|c|c|c|c|c|c|}
\hline COMMUNITY & POPULATION & $\begin{array}{l}\text { SUAVIVAL } \\
\text { (acute } \\
\text { toxicity) }\end{array}$ & $\begin{array}{l}\text { NUTAITION } \\
\text { (outro- } \\
\text { phication) }\end{array}$ & $\begin{array}{l}\text { PAODUCTIVITY } \\
\text { \{growth and } \\
\text { reproduction\} }\end{array}$ & $\begin{array}{c}\text { STABILIT } \\
\text { (community } \\
\text { structure) } \\
\end{array}$ \\
\hline \multirow[t]{6}{*}{ BENTHIC: } & BACTERIA & $311=5$ & $000=0$ & $211=4$ & $322=7$ \\
\hline & ALGAE & $311=5$ & $000=0$ & $221=5$ & \\
\hline & MACROPHYTES & $211=4$ & $000=0$ & $111=3$ & \\
\hline & PAOTOZOANS & $311=5$ & $000=0$ & $211=4$ & \\
\hline & HIGHER INVERTEBRATES & $321=6$ & NA & $322=7$ & \\
\hline & VERTEERATES & $321=6$ & NA & $322=7$ & \\
\hline \multirow[t]{4}{*}{ PLANKTONIC: } & BACTEAIA & $311=5$ & $000=0$ & $111=3$ & $211=4$ \\
\hline & ALGAE & $3 \div 1=5$ & $000=0$ & $111=3$ & \\
\hline & PAOTOZOANS & $311=5$ & $000=0$ & $2111-4$ & \\
\hline & HIGHER INVEATEBRATES & $311=5$ & NA & $211: 4$ & \\
\hline \multirow[t]{3}{*}{ NEKTONIC: } & SURFACE & $320=5$ & NA & $221=5$ & $322=7$ \\
\hline & PAOFUNOAL & $320=5$ & NA & $221=6$ & \\
\hline & MIGAATORY & $330=6$ & NA & $331=7$ & \\
\hline CIVILIZED: & HUMAN \{HEALTH! & $000=0$ & NA & $000=0$ & $000: 0$ \\
\hline
\end{tabular}

20 TONS $11.8 \times 10^{7} \mathrm{~g}$ OF $\mathrm{NH}_{3}$ SPILLED INTO A MEDIUM-SIZED RIVER OVER A PEAIOD OF 1 HOUR THE ESTIMATED BOUNDARY CONCENTRATIONS OF NH, IN DOWNSTREAM WATER AAE 3 TO $300 \mathrm{mg} / \mathrm{L}$.



D-7 


\section{TABLE D.6. Hazards Ratings for Scenario 6}

\begin{tabular}{|c|c|c|c|c|c|}
\hline COMMUNITY & POPULATION & $\begin{array}{c}\text { SURVIVAL } \\
\text { (acute } \\
\text { toxicity) }\end{array}$ & $\begin{array}{c}\text { NUTAITION } \\
\text { (eutro- } \\
\text { phication| }\end{array}$ & $\begin{array}{l}\text { PRODUCTIVITY } \\
\text { 'growth and } \\
\text { reproduction\} }\end{array}$ & $\begin{array}{r}\text { STABILITY } \\
\text { \{community } \\
\text { otructure| }\end{array}$ \\
\hline \multirow[t]{6}{*}{ BENTHIC: } & BACTERIA & $311=5$ & 0000 & $211=4$ & $322=7$ \\
\hline & ALGAE & $311=5$ & 00000 & $221=5$ & \\
\hline & MACROPHYTES & $2+1: 4$ & $\begin{array}{llll}0 & 0 & 0 & 0\end{array}$ & $111=3$ & \\
\hline & PROTOZOANS & 3115 & 000.0 & $2,1=4$ & \\
\hline & HIGHER INVERTEBRATES & $321=6$ & NA & $322=7$ & \\
\hline & VERTEGRATES & $321=6$ & NA & $322=7$ & \\
\hline \multirow[t]{4}{*}{ PLANKTONIC: } & BACTERIA & $311=5$ & $000=0$ & $111=3$ & $211 \div 4$ \\
\hline & ALGAE & $311=5$ & $000-0$ & $\begin{array}{llll}1 & 1 & 1 & 3\end{array}$ & \\
\hline & PAOTOZOANS & $\begin{array}{llll}3 & 1 & 1 & 5\end{array}$ & 0000 & $211=4$ & \\
\hline & HIGHER INVEATEBRATES & $\begin{array}{llll}3 & 1 & 1 & 5\end{array}$ & NA & $211=4$ & \\
\hline \multirow[t]{3}{*}{ NEKTONIC: } & SURFACE & $320-5$ & NA & $221=5$ & $322=7$ \\
\hline & PROFUNDAL & $320=5$ & NA & 2215 & \\
\hline & MIGAATORY & $330=6$ & NA & 331.7 & \\
\hline CIVILIZED: & HUMAN (HEALTH) & $000 \quad 0$ & NA & $000=0$ & $000: 0$ \\
\hline
\end{tabular}

a 60 TONS $\left(5.4 \times 10^{7} \mathrm{~g}\right.$ ) OF $\mathrm{NH}_{3}$ AHE SPILLED INTO A MEDIUM-SIZED RIVER OVEF A PERIOD OF 1 HOUR THE ESTIMATED BOUNDARY CONCENTRATIONS OF NH, IN DOWNSTREAM WATER ARE 9 TO $900 \mathrm{mg} / \mathrm{L}$.






\section{TABLE 0.7. Hazards Ratings for Scenario 7}

SCENARIO 7:

A PIPELINE ACCIDENT SPILLS 300 TONS OF NH $_{3}$ INSTANTANEOUSLY INTO A SMAU LAKE. PAODUCING CONCENTRATIONS OF 30 TO $3000 \mathrm{mg} / \mathrm{L}$ IN THE TOP $1 \mathrm{~m} .{ }^{\text {a }}$ ASSESSMENT MATRICES THAT ARE NOT APPLICABLE TO THIS SCENARIO ARE NOTED AS "NA".

\begin{tabular}{|c|c|c|c|c|c|}
\hline COMMUNITY & POPULATION & $\begin{array}{l}\text { SURVIVAL } \\
\text { (acute } \\
\text { toxicity) }\end{array}$ & $\begin{array}{c}\text { NUTRITION } \\
\text { (eutro- } \\
\text { phication) }\end{array}$ & $\begin{array}{l}\text { PRODUCITIVITY } \\
\text { (growth and } \\
\text { reproduction) }\end{array}$ & $\begin{array}{c}\text { STABILITY } \\
\text { (communit } \\
\text { structure) }\end{array}$ \\
\hline \multirow[t]{6}{*}{ BENTHIC: } & BACTERIA & $221=5$ & $000=0$ & $321=6$ & $332=8$ \\
\hline & ALGAE & $331=7$ & $000=0$ & $331=7$ & \\
\hline & MACROPHYTES & $331=7$ & $000=0$ & $331=7$ & \\
\hline & PROTOZOANS & $331=7$ & $000=0$ & $331=7$ & \\
\hline & HIGHER INVERTEBRATES & $331=7$ & NA & $332=8$ & \\
\hline & VERTEBRATES & $331=7$ & NA & $332=8$ & \\
\hline \multirow[t]{4}{*}{ PLANKTONIC: } & BACTERIA & $331=7$ & $000=0$ & $321=6$ & $332=8$ \\
\hline & ALGAE & $331=7$ & $000=0$ & $332=8$ & \\
\hline & PROTOZOANS & $331=7$ & $000=0$ & $332=8$ & \\
\hline & HIGHER INVERTEBRATES & $331=7$ & NA & $332=8$ & \\
\hline \multirow[t]{3}{*}{ NEKTONIC: } & SURFACE & $331=7$ & NA & $332=8$ & $332=8$ \\
\hline & PROFUNDAL & $331=7$ & NA & $332=8$ & \\
\hline & MIGRATORY & $331=7$ & NA & $332=8$ & \\
\hline CIVILIZED: & HUMAN (HEALTH) & $000=0$ & NA & $000=0$ & $000=0$ \\
\hline
\end{tabular}

300 TONS $\left(2.7 \times 10^{8} \mathrm{~g}\right)$ OF $\mathrm{NH}_{3}$ ARE SPILLED INSTANTANEOUSLY INTO A SMALL LAKE AND MIXED TO A DEPTH OF $1 \mathrm{~m}$. THE ESTIMATED BOUNDARY CONCENTRATIONS OF $\mathrm{NH}_{3}$ IN THIS TOP LAYER OF WATER ARE $30 \mathrm{TO} 3000 \mathrm{mg} / \mathrm{L}$.






\section{TABLE D.8. Hazards Ratings for Scenario 8}

SCENARIO B:

A PIPELINE ACCIDENT SPILLS 300 TONS OF NH INTO A SMALL RIVEA OVER A PERIOD OF 1 HOUF. PRODUCING CONCENTRATIONS OF 4000 TO $400,000 \mathrm{mg} / L_{\text {OOWNSTREAM. }}$. ASSESSMENT MATRICES THAT ARE NOT APPIICABLE TO THIS SCENARIO ARE NOTED AS "NA".

\begin{tabular}{|c|c|c|c|c|c|}
\hline COMMUNITY & POPULATION & $\begin{array}{l}\text { SURVIVAL } \\
\text { \{acute } \\
\text { toxicity| }\end{array}$ & $\begin{array}{c}\text { NUTRITION } \\
\text { (eutro- } \\
\text { phication) }\end{array}$ & $\begin{array}{l}\text { PROOUCTIVITY } \\
\text { (growth and } \\
\text { reproduction) }\end{array}$ & $\begin{array}{c}\text { STABILITY } \\
\text { (community } \\
\text { structurel }\end{array}$ \\
\hline \multirow[t]{6}{*}{ BENTHIC: } & BACTERIA & $331=7$ & $000=0$ & $331-7$ & $332=8$ \\
\hline & ALGAE & $331-7$ & $000=0$ & $331-7$ & \\
\hline & MACROPHYTES & $331=7$ & $000-0$ & $331=7$ & \\
\hline & PROTOZOANS & $331=7$ & $000=0$ & $331=7$ & \\
\hline & HIGHER INVERTEBRATES & $331=7$ & NA & $331=7$ & \\
\hline & VEATEBRATES & $331-7$ & NA & $331=7$ & \\
\hline \multirow[t]{4}{*}{ PLANKTONIC: } & QACTERIA & $331=7$ & $000=0$ & $331=7$ & $332=B$ \\
\hline & ALGAE & $331=7$ & $000=0$ & $331=7$ & \\
\hline & PAOTOZOANS & $331=7$ & $000-0$ & $331=7$ & \\
\hline & HIGHER INVERTEBAATES & $331-7$ & NA & $331-7$ & \\
\hline \multirow[t]{3}{*}{ NEKTONIC: } & SURFACE & $330: 6$ & NA & $331=7$ & $332=8$ \\
\hline & PROFUNDAL & $330 \div 6$ & NA & $331=7$ & \\
\hline & MIGRATORY & $330=6$ & NA & $331=7$ & \\
\hline CIVILIZED: & HUMAN (HEALTH) & $200-2$ & NA & $000=0$ & $000=0$ \\
\hline
\end{tabular}

a 300 TONS $\left(2.7 \times 10^{\circ} \mathrm{g}\right)$ OF $\mathrm{NH}_{3}$ ARE SPILLED INTO A SMALL RIVER OVER A PEFIOD OF 1 HOUP. THE ESTIMATED BOUNDARY CONCENTRATIONS OF NH IN DOWNSTAEAM WATER ARE 4000 TO $400,000 \mathrm{mg} / \mathrm{L}$.

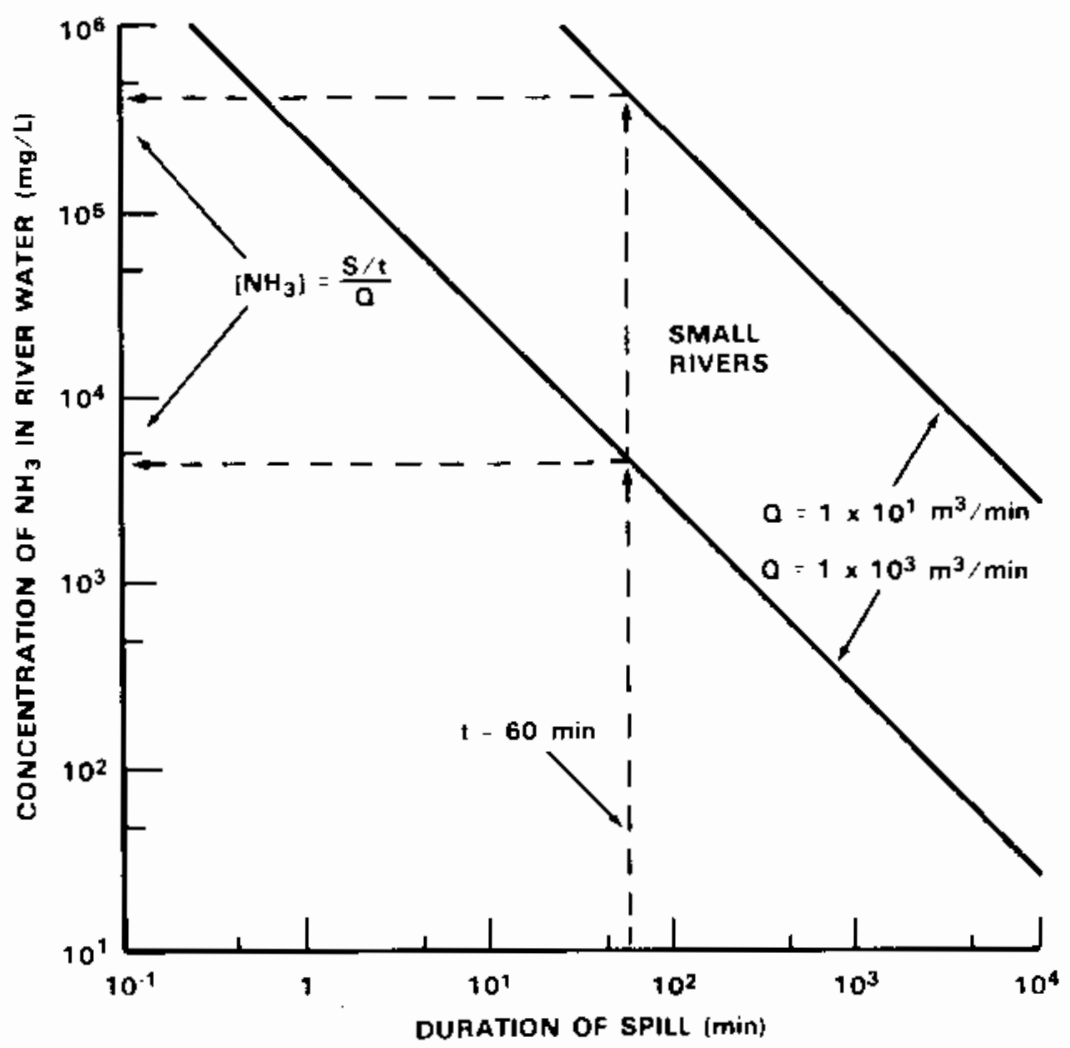




\section{D.2 RATING THE HAZARDS FOR TERRESTRIAL SPILL SCENARIO}

Expected impacts generated by each of the terrestrial spill scenarios were rator in terms of potential hazards and are shown in Table D-9. A rating of "7" would include those impacts which are so small that no evident damage to the individual or the population can be seen. In the case of floral components, the addition of small amounts of ammonia may actually be stimulatory to growth. A rating of "2" would include those impacts which cause mild visible or physiological damage (few fatalities) to most individuals. A "3" rating would include impacts which may be detrimental (fatal or debilitating) to the individual to the point that the population could be impacted. A "4" rating would involve an impact which severely depletes most populations within the affected area. This rating may potentially bring about successional changes within natural occurring vegetation or heavy economic loss in cultivated crop species and farm animals.

In addition Table D- 9 contains a ranking of the relative amount of information available from which to judge the impact. In most cases information was nonexistent or poor. 
TABLE D.9. Impact Ratings for Ammonia Spill Scenarios in Forest and Grassland Ecosystems

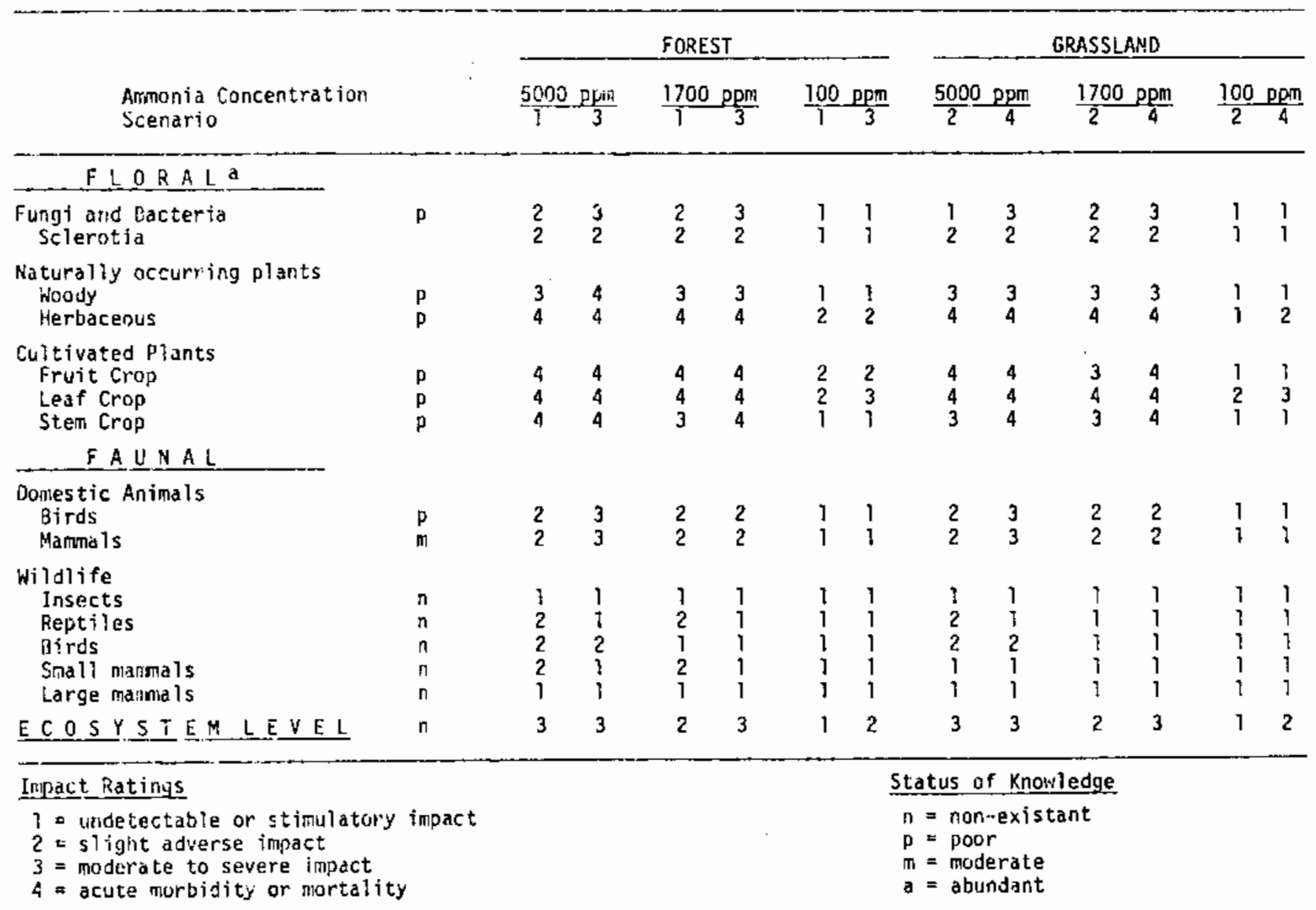

Impacts of naturally occurring floral components are based on times of the season corresponding to fruit maturation; cultivatad species impacts are based on times of the season corresponding to peak harvest. 


\section{D.3 RATING THE HAZARDS FOR MARINE SPILL SCENARIOS}

Expected impacts generated by each of the marine spill scenarios were rated in terms of potential hazards (Table D-1D). The total hazards rating (H) defines the degree of risk caused by spills of ammonia in the different marine environments. This index is composed of a ranking of the biological hazards based on a ranking of the biological effects whether toxic or stimulating, the probable recovery time for the populations and the uncertainty of knowledge as well as a ranking of the importance of the resource to man. For any particular hazard category the lower the ranking the less the impact. Thus for the total hazard rating $(H)$ a value of 6 means a critical impact, 4 - serious impact and 2 slight to moderate impact. 
TABLE D.10. Hazard Ratings for Marine SpiTl Scenarios

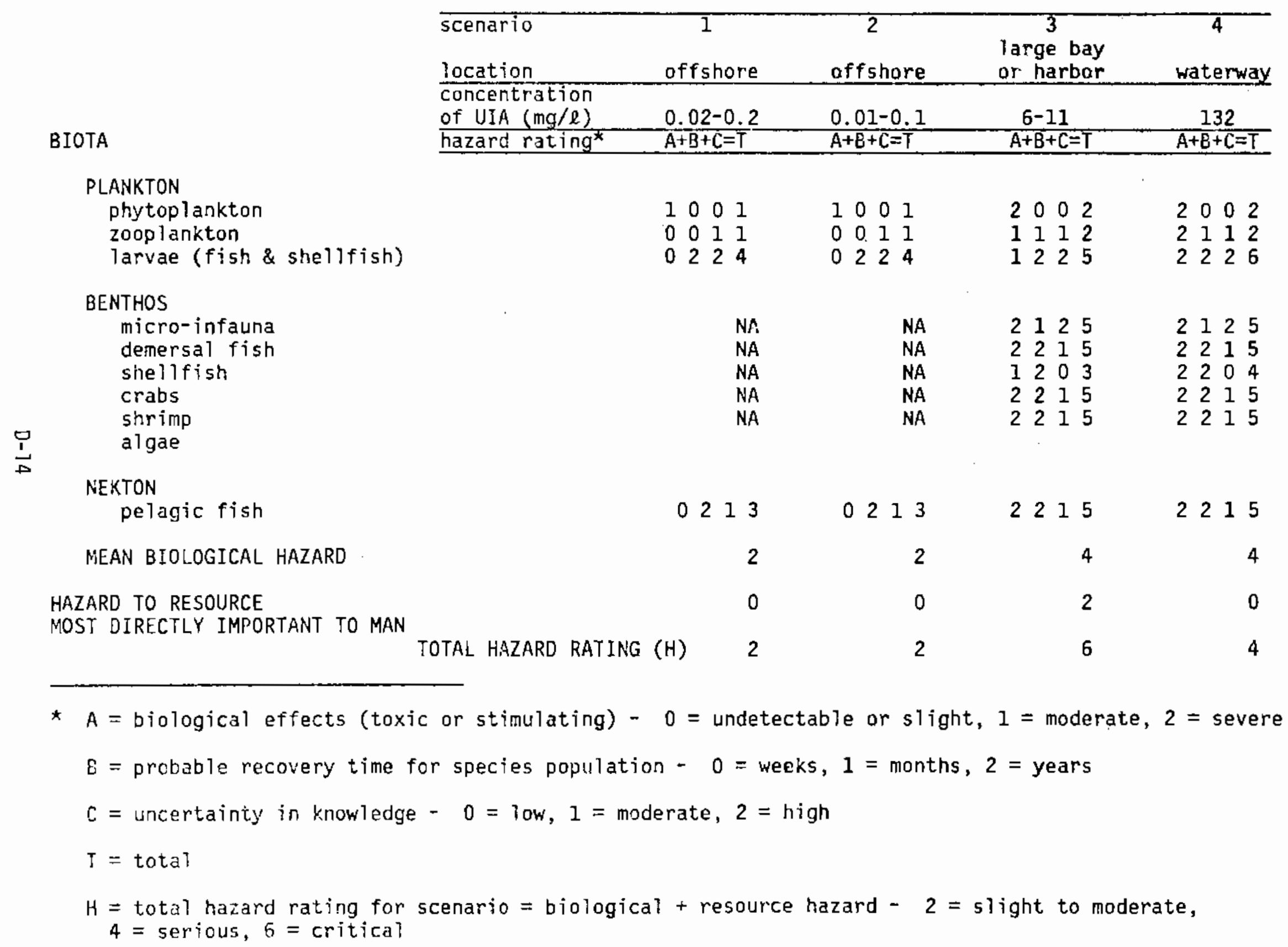




\section{OISTRIBUTION}

No, of

Copies

A. A. Churm

DOE Patent Division

9800 South Cass Avenue

Argonne, IL 60439

20 J. M. Cece (EP-32)

Office of Environmental

Protection, Safety and

Preparedness

U.S. Department of Energy

Washington, D.C. 20545

20 H. F. Walter (EP-32)

Office of Environmental Protection, Safety and

Preparedness

U.S. Department of Energy

Washington, D.C. 20545

27 DOE Technical Information Center
A. A. ATlen
Alaskan Beaufort Sea
0ilspill Response Body
6700 Arctic Spur Road
Anchorage, AK 99502

J. A. Anderson

South Georgia Natural Gas Company

P. 0. Box 1279

Thomasvilie, GA 31792

P. J. Anderson

Institute of Gas Technology

3424 South State Street

Chicago, IL 60616

S. M. Barkin

Committee on Hazardous

Materials

National Research Council

2101 Constitution Avenue

Washington, D.C. 20418
No. of

Copies
A. C. Barrell

Major Hazards Assessment Unit Health and Safety Executive 25 Chapel Street

London, NW] 5DT, UK

C. Batty

British Petroleum North American, Inc.

$620 \mathrm{Fifth}$ Avenue

New York, NY 10020

L. E. Be1]

Western LNG Terminal Associates

700 South Flower Street

Suite 3300

Los Angeles, CA 90017

W. M. Benkert

American Institute of

Merchant Shipping

1625 K Street, N.W.

Washington, D.C. 20006

G. F. Bennett

Professor of Biochemical

Engineering

University of Toledo

2801 Bancroft Street

Toledo, oh 43606

E. Bia1ik

New York State Attorney

General office

2 World Trade Center

New York, NY 10047

K. Blower

Standard 0 il of Ohio

1748 Gujldhall Building

Cleveland, $\mathrm{OH} 44115$ 
No. of

Copies

F. Bodurtha

DuPont Company

Louviers Building 1351

Wilmington, DE 19898

A. Boni

Science Applications

Inc.

1200 Prospect Street

La Jolla, CA 92037

W. J. Bradford

01 in Corporation

120 Long Ridge Road

Stamford, CT 06904

W. C. Brasie

Dow Chemical USA

633 Building

Midland, MI 48640

F. E. Brinker

Trunkline LNG Company

P. 0. Box 1642

Houston, TX 77001

W. Brobst

The Transport Environment

285 01d Squaw Drive

Kitty Hawk, NC 27949

S. J. Broussard, P.E.

Manager, Occidental Chemical Company

P. 0. Box 1185

Houston, TX 77001

C. P. Buckley

Boston Gas Company

One Beacon Street

Boston, MA 021D8

D. J. Campbell

Trunkl ine LNG Company

P. 0. Box 1642

Houston, TX 77001
No. of

Copies

T. Carlisle

Senior Mechanical Safety

Engineer

Santa Fe Pipeline Company

1200 Thompson Building

Tulsa, OK 74103

A. M. Clarke

Algonquin Gas Transmission Company

1284 Soldiers Field Road

Boston, MA 02135

S. Colgate

Los Alamos National Laboratory

Los Alamos, NM 87545

G. Colonna

U.S. Coast Guard (G-DMT-1)

2100 Second Street, S.W.

Washington, D.C. 20593

Committee on Commerce, Science and Transportation

U.S. Senate

Washington, D.C. 20510

C. Corbett

Commandant (G-WEP)

U.S. Coast Guard

2100 Second Street, S.W.

Washington, D.C. 20593

P. Cubbage

British Gas Corporation

Research \& 0evelopment Station

Midlands Research Station

Whaft Lane, Solihull, West Midlands B9K 2JW

ENGLAND

R. Danielson

Bay State Gas Company

120 Royal1 Street

Canton, MA 02021 
No. of

Copies

R. E, DeHart, II

Union Carbide Corporation

P. 0. Box 8361

South Charleston, WV 25303

W. Dennis

Office of Pipeline Safety

Regulations

4007 th Street, S.W.

Washington, D.C. 20590

L. C. Doelp

Corporate Engineering

Air Products and Chemicals

Allentown, PA 18105

E. Drake

Arthur D. Little, Inc.

Acorn Park

Cambridge, MA 02140

F. Edeskuty

Los Alamos Scientific

Laboratory

P. 0. Box 1663

Los Alamos, NM 87545

J. Edgell

Bulk Plant Operations

Columbia Hydrocarbon

Corporation

1600 Dublin Road

Columbus, $\mathrm{OH} 43215$

R. J. Eiber

Battelle Columbus Laboratories

505 King Avenue

Columbus, $\mathrm{OH} 43201$

T. Eichler

IIT Research Institute

10 West 35 th Street

Chicago, IL 60616
No. of

Copies.

\author{
N. Eisenberg \\ U.S. Nuclear Regulatory \\ Commission \\ 5650 Nicholson Lane \\ Rockvi]le, MD 20852 \\ W. G. England \\ Energy Resources Company, Inc. \\ 3344 North Torrey Pines Court \\ La Jolla, CA 92037 \\ J. A. Fay \\ Department of Mechanical \\ Engineering \\ Massachusetts Institute of \\ Technology \\ Cambridge, MA 02139 \\ J. P. Frazier \\ Natural Gas Pipeline Company \\ of America \\ 122 South Michigan Avenue \\ Chicago, IL 60603
}

S. Fujinami

Tankage Designing Section

Kawasaki Heavy Industries, LTD

118, Futatsuzuka, Noda-shi, Chiba 278, JAPAN

M. Futana

No. 3 Group Chemical Plant and Machinery Department B

Mitsubishi Heavy Industries, LTD

118, Ichigaya Tomihisa-Cho, Shinjuku-ku

Tokyo 162 , JAPAN

R. D. Gerges

Manager, Process Hazard Analys is

Rohm \& Has Company

Engineering Oivision

Box 584

Bristol, PA 19007 
No. of

Copies

D. Gideon

Battelle Columbus Laboratories

505 King Avenue

Columbus, $\mathrm{OH} 43201$

E. Graham

British Gas Corporation

59 Bryanston Street

London WIA 2A2, UK

K. Hagiwara

No. I Sales Department

J.G.C. Corporation

2-1, Otemachi 2-chome, Chiyoda-ku

Tokyo 100, JAPAN

E. Halevy

Scientific Counselor

Embassy of Israe]

1621 22nd Street, N.W.

Washington, D.C. $2000 \mathrm{~B}$

W. T. Hanna

Battelle Columbus Laboratories

505 King Avenue

Columbus, $\mathrm{OH} 43201$

H. C. Hardee

Supervisor, Fluid Mechanics and Heat Transfer

Sandia Laboratories

Albuquerque, NM 87115

J. Havens

College of Engineering

University of Arkansas

227 Engineering Building

Fayetteville, AR 72701

R. W. Headrick

Pacific Gas and Electric Company

77 Beale Street

San Francisco, CA 94106
No. of

Copies

T. Hellman

Director, ENRL Services

Allied Corporation

P. 0. Box 2120

Houston, TX 77001

E. W. Hofer

Process Engineering Manager

Allied Corporation

P. 0. Box 2105R

Morristown, NJ 07960

10 W. J. Hogan

Lawrence Livermore Laboratory

P. 0. Box 808

Livermore, CA 94550

C. C. Hong

Columbia Gas System Service Corporation

1600 Dublin Road

Columbus, $\mathrm{OH} \quad 43215$

W. B. Howard

Manager, Process Safety

Monsanto

800 North Lindbergh Boulevard

St. Louis, MO 63166

P. E. Hyam

Directorate Staff

Imperial Chemical Industries

Box $]$

Billingham Cleveland

TS23 1LB ENGLAND

D. Igo

Transportation Research

Department of Transportation

4007 th Street, S.W.

Washington, D.C. 20590

K. Ishida

Technical Department

Measuring Instrumentation

Division

Fuji Electric Company, LTD

No. I, Fuji-machi, Hino-shi, Tokyo 191, JAPAN 
No. of

Copies

F. Jeglic
National Energy Board
473 A1bert Street
Ottawa, Ontario K1A OE5
CANADA

W. H. Johnson

National L. P. Gas

Association

1301 West 22nd Street

Oak Brook, IL 60521

C. L. Jones

Energy Counselor

British Embassy

3100 Massachusetts Avenue,

N.W.

Washington, D.C. 20008

L. J. S. Kaplan

Dangerous Commodities Review Committee Officer

Railway Transport Committee

Ottawa, K1A ON9, CANADA

J. W. Kime

U.S. Coast Guard (G-W)

2100 Second Street

Washington, D.C. 20593

W. C. Kohfeldt

Exxon Chemical Company

P. 0. Box 27!

Florham Park, NJ 07932

H. J. Kolodner

Director, Corporate Safety

Celanese Corporation

P. 0. Box 32414

Charlotte, NC 28232

L. M. Krasner

Factory Mutual Research Corporation

1151 Boston - Providence Turnpike

Norwood, MA 02062
No. of

Copies

J. K. Lathrop

National Fire Protection

Association, Inc.

470 Atlantic Avenue

Boston, MA 02210

P. E. Laurie

Acres Consulting Services Limited

5259 Dorchester Road

P. 0. Box 1001

Niagara Falis, CANADA L2E 6Wl

J. A. Lawrence

Vice President and Manager of Nitrogen Operations

CF Industries, Inc.

Salem Lake Drive

Long Grove, IL 60047

L. Lemon

Energy and Minerals Research Company

P. 0. Box 389

Exton, PA 19341

M. Levy

Columbia LNG Corporation

20 Montchanin Road

Wilmington, DL 19807

D. J. Lewis

Imperial Chemical Industries, LTD

Mond Division, Research and Development Department

P. 0. Box 7 Winnington

Northwich Cheshire, CW8 40J, UK

J. P. Lewis

Project Technical Liaison

Associates, Inc.

505 North Belt, Suite 260

Houston, TX 77060

C. D. Lind

Code 3262

U.S. Naval Weapons Center

China Lake, CA 93555 
No. of

Copies

G. Logan

Phillips Chemical Company

Seneca Building

Bartlesville, OK 74004

P. Lunnie

Asst. VP, Industrial Relations

Director, OSH

National Association of

Manufacturers

1776 F Street, N.W.

Washington, D.C. 20006

L. Malion

Committee on Merchant Marine and Navy

House of Representatives

Washington, 0.C. 20515

J. Manney

American Petroleum Institute

2101 L Street, N.W.

Washington, D.C. 20037

Commanding Officer

Marine Safety Office

U.S. Coast Guard

Baltimore, MD 21202

D. H. Markstein

Factory Mutual Research

Corporation

1151 Boston - Providence

Turnpike

Norwood, MA 02062

J. Martin

Shell International Gas

Shell Centre

London, SET 7NA, UK

W. E. Martinsen

Applied Technology Corporation

P. 0. Box FF

Norman, OK 73070
No. of

Copies

\author{
J. D. Massie \\ The Fertilizer Institute \\ 1015 18th Street N.W. \\ washington, 0.C. 20036
}

M. Matallana

Spanish Embassy (Room 1020)

1875 Connecticut Avenue, N.W.

Washington, D.C. 20009

Y. Matsui

Systems Department

Toyo Engineering Corporation

12-70, Higashi-funabashi 6-chome

Funabashi-shi, Chiba 273, JAPAN

H. Mayo

COOP Farm Chemical Association

P. 0. Box 308

Lawrence, KS 66044

R. N. Meroney

Fluid Mechanics and Wind Engineering Program

Department of Civil Engineering

Colorado State University

Fort Collins, CO 80523

R. C. Mill

Exxon Chemical Company

200 Park Avenue

P. 0. Box 271

Fiorham Park, NJ 07932

R. Morrison

Boston Gas Company

One Beacon Street

Boston, MA 02108

N. Neafus

EOECO Engineering Company

1601 South Main Street

P. 0. Box 589

Tulsa, OK 74101 
No. of

\section{Copies}

J. A. Nicholls

Department of Aerospace

Engineering

University of Michigan

Ann Arbor, MI 48109

R. Norton

Distrigas, Inc.

125 High Street

Boston, MA 02110

0 . Okawa

Chiyoda Chemical Engineering Company

P. 0. Box 10

Tsurumi, Yokohama 230, JAPAN

A. K. Oppenheim

Department of Mechanical

Engineering

University of California

Berkeley, CA 94720

P. M. Ordin, P.E.

16705 Van Aken Boulevard

Shaker Heights, $\mathrm{OH} 44120$

J. C. Pace, Jr.

Long Island Lighting Company

175 East 01d Country Road

Hicksville, NY 11801

M. C. Parnarouskis

U.S. Coast Guard (G-DMT-1)

2100 2nd Street, S.W.

Washington, D.C. 20593

H. Pasman

Prins Maurits Laboratory TN0

Technological Research

P. 0. Box 45

2280 AA Rijswikj, NETHERLANDS

E. Pearlman

JRB Associates

8400 Westpark Drive

McLean, VA 22102
No. of

Copies

\author{
J. Peebles \\ Commandant (G-WPE) \\ U.S. Coast Guard \\ 2100 Second Street, S.W. \\ Washington, D.C. 20593 \\ W. H. Penn \\ Tennessee Gas Pipeline Company \\ P. 0. Box 2511 \\ Houston, TX 77001 \\ H. W. Peter \\ Brooklyn Union Gas Company \\ 195 Montague Street \\ Brooklyn, NY 11201 \\ C. Peterson \\ SRI Washington \\ 1611 North Kent Street \\ Rosslyn Plaza \\ Arlington, VA 22209
}

R. E. Petsinger

LNG Services, Inc.

1815 Washington Road

Pittsburgh, PA 15241

C. N. Petterson

Northwest Natural Gas Company 123 Northwest Flanders Street Portland, OR 97209

\section{A. Pfeiffer \\ Institute for Reactor Safety \\ Glodkengrasse 2 \\ 5000 Cologne 1 \\ FEDERAL REPUBLIC OF GERMANY}

W. B. Porter

Process Engineer

W. R. Grace Company

100 North Ma in Street

Memphis, TN 38101
A. A. Putnam
Battelle Columbus Laboratories
$505 \mathrm{King}$ Avenue
Columbus, $\mathrm{OH} 43201$ 
No. of

Copies

P. Raj

Technology and Management

Systems, Inc.

102 Drake Road

Burlington, MA 01803

R. C. Reid

Department of Chemical

Engineering

Masschusetts Institute

of Technology

Cambridge, MA 02139

A. Roberts

Office of Hazardous Materials

Regulations

Department of Transportation

Transpoint Building

2100 Second Street, S.W.

Washington, D.C. 20590

A. Rosenbaum

Nationa1 Tank Truck

Carriers, Inc.

1616 P Street, N.W.

Washington, D.C. 20036

P. Rothberg

CRS/SPR

Library of Congress

Washington, D.C. 20450

M. I. Rudnicki

Aerojet Energy Conversion Company

P.0. Box 13222

Sacramento, CA 95813

Monsieur A. Salvadori

Gaz de France

Direction des Etudes et Techniques Nouvelles

Department des Etudes Cryogenics, Industrielles et Metallurgiques

23, rue Philibert-Delorme

Paris-17, FRANCE
No. of

Copies

L. Santman

Materials Transportation

Bureau

U.S. Department of

Transportation

4D0 7th Street, S.W.

Washington, D.C. 20590

L. Sarkes

American Gas Association

1515 Wilson Boulevard

Arlington, VA 22209

L. C. Schaller

E. I. du Pont de Nemours \& Co.

12430 Nemours Building

Wilmington, DE 19898

M. Scherb

P. 0. Box AG

Beverly Hills, CA 90213

B. Schnurmian, CPCU

Reed Stenhouse

1010 Collingwood Drive

St. Louis, MO 63132

H. P. Schoor

Brooklyn Union Gas Company

195 Montague Street

Brooklyn, NY 11201

S. Schreiber

Allied Corporation

P. 0. Box 2332R

Morristown, NH 07960

R. J. Schuttler

Manager

Hooker Chemicals

P. 0. Box 728

Niagara Falls, NY 14302 
No. of

Copies

R. F. Schwab

Manager, Process Safety \& Loss

Prevention

Allied Corporation

P. 0. Box 2332R

Morristown, NJ 07960

J. G. Seay

Institute of Gas Technology

3424 South State Street.

Chicago, IL 60616

P. Seay

Technical Division

Office of Hazardous Materials Regulations

Materials Transportation Bureau 400 Seventh Street, S.W.

Washington, D.C. 20590

3. Seel inger

Office of Commercial Development

U.S. Maritime Administration

U.S. Department of Commerce

Washington, D.C. 20230

S. M. Settle

Associate Director, $05 \mathrm{H}$

NAM

1776 F Street, N.W.

Washington, D.C. 20006

R. B. Smith

Battelle Columbus Laboratories

$505 \mathrm{King}$ Avenue

Columbus, $\mathrm{OH} \quad 4320 \mathrm{~T}$

J. Sorel

French Atomic Energy Commission

29 Rue de la Federation

Paris 15, FRANCE

J. K. Speckhals

Columbia LNG Corporation

20 Montchanin Road

Wilmington, DE 19807
No. of

Copies

Spill Technology Newletter

Environmental Protection Service

Ottawa, Ontario KIA 1 C8 CANADA

A. N. Stewart

San Diego Gas \& Electric Company

P. 0. Box 1831

San Diego, CA 92112

R. A. Strehiow

105 Transportation Building

University of Illinois

Urbana, IL 61801

J. D. Swanburg

Supt. of Process Engineering

Union Chemical Division

Union 0il Company of California

P. 0. Box 1280

Brea, CA 92621

B. Sweedler

Nationa1 Transportation

Safety Board

800 Independence Avenue

Washington, D.C. 20591

T. Tanaka

System Engineering Department

J. G. C. Corporation

14-1, Bessho-cho 1-chome, Minami-ku

Yokohama-shi, Kanagawa 232 JAPAN

J. Tatematsu

Technology Transfer Institute

Kyodo Building

3-1, Akasaka 4-chome, Minato-ku

Tokyo 105, JAPAN

M. J. Turner

Health and Safety Executive

25 Chapel Street

London NW] 5DT

ENGLAND 
No. of

Copies

T. Uozumi

Assistant to the Manager

EDP Education Department

Fujitsu LTD

17-25, Shinkamata 1-chome, Ohta-ku

Tokyo 144 , JAPAN

W. Walls

National Fire Protection Agency

470 Atlantic Avenue

Boston, MA 02210

S. K. Wakamiya

Product Engineering Division

National Bureau of Standards

Department of Commerce

Washington, D.C. 20234

D. J. Watters

Union Carbide Corporation

P. 0. Box 8361

South Charleston, WV 25303

S. Weirsma

Gas Research Institute

86D0 West Bryn Mawr Avenue

Chicago, IL 60631

J. R. Welker

Applied Technology Corporation

P. 0. Box FF

Norman, OK 73070

M. M. Williams

U.S. Coast Guard

Technical Advisor (G-MHM/83)

400 Seventh Street, S.W.

Washington, D.C. 20590

W. Wilson

San Diego Gas \& Electric Company

P. 0. Box 1831

San Diego, CA 92112

RADM K. E. Wiman

U.S. Coast Guard (G-D)

2lDo Second Street, S.W.

Washington, D.C. 20593
No. of

Copies

B. Witcowski

NASA Langley

Hampton, VA 23665

R. E. Witter

Monsanto Company

800 North Lindbergh Boulevard

St. Louis, M0 63166

J. L. Woodward

Exxon Research \& Engineering

P. 0. Box 101

Florham Park, NJ 07932

R. Zalosh

Factory Mutual Research

1151 Boston-Providence Turnpike

Norwood, MA 02062

ONSITE

DOE Richland Operations

H. E. Ransom

30 Pacific Northwest Laboratory

G. F. Athey

H. J. Bomelburg

D. L. Brenchley (10)

C. A. Counts

C. A. Cowan

J. G. DeSteese

W. J. Eadie

R. M. Emery

M. A. Gerber

J. T. Hardy

P. C. Owczarski

P. J. Pelto

T. M. Poston

J. C. Warren

Library (5)

Publishing Coordination Ha (2) 